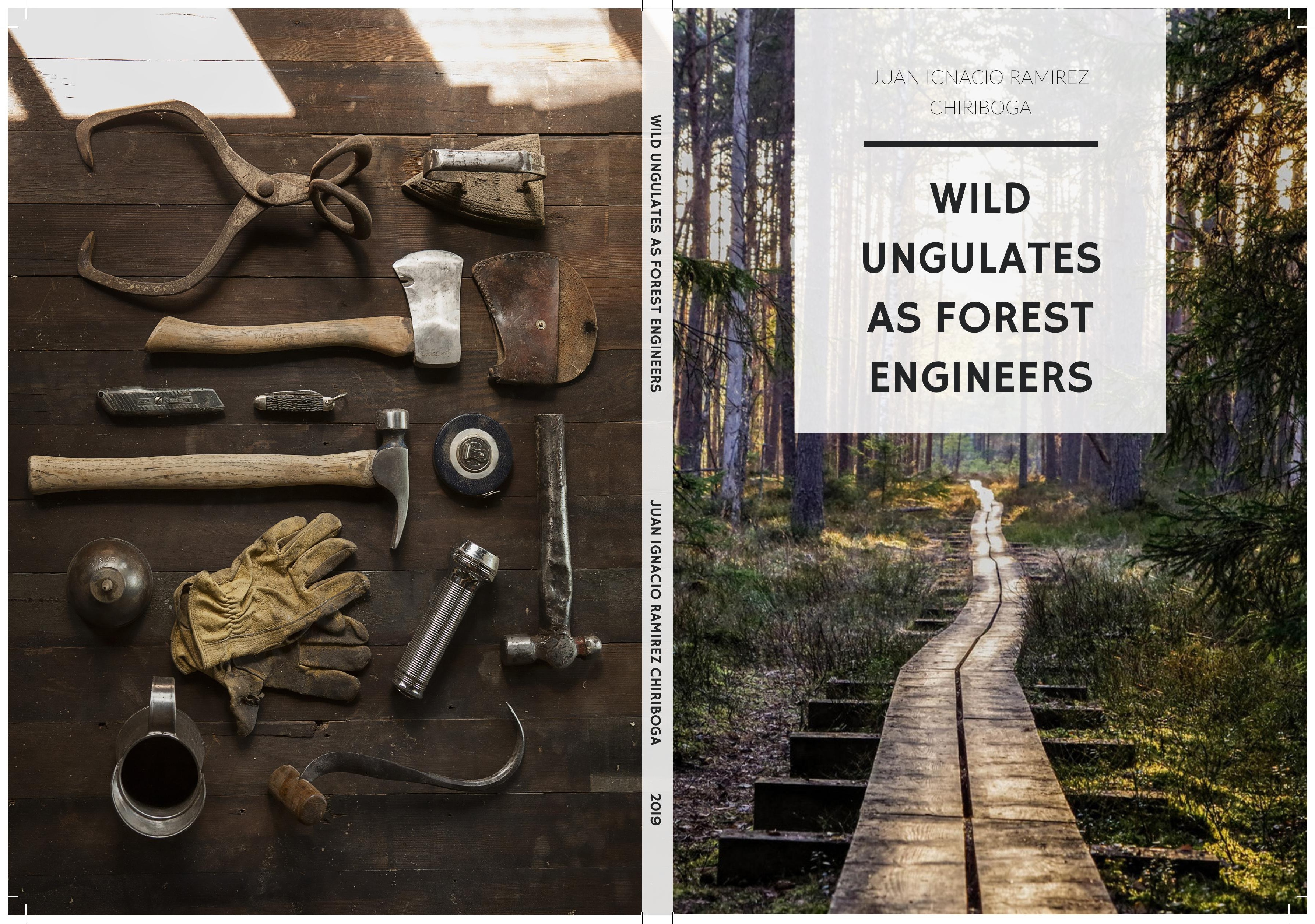




\section{Propositions}

1. Forest type and light play a more important role than deer browsing on forest understory composition.

(this thesis)

2. Ungulate presence promotes cascading effects on other trophic levels in the nutrient cycling chain, but not on litter decomposition.

(this thesis)

3. Open access publishing has favoured exchange of research ideas amongst scientists but has failed to increase the application of research findings for nature conservation.

4. Scientific articles are like rainforest tree species; there are not only a lot of them, but there is also a lot of redundancy.

5. Scientific research and rock climbing share the same confusion: people are mainly focused on the final destination, yet the journey is the most important.

6. Tropical rainforest conservation in the $21^{\text {st }}$ century is played as a Monopoly board game, where money is the winner and the natural capital the loser.

Propositions belonging to the thesis, entitled

Wild ungulates as forest engineers

Juan Ignacio Ramírez Chiriboga

Wageningen, 10 October 2019 


\section{Wild ungulates as forest engineers}

Juan Ignacio Ramírez Chiriboga 


\section{Thesis committee}

\section{Promotor}

Prof. Dr L. Poorter

Personal chair at the Forest Ecology and Forest Management Group

Wageningen University \& Research

\section{Co-promotors}

Dr J. den Ouden

Assistant Professor at the Forest Ecology and Forest Management Group

Wageningen University \& Research

Dr P. A. Jansen

Associate Professor at the Resource Ecology Group

Wageningen University \& Research

\section{Other members}

Prof. Dr W. H. van der Putten, NIOO and Wageningen University \& Research

Dr D. Kuijper, Mammal Research Institute Polish Academy of Science, Poland

Dr M. Rowcliffe, Zoological Society of London, UK

Dr C. Smit, University of Groningen

This research was conducted under the auspices of the Wit Graduate School for Production Ecology and Resource Conservation, the Netherlands. 


\title{
Wild ungulates as forest engineers
}

\author{
Juan Ignacio Ramírez Chiriboga
}

Thesis

submitted in fulfilment of the requirements for the degree of doctor at Wageningen University by the authority of the Rector Magnificus

$$
\text { Prof. Dr A. P. J. Mol, }
$$
in the presence of the

Thesis Committee appointed by the Academic Board to be defended in public

on Thursday 10 October 2019 at 11 a.m. in the Aula. 
Juan Ignacio Ramírez Chiriboga

Wild ungulates as forest engineers

159 pages

PhD thesis, Wageningen University, Wageningen, NL (2019)

With references, with summary in English

ISBN: 978-94-6395-107-4

Doi: https://doi.org/10.18174/499087 


\section{Table of Contents}

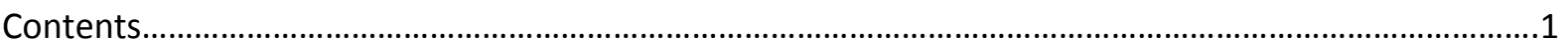

Chapter 1

General introduction

Chapter 2 .

Effects of wild ungulates on the regeneration, structure and functioning of temperate forests: a semiquantitative review (Journal of Forest Ecology and Management)

Chapter 3.

The dose-response relationship between deer and a temperate forest understory: a camera trapping approach (Submitted)

Chapter 4. . .71

Long-term effects of wild ungulates on the structure, composition and succession of temperate forests (Journal of Forest Ecology and Management)

Chapter 5 . . .93

Above and below-ground cascading effects of wild ungulates in a temperate forest (Submitted)

Chapter 6 .

General synthesis

References.

Summary

Acknowledgments. .151

Short Biography 155

List of publications. .156

PE\&RC training and educational statement. 157 


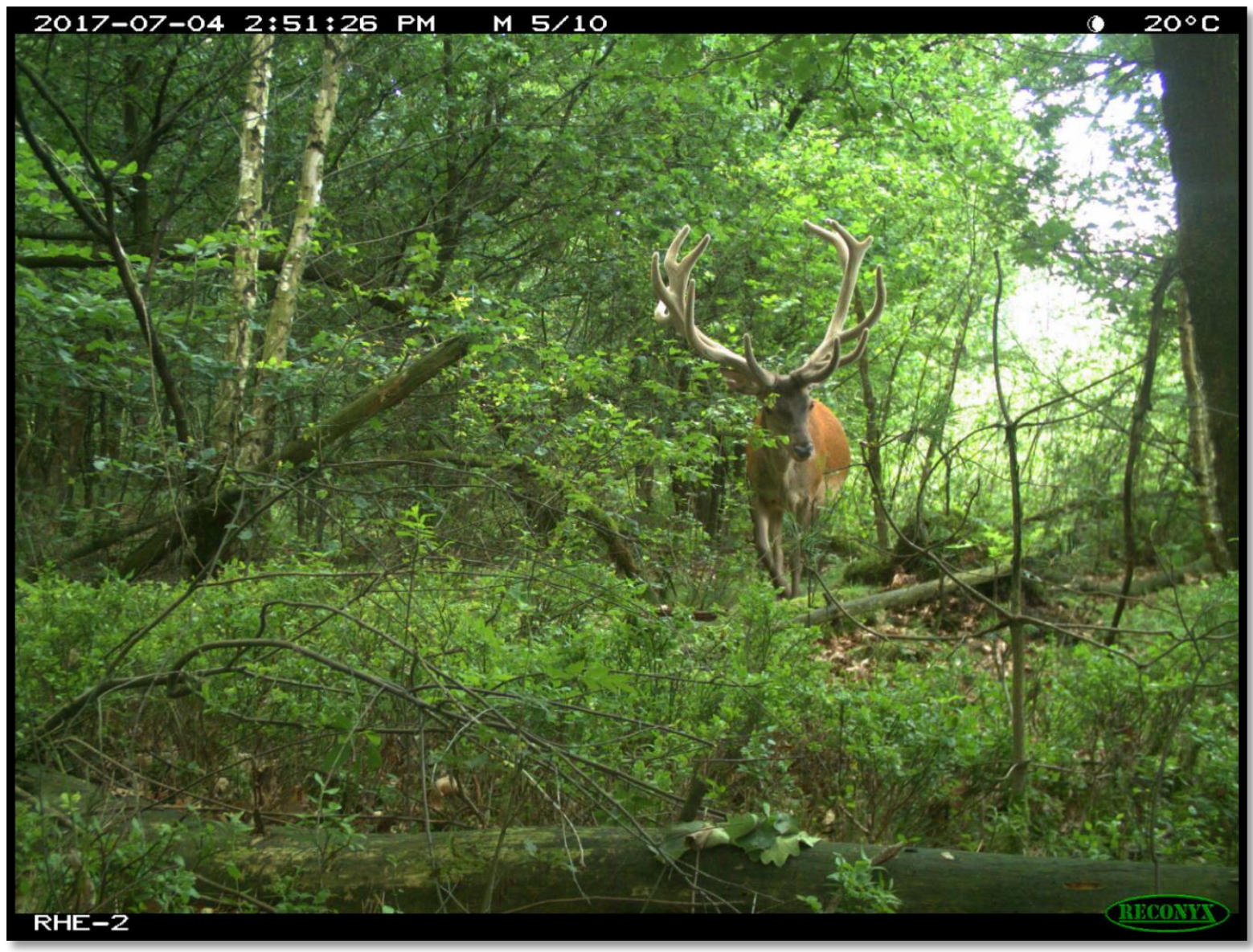

Page 2 


\section{CHAPTER ONE}

General introduction

Author

Juan Ignacio Ramírez 


\section{Plant-animal interactions}

\section{Keystone species \& forest engineers}

Large wild ungulates are defined as odd and even-toed animals that mainly feed on vegetation, although some are omnivores. Across different biomes, large ungulates are regarded to be keystone species for two reasons: (1) these animals have a disproportional effect on the vegetation community relative to their abundance, and (2) they play a crucial role in the way an ecosystem functions (Waller \& Alverson 1997). Consequently, without ungulates, ecosystems would be dramatically different. Similarly, some wild ungulates are also regarded as ecosystem engineers - species that significantly modify their habitat - as they can shift forest species composition from broadleaf to conifer species (Coverdale et al. 2016). For example, by toppling adult trees and browsing on palatable trees, moose can increase light availability in the understory and shift tree species composition from shade-tolerant to lightdemanding species (Mathisen et al. 2010). Wild ungulates in the northern hemisphere have increased in abundance (Reimoser 2003) because of ungulate reintroduction, abonnement of agricultural land, competitive release from domestic ungulates, absence of top predators, stricter hunting regulations and improvement of habitat quality (Kuiters et al. 1996; Rooney 2001; Côté et al. 2004). A high abundance of ungulates may lead to an excessive top-down control on tree regeneration.

Most discussions on ungulate abundance in temperate forests have focused on the carrying capacity from an animal perspective; i.e., how many healthy ungulates can be sustained in a given area (Picton 1984; Clutton-Brock \& Albon 1992)? Less attention has been paid to the carrying capacity from a forest perspective; i.e., how many ungulates can a given forest area sustain without significant reductions in tree regeneration, productivity, timber production, and other ecosystem services (Gill 1992b; Clutton-Brock et al. 2004)? This thesis aims to evaluate the effects of wild ungulates on temperate forests at different scales. That is, how do wild ungulates affect forests at different 1 ) spatial scales (from areas with low to areas with high ungulate abundance)? 2) temporal scales (from short-term to long-term effects)? and 3) hierarchical scales (from trophic levels of primary producers to detritivores)?

\section{What determines ungulate density on temperate forests?}

As most ungulate densities are supra optimal for forest regeneration, structure and functioning, the question then becomes what determines ungulate density? Ungulate 
densities are shaped by top-down control by predators and bottom-up control by food resources. Top-down control by predation and culling directly reduces ungulate density (McGraw \& Furedi 2005). Bottom-up control by plants can also control ungulate density by limiting food availability. For example young forests have a relatively large proportion of young nutrient-rich leaves, twigs, and bark and can thus support higher ungulate densities than old-growth forests (Putman 1996). As young forests develop, the capacity to support ungulates decreases because light limitation hampers the growth of new and fresh shoots of understory plants. In later successional stages, canopy trees die, leading to greater light availability in the lower forest strata, resulting in more tree regeneration and food supply, and hence higher ungulate density (Kuiters et al. 1996).

In reality ungulates are controlled by a combination of top-down and bottom-up control. For example when predators control ungulates population in a grassland system, the level of herbivory reduces and the system does not change from a grass towards a thorn-shrub dominated state (Van Langevelde et al. 2003). Similarly, open spaces such as grasslands can control local ungulate population through habitat preference because ungulates avoid open areas in order to escape predation (Riginos \& Grace 2008).

Ungulate density is also shaped by other factors such as body size, reproductive behaviour and competition. First, body mass is very important in determining animal density; large animals have large per capita food requirements and occur therefore at lower densities than small animals (Damuth 1987). Second, reproductive behaviour of $r$ and $k$ strategy animals determines offspring numbers and thus probable species local density (Pianka 1970). Third, at high population densities, ungulates are highly prone to resource intra-specific competition (Courchamp et al. 1999), but are safer from predators (Hager \& Helfman 1991).

\section{Ungulate effects: from micro-patch to landscape}

Ungulates affect their environment at different spatial scales (Fig. 1.1), ranging from forestpatch $\left(<5 \mathrm{~m}^{2}\right)$ to forest landscape $\left(>100 \mathrm{~km}^{2}\right)$ (Hobbs 1996). 


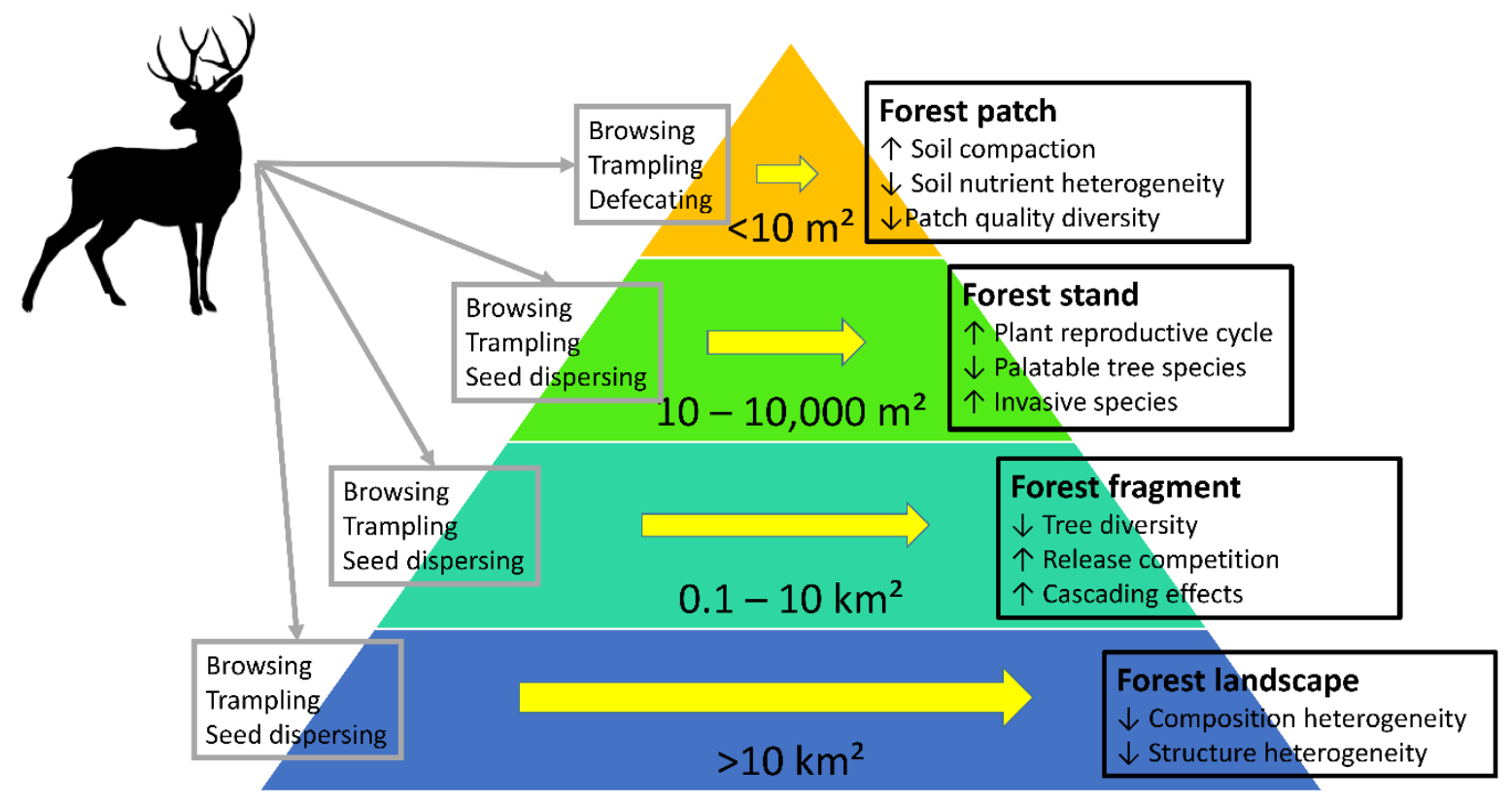

Figure 1.1. Ungulates interact with forests at different spatial scales, ordered by size: forest patch $\left(<10 \mathrm{~m}^{2}\right.$ orange), forest stand (10-10,000 $\mathrm{m}^{2}$ - green), forest fragment (0.1-10 $\mathrm{km}^{2}$ - cyan) and forest landscape (>10 $\mathrm{km}^{2}$ - purple). In grey squares the main interacting mechanisms and in black squares the resulting effects, upward arrows indicate that ungulates increase the response variable, downward arrows indicate that ungulates decrease the variable.

\section{Forest patch}

Homogenous small $\left(<10 \mathrm{~m}^{2}\right)$ forest areas that have few trees and similar (a)biotic conditions are typically referred to as a forest patch. In these areas, feeding behaviour by ungulates creates nutrient heterogeneity at micro-scales $\left(0.1-10 \mathrm{~m}^{2}\right)$ by removing nutrients from the system and releasing them again in different areas when the animal defecates or dies (Hobbs 1996). At high ungulate densities, essential nutrients may be locally removed to such extent that the primary production is reduced (Putman 1996; Rooney \& Waller 2003). Physical trampling increases soil compaction, which may lead to higher water runoff and soil erosion, and decreased plant establishment, growth and survival (Heckel et al. 2010). These effects can last up to 30 years (Bassett et al. 2005). Intensive browsing also has cascading effects on soil biota, as overgrazing leads to a reduction in mycorrhiza abundance and their expression (Rossow et al. 1997). 


\section{Forest stand}

A forest area $\left(10-10,000 \mathrm{~m}^{2}\right)$ with similar composition, structure and age is referred to as a forest stand. In these areas, herbivory triggers important phenotypic traits that increases tree adaptation to ungulates, for example: younger reproductive age (Putman 1996; Gordon \& Prins 2008). In general, tree species with high nutrient concentrations, low chemical and physical defences and low cell wall content are more susceptible to browsing due to their high palatability; on the contrary, less palatable species are associated with low nutrient content, high physical and chemical defences and high cell wall content (Gill 1992b).

Intensive browsing may lead to dramatic changes in tree species composition by depleting all palatable broadleaved species, while less palatable species such as conifers can increase in abundance (Gill \& Beardall 2001). In western Europe, broadleaved species like aspen (Populus tremula), mountain-ash (Sorbus aucuparia) and willow (Salix caprea) are among the most susceptible species to browsing, whereas coniferous species like scots pine (Pinus sylvestris), spruce (Picea abies) and black pine (Pinus nigra) are the least susceptible species (Gill 1992b). Intensive browsing of native species can also facilitate the establishment and the success of invasive plant species in forests through competitive release, especially for invasive species that have a high reproduction, dispersal and growth rate (Knight et al. 2009). Furthermore, high ungulate densities can also change forest composition in a less resilient ecosystem by introducing large amounts of invasive species (Gill \& Beardall 2001).

\section{Forest fragment}

A collection of forest stands in an area (0.1-10 km2) with similar (a)biotic conditions is normally referred to as a forest fragment. In these areas, herbivory may also trigger important life history responses on trees that compensate for damage. For instance, trees can compensate for browsing by mobilizing reserves to increase growth rate, development of side shoots, flushing of new leaves as well as production of secondary metabolisms that reduces herbivory (Putman 1996; Rooney \& Waller 2003). All of these traits tend to increase species fitness by reducing browsing risk and thus there is no proportional effect between detached plant biomass and browsing intensity (Van Hees et al. 1996). Regarding species sex ratio, Heckel et al. (2010) demonstrated that in high densities deer can shift the sex ratio of palatable plants (Heckel et al. 2010) toward males because small plants tend to allocate to male function and 
large plants to female. High ungulate densities may therefore hamper the reproduction and growth of understory populations.

Browsing has a direct effect on plant species composition and diversity within a community. For example, palatable species can suffer from an important decrease in abundance with intensive browsing (McGraw \& Furedi 2005), whereas less palatable species populations may be released from resource competition at high ungulates density (Heckel et al. 2010). On the other hand, high ungulate densities can also trigger indirect changes to the community diversity and composition by affecting ecological relationships among species and promoting cascading effects; for example, deer can reduce understory vegetation which translates into less refuge for rodents to evade predation (Putman 1996; Rooney \& Waller 2003). Herbivory may generate a trophic cascade that can reduce forest resilience and eventually push the forest fragment through a tipping point to another alternative stable state, such as heathland (Côté et al. 2004). For instance, young forests in the Scandinavian mountain range are dominated by birch and spruce. However, if birch is heavily browsed by ungulates, then spruce is unable to establish due to the lack of shelter against harsh climatic conditions. As a result, pine becomes the only dominant species and brings along drastic changes to soil fertility and thereby to the landscape (Danell et al. 2003).

\section{Forest landscape}

A continuous forest ecosystem that covers large land extensions $\left(>10 \mathrm{~km}^{2}\right)$ and which could potentially defer in (a)biotic conditions is referred as a forest landscape. Forests landscapes with a high diversity in both horizontal and vertical structure will offer the widest range of ecological niches, which in turn translates to a high species diversity. Moderate browsing increases horizontal and vertical heterogeneity in the landscape and thus promoting niche partitioning for other species. However, in smaller forests, moderate browsing decreases tree diversity because local species abundance will be reduced to the point that reproduction and establishment are compromised (Reimoser et al. 1999). Furthermore, in most cases, high ungulate densities reduce structural forest heterogeneity thus affecting the system's ability to provide shelter from predators and weather, and reduce accessibility to food supplies (Putman 1996; Rooney 2001). 


\section{Ungulate-forest dose-response curve}

The role of herbivores in shaping natural ecosystems across the world has been a topic of much debate during the last decades (Cyr \& Face 1993; Gill \& Morgan 2010). Empirical studies in temperate forests suggest that ungulates exert strong top-down control on forest structure and dynamics through herbivory (Kuijper et al. 2010a), yet the top-down control strength mainly depends on ungulate abundance and site conditions (Gill \& Morgan 2010). Hence, it is essential to understand the shape of the dose-response curve between the dose (i.e., wild ungulate abundance) and the response (i.e., the response of different forest attributes). From a theoretical perspective, a hump-shape is assumed for the dose-response curve (Fuller \& Gill 2001; Rooney \& Waller 2003). For example, forests with few ungulates may have a low tree diversity because important mechanisms that increase coexistence and diversity, such as seed dispersal, selective browsing and faeces deposition are limited (Reimoser \& Putman 2011). When herbivory levels are intermediate, in accordance with the intermediate disturbance hypothesis (Wilkinson 1999; Ramirez et al. 2018), ungulates create forest heterogeneity and reduce plant competition (Kuiters et al. 1996; Fuller \& Gill 2001; Lucas et al. 2013), which in turn facilitates the establishment of rare tree species. While at high densities ungulates may have a negative effect by consuming palatable species and thus reducing forest structure and diversity (Tyler et al. 2008; Schippers et al. 2014). Yet, the actual observed shape of the doseresponse curve may vary between linear (Nuttle et al. 2014) to a non-linear shape (Tremblay et al. 2006), and this is still contested because a variety of methods with different accuracy levels have been implemented to estimate the dose (Koster \& Hart 1988).

\section{Research questions, hypotheses, and thesis outline}

Wild ungulates play an important role in the diversity, structure and functioning of temperate forests. However, these effects are highly dependent on ungulate density, successional forest stage and the ungulate assemblage composition. Yet, there is a limited number of field and experimental studies that elaborate on these important factors, mainly because there is a lack of long-term studies that experimentally regulate ungulate occurrence (for example through ungulate exclosures) (White 2012). Also, few studies have assessed a complete gradient in wild ungulate abundance across the same region (Nuttle et al. 2014), or quantified the relative abundance of different ungulate species in the ungulate community (Kamler et al. 2010). 
This thesis aims to evaluate the impacts of wild ungulates on a suite of forest attributes at different spatial, temporal, and hierarchical scales. Specifically, the following research questions are addressed: 1) what is the shape of the dose-response curve between wild ungulate abundance and forest responses (i.e., the spatial scale)? 2) what are the long-term effects of wild ungulates on forests (i.e., the temporal scale)? and 3) what are the cascading of wild ungulates on different trophic levels (i.e., the hierarchical scale) (Fig. 1.2)? This thesis focuses on temperate forests, especially from the Veluwe region in the Netherlands. To tackle these questions, novel and robust methods were designed such as camera traps paired to vegetation plots, litter bags placed inside and outside animal exclosures and a chronosquence of forest succession in presence and absence of ungulates.

To understand the overall impact of ungulates in temperate forests, chapter two evaluates with a quantitative literature review the effect of ungulates on different forest attributes. As the exact shape of the ungulate-forest dose-response curve is unknown, a variety of shapes are assessed, and potential tipping points of critical ungulate abundances are identified. Although such a global meta-analysis allows to draw generalizations, it is by definition crude, as the reviewed studies differ in site conditions, how ungulate abundance was measured and how forest responses were quantified. These confounding factors may have affected the shape of the observed dose-response curve. To address this knowledge gap, chapter three evaluates the exact shape of the dose-response curve, by assessing a similar forest type (mixed temperate forests) growing on similar site conditions (mesic climate and sandy soils) across ten forest sites in the Veluwe, the Netherlands. The forest differed widely in ungulate abundance, which could be quantified in a consistent way by using a novel cameratrapping approach and linking the ungulate abundance to forest regeneration. Such a short field study allows to assess the short-term effects of ungulates, which can be minor, but can accumulate over time. Moreover, through selective browsing ungulates can intervene in competitive interactions that release some tree species from suppression, which modifies the structure and composition of the future forest. Few studies have evaluated the long-term effects of ungulates in an experimental way. To address this knowledge gap, in chapter four a long-term chronosequence study (1-33 years) assesses the long-term impacts of ungulates on forest composition. Finally, while many studies have assessed herbivore-plant interactions, relatively few have evaluated their cascading impacts on other trophic levels, specially the complete cascading cause-and-effect chain. This is why chapter five evaluates if and how 
ungulate browsing and trampling have cascading effects on lower trophic levels and on nutrient decomposition and mineralization. In the following sections, an outline is given on the different chapters, their research questions, hypothesis and approach.

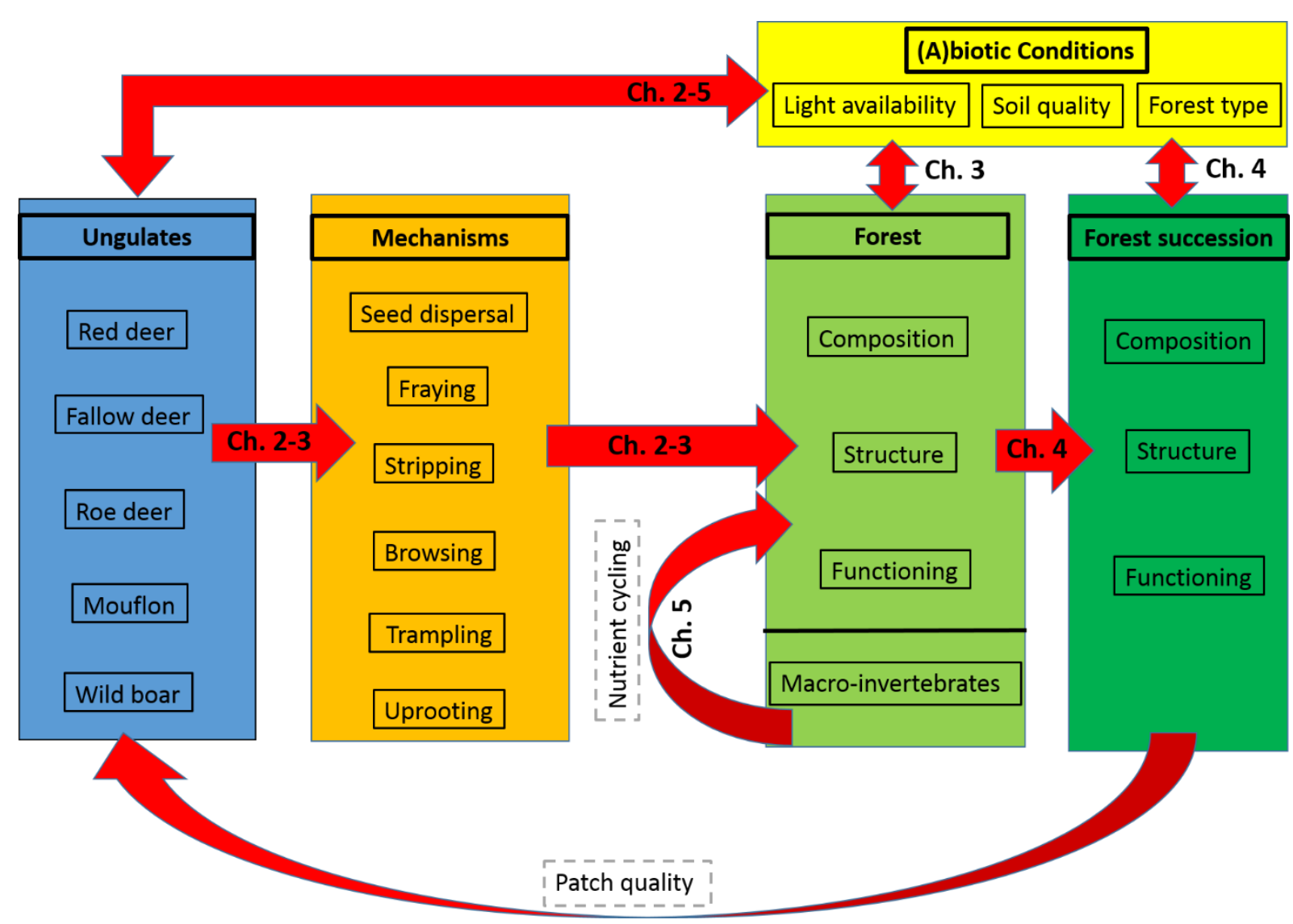

Figure 1.2. Conceptual diagram showing the relationship between the four research chapters and their research questions. The blue box represents the main ungulate species; the orange box represents the mechanisms of ungulate-forest interactions; the light green box indicates the different forest components; the dark green box indicates the different forest components during forest succession, and in the yellow box the main (a)biotic conditions that affect ungulates and the forest vegetation. Red arrows represent relationships between the research components and chapter numbers indicate the relationships studied for each of the chapters. Ch. 2., what is the global dose-response curve between ungulates and forests? Ch. 3., what is the shape of the doseresponse curve? Ch. 4., how do ungulate effects build-up over the long-term? Ch5., what are the cascading effects of ungulates on other trophic levels and nutrient cycling?

Chapter two: what is the global dose-response curve between ungulates and forests? To evaluate how wild ungulates affect temperate forest attributes, a global quantitative literature review was conducted. This meta-analysis provided a better understanding on how 
ungulate density affect temperate forests, as well as important tipping points when the effect switches from negative to neutral. From a total of 164 studies, eight forest attributes associated to forest regeneration, structure and functioning were evaluated and related to ungulate density. Different dose-response curve shapes were evaluated using multinomial logistic regression models. It was hypothesized that the dose-response curve shows a humpshaped curve, where low ungulate density promotes neutral and positive effects by creating new opportunities for rare species; whereas high ungulate densities would trigger negative effects on forests, mainly by selective browsing and trampling.

Chapter three: what is the shape of the dose-response curve?

The meta-analysis of chapter two indicates how ungulates affect forest regeneration. However, such a general approach is by definition crude, as the studies differ in site conditions. To evaluate the exact shape of the dose-response curve for a range of forest attributes, a field study was conducted in ten forest sites that differ largely in ungulate abundance and that were distributed across the Veluwe. For this, a network of 21 camera traps paired with vegetation plots scattered across ten sites of $1 \mathrm{~km}^{-2}$ in the Veluwe region were used. As ungulates browse preferentially on palatable broadleaf tree species, it was hypothesized that an increase in ungulate abundance would lead to a shift in tree species composition, from a mixed broadleaved and conifer forest to a conifer-dominated forest. It was also hypothesized that high ungulate abundance would decrease forest diversity and structure (e.g., basal area and stem density) as excessive herbivory keeps forests in an earlysuccessional state, which is mainly dominated by pioneer species.

\section{Chapter four: how do ungulate effects build-up over the long-term?}

Short-term ungulate effects may be modest, but they may accrue over time. To evaluate the long-term effects of ungulates on temperate forest succession a controlled chronosequence experiment was used in which a set of 17 fenced and unfenced plots ranging in age from 1 to 33 years since establishment at the Veluwe were surveyed. It was hypothesized that soon after ungulates are excluded from the system, forest succession, diversity and structure will deviate in terms of forest structure and composition due to browsing and trampling. For example, ungulates through browsing and trampling will arrest forest succession in the 
unfenced plots from a combination of shade-tolerant and light-demanding tree species to a forest dominated by light-demanding (less palatable) tree species.

Chapter five: what are the cascading effects of ungulates on other trophic levels and nutrient cycling?

Apart from direct impacts on the vegetation, ungulate may have cascading effects on other trophic levels and ecosystem processes. To analyse the complete cascading effect chain, and the pathways through which ungulates affect lower trophic levels, a study was carried out. The complete trophic chain was analysed by examining how ungulate presence directly affects understory vegetation and soil quality, which in turn leads to indirect changes in other trophic levels such as soil macro-invertebrates and ecosystem processes like nutrient cycling. This was performed on a network of twelve fenced and unfenced plots that were established across the Veluwe. The cascading network and pathways were formally analysed using statistical path modelling. It was hypothesized that ungulates, through browsing and trampling, can shift tree species composition in the forest's understory. This may lead to changes in the amount of litter, abundance and composition of soil invertebrates, which in turn may affect decomposition rates and nutrient cycling.

\section{Chapter six: general synthesis}

The overall synthesis of the thesis is presented where the main outcomes of each of the chapters are discussed and integrated to provide an overall picture of how ungulates affect Dutch temperate forest on sandy soils. These findings are then analysed in a broader perspective of temperate forest ecology and plant-animal interactions. Finally, recommendations for future research and the management of ungulates and temperate forests are provided.

\section{Study area and main species}

Research for this thesis has been carried out in the Veluwe region, a natural managed area located in the central part of the Netherlands. With a total extension of $1200 \mathrm{~km}^{2}$, it is the largest natural area in the country. This area was selected because ungulate abundance varies strikingly due to different management objectives of terrain owners; therefore, it is possible to study the effects of multiple ungulate species on forest regeneration. The Veluwe has 
brown podzols developed on a parent material of Pleistocene loamy sands (Kuiters \& Slim 2002). This poor sandy soil provides the advantage that ungulate impact is much higher than in more fertile soils because plants have unlimited resources to develop (Cromsigt \& Kuijper 2011). Stakeholders from this area plan to transition the century old scots pine to a mix forest composed of conifer and broadleaf species; hence, it is necessary to understand how ungulates intervene in this transition.

In terms of environmental characteristics, annual average precipitation is $900 \mathrm{~mm}^{-1}$ with an annual average temperature of $9.4^{\circ} \mathrm{C}$, with a minimum of $2.5^{\circ} \mathrm{C}$ in January and a maximum of $16.4^{\circ} \mathrm{C}$ in July. The area, which is characterized by having small hills and ridges, is covered by a combination of woodland, drift sands and heathland. Forest is the predominant vegetation, with two thirds of the total extension; the different forest fragments are connected by wildlife corridors. The main plant species are Pinus sylvestris, Quercus rubra, Quercus robur, Fagus sylvatica, Picea abies, Larix kaempferi, Pseudotsuga menziessi, and Betula pendula. On the other hand, the assemblage of ungulates is composed by Cervus elaphus (red deer), Dama dama (fallow deer), Capreolus capreolus (roe deer), Sus scrofa (wild boar) and in some places Ovis orientalis (mouflon) (Kuiters \& Slim 2002).

Box 1.1. Scientific terminology. Glossary with concepts and their respective definition, which are generally used throughout the entire thesis.

Abiotic conditions - non-living factors such as light availability, soil conditions and precipitation, that can influence organisms and the functioning of the environment.

Alternative stable states - Ecological systems may have several ecological states that shift from one to the other after a perturbation. Each stable state has its own set of unique environmental conditions and community types (Scheffer et al. 2001), for example forest and heathland.

Apex predator - predator on top of the food chain, for example: grey wolves.

Biotic conditions - are considered all the living organisms that can influence the natural system, such as: autotrophs and heterotrophs.

Bottom-up control - occurs when lower trophic levels in an ecosystem control the population or structure of higher trophic levels.

Cascading effects - often occurs when the abundance or behaviour of a species in a certain trophic level is altered and consequently the effect modifies the lower or upper trophic level by suppressing or releasing it (Folke et al. 2004).

Ecosystem resilience - The capacity of an ecological system to recover and bounce back into the initial conditions after a perturbation, including species composition, ecosystem structure and functioning (Holling 1973).

Forest diversity - is the variation of species that are present within an ecological community, which is often measured as species number.

Forest structure - refers to how forests are organized in terms of a vertical layering (emergent layer, canopy, understory and forest floor), as well as the horizontal distribution of forests (forest patchiness).

Forest functioning - species and the physical environment of a system can be seen as one dynamic unit that is responsible for driving a specific set of processes. E.g., organic decomposition is mainly driven by invertebrates and temperature (Reiss et al. 2009). 
Metabolic weight - refers to the amount of body tissue that absorbs and metabolises nutrients (e.g. muscle) in a species body, rather than total body weight. Metabolic weight is calculated with the following formula: weight $^{0.75}$ (Kleiber 1947).

Niche differentiation - Species that compete can coexist if they differentiate on how they use their environment - i.e., niche (Hardin 1960).

Palatability - can be defined as the appealingness of an specific food item, a palatable food normally includes good structure and taste that facilitates digestion and energy release (Gill 1992a).

Tipping point - is the point at which a relatively small disturbance promotes a switch in the ecosystem stable state. At this point, the ecosystem may no longer be able to return to its original state (Scheffer et al. 2001).

Top-down control - occurs when higher trophic levels in an ecosystem control the population or structure of lower trophic levels.

Trophic level - is the physical position of an organisms in the food chain, normally the number of steps from the beginning of the food chain is equivalent to the trophic level.

Trophic rewilding - occurs when a species is reintroduced into a system with the aim of triggering a cascading effect on other trophic levels. Usually trophic rewilding is applied for restoring an ecosystem (Svenning et al. 2015). 


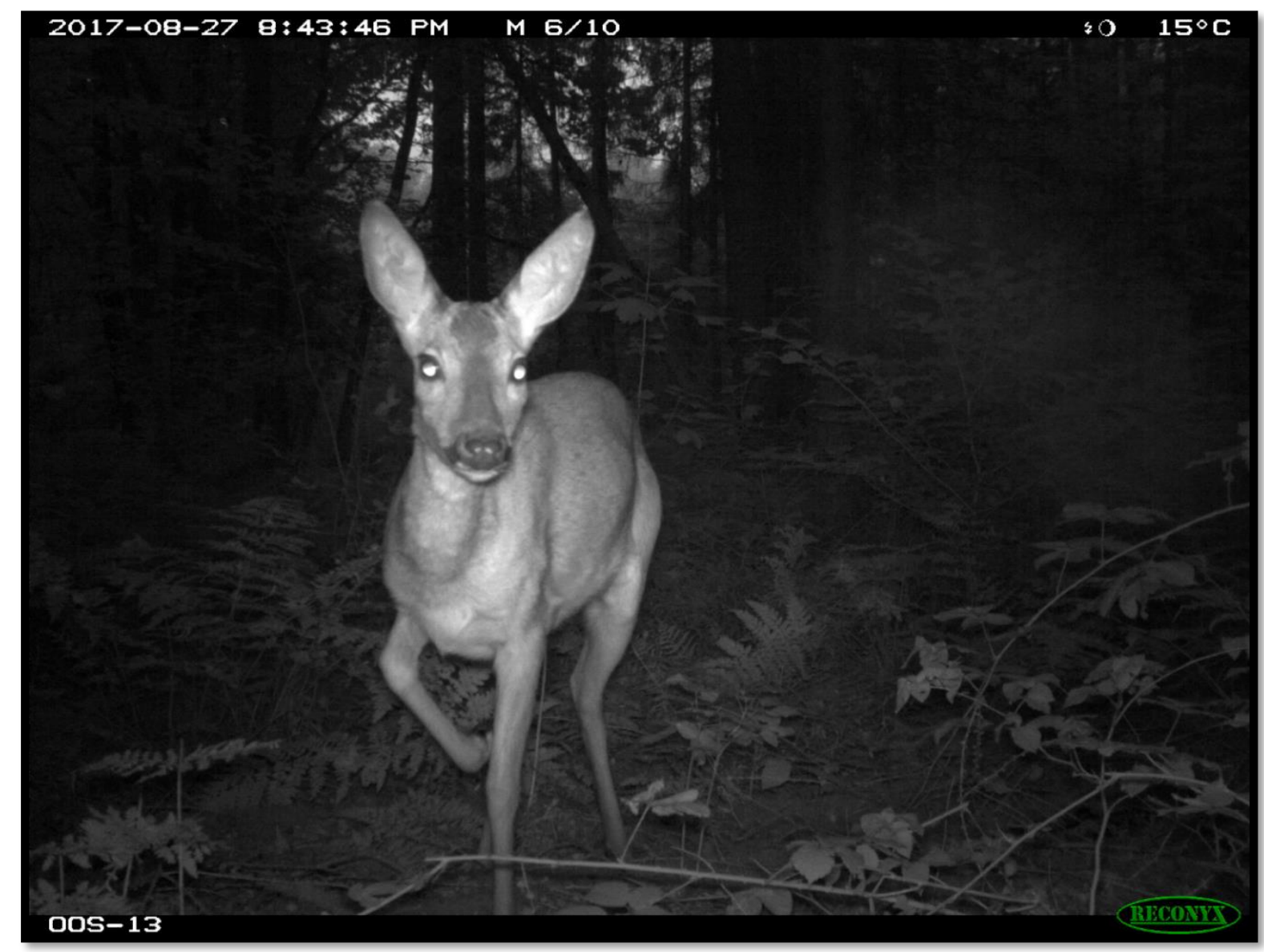




\section{CHAPTER TWO}

Effects of wild ungulates on the regeneration, structure and functioning of temperate forests: a semi-quantitative review

Published in Forest Ecology and Management 424 (2018) 406-419

Authors

Juan Ignacio Ramirez; Patrick A. Jansen \& Lourens Poorter 


\section{Abstract}

Wild ungulates such as red deer, roe deer and wild boar are key drivers of forest ecosystems. Across the northern hemisphere, their range and abundance are increasing, while at the same time forest conversion and habitat fragmentation have led to a large variation in ungulate density and composition among areas. Understanding ungulate density impacts are important in order to prevent shifts towards undesired states, such as from forest to heathland Here, we assess the effects of ungulate density on forest regeneration, development and functioning. We carried out a systematic literature review of 433 published studies in temperate forests, and used the data to model dose-response curves of the effects of ungulate density on three sets of forest attributes; tree regeneration (abundance, species richness and composition), forest structure (horizontal and vertical), and forest functioning (nutrient cycling in soil, timber and food production). Ungulate density averaged $23.6 \mathrm{~km}^{-2}$ across studies. Ungulates had a negative effect on forest regeneration, structure and functioning in $70 \%$ of the evaluated cases. The dose-response curves had a sigmoidal, rather than a unimodal shape. Critical tipping points, where ungulates started to have a negative effect on forest regeneration, were found at an ungulate metabolic weight density of $115 \mathrm{~kg} \mathrm{~km}^{-2}$ for forest regeneration, $141 \mathrm{~kg}$ $\mathrm{km}^{-2}$ for forest structure, and $251 \mathrm{~kg} \mathrm{~km}^{-2}$ for forest functioning, which is roughly equivalent to 10,13 and 23 roe deer per $\mathrm{km}^{2}$. Forest regeneration was most sensitive to immediate browsing and trampling impacts of small seedlings, while forest functioning was least sensitive because of time lags. However, these effects may build up over time. We suggest research priorities for studying ungulate-plant interactions in temperate forests, and make management recommendations how to balance wildlife with a functioning forest.

\section{Abbreviations}

MWD = metabolic weight density

\section{Introduction}

Wild ungulates are increasing in density across the northern hemisphere (Clutton-Brock \& Albon 1992; Reimoser 2003; Pellerin et al. 2010a) because of ungulate reintroduction, abandonment of agricultural land, competitive release from domestic ungulates, absence of top predators, stricter hunting regulations and improvement of habitat quality (Kuiters et al. 
1996; Rooney 2001; Côté et al. 2004). Apart from inter-annual fluctuation, habitat quality and predation, conversion of natural forests to managed forests (Gordon \& Prins 2008) has led to the isolation of ungulates in different forest fragments (Kuiters et al. 1996). This has resulted in a large variation in ungulate density between fragments, and hence, a large variation in ungulate effects on the environment. Many temperate forests currently harbour large ungulate populations resulting in intensive plant-animal interactions. Whether these population levels are acceptable is the subject of intensive debate among stakeholders (Horsley et al. 2003).

Ungulates affect ecosystems through browsing, trampling, fraying, stripping, uprooting, defecating and seed dispersing (Bruinderink \& Hazebroek 1996; Reimoser 2003; Pellerin et al. 2010a). These interactions are key determinants of the structure and dynamics of woody ecosystems. For instance, when ungulates are regulated naturally by predation and intraspecific competition, large herbivores can remove up to $10 \%$ of the above ground vegetation. These regulations include: bottom-up control, where plants limit ungulate populations by chemical and structural defences that prevent herbivory, and top-down control, where predators regulate ungulates by predation (Terborgh et al. 2001).

Ungulates affect ecosystems at different organizational, spatial, and temporal scales, ranging from the local patch up to the landscape scale. For instance, removal of the vegetation biomass has implications for local plant composition and structure, and with time this may lead to changes in soil fertility and the landscape, thus affecting the entire food web. (Gordon \& Prins 2008; Prins \& Fritz 2008; Svenning et al. 2015). Their effect can enhance or reduce natural processes and patterns; which may directly affect species regeneration, forest structure and ecosystem functioning (Reimoser 2003).

Whether ungulates have a positive or negative impact on ecosystems depends on their density, browsing intensity, local biotic and abiotic conditions, and forest management (Van Hees et al. 1996; Heckel et al. 2010; Pellerin et al. 2010a). Because of their important role in ecosystem functioning, ungulates are considered to be keystone species and landscape modifiers (Rooney 2001). Hence understanding the relationship between ungulate abundance and forest regeneration is fundamental.

Whether ungulates have positive, neutral, or negative effects on forest attributes depends on the shape of the dose-response curve and lag times (Nuttle et al. 2014). The most plausible shape of this dose-response curve is unimodal (Rooney \& Waller 2003). At low 
ungulate density, forests have a low plant species diversity because of a structurally uniform and dense vegetation with little heterogeneity in light and habitats. At intermediate ungulate density, forests have higher habitat heterogeneity due to vegetation removal, seed bed preparation (by litter removal and soil disturbance), and seed dispersal (Lucas et al. 2013). At the same time, ungulates may steer plant competition and succession through selective browsing on palatable species, thus facilitating the establishment of other plant species (Kuiters et al. 1996; Fuller \& Gill 2001; Brullhardt et al. 2015). Furthermore, as a result from low ungulate trampling, soil compaction is low and thus facilitating seedling establishment. At high ungulate density, however, tree regeneration is hampered by over-browsing, while selective browsing may lead to suppression of palatable species thus reducing tree species diversity (Tyler et al. 2008; Schippers et al. 2014). In ecotone transitions, it is even possible that forest shifts towards an alternative stable grassland state (Côté et al. 2004), with a high degree of soil compaction, low stem density and almost no canopy cover.

Understanding ungulate density impacts are important in order to prevent shifts towards undesired states, such as from forest to heathland (Scheffer et al. 2001; Folke et al. 2004). However, despite a wealth of studies that have assessed the effect of ungulates on vegetation, we know very little about the shape of the dose response curve between ungulate density and forest attributes, and whether there are critical thresholds and tipping points (Putman et al. 2011a; Reimoser \& Putman 2011).

Here, we aim to 1) provide a synthesized review on the effects of ungulate density on the regeneration, structure and functioning of temperate forests, from both northern and southern hemispheres, 2) quantify the dose-response relationships between ungulate densities and forest attributes, and 3) identify potential thresholds and tipping points for each dose-response. Our study provides a first global average estimate of what ungulate densities may be critical for forest development in temperate zone. We then discuss ungulate management strategies and identify research priorities for animal-plant interactions in temperate forests.

\section{Methods}

We searched three literature data bases (CAB Abstract, Web of Science and Scopus) for scientific publications on the effects of wild ungulates on temperate deciduous forests. 
Although ungulate species are currently increasing in range and density especially in Central Europe and North America, ungulate species from other continents were included as well to have a wider overview. We used the following combination of keywords: "(mammals or mammal or mammalia or deer or mouflon or wild boar) and (forest or trees or forests) and (seed dispersal or browsing or trampling or stripping or defecating or rooting or fraying) and (structure or species richness or abundance or functioning) and (temperate or seasonal or deciduous)". We retrieved 469 articles, from which 164 studies were utilized for our analysis because they yielded information on the study region, ungulate species, ungulate abundance and effects on different forest response variables. All extracted information was organized in an Excel file by response variable. For each reported case, corresponding information on the type of effect, ungulate species, ungulate abundance/density and research area was incorporated.

\section{Forest responses}

All response effects were then grouped into three broad response attributes, each consisting of 2-3 similar forest components. This was done in order to have enough data points and statistical power for the analysis. The three forest response attributes consist of forest regeneration (i.e., the amount, diversity, and seedlings and saplings composition), forest structure (i.e., horizontal patch structure and vertical forest layering), and forest functioning (i.e., nutrient cycling in soil, tree growth and provision of wild forest food). Because studies differed widely in the temporal scale, survey design, environmental conditions, response variables used and measurements procedures, we quantified ungulate effects in a qualitative way, mainly to enhance comparability across a large array of heterogeneous studies. For each response variable, it was evaluated whether ungulate presence or density had a significantly positive (1), significantly negative (-1), or no significant effect (0). In total, we compiled 435 cases.

\section{Ungulate density}

For each study, the ungulate species and density were recorded. To be able to assess the combined effects of different species, ungulate density was expressed as metabolic weight density (MWD) using the following formula: MWD $=$ mass $^{0.75}$ (Kleiber 1947). This allowed the standardization of ungulate density based on their nutritional needs. A standard body 
mass (in kg) was used for the different ungulate species (Table 2.1). If a mix of ungulates was presented without identification we used $96 \mathrm{~kg}$ as an average for the most common cervidae species presented across the studies.

Table 2.1. Ungulate standard weight and representation of ungulate species from total number of reported species.

\begin{tabular}{lllll}
\hline Common name & Species & Weight & \% & Source \\
& & $\mathbf{( k g )}$ & & \\
\hline Buffalo & Bison bison & 650 & 1.1 & (Lott \& Galland 1987) \\
Elk & Alces alces & 425 & 3.6 & (Stephenson et al. 1998) \\
Red deer & Cervus canadensis & 250 & 1.9 & (Cook et al. 2003) \\
Sika deer & Cervus elaphus & 190 & 11.2 & (Gill \& Morgan 2010) \\
Wild boar & Cervus nippon & 110 & 5.8 & (Suzuki et al. 2001) \\
Fallow deer & Sus scrofa & 80 & 9.4 & (Genov \& Massei 2004) \\
White-tailed deer & Odoma dama & 65 & 2.8 & (Gill \& Morgan 2010) \\
Chamois & Rupicapra rupicapra & 35 & 1.1 & (Garcia-Gonzalez \& Cuartas 1996) \\
Roe deer & Capreolus capreolus & 25 & 7.1 & (De Jong et al. 1995) \\
Black-tailed deer & Muntiacus reevesi & 18 & 2.6 & (Parker et al. 1993) \\
Pudu & Pudu pudu & 12 & 1.1 & (Merino et al. 2005) \\
Ungulates & Mix of species & 96 & 24 & \\
\hline
\end{tabular}

\section{Statistical Analysis}

We compared the relative frequency of response types (positive, neutral or negative) for each forest component with Chi-square tests. We used Multinomial Logistic Regression analysis to fit dose-response curves, in which ungulate density was expressed in terms of MWD, and ungulate effects were classified as being significantly positive (1), not significant (0) or significantly negative (-1). All model assumptions are met, such as: an independent continuous variable, a nominal continuous variable, independent observation, low multi-collinearity and large sample size. The independent variable, MWD, was transformed to $\log _{10}$. These models have a sigmoid shape. To allow for unimodal responses to ungulate density, we evaluated whether adding the square of ungulate density significantly improved the model (Augustin et al. 2001; Merino et al. 2005). Dose-response curves were fitted for all three forest attribute responses (forest regeneration, forest structure and forest functioning) to increase power and obtain generalities, as well as for each of the individual 8 response variables to obtain more 
detailed insight. For each analysis, we calculated $\mathrm{Chi}^{2}$, the coefficient of determination, the probability value and the degrees of freedoms of the model. To identify critical ungulate densities that reflect tipping points in forest response, we quantified at what ungulate density value did the average response value, as fitted by the curve, became greater than 0.5 (from neutral to positive) or smaller than -0.5 (from neutral to negative).

\section{Results}

Ungulate effects on forest regeneration, structure, and functioning

From the total of 435 cases compiled, 50.5\% were situated in North America, 31.9\% in Europe, $7.2 \%$ in Oceania, $6.8 \%$ in Asia and $3.6 \%$ in South America. Ungulates had a significantly negative effect on forest attributes on most (70\%) of the cases. In $11 \%$ of the cases a significantly positive effect was reported, ranging from food production with $0 \%$ to horizontal structure with $22 \%$ (Fig. 2.1). In $19 \%$ of the cases no effect was detected.

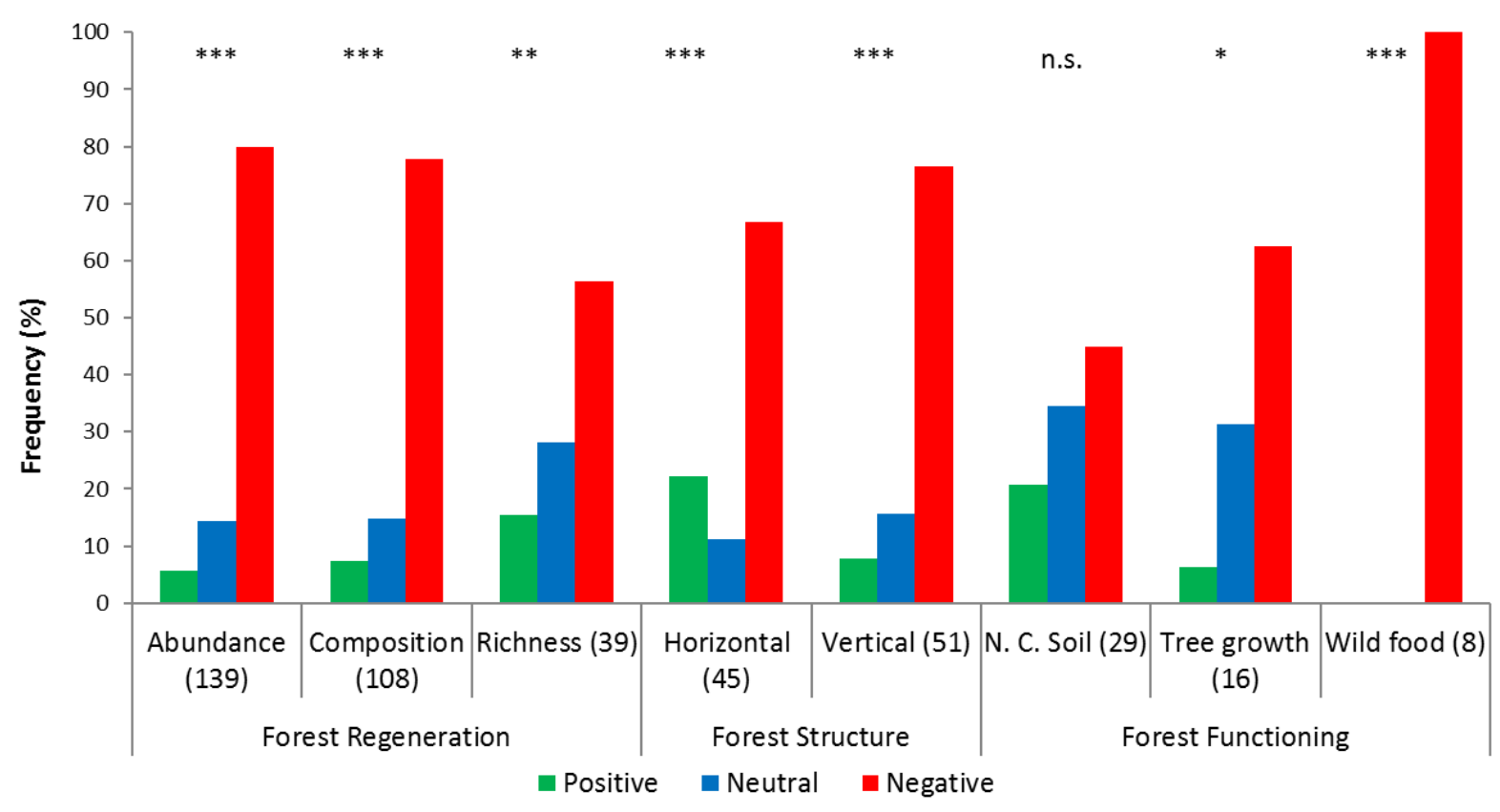

Figure 2.1. Relative frequency of ungulate effects (significantly positive, neutral, or significantly negative) on forest regeneration (abundance, composition and richness), forest structure (horizontal and vertical) and forest functioning (nutrient cycling in soil and the provision of food and timber). The sample size is given in parentheses. Significant differences in the relative frequency of response types (positive, neutral or negative) within a forest component are tested with a Chi-square test (d.f. $=2$ ) and indicated by asterisks. ${ }^{*} P<0.05,{ }^{* *} P<0.01,{ }^{* * *} P<0.001$ and n.s. $P>0.05$. 
Negative effects of ungulates were most frequently reported for wild food provision (in 100\% of 8 cases), on regeneration abundance (in $79 \%$ of 139 cases) and forest composition (in $78 \%$ of 108 cases). Positive effects were most frequently reported for horizontal forest structure (in $22 \%$ of 45 cases) and on nutrient cycling in soil (in $21 \%$ of 29 cases). Finally, ungulates had most often non-significant effects on timber production (in $31 \%$ of the cases) and nutrient cycling in soil (in 35\% of the cases).

Ungulate densities varied from $<1$ to $>300 \mathrm{~km}^{-2}$ across studies. Average ungulate density was greater for studies that reported a negative effect on forest attributes (on average 28 ind $\mathrm{km}^{-2}$ ), than for studies that reported positive or neutral effects on the different forest attributes (on average 15 and 11 ind $\mathrm{km}^{-2}$ respectively) (Fig. 2.2).

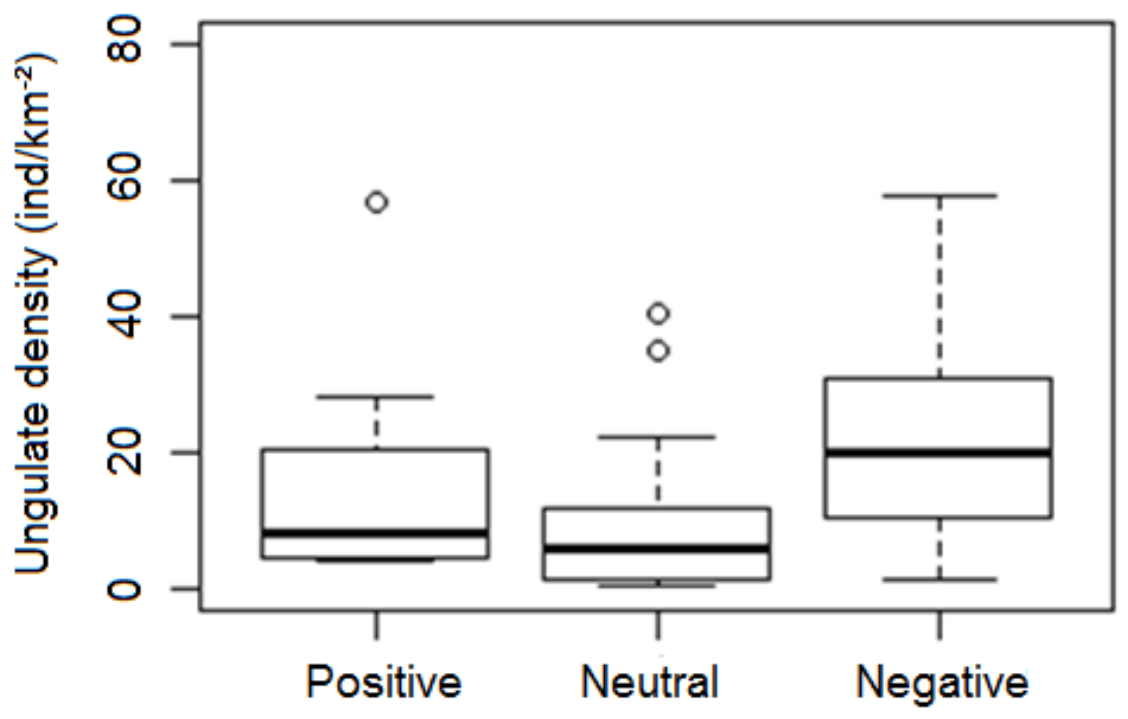

Figure 2.2. Positive, negative and neutral effects of wild ungulates on different forest attributes are associated with different ungulate densities (Kruskal-Wallis test, Chi square $=16.78, P<0.001$ ). The reported number of cases are 20 for positive, 39 for neutral and 162 for negative. Boxplots of ungulate densities are shown and their significance test; positive vs. neutral $P=0.081$, positive vs. negative $P<0.000$, neutral vs. negative $P<0.000$ (pairwise-Mann-Whitney U test). Horizontal "line" indicates the median. The "box" represents the middle 50\% of scores for the group. The upper and lower "whiskers" represent scores outside the middle 50\%. Outliers are plotted as individual "points".

\section{Dose-response relationships}

The dose-response curves (Fig. 2.3, Appendix A.1) reported effects on forest attributes, which were more negative as ungulate abundance increased. This was the case for forest regeneration (Multinomial logistic regression, $\mathrm{X}^{2}=36.80, \mathrm{R}^{2}=0.20, \mathrm{P}<0.001$, $\mathrm{df}=2$, Fig. 2.3), 
forest structure $\left(X^{2}=24.88, R^{2}=0.33, P<0.001, d f=2\right.$ Fig. 2.3), as well as forest functioning $\left(X^{2}=7.84, R^{2}=0.22, P=0.02, d f=2\right.$ Fig. 2.3$)$. The dose-response curves were generally sigmoidal declining, and no unimodal curves were found. The thresholds, where ungulates tended to switch from generally neutral effects towards significantly negative effects was observed at a value of -0.5 . The threshold was lowest $\left(\log _{10} 2.06\right.$, or $115 \mathrm{~kg}$ of metabolic weight $\left.\mathrm{km}^{-2}\right)$ for forest regeneration, the threshold occurred at intermediate ungulate density $\left(\log _{10} 2.15\right.$ or $141 \mathrm{~kg} \mathrm{~km}^{-2}$ ) for forest structure and the threshold occurred at highest ungulate densities ( $\log _{10} 2.40$ or $251 \mathrm{~kg} \mathrm{~km}^{-2}$ ) in the case of forest functioning. Across the evaluated studies, the average MWD was $\log _{10} 2.306$ or $202 \mathrm{~kg} \mathrm{~km}^{-2}$.

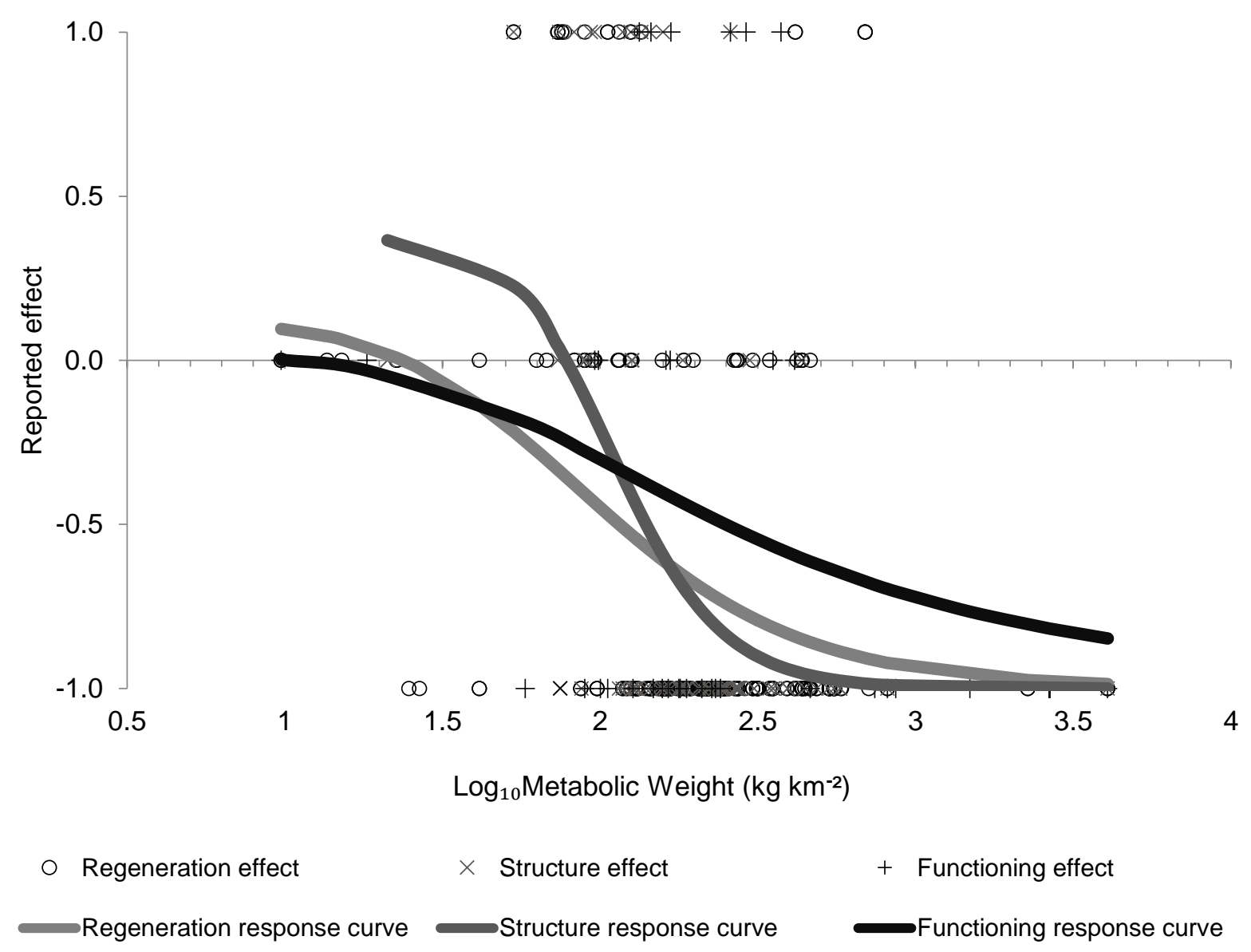

Figure 2.3. Dose-response relationship between Metabolic Weight Density and the probability of studies reporting a significantly negative (-1), neutral (0) or significantly positive (1) effect on each forest attribute - Forest regeneration ( $N=221$ cases), forest structure $(N=84)$ and forest functioning $(N=42)$ - summarized with multinomial logistic regression curves. Each of the forest attributes are shown with different shades of grey and different symbols. 


\section{Discussion}

How ungulates affect temperate forests is a major concern of forest and nature managers, especially in regions where ungulates are increasing in abundance (Pellerin et al. 2010a). This study is the first semi-quantitative review on the effects of ungulate abundance on temperate forests at a global scale. Dose-response curves that we fitted to link reported effects of ungulates to ungulate density revealed that effects on a variety of forest characteristics changed from neutral to generally negative as ungulate density increased. There was no optimum density for a positive effect on forests, but rather a gradual decline with an increasing density, followed by a steep decline (inverted sigmoidal curve). As ungulate density increased, there was a rapid shift from neutral to negative effects on the regeneration, structure and functioning of forests around a MWD of $169 \mathrm{~kg} \mathrm{~km}^{-2}$, which is equivalent to 15 roe deer per $\mathrm{km}^{2}$ or 8 white-tailed deer per $\mathrm{km}^{2}$.

\section{Ungulate effects on forests}

Negative effects were clearly more frequent than positive and neutral effects (Fig. 2.1). From all response variables, ungulates had the strongest negative effect on food production (in $100 \%$ of the cases), although the sample is too small $(\mathrm{N}=8)$ to draw strong conclusions. Regeneration abundance and forest composition decreased in $79 \%$ and $78 \%$ of the cases, as selective browsing reduced the abundance of palatable species and increased the abundance of less palatable species through competitive release (Schippers et al. 2014).

Ungulates had the strongest positive effect on horizontal forest structure (in $22 \%$ of the cases). This is explained by the fact that ungulates create horizontal heterogeneity by generating open areas by vegetation removal and by dispersing seeds, thus promoting tree species distribution across the forest (Eycott et al. 2007). Nutrient cycling in soil increased (in $21 \%$ of the cases), as ungulates increase nutrient availability and heterogeneity through defecation and litter removal from the forest floor (Murray et al. 2014).

Ungulates had most often neutral, i.e., non-significant effects on timber production ( $31 \%$ of the cases) and nutrient cycling in soil (in $35 \%$ of the cases), probably because a larger time span (>50 years) is needed for ungulates to affect wood production (Welch \& Scott 1998) and the entire trophic levels in order to change local soil conditions. 
Thresholds: ungulate densities

Our results indicate that ungulates negatively affect regeneration in temperate forests beyond densities of $115 \mathrm{~kg} \mathrm{~km}^{-2}$ (MWD), which is equivalent to 2.3 red deer, 4.3 wild boar, 5.3 whitetailed deer or 10.2 roe deer $\mathrm{km}^{-2}$. The high apparent sensitivity of regeneration to ungulates is probably because seedlings and saplings are relatively vulnerable to intermediate browsing and trampling, and because seedlings and saplings are highly dynamic and respond rapidly to environmental change. Our results are similar to the threshold density of 4 red deer suggested in a Scottish forest study (Putman et al. 2011a), but below the suggested threshold density of 14 deer $\mathrm{km}^{-2}$ for a mix of deer species (roe, muntjac and fallow deer) in a lowland UK forest (Gill \& Morgan 2010). This variation can be explained by a combination of primary productivity and ungulate composition. Our estimates are not representative for one particular area, but represent the general pattern across all temperate forests globally.

We found that ungulates negatively affect forest structure beyond a MWD of $141 \mathrm{~kg}$ $\mathrm{km}^{-2}$, which is equivalent to 2.7 red deer, 5.2 wild boar, 6.5 white-tailed deer or 12.5 roe deer. The fact that the threshold is higher than forest regeneration reflects that stem density and development of less palatable species is relatively insensitive to ungulates. Our estimates are similar to stem density thresholds reported in earlier studies, e.g., 8 white-tailed deer $\mathrm{km}^{-2}$ in a Pennsylvanian forest (Horsley et al. 2003) and 4-8 white-tailed deer in a Wisconsin forest (Alverson et al. 1988).

Finally, forest functioning was negatively affected beyond a MWD of $251 \mathrm{~kg} \mathrm{~km}^{-2}$, which is equivalent to 4.9 red deer, 9.4 wild boar, 11.6 white-tailed deer or 22.5 roe deer. The threshold is again higher for forest functioning, probably because browsing limits regeneration growth and reproduction. These threshold estimates are similar to 4 red deer $\mathrm{km}^{-2}$ in a British forest (Holloway 1967) and 7-15 white-tailed deer per $\mathrm{km}^{-2}$ in a Pennsylvanian forest (Tilghman 1989), but much higher than 4-12 roe deer reported in a British commercial forest (Reimoser \& Putman 2011). This variation can be explained by different methods used to estimate ungulate density and their effect on vegetation, as well as other factors that mediate these interactions such as primary productivity. For example, more fertile soils and higher primary productivity allow for higher ungulate densities (Cromsigt \& Kuijper 2011).

Our multinomial logistical regression analysis was only based on whether a significant ungulate effect (positive or negative) was detected in the original studies, and not based on effect sizes. This allowed us to include a greater number of studies with a variety of 
methodologies. Future research could study effect sizes, to get a more precise estimate of ungulate impacts.

Although our data came from temperate forest studies from all continents, most cases (82\%) came from North American and European forests, reflecting the common bias in research efforts. Similarly, due to our search criteria, we recognise that our study has bias towards deer species, relegating other wild ungulate species, such as: moose and elk.

We acknowledge that not all temperate forests respond equally to different ungulates densities and composition, hence that a single dose-response relationship cannot represent the reality of all temperate deciduous forests. We used MWD rather than absolute density, taking the metabolic properties of these different species into account. We acknowledge that such an approach is still not perfect because ungulate species also have different behaviour, that is not entirely explained by their metabolic weight. The tipping points we have identified are likely to be higher in more fertile systems, and lower in more infertile systems (Cromsigt \& Kuijper 2011).

Managing ungulate effects on forests; towards an optimal ungulate density

Our results suggest that switching from negative to neutral or even positive ungulate effects it is necessary to reduce ungulate densities, at least temporarily. Such a release of plants from natural enemies provides a time window of opportunity for tree regeneration (Nuttle et al. 2014). Once saplings attain a minimum size (e.g., 1.6 or $2.0 \mathrm{~m}$ in height, depending on the particular ungulate assemblage) they can escape herbivore pressure, because their top shoot is out of ungulate reach, and because plants are sufficiently robust to recover from herbivory (Motta 2003; Renaud et al. 2003) and fraying. The time window needed for forest recovery depends on seed availability and tree species growth rate. Hence, for lowland central Europe it will be relatively short (i.e., 3 years) for fast-growing light-demanding species (e.g., Betula pendula and Pinus sylvestris), the time window of recovery will be relatively long (i.e., 10 years) for slow-growing and palatable species (Quercus robur, Quercus petrea, and Tilia cordata). Whereas if the system experiences neutral or even positive effects from ungulates, it is expected that the three main plant defence mechanisms (resistance, tolerance and escape) are enough to secure their establishment and reproduction (Lindroth \& St. Clair 2013).

Forest managers and stakeholders can enhance forest heterogeneity at different spatiotemporal scales by rotating ungulate exclosures at different frequencies (e.g., 3-10 
years) and sizes (e.g., 0.1-1 ha) (Augustine \& Frelich 1998), by offering alternative foliage for ungulates, changing landscape structure such as shelter provision or even by modifying the forest edge (Reimoser \& Putman 2011). Forest managers can also steer the landscape of fear by reintroducing top predators (Sergio et al. 2008), varying hunting pressure over space and time (Cromsigt et al. 2013), or managing ungulate sex ratio within a population, for instance limiting the number of reproducing females (Clutton-Brock et al. 2004).

Rewilding natural areas with apex predators, might bring ungulates density into balance again and thus secure regeneration establishment and development. Predators can eventually restore top-down interactions and associated cascading effects that culling and game hunting have failed to achieve. On natural areas trophic rewilding gives the opportunity of self-regulation, thus providing new opportunities for the entire ecological community and reducing human interference (Svenning et al. 2015).

\section{Research priorities and outlook}

We used qualitative data to characterize the responses from a wide variety of temperate forests and showed a non-linear relationship between ungulate density and forest regeneration (Gill \& Morgan 2010). However, the coefficient of determination was rather low, indicating a high variability among independent and dependent variables. To better understand how ungulate density affects forest development, the dose-response curves should be produced more accurately. Our study is a first important step based on data from literature review, but results were combined from studies in many different forest systems, which used different methods to quantify ungulate densities and forest responses. Modern techniques, such as surveys with camera traps, can provide more accurate and more standardized ungulate density estimates, by detecting animals with a wide range in body sizes and different levels of shyness, 24 hrs per day (Rowcliffe et al. 2011).

\section{Conclusions}

Understanding effects of wild ungulates is essential to the management and conservation of temperate forests. Much of the recent debate on ungulate management has focused on the carrying capacity of forests from an animal perspective. However, for managers, it is also important to identify how many ungulates a forest can handle before forest regeneration is compromised. Our results suggest a crucial role of ungulate density in forest regeneration, 
structure, and functioning. At low ungulate density forest regeneration, structure and functioning are maintained, whereas at intermediate to high ungulate densities the different forest attributes are negatively affected.

\section{Acknowledgements}

This work was supported by the Secretaría de Educación Superior, Ciencia, Tecnología e Inovación del Ecuador, Convocatoria Abierta 2012. 


\section{Appendix A.}

\section{A.1 Multinomial regression curves for forest regeneration}

Abundance refers to the amount of seedling, saplings and poles in the forest. Multinomial logistic regression, $X^{2}=21.33, R^{2}=0.25, P<0.001, d f=2$.

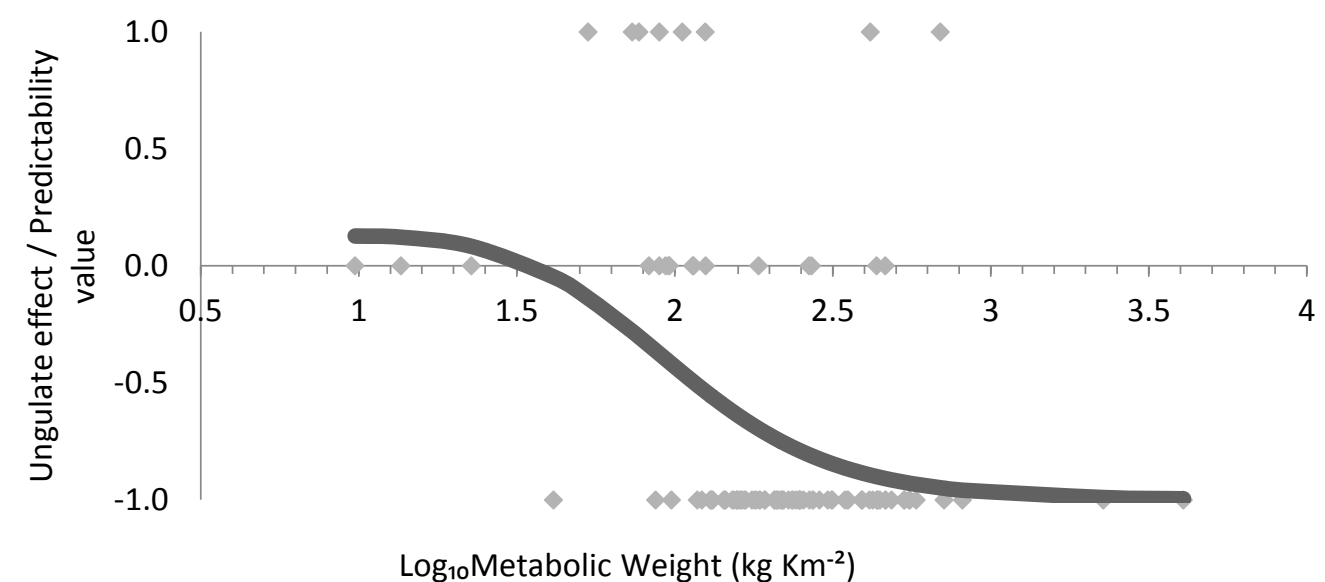

Diversity refers to species richness and diversity. Multinomial logistic regression, $X^{2}=1.54, R^{2}=0.05, P<0.463, d f=2$.

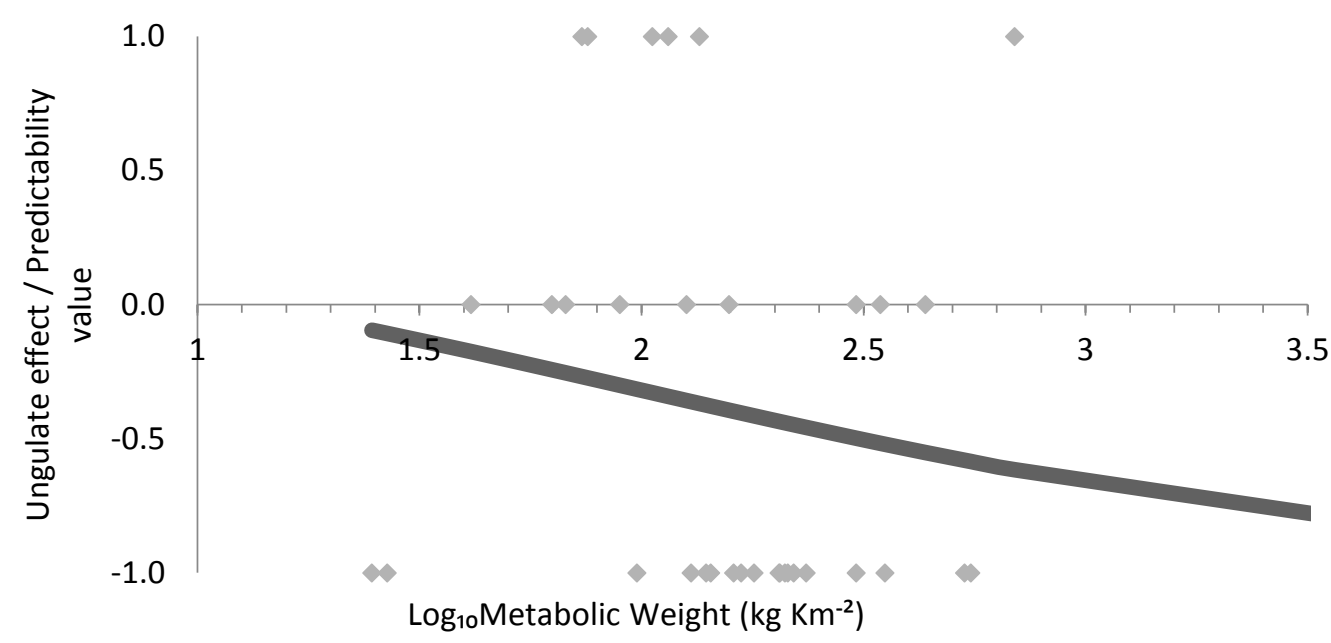


Composition refers to the proportion of a group of tree species compared to another group of tree species. Literature often compares conifer and broadleaved proportions. Multinomial logistic regression, $X^{2}=15.74$, $R^{2}=0.23, P<0.001, d f=2$.

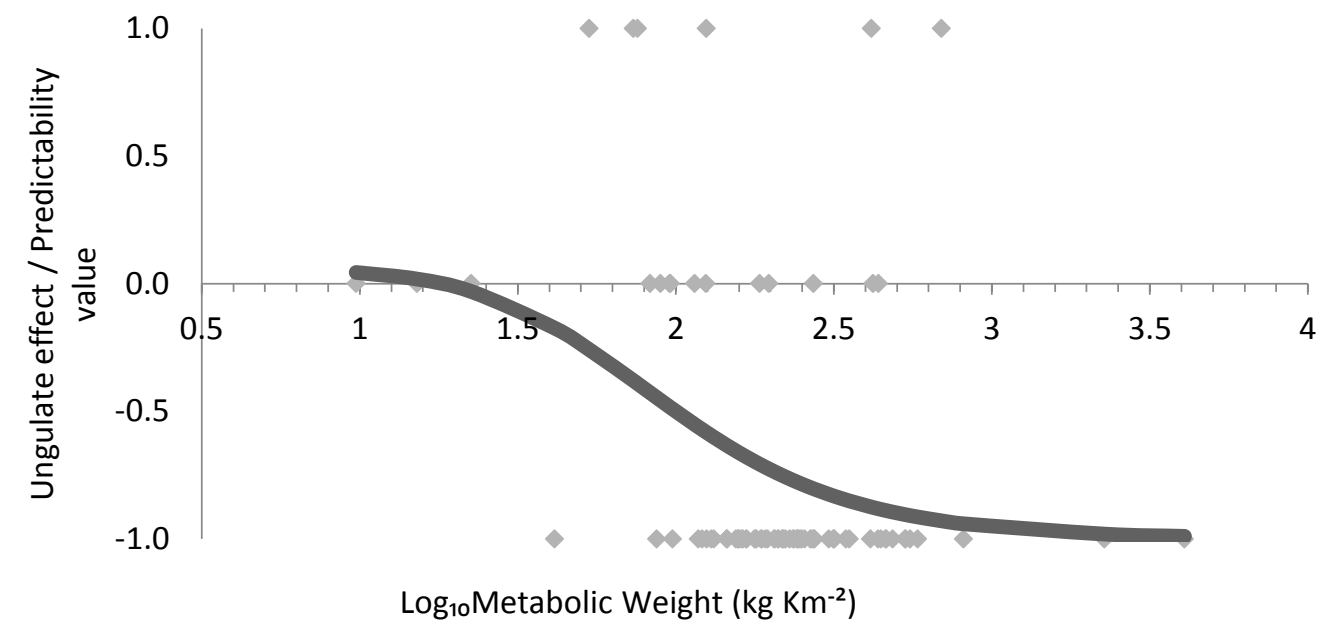

\section{A.2. Multinomial regression curves for forest structure}

Horizontal structure refers to the range and distribution of tree species in a forest. Multinomial logistic regression, $X^{2}=22.66, R^{2}=0.57 P<0.001, d f=2$.

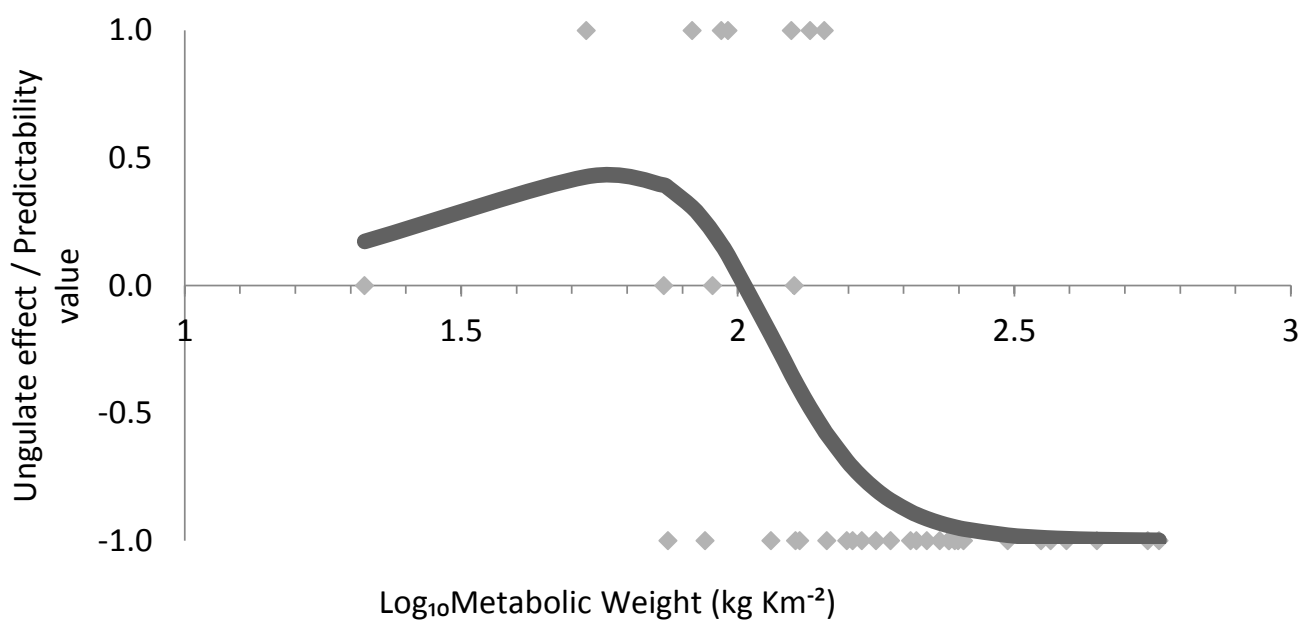


Vertical structure refers to the vertical layering of the forest, which includes undergrowth, understorey, canopy and emergent layer. Multinomial logistic regression, $X^{2}=7.28, R^{2}=0.20 P=0.026, d f=2$.

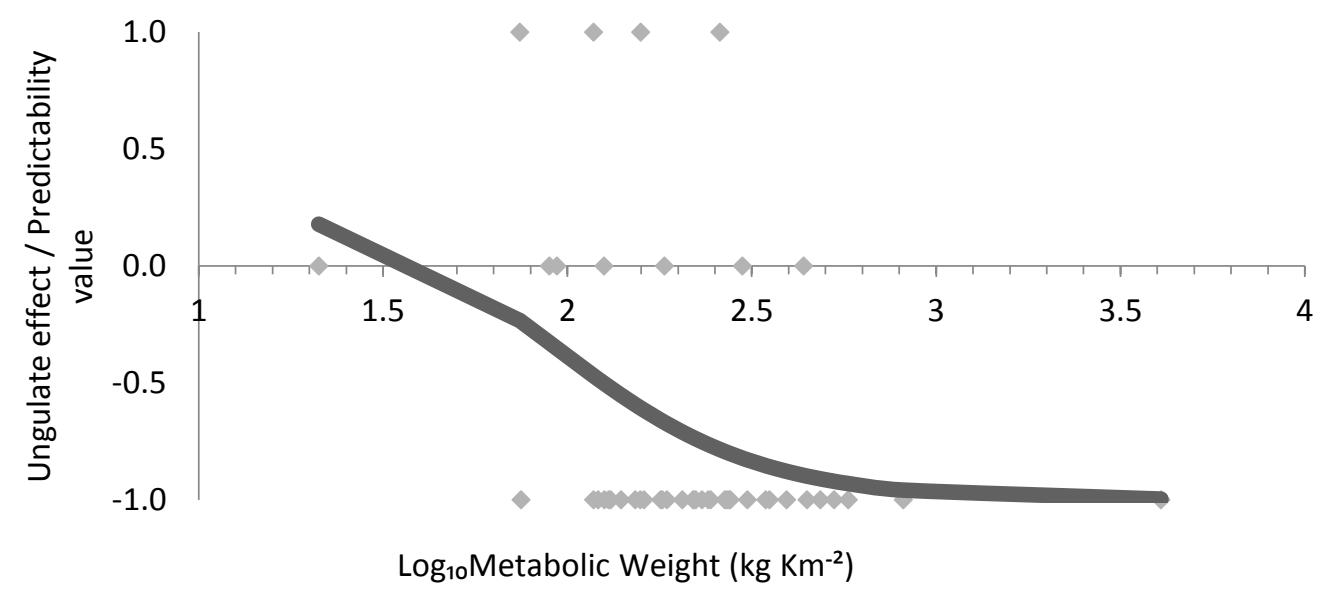

\section{A.3. Multinomial regression curves for forest functioning}

Nutrient cycling in soil refers to disruption of the processes related to the formation of soil and nutrient availability. Multinomial logistic regression, $X^{2}=9.57, R^{2}=0.39 P=0.008, d f=2$.

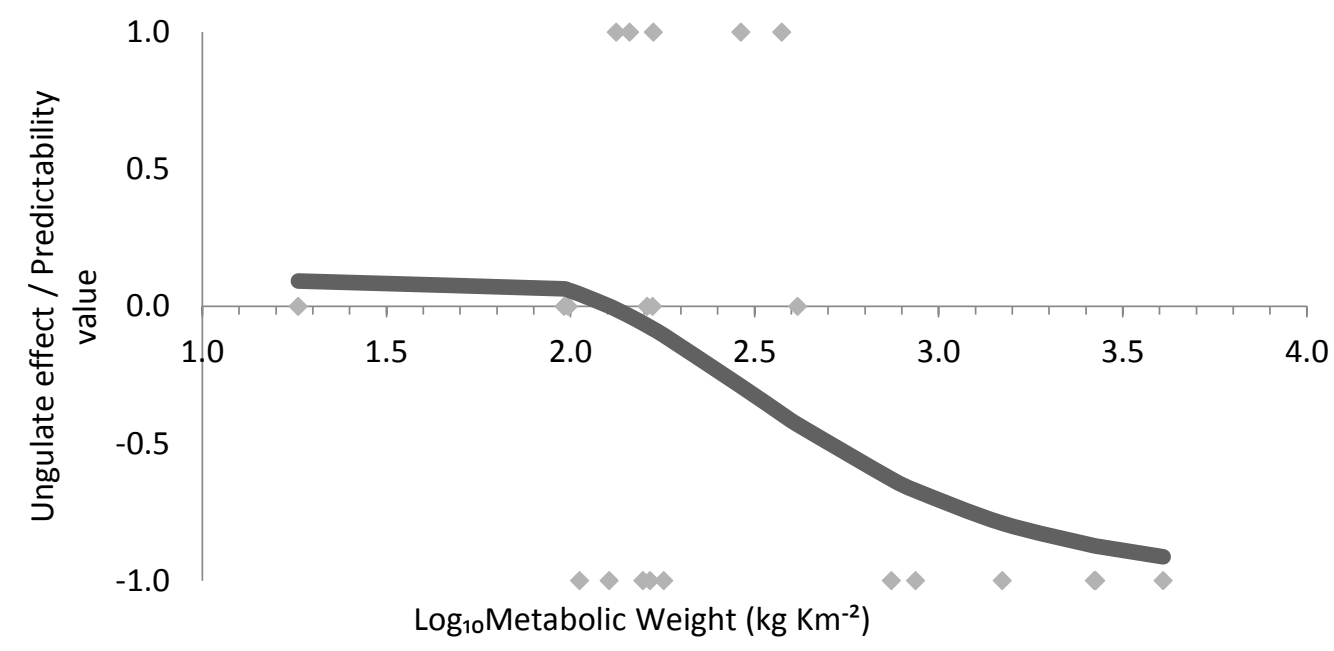


Tree growth refers mainly to the amount of woody biomass produced by trees. Multinomial logistic regression, $X^{2}=2.55, R^{2}=0.28 P=0.279, d f=2$.

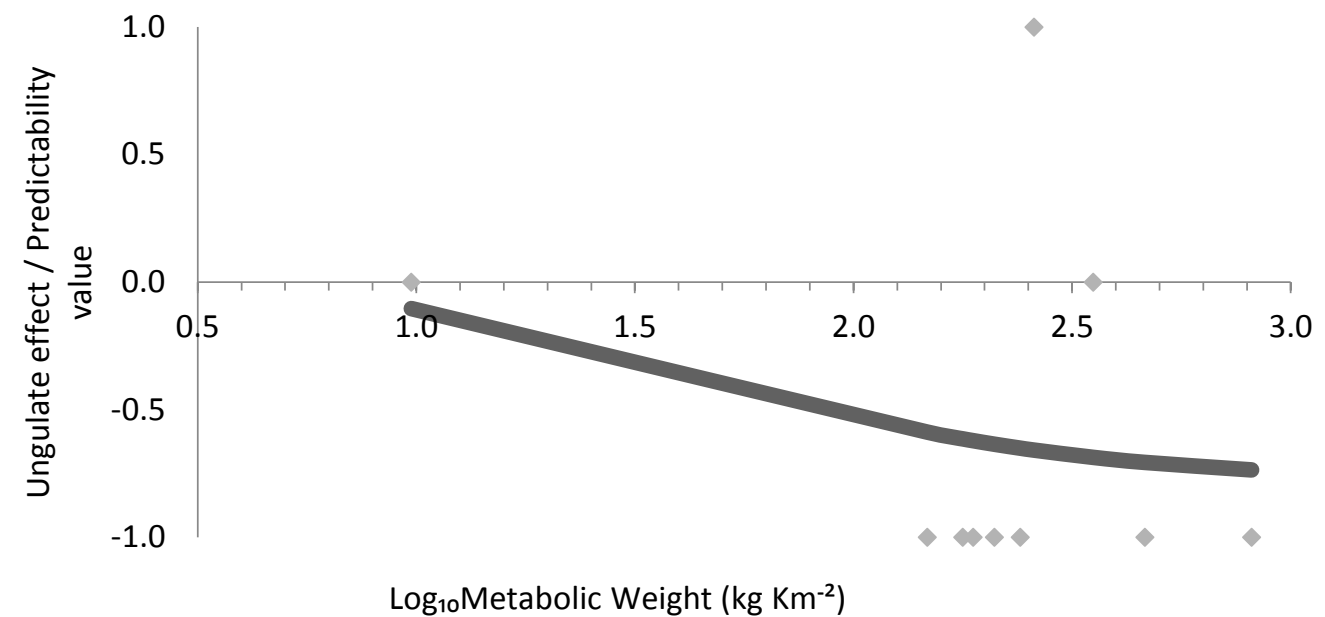

Wild food refers to the provision of wild food on forests, example fruits and nuts. Predicted regression curve does not apply due to insufficient sample size.

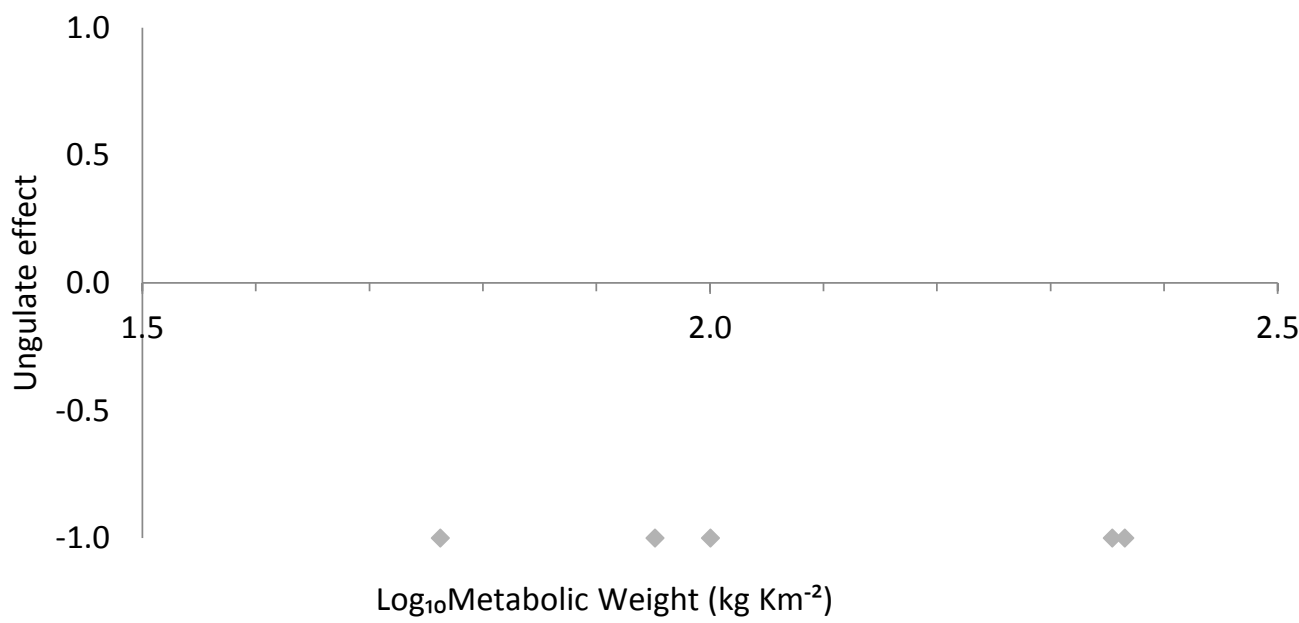




\section{Appendix B.}

\section{List of papers reviewed}

Abrams, M. D. (2003). Where has all the white oak gone? Bioscience, 53(10), 927-939. doi:10.1641/00063568(2003)053[0927:whatwo]2.0.co;2

Abrams, M. D., Copenheaver, C. A., Terazawa, K., Umeki, K., Takiya, M., \& Akashi, N. (1999). A 370-year dendroecological history of an old-growth Abies-Acer-Quercus forest in Hokkaido, northern Japan. Canadian Journal of Forest Research-Revue Canadienne De Recherche Forestiere, 29(12), 1891-1899. doi:10.1139/cjfr-29-12-1891

Abrams, M. D., \& Orwig, D. A. (1996). A 300-year history of disturbance and canopy recruitment for cooccurring white pine and hemlock on the Allegheny Plateau, USA. Journal of Ecology, 84(3), 353-363. doi:10.2307/2261198

Abrams, M. D., van de Gavel, S., Dodson, R. C., \& Copenheaver, C. A. (2000). The dendroecology and climatic impacts for old-growth white pine and hemlock on the extreme slopes of the Berkshire Hills, Massachusetts, USA. Canadian Journal of Botany-Revue Canadienne De Botanique, 78(7), 851-861.

Akashi, N., \& Nakashizuka, T. (1999). Effects of bark-stripping by Sika deer (Cervus nippon) on population dynamics of a mixed forest in Japan. Forest Ecology and Management, 113(1), 75-82. doi:10.1016/s0378-1127(98)00415-0

Akashi, N., Unno, A., \& Terazawa, K. (2015). Significance of woody browse preferences in evaluating the impact of sika deer browsing on tree seedlings. Journal of Forest Research, 20(4), 396-402. doi:10.1007/s10310-015-0492-3

Allombert, S., Gaston, A. J., \& Martin, J. L. (2005). A natural experiment on the impact of overabundant deer on songbird populations. Biological Conservation, 126(1), 1-13. doi:10.1016/j.biocon.2005.04.001

Allombert, S., Stockton, S., \& Martin, J. L. (2005). A natural experiment on the impact of overabundant deer on forest invertebrates. Conservation Biology, 19(6), 1917-1929. doi:10.1111/j.1523-1739.2005.00280.x

Ammer, C. (1996). Impact of ungulates on structure and dynamics of natural regeneration of mixed mountain forests in the Bavarian Alps. Forest Ecology and Management, 88(1-2), 43-53. doi:10.1016/s03781127(96)03808-x

Anderson, R. C., Corbett, E. A., Anderson, M. R., Corbett, G. A., \& Kelley, T. M. (2001). High white-tailed deer density has negative impact on tallgrass prairie forbs. Journal of the Torrey Botanical Society, 128(4), 381-392. doi:10.2307/3088670

Asnani, K. M., Klips, R. A., \& Curtis, P. S. (2006). Regeneration of woodland vegetation after deer browsing in Sharon Woods Metro Park, Franklin County, Ohio. Ohio Journal of Science, 106(3), 86-92.

Augustine, D. J., \& Frelich, L. E. (1998). Effects of white-tailed deer on populations of an understory forb in fragmented deciduous forests. Conservation Biology, 12(5), 995-1004. doi:10.1046/j.15231739.1998.97248.x

Barancekova, M., Krojerova-Prokesova, J., \& Homolka, M. (2007). Impact of deer browsing on natural and artificial regeneration in floodplain forest. Folia Zoologica, 56(4), 354-364.

Barrios-Garcia, M. N., Relva, M. A., \& Kitzberger, T. (2012). Patterns of use and damage by exotic deer on native plant communities in northwestern Patagonia. European Journal of Wildlife Research, 58(1), 137-146. doi:10.1007/s10344-011-0554-6

Bassett, I., Simcock, R., \& Mitchell, N. (2005). Consequences of soil compaction for seedling establishment: Implications for natural regeneration and restoration. Austral Ecology, 30(8), 827-833.

Beauchamp, V. B., Ghuznavi, N., Koontz, S. M., \& Roberts, R. P. (2013). Edges, exotics and deer: the seed bank of a suburban secondary successional temperate deciduous forest. Applied Vegetation Science, 16(4), 571-584. doi:10.1111/avsc.12036

Bellingham, P. J., \& Allan, C. N. (2003). Forest regeneration and the influences of white-tailed deer (Odocoileus virginianus) in cool temperate New Zealand rain forests. Forest Ecology and Management, 175(1-3), 71-86. doi:10.1016/s0378-1127(02)00122-6

Beschta, R. L., \& Ripple, W. J. (2008). Wolves, trophic cascades, and rivers in the Olympic National Park, USA. Ecohydrology, 1(2), 118-130. doi:10.1002/eco.12

Blackhall, M., Veblen, T. T., \& Raffaele, E. (2015). Recent fire and cattle herbivory enhance plant-level fuel flammability in shrublands. Journal of Vegetation Science, 26(1), 123-133. doi:10.1111/jvs.12216

Bork, E. W., Carlyle, C. N., Cahill, J. F., Haddow, R. E., \& Hudson, R. J. (2013). Disentangling herbivore impacts on Populus tremuloides: a comparison of native ungulates and cattle in Canada's Aspen Parkland. Oecologia, 173(3), 895-904. doi:10.1007/s00442-013-2676-x 
Bork, E. W., Hudson, R. J., \& Bailey, A. W. (1997). Populus forest characterization in Elk Island National Park relative to herbivory, prescribed fire, and topography. Canadian Journal of Botany-Revue Canadienne De Botanique, 75(9), 1518-1526.

Boucher, S., Crete, M., Ouellet, J. P., Daigle, C., \& Lesage, L. (2004). Large-scale trophic interactions: Whitetailed deer growth and forest understory. Ecoscience, 11(3), 286-295.

Boulanger, V., Baltzinger, C., Said, S., Ballon, P., Ningre, F., Picard, J. F., \& Dupouey, J. L. (2011). Deer-mediated expansion of a rare plant species. Plant Ecology, 212(2), 307-314. doi:10.1007/s11258-010-9823-9

Bowman, D., \& Panton, W. J. (1991). Sign and habitat impact of bateng (Bos javinicus) and pig (Sus scrofa), Cobourg peninsula, northern Australia. Australian Journal of Ecology, 16(1), 15-17. doi:10.1111/j.1442-9993.1991.tb01477.x

Bruinderink, G. G., \& Hazebroek, E. (1996). Wild boar (Sus scrofa scrofa L.) rooting and forest regeneration on podzolic soils in the Netherlands. Forest Ecology and Management, 88(1), 71-80.

Brullhardt, M., Risch, A. C., Filli, F., Haller, R. M., \& Schutz, M. (2015). Spatiotemporal dynamics of natural tree regeneration in unmanaged subalpine conifer forests with high wild ungulate densities. Canadian Journal of Forest Research, 45(6), 607-614. doi:10.1139/cjfr-2014-0358

Buesching, C. D., Newman, C., Jones, J. T., \& Macdonald, D. W. (2011). Testing the effects of deer grazing on two woodland rodents, bankvoles and woodmice. Basic and Applied Ecology, 12(3), 207-214. doi:10.1016/j.baae.2011.02.007

Callan, R., Nibbelink, N. P., Rooney, T. P., Wiedenhoeft, J. E., \& Wydeven, A. P. (2013). Recolonizing wolves trigger a trophic cascade in Wisconsin (USA). Journal of Ecology, 101(4), 837-845. doi:10.1111/13652745.12095

Cardinal, E., Martin, J. L., \& Cote, S. D. (2012). Large herbivore effects on songbirds in boreal forests: lessons from deer introduction on Anticosti Island. Ecoscience, 19(1), 38-47. doi:10.2980/19-1-3441

Carson, W. P., Banta, J. A., Royo, A. A., \& Kirschbaum, C. (2005). Plant communities growing on boulders in the Allegheny National Forest: Evidence for boulders as refugia from deer and as a bioassay of overbrowsing. Natural Areas Journal, 25(1), 10-18.

Chen, J. R., Wang, Q. L., Li, M., Liu, F., Li, W., \& Yin, L. Y. (2013). Effects of deer disturbance on soil respiration in a subtropical floodplain wetland of the Yangtze River. European Journal of Soil Biology, 56, 65-71. doi:10.1016/j.ejsobi.2013.02.007

Chollet, S., Baltzinger, C., Ostermann, L., Saint-Andre, F., \& Martin, J. L. (2013). Importance for forest plant communities of refuges protecting from deer browsing. Forest Ecology and Management, 289, 470477. doi:10.1016/j.foreco.2012.10.043

Chollet, S., Bergman, C., Gaston, A. J., \& Martin, J. L. (2015). Long-term consequences of invasive deer on songbird communities: Going from bad to worse? Biological Invasions, 17(2), 777-790. doi:10.1007/s10530-014-0768-0

Comisky, L., Royo, A. A., \& Carson, W. P. (2005). Deer browsing creates rock refugia gardens on large boulders in the Allegheny National Forest, Pennsylvania. American Midland Naturalist, 154(1), 201-206. doi:10.1674/0003-0031(2005)154[0201:dbcrrg]2.0.co;2

De Jong, C., Gill, R., Van Wieren, S., \& Burlton, F. (1995). Diet selection by roe deer Capreolus capreolus in Kielder Forest in relation to plant cover. Forest Ecology and Management, 79(1), 91-97.

Diaci, J., Rozenbergar, D., Anic, I., Mikac, S., Saniga, M., Kucbel, S., . . Ballian, D. (2011). Structural dynamics and synchronous silver fir decline in mixed old-growth mountain forests in Eastern and Southeastern Europe. Forestry, 84(5), 479-491. doi:10.1093/forestry/cpr030

Didier, K. A., \& Porter, W. F. (2003). Relating spatial patterns of sugar maple reproductive success and relative deer density in northern New York State. Forest Ecology and Management, 181(1-2), 253-266. doi:10.1016/s0378-1127(03)00137-3

Diwold, K., Dullinger, S., \& Dirnbock, T. (2010). Effect of nitrogen availability on forest understorey cover and its consequences for tree regeneration in the Austrian limestone Alps. Plant Ecology, 209(1), 11-22. doi:10.1007/s11258-009-9715-z

Eschtruth, A. K., \& Battles, J. J. (2008). Deer herbivory alters forest response to canopy decline caused by an exotic insect pest. Ecological Applications, 18(2), 360-376. doi:10.1890/07-0446.1

Eycott, A. E., Watkinson, A. R., Hemami, M. R., \& Dolman, P. M. (2007). The dispersal of vascular plants in a forest mosaic by a guild of mammalian herbivores. Oecologia, 154(1), 107-118. doi:10.1007/s00442007-0812-1

Filazzola, A., Tanentzap, A. J., \& Bazely, D. R. (2014). Estimating the impacts of browsers on forest understories using a modified index of community composition. Forest Ecology and Management, 313, 10-16. doi:10.1016/j.foreco.2013.10.040 
Fisichelli, N., Frelich, L. E., \& Reich, P. B. (2012). Sapling growth responses to warmer temperatures 'cooled' by browse pressure. Global Change Biology, 18(11), 3455-3463. doi:10.1111/j.1365-2486.2012.02785.x

Fisichelli, N. A., Frelich, L. E., Reich, P. B., \& Eisenhauer, N. (2013). Linking direct and indirect pathways mediating earthworms, deer, and understory composition in Great Lakes forests. Biological Invasions, 15(5), 1057-1066. doi:10.1007/s10530-012-0350-6

Forsyth, D. M., Wilson, D. J., Easdale, T. A., Kunstler, G., Canham, C. D., Ruscoe, W. A., . . Coomes, D. A. (2015). Century-scale effects of invasive deer and rodents on the dynamics of forests growing on soils of contrasting fertility. Ecological Monographs, 85(2), 157-180. doi:10.1890/14-0389.1.sm

Frerker, K., Sabo, A., \& Waller, D. (2014). Long-Term Regional Shifts in Plant Community Composition Are Largely Explained by Local Deer Impact Experiments. Plos One, 9(12), 17. doi:10.1371/journal.pone.0115843

Frerker, K., Sonnier, G., \& Waller, D. M. (2013). Browsing rates and ratios provide reliable indices of ungulate impacts on forest plant communities. Forest Ecology and Management, 291, 55-64. doi:10.1016/j.foreco.2012.11.041

Furedi, M., \& McGraw, J. B. (2004). White-tailed deer: Dispersers or predators of American ginseng seeds? American Midland Naturalist, 152(2), 268-276. doi:10.1674/00030031(2004)152[0268:wddopo]2.0.co;2

Genov, P. V., \& Massei, G. (2004). The environmental impact of wild boar. Galemys: Boletín informativo de la Sociedad Española para la conservación y estudio de los mamíferos, 16(1), 135-145.

Gill, R., \& Beardall, V. (2001). The impact of deer on woodlands: the effects of browsing and seed dispersal on vegetation structure and composition. Forestry, 74(3), 209-218.

Gill, R., \& Morgan, G. (2010). The effects of varying deer density on natural regeneration in woodlands in lowland Britain. Forestry, 83(1), 53-63.

Goetsch, C., Wigg, J., Royo, A. A., Ristau, T., \& Carson, W. P. (2011). Chronic over browsing and biodiversity collapse in a forest understory in Pennsylvania: Results from a 60 year-old deer exclusion plot. Journal of the Torrey Botanical Society, 138(2), 220-224.

Gomez, J. M., Garcia, D., \& Zamora, R. (2003). Impact of vertebrate acorn- and seedling-predators on a Mediterranean Quercus pyrenaica forest. Forest Ecology and Management, 180(1-3), 125-134. doi:10.1016/s0378-1127(02)00608-4

Gotmark, F. G., Berglund, A., \& Wiklander, K. (2005). Browsing damage on broadleaved trees in semi-natural temperate forest in Sweden, with a focus on oak regeneration. Scandinavian Journal of Forest Research, 20(3), 223-234. doi:10.1080/02827580510008383

Haaverstad, O., Hjeljord, O., \& Wam, H. K. (2014). Wild boar rooting in a northern coniferous forest - minor silviculture impact. Scandinavian Journal of Forest Research, 29(1), 90-95. doi:10.1080/02827581.2013.865781

Hanberry, P., Hanberry, B. B., Demarais, S., Leopold, B. D., \& Fleeman, J. (2014). Impact on plant communities by white-tailed deer in Mississippi, USA. Plant Ecology \& Diversity, 7(4), 541-548. doi:10.1080/17550874.2013.842615

Harmer, R. (2001). The effect of plant competition and simulated summer browsing by deer on tree regeneration. Journal of Applied Ecology, 38(5), 1094-1103. doi:10.1046/j.1365-2664.2001.00664.x

Heckel, C. D., Bourg, N. A., McShea, W. J., \& Kalisz, S. (2010). Nonconsumptive effects of a generalist ungulate herbivore drive decline of unpalatable forest herbs. Ecology, 91(2), 319-326.

Hedl, R., Kopecky, M., \& Komarek, J. (2010). Half a century of succession in a temperate oakwood: from species-rich community to mesic forest. Diversity and Distributions, 16(2), 267-276. doi:10.1111/j.1472-4642.2010.00637.x

Henden, J. A., Ims, R. A., Yoccoz, N. G., \& Killengreen, S. T. (2011). Declining willow ptarmigan populations: The role of habitat structure and community dynamics. Basic and Applied Ecology, 12(5), 413-422. doi:10.1016/j.baae.2011.05.006

Heuze, P., Schnitzler, A., \& Klein, F. (2005). Consequences of increased deer browsing winter on silver fir and spruce regeneration in the Southern Vosges mountains: Implications for forest management. Annals of Forest Science, 62(2), 175-181. doi:10.1051/forest:2005009

Holm, J. A., Thompson, J. R., McShea, W. J., \& Bourg, N. A. (2013). Interactive effects of chronic deer browsing and canopy gap disturbance on forest successional dynamics. Ecosphere, 4(11), 23. doi:10.1890/es1300223

Holmes, S. A., Curran, L. M., \& Hall, K. R. (2008). White-tailed deer (Odocoileus virginianus) alter herbaceous species richness in the Hiawatha National Forest, Michigan, USA. American Midland Naturalist, 159(1), 83-97. doi:10.1674/0003-0031(2008)159[83:wdovah]2.0.co;2 
Holmes, S. A., Webster, C. R., Flaspohler, D. J., \& Froese, R. E. (2009). Death and Taxus: the high cost of palatability for a declining evergreen shrub, Taxus canadensis. Canadian Journal of Forest ResearchRevue Canadienne De Recherche Forestiere, 39(7), 1366-1374. doi:10.1139/x09-064

Holt, C. A., Fuller, R. J., \& Dolman, P. M. (2011). Breeding and post-breeding responses of woodland birds to modification of habitat structure by deer. Biological Conservation, 144(9), 2151-2162. doi:10.1016/j.biocon.2011.05.004

Hornberg, S. (2001). Changes in population density of moose (Alces alces) and damage to forests in Sweden. Forest Ecology and Management, 149(1-3), 141-151. doi:10.1016/s0378-1127(00)00551-x

Horsley, S. B., Stout, S. L., \& DeCalesta, D. S. (2003). White-tailed deer impact on the vegetation dynamics of a northern hardwood forest. Ecological Applications, 13(1), 98-118. doi:10.1890/10510761(2003)013[0098:wtdiot]2.0.co;2

Husheer, S. W., Allen, R. B., \& Robertson, A. W. (2006). Suppression of regeneration in New Zealand mountain beech forests is dependent on species of introduced deer. Biological Invasions, 8(4), 823-834. doi:10.1007/s10530-005-4011-x

Husheer, S. W., Coomes, D. A., \& Robertson, A. W. (2003). Long-term influences of introduced deer on the composition and structure of New Zealand Nothofagus forests. Forest Ecology and Management, 181(1-2), 99-117. doi:10.1016/s0378-1127(03)00120-8

Husheer, S. W., \& Frampton, C. M. (2005). Fallow deer impacts on Wakatipu beech forest. New Zealand Journal of Ecology, 29(1), 83-94.

Husheer, S. W., Hansen, Q. W., \& Urlich, S. C. (2005). Effects of red deer on tree regeneration and growth in Aorangi Forest, Wairarapa. New Zealand Journal of Ecology, 29(2), 271-277.

Ito, H., \& Hino, T. (2008). Effects of deer and mice on seedling survival in a temperate mixed forest of Japan. Forest Ecology and Management, 256(1-2), 129-135. doi:10.1016/j.foreco.2008.04.016

Joys, A. C., Fuller, R. J., \& Dolman, P. M. (2004). Influences of deer browsing, coppice history, and standard trees on the growth and development of vegetation structure in coppiced woods in lowland England. Forest Ecology and Management, 202(1-3), 23-37. doi:10.1016/j.foreco.2004.06.035

Kain, M., Battaglia, L., Royo, A., \& Carson, W. P. (2011). Over-browsing in Pennsylvania creates a depauperate forest dominated by an understory tree: Results from a 60-year-old deer exclosure. Journal of the Torrey Botanical Society, 138(3), 322-326.

Kalisz, S., Spigler, R. B., \& Horvitz, C. C. (2014). In a long-term experimental demography study, excluding ungulates reversed invader's explosive population growth rate and restored natives. Proceedings of the National Academy of Sciences of the United States of America, 111(12), 4501-4506. doi:10.1073/pnas.1310121111

Kamler, J., Homolka, M., Barancekova, M., \& Krojerova-Prokesova, J. (2010). Reduction of herbivore density as a tool for reduction of herbivore browsing on palatable tree species. European Journal of Forest Research, 129(2), 155-162. doi:10.1007/s10342-009-0309-z

Kay, S. (1993). Factors affecting severity of deer browsing damage within coppiced woodlands in the south of England. Biological Conservation, 63(3), 217-222.

Kern, C. C., Reich, P. B., Montgomery, R. A., \& Strong, T. F. (2012). Do deer and shrubs override canopy gap size effects on growth and survival of yellow birch, northern red oak, eastern white pine, and eastern hemlock seedlings? Forest Ecology and Management, 267, 134-143. doi:10.1016/j.foreco.2011.12.002

Kirschbaum, C. D., \& Anacker, B. L. (2005). The utility of Trillium and Maianthemum as phyto-indicators of deer impact in northwestern Pennsylvania, USA. Forest Ecology and Management, 217(1), 54-66. doi:10.1016/j.foreco.2005.05.001

Kisanuki, H., Nakasu, M., Nakai, A., \& Yurugi, Y. (2008). Predicting the population dynamics of three understory broad-leaved evergreen species under the influence of Sika deer in primary and secondary forests of mid-western Japan. Journal of Forest Research, 13(1), 52-58. doi:10.1007/s10310-007-0054-4

Klopcic, M., Jerina, K., \& Boncina, A. (2010). Long-term changes of structure and tree species composition in Dinaric uneven-aged forests: are red deer an important factor? European Journal of Forest Research, 129(3), 277-288. doi:10.1007/s10342-009-0325-z

Knight, T. M., Dunn, J. L., Smith, L. A., Davis, J., \& Kalisz, S. (2009). Deer facilitate invasive plant success in a Pennsylvania forest understory. Natural Areas Journal, 29(2), 110-116.

Koda, R., \& Fujita, N. (2011). Is deer herbivory directly proportional to deer population density? Comparison of deer feeding frequencies among six forests with different deer density. Forest Ecology and Management, 262(3), 432-439. doi:10.1016/j.foreco.2011.04.009 
Kraft, L. S., Crow, T. R., Buckley, D. S., Nauertz, E. A., \& Zasada, J. C. (2004). Effects of harvesting and deer browsing on attributes of understory plants in northern hardwood forests, Upper Michigan, USA. Forest Ecology and Management, 199(2-3), 219-230. doi:10.1016/j.foreco.2004.05.044

Kuijper, D. P. J., Cromsigt, J., Jedrzejewska, B., Miscicki, S., Churski, M., Jedrzejewski, W., \& Kweczlich, I. (2010). Bottom-up versus top-down control of tree regeneration in the Bialowieza Primeval Forest, Poland. Journal of Ecology, 98(4), 888-899. doi:10.1111/j.1365-2745.2010.01656.x

Kuijper, D. P. J., Jedrzejewska, B., Brzeziecki, B., Churski, M., Jedrzejewski, W., \& Zybura, H. (2010). Fluctuating ungulate density shapes tree recruitment in natural stands of the Bialowieza Primeval Forest, Poland. Journal of Vegetation Science, 21(6), 1082-1098. doi:10.1111/j.1654-1103.2010.01217.x

Kuiters, A. T., \& Slim, P. A. (2002). Regeneration of mixed deciduous forest in a Dutch forestheathland,following a reduction of ungulate densities. Biological Conservation, 105(1), 65-74. doi:10.1016/s0006-3207(01)00204-x

Kullberg, Y., \& Bergstrom, R. (2001). Winter browsing by large herbivores on planted deciduous seedlings in southern Sweden. Scandinavian Journal of Forest Research, 16(4), 371-378. doi:10.1080/02827580152496768

Kumar, S., Takeda, A., \& Shibata, E. (2006). Effects of 13-year fencing on browsing by sika deer on seedlings on Mt. Ohdaigahara, central Japan. Journal of Forest Research, 11(5), 337-342. doi:10.1007/s10310-0060216-9

Kumbasli, M., Makineci, E., \& Cakir, M. (2010). Long term effects of red deer (Cervus elaphus) grazing on soil in a breeding area. Journal of Environmental Biology, 31(1-2), 185-188.

Laskurain, N. A., Aldezabal, A., Olano, J. M., Loidi, J., \& Escudero, A. (2013). Intensification of domestic ungulate grazing delays secondary forest succession: evidence from exclosure plots. Journal of Vegetation Science, 24(2), 320-331. doi:10.1111/j.1654-1103.2012.01469.x

Liang, S. Y., \& Seagle, S. W. (2002). Browsing and microhabitat effects on riparian forest woody seedling demography. Ecology, 83(1), 212-227. doi:10.2307/2680133

Ligot, G., Gheysen, T., Lehaire, F., Hebert, J., Licoppe, A., Lejeune, P., \& Brostaux, Y. (2013). Modeling recent bark stripping by red deer (Cervus elaphus) in South Belgium coniferous stands. Annals of Forest Science, 70(3), 309-318. doi:10.1007/s13595-012-0253-9

Long, R. P., Brose, P. H., \& Horsley, S. B. (2012). Responses of northern red oak seedlings to lime and deer exclosure fencing in Pennsylvania. Canadian Journal of Forest Research-Revue Canadienne De Recherche Forestiere, 42(4), 698-709. doi:10.1139/x2012-025

Long, Z. T., Pendergast, T. H., \& Carson, W. P. (2007). The impact of deer on relationships between tree growth and mortality in an old-growth beech-maple forest. Forest Ecology and Management, 252(1-3), 230238. doi:10.1016/j.foreco.2007-06.034

Lucas, R. W., Salguero-Gomez, R., Cobb, D. B., Waring, B. G., Anderson, F., McShea, W. J., \& Casper, B. B. (2013). White-tailed deer (Odocoileus virginianus) positively affect the growth of mature northern red oak (Quercus rubra) trees. Ecosphere, 4(7), 15. doi:10.1890/es13-00036.1

Lyly, M., Klemola, T., Koivisto, E., Huitu, O., Oksanen, L., \& Korpimaki, E. (2014). Varying impacts of cervid, hare and vole browsing on growth and survival of boreal tree seedlings. Oecologia, 174(1), 271-281. doi:10.1007/s00442-013-2761-1

Mansson, J., \& Jarnemo, A. (2013). Bark-stripping on Norway spruce by red deer in Sweden: level of damage and relation to tree characteristics. Scandinavian Journal of Forest Research, 28(2), 117-125. doi:10.1080/02827581.2012.701323

Mansson, J., Kalen, C., Kjellander, P., Andren, H., \& Smith, H. (2007). Quantitative estimates of tree species selectivity by moose (Alces alces) in a forest landscape. Scandinavian Journal of Forest Research, 22(5), 407-414. doi:10.1080/02827580701515023

Martin, J. L., \& Baltzinger, C. (2002). Interaction among deer browsing, hunting, and tree regeneration. Canadian Journal of Forest Research-Revue Canadienne De Recherche Forestiere, 32(7), 1254-1264. doi:10.1139/x02-043

Martin, T. G., Arcese, P., \& Scheerder, N. (2011). Browsing down our natural heritage: Deer impacts on vegetation structure and songbird populations across an island archipelago. Biological Conservation, 144(1), 459-469. doi:10.1016/j.biocon.2010.09.033

Mathisen, K. M., Buhtz, F., Danell, K., Bergstrom, R., Skarpe, C., Suominen, O., \& Persson, I. L. (2010). Moose density and habitat productivity affects reproduction, growth and species composition in field layer vegetation. Journal of Vegetation Science, 21(4), 705-716. doi:10.1111/j.1654-1103.2010.01180.x 
Matonis, M. S., Walters, M. B., \& Millington, J. D. A. (2011). Gap-, stand-, and landscape-scale factors contribute to poor sugar maple regeneration after timber harvest. Forest Ecology and Management, 262(2), 286298. doi:10.1016/j.foreco.2011.03.034

McColley, S. D., Tyers, D. B., \& Sowell, B. F. (2012). Aspen and Willow Restoration Using Beaver on the Northern Yellowstone Winter Range. Restoration Ecology, 20(4), 450-455. doi:10.1111/j.1526100X.2011.00792.x

McGarvey, J. C., Bourg, N. A., Thompson, J. R., McShea, W. J., \& Shen, X. L. (2013). Effects of Twenty Years of Deer Exclusion on Woody Vegetation at Three Life-History Stages in a Mid-Atlantic Temperate Deciduous Forest. Northeastern Naturalist, 20(3), 451-468. doi:10.1656/045.020.0301

McGraw, J. B., \& Furedi, M. A. (2005). Deer browsing and population viability of a forest understory plant. Science, 307(5711), 920-922. doi:10.1126/science.1107036

McShea, W. J., \& Rappole, J. H. (2000). Managing the abundance and diversity of breeding bird populations through manipulation of deer populations. Conservation Biology, 14(4), 1161-1170. doi:10.1046/j.1523-1739.2000.99210.x

Merli, E., \& Meriggi, A. (2006). Using harvest data to predict habitat-population relationship of the wild boar Sus scrofa in Northern Italy. Acta Theriologica, 51(4), 383-394. doi:10.1007/bf03195185

Metslaid, M., Koster, K., Jogiste, K., Randveer, T., Voolma, K., \& Moser, W. K. (2013). The Effect of Simulated Bark Stripping by Moose on Scots Pine Height Growth: an Experimental Treatment. Baltic Forestry, 19(1), 61-66.

Michels, G. H., Vieira, E. M., \& de Sa, F. N. (2012). Short- and long-term impacts of an introduced large herbivore (Buffalo, Bubalus bubalis L.) on a neotropical seasonal forest. European Journal of Forest Research, 131(4), 965-976. doi:10.1007/s10342-011-0568-3

Millington, J. D. A., Walters, M. B., Matonis, M. S., Laurent, E. J., Hall, K. R., \& Liu, J. G. (2011). Combined longterm effects of variable tree regeneration and timber management on forest songbirds and timber production. Forest Ecology and Management, 262(5), 718-729. doi:10.1016/j.foreco.2011.05.002

Millington, J. D. A., Walters, M. B., Matonis, M. S., \& Liu, J. G. (2013). Modelling for forest management synergies and trade-offs: Northern hardwood tree regeneration, timber and deer. Ecological Modelling, 248, 103-112. doi:10.1016/j.ecolmodel.2012.09.019

Monzon, A., da Silva, S. V., \& Manso, F. T. (2012). Integrating the deer (Cervus elaphus) in the Portuguese forests: Impacts and new challenges for forest certification. Forest Ecology and Management, 267, 1-6. doi:10.1016/j.foreco.2011.11.042

Moser, B., Schutz, M., \& Hindenlang, K. E. (2006). Importance of alternative food resources for browsing by roe deer on deciduous trees: The role of food availability and species quality. Forest Ecology and Management, 226(1-3), 248-255. doi:10.1016/j.foreco.2006.01.045

Motta, R. (2003). Ungulate impact on rowan (Sorbus aucuparia L.) and Norway spruce (Picea abies (L.) Karst.) height structure in mountain forests in the eastern Italian Alps. Forest Ecology and Management, 181(1-2), 139-150. doi:10.1016/s0378-1127(03)00128-2

Murata, I., Saruki, S., Kubota, K., Inoue, S., Tashiro, N., Enoki, T., . . . Inoue, S. (2009). Effects of sika deer (Cervus nippon) and dwarf bamboo (Sasamorpha borealis) on seedling emergence and survival in cooltemperate mixed forests in the Kyushu Mountains. Journal of Forest Research, 14(5), 296-301. doi:10.1007/s10310-009-0131-y

Murphy, M. J., Inman-Narahari, F., Ostertag, R., \& Litton, C. M. (2014). Invasive feral pigs impact native tree ferns and woody seedlings in Hawaiian forest. Biological Invasions, 16(1), 63-71. doi:10.1007/s10530013-0503-2

Murray, B. D., Webster, C. R., \& Bump, J. K. (2013). Broadening the ecological context of ungulate-ecosystem interactions: the importance of space, seasonality, and nitrogen. Ecology, 94(6), 1317-1326.

Murray, B. D., Webster, C. R., \& Bump, J. K. (2014). A Migratory Ungulate Facilitates Cross-Boundary Nitrogen Transport in Forested Landscapes. Ecosystems, 17(6), 1002-1013. doi:10.1007/s10021-014-9796-y

Mysterud, A., \& Østbye, E. (2004). Roe deer (Capreolus capreolus) browsing pressure affects yew (Taxus baccata) recruitment within nature reserves in Norway. Biological Conservation, 120(4), 545-548.

Naaf, T., \& Wulf, M. (2007). Effects of gap size, light and herbivory on the herb layer vegetation in European beech forest gaps. Forest Ecology and Management, 244(1-3), 141-149. doi:10.1016/j.foreco.2007.04.020

Niwa, S., Mariani, L., Kaneko, N., Okada, H., \& Sakamoto, K. (2011). Early-stage impacts of sika deer on structure and function of the soil microbial food webs in a temperate forest: A large-scale experiment. Forest Ecology and Management, 261(3), 391-399. doi:10.1016/j.foreco.2010.10.024 
Nomiya, H., Suzuki, W., Kanazashi, T., Shibata, M., Tanaka, H., \& Nakashizuka, T. (2003). The response of forest floor vegetation and tree regeneration to deer exclusion and disturbance in a riparian deciduous forest, central Japan. Plant Ecology, 164(2), 263-276. doi:10.1023/a:1021294021438

Nunez, M. A., Relva, M. A., \& Simberloff, D. (2008). Enemy release or invasional meltdown? Deer preference for exotic and native trees on Isla Victoria, Argentina. Austral Ecology, 33(3), 317-323. doi:10.1111/j.14429993.2007.01819.x

Nuttle, T., Ristau, T. E., \& Royo, A. A. (2014). Long-term biological legacies of herbivore density in a landscapescale experiment: forest understoreys reflect past deer density treatments for at least 20 years. Journal of Ecology, 102(1), 221-228. doi:10.1111/1365-2745.12175

Olesen, C. R., \& Madsen, P. (2008). The impact of roe deer (Capreolus capreolus), seedbed, light and seed fall on natural beech (Fagus sylvatica) regeneration. Forest Ecology and Management, 255(12), 39623972. doi:10.1016/j.foreco.2008.03.050

Patel, A., \& Rapport, D. J. (2000). Assessing the impacts of deer browsing, prescribed burns, visitor use, and trails on an oak-pine forest: Pinery Provincial Park, Ontario, Canada. Natural Areas Journal, 20(3), 250260.

Pellerin, M., Said, S., Richard, E., Hamann, J. L., Dubois-Coli, C., \& Hum, P. (2010). Impact of deer on temperate forest vegetation and woody debris as protection of forest regeneration against browsing. Forest Ecology and Management, 260(4), 429-437. doi:10.1016/j.foreco.2010.04.031

Pepin, D., Renaud, P. C., Boscardin, Y., Goulard, A., Mallet, C., Anglard, F., \& Ballon, P. (2006). Relative impact of browsing by red deer on mixed coniferous and broad-leaved seedlings - An enclosure-based experiment. Forest Ecology and Management, 222(1-3), 302-313. doi:10.1016/j.foreco.2005.10.034

Perea, R., Girardello, M., \& San Miguel, A. (2014). Big game or big loss? High deer densities are threatening woody plant diversity and vegetation dynamics. Biodiversity and Conservation, 23(5), 1303-1318. doi:10.1007/s10531-014-0666-x

Persson, I. L., Pastor, J., Danell, K., \& Bergstrom, R. (2005). Impact of moose population density on the production and composition of litter in boreal forests. Oikos, 108(2), 297-306. doi:10.1111/j.00301299.2005.13844.x

Powers, M. D., \& Nagel, L. M. (2009). Pennsylvania sedge cover, forest management and Deer density influence tree regeneration dynamics in a northern hardwood forest. Forestry, 82(3), 241-254. doi:10.1093/forestry/cpp003

Prietzel, V. J., \& Ammer, C. (2008). Mixed mountain forests of the Bavarian Limestone Alps: Reduction of ungulate density results not only in increased regeneration success but also in improved soil fertility. Allgemeine Forst Und Jagdzeitung, 179(5-6), 104-112.

Reimoser, F., \& Gossow, H. (1996). Impact of ungulates on forest vegetation and its dependence on the silvicultural system. Forest Ecology and Management, 88(1-2), 107-119. doi:10.1016/s03781127(96)03816-9

Relva, M. A., Castan, E., \& Mazzarino, M. J. (2014). Litter and soil properties are not altered by invasive deer browsing in forests of NW Patagonia. Acta Oecologica-International Journal of Ecology, 54, 45-50. doi:10.1016/j.actao.2012.12.006

Relva, M. A., Nunez, M. A., \& Simberloff, D. (2010). Introduced deer reduce native plant cover and facilitate invasion of non-native tree species: evidence for invasional meltdown. Biological Invasions, 12(2), 303311. doi:10.1007/s10530-009-9623-0

Relva, M. A., \& Veblen, T. T. (1998). Impacts of introduced large herbivores on Austrocedrus chilensis forests in northern Patagonia, Argentina. Forest Ecology and Management, 108(1-2), 27-40. doi:10.1016/s03781127(97)00313-7

Reyes, G., \& Vasseur, L. (2003). Factors influencing deer browsing damage to red spruce (Picea rubens) seedlings in coastal red spruce-balsam fir stands of southwestern Nova Scotia. Forest Ecology and Management, 186(1-3), 349-357. doi:10.1016/s0378-1127(03)00303-7

Richer, M. C., Ouellet, J. P., Lapointe, L., Crete, A., \& Huot, J. (2005). Impacts of white-tailed deer grazing in hay fields of southern Quebec. Wildlife Society Bulletin, 33(4), 1274-1281. doi:10.2193/00917648(2005)33[1274:iowdgi]2.0.co;2

Rogers, P. C., \& Mittanck, C. M. (2014). Herbivory strains resilience in drought-prone aspen landscapes of the western United States. Journal of Vegetation Science, 25(2), 457-469. doi:10.1111/jvs.12099

Rogerson, J. E., Bowman, J. L., Tymkiw, E. L., Colligan, G. M., \& Vasilas, B. L. (2014). The Impacts of White-Tailed Deer Browsing and Distance From the Forest Edge on Soybean Yield. Wildlife Society Bulletin, 38(3), 473-479. doi:10.1002/wsb.442 
Rooney, T. P., \& Gross, K. (2003). A demographic study of deer browsing impacts on Trillium grandiflorum. Plant Ecology, 168(2), 267-277. doi:10.1023/a:1024486606698

Royo, A. A., Collins, R., Adams, M. B., Kirschbaum, C., \& Carson, W. P. (2010). Pervasive interactions between ungulate browsers and disturbance regimes promote temperate forest herbaceous diversity. Ecology, 91(1), 93-105. doi:10.1890/08-1680.1

Ruzicka, K. J., Groninger, J. W., \& Zaczek, J. J. (2010). Deer Browsing, Forest Edge Effects, and Vegetation Dynamics Following Bottomland Forest Restoration. Restoration Ecology, 18(5), 702-710. doi:10.1111/j.1526-100X.2008.00503.x

Sage, R. B., Hollins, K., Gregory, C. L., Woodburn, M. I. A., \& Carroll, J. P. (2004). Impact of roe deer Capreolus capreolus browsing on understorey vegetation in small farm woodlands. Wildlife Biology, 10(2), 115120.

Salk, T. T., Frelich, L. E., Sugita, S., Calcote, R., Ferrari, J. B., \& Montgomery, R. A. (2011). Poor recruitment is changing the structure and species composition of an old-growth hemlock-hardwood forest. Forest Ecology and Management, 261(11), 1998-2006. doi:10.1016/j.foreco.2011.02.026

Schippers, P., van Teeffelen, A. J. A., Verboom, J., Vos, C. C., Kramer, K., \& WallisDeVries, M. F. (2014). The impact of large herbivores on woodland-grassland dynamics in fragmented landscapes: The role of spatial configuration and disturbance. Ecological Complexity, 17, 20-31. doi:10.1016/j.ecocom.2013.07.002

Seagle, S. W., \& Liang, S. Y. (2001). Application of a forest gap model for prediction of browsing effects on riparian forest succession. Ecological Modelling, 144(2-3), 213-229. doi:10.1016/s03043800(01)00373-8

Smit, C., Vandenberghe, C., den Ouden, J., \& Muller-Scharer, H. (2007). Nurse plants, tree saplings and grazing pressure: changes in facilitation along a biotic environmental gradient. Oecologia, 152(2), 265-273. doi:DOI 10.1007/s00442-006-0650-6

Stritar, M. L., Schweitzer, J. A., Hart, S. C., \& Bailey, J. K. (2010). Introduced ungulate herbivore alters soil processes after fire. Biological Invasions, 12(2), 313-324. doi:10.1007/s10530-009-9624-z

Suzuki, M., \& Ito, E. (2014). Combined effects of gap creation and deer exclusion on restoration of belowground systems of secondary woodlands: A field experiment in warm-temperate monsoon Asia. Forest Ecology and Management, 329, 227-236. doi:10.1016/j.foreco.2014.06.028

Suzuki, M., Miyashita, T., Kabaya, H., Ochiai, K., Asada, M., \& Kikvidze, Z. (2013). Deer herbivory as an important driver of divergence of ground vegetation communities in temperate forests. Oikos, 122(1), 104-110. doi:10.1111/j.1600-0706.2012.20431.x

Tahtinen, B., Murray, B. D., Webster, C. R., Tarasoff, C. S., \& Burton, A. J. (2014). Does Ungulate Foraging Behavior in Forest Canopy Gaps Produce a Spatial Subsidy with Cascading Effects on Vegetation? Forest Science, 60(5), 819-829. doi:10.5849/forsci.13-080

Tanentzap, A. J., Burrows, L. E., Lee, W. G., Nugent, G., Maxwell, J. M., \& Coomes, D. A. (2009). Landscape-level vegetation recovery from herbivory: progress after four decades of invasive red deer control. Journal of Applied Ecology, 46(5), 1064-1072. doi:10.1111/j.1365-2664.2009.01683.x

Tsujino, R., \& Yumoto, T. (2004). Effects of sika deer on tree seedlings in a warm temperate forest on Yakushima Island, Japan. Ecological Research, 19(3), 291-300. doi:10.1111/j.1440-1703.2004.00638.x

Tyler, C. M., Davis, F. W., \& Mahall, B. E. (2008). The relative importance of factors affecting age-specific seedling survival of two co-occurring oak species in southern California. Forest Ecology and Management, 255(7), 3063-3074. doi:10.1016/j.foreco.2008.01.073

Van Hees, A. F. M., Kuiters, A. T., \& Slim, P. A. (1996). Growth and development of silver birch, pedunculate oak and beech as affected by deer browsing. Forest Ecology and Management, 88(1-2), 55-63. doi:10.1016/s0378-1127(96)03809-1

Vila, A. R., \& Borrelli, L. (2011). Cattle in the Patagonian forests: Feeding ecology in Los Alerces National Reserve. Forest Ecology and Management, 261(7), 1306-1314. doi:10.1016/j.foreco.2011.01.009

Vila, B., Torre, F., Martin, J. L., \& Guibal, F. (2003). Response of young Tsuga heterophylla to deer browsing: developing tools to assess deer impact on forest dynamics. Trees-Structure and Function, 17(6), 547553. doi:10.1007/s00468-003-0272-0

Ward, A. I., White, P. C. L., Smith, A., \& Critchley, C. H. (2004). Modelling the cost of roe deer browsing damage to forestry. Forest Ecology and Management, 191(1-3), 301-310. doi:10.1016/j.foreco.2003.12.018

Webster, C. R., Jenkins, M. A., \& Rock, J. H. (2005). Long-term response of spring flora to chronic herbivory and deer exclusion in Great Smoky Mountains National Park, USA. Biological Conservation, 125(3), 297 307. doi:10.1016/j.biocon.2005.03.027 
Welch, D., \& Scott, D. (1998). Bark-stripping damage by red deer in a Sitka spruce forest in western Scotland IV. Survival and performance of wounded trees. Forestry, 71(3), 225-235. doi:10.1093/forestry/71.3.225

White, M. A. (2012). Long-term effects of deer browsing: Composition, structure and productivity in a northeastern Minnesota old-growth forest. Forest Ecology and Management, 269, 222-228. doi:10.1016/j.foreco.2011.12.043

Willis, J. L., Walters, M. B., \& Gottschalk, K. W. (2015). Scarification and gap size have interacting effects on northern temperate seedling establishment. Forest Ecology and Management, 347, 237-246. doi:10.1016/j.foreco.2015.02.026

Wright, D. M., Tanentzap, A. J., Flores, O., Husheer, S. W., Duncan, R. P., Wiser, S. K., \& Coomes, D. A. (2012). Impacts of culling and exclusion of browsers on vegetation recovery across New Zealand forests. Biological Conservation, 153, 64-71. doi:10.1016/j.biocon.2012.04.033 


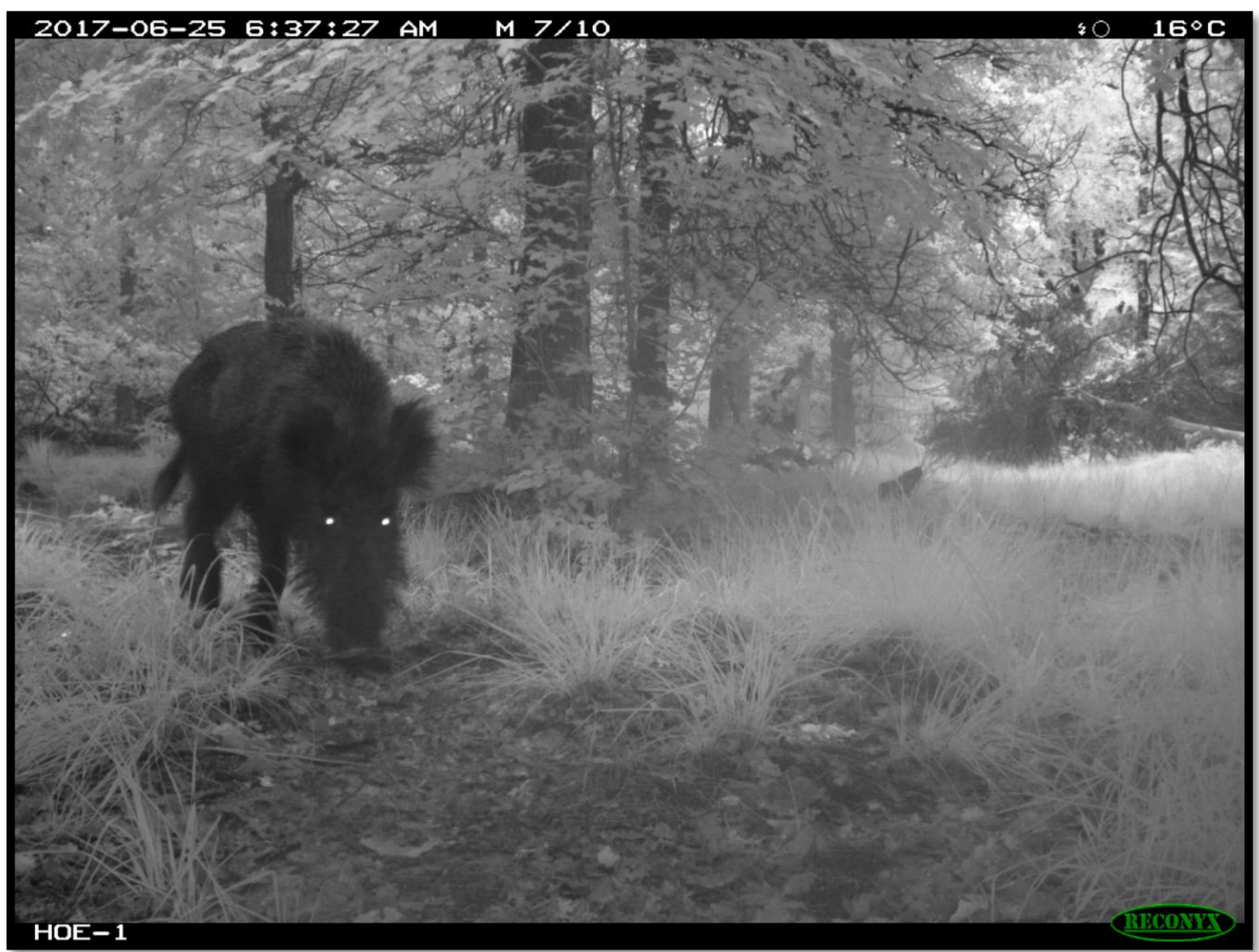




\section{CHAPTER THREE}

The dose-response relationship between deer and a temperate forest understory: a camera trapping approach

Submitted to Ecosystems

Authors

Juan Ignacio Ramirez; Patrick A. Jansen; Jan den Ouden ${ }^{1}$; Xuqing Li; Palma lacobelli; Natalie Herdoiza \& Lourens Poorter 


\section{Abstract}

Ungulates exert strong top-down control on the structure and dynamics of forests, and these effects are exacerbated as ungulate population increases in the northern hemisphere. The dose-response relationship between wild ungulates and plant recruitment in temperate forests, however, remains poorly documented. Here, we combined camera trapping and vegetation surveys to quantify the dose-response relationship between a deer-browsing guild (red, fallow and roe deer) and forest regeneration in temperate mixed forests at the Veluwe, the Netherlands. At ten sites that widely ranged in the abundance and species composition of deer, we used camera traps to quantify habitat utilization by deer, and vegetation surveys to quantify tree regeneration, forest structure and browsing and assessed the shape of the doseresponse relationship. Five of the eleven forest variables measured were related with deer utilization level. With increasing red deer utilization there was a decrease of litter depth. With increasing fallow deer utilization, there was a decrease in sapling richness. With increasing roe deer utilization, there was a decrease in sapling richness and diversity and shrub cover, and an increase of sapling stem density. The dose-response relationship between deer utilization and different forest attributes followed a linear $\log _{10}$ shape, yet when back transformed the response followed a curvilinear response, large changes at low followed by small changes at high utilization level, yet the exact shape of the curve can vary according to (a)biotic factors of each study location. Deer decreased tree species richness and diversity and the depth of the litter layer and increased sapling density. Considering that the slopes of the responses were quite slight, we can conclude that the influence that deer have on temperate forest structure and diversity is existent, yet limited.

\section{Abbreviations}

TR=Trap Rate; UL=Utilization Level; GLMM=Generalized Linear Mixed Model; PCA=Principal Component Analysis

\section{Introduction}

Ungulates affect ecosystems through a variety of direct and indirect interactions with the vegetation. Direct interactions include browsing, trampling, fraying, stripping and uprooting (Groot Bruinderink \& Hazebroek 1996; Reimoser 2003; Pellerin et al. 2010a), while indirect 
interactions include seed dispersing, defecating, and urinating (Hobbs 1996; Gill \& Beardall 2001). As these interactions influence the structure and dynamics of woody ecosystems, wild ungulates are regarded as keystone species (Waller \& Alverson 1997). The strength of these interactions varies spatially and temporally, and the strongest interactions occur at high ungulate densities (Rooney \& Waller 2003). In systems with high primary productivity, ungulates may have a weak impact on the vegetation as it recovers quickly, whereas in systems with low productivity the impact of ungulates might be especially strong because plants lack nutrients to develop and mitigate herbivory (Van Hees et al. 1996; Heckel et al. 2010; Pellerin et al. 2010a).

In the Northern hemisphere, wild ungulate populations are increasing (Clutton-Brock \& Albon 1992; Rooney 2001; Reimoser 2003; Pellerin et al. 2010a) because of reintroduction projects, abandonment of agricultural land, reduced competition with domestic ungulates, absence of top predators, reduced hunting and improvement of habitat quality (Kuiters et al. 1996; Rooney 2001; Côté et al. 2004; Apollonio et al. 2010). In parallel, the fragmentation of natural forests by infrastructure and agricultural fields (Gordon \& Prins 2008) has led to the isolation of ungulates in forest fragments (Kuiters et al. 1996). Forest fragmentation has resulted in a large variation in the density and species composition of ungulate assemblages, and hence, a large variation in ungulate effects on the environment (Reimoser 2003).

The role of herbivores in shaping natural ecosystems across the world has been a topic of much debate during the last decades (Cyr \& Face 1993; Gill \& Morgan 2010). Empirical studies in temperate forests suggest that ungulates exert strong top-down control on forest structure and dynamics through herbivory (Kuijper et al. 2010a), which may negatively affect forest conservation goals (Pastor et al. 1993). On the other hand, wild ungulates can enhance species diversity and functioning in a non-linear way (Rooney \& Waller 2003) when herbivory levels are intermediate, in accordance with the intermediate disturbance hypothesis (Wilkinson 1999; Ramirez et al. 2018). For example, forests with intermediate ungulates densities may increase forest structure and tree diversity (Gill \& Morgan 2010) by creating forest heterogeneity and reducing plant competition (Kuiters et al. 1996; Fuller \& Gill 2001; Lucas et al. 2013). Forests with few ungulates may have a low tree diversity because important mechanisms that increase coexistence and diversity, such as seed dispersing, selective browsing and defecating are limited (Reimoser \& Putman 2011). While at high densities, 
ungulates may have a negative effect by consuming most of the palatable species and thus reducing forest structure and diversity (Tyler et al. 2008; Schippers et al. 2014).

The exact dose-response relationship varies with environmental conditions, the vegetation type, the ungulate composition and abundance. For example, a global metaanalysis (Ramirez et al. 2018) found a non-linear relationship between ungulate density and forest recruitment, where at intermediate ungulate density $\left(>12-14\right.$ roe deer $\left.\mathrm{km}^{-2}\right)$ seedling establishment and forest succession were reduced. An additional complication is that most past studies have estimated ungulate density with a variety of methods, such as indirect and incomplete animal counts. Thus, the dose-response relationships between wild ungulate abundance and different temperate forest attributes are highly variable across studies (Gill 1992a; Putman et al. 2011a; Reimoser \& Putman 2011). To reconcile these seemingly contrasting findings, there is a need to study effects along a full gradient of ungulate density in a single system, using a single method.

This study aimed to determine the shape of the dose-response relationship between wild deer and different forest attributes in a temperate forest in the Netherlands. We used a novel approach that involved arrays of camera traps paired with vegetation transects across 10 forest sites that varied widely in deer abundance. We predicted that an increase in deer abundance would lead to a non-linear: (H1) increase in browsing, fraying, stripping, uprooting and trampling (Rooney \& Waller 2003); (H2) a reduction of stem density and basal area by browsing and trampling on tree regeneration (Gill \& Beardall 2001; Russell et al. 2001); (H3) a reduction in sapling richness and diversity, and increase in conifer proportion by actively browsing on broadleaved individuals, and favouring conifers through competitive release (Côté et al. 2004); (H4) a reduction in understory cover (moss and shrubs) and canopy cover by browsing and trampling (Ramirez et al. 2019), and (H5) a reduction or increase in the depth of litter and fragmented layers. Deer can either reduce litter depth on the forest floor by removing litter (Hobbs 1996) and by changing the species composition of the stand to evergreen coniferous species that have a lower litter production rate (Husheer et al. 2005); or increase the litter depth by shifting species composition toward conifers which have more recalcitrant leaves, resulting in an accumulation of litter over time. The relative importance of these two processes determines the depth of the litter layer. 


\section{Methods}

\section{Study area}

Fieldwork was conducted at the Veluwe, a $1200 \mathrm{~km}^{2}$ forest-heathland complex located in the central part of the Netherlands. Average annual precipitation is $850 \mathrm{~mm} \mathrm{yr}^{-1}$. Average annual temperature is $10.5^{\circ} \mathrm{C}$, with mean monthly temperature ranging from $3.6^{\circ} \mathrm{C}$ in January to $18^{\circ} \mathrm{C}$ in July (KNMI 2018). The main soil types are xeric humic podzols and brown earths (inceptisols), depending on the parent material that ranges from Aeolic drift and cover sands to Pleistocene loamy fluvioglacial sands (Kuiters \& Slim 2002). The Veluwe is covered by a mosaic of forests, agricultural land, drift sands and heathland, where forests cover two thirds of the total area. The main tree species are the native conifer Pinus sylvestris, and broadleaved Quercus robur, Fagus sylvatica, and Betula pendula, and the introduced conifers Larix kaempferi and Pseudotsuga menziesii. Assemblages of browsing ungulates vary across the Veluwe, and include roe deer (Capreolus capreolus with an average body mass of $25 \mathrm{~kg}$ ), fallow deer (Dama dama, $65 \mathrm{~kg}$ ) and red deer (Cervus elaphus, $190 \mathrm{~kg}$ ) (Ramirez et al. 2018). In some areas of the Veluwe cattle, horses and mouflon are present, but not in our research sites. The area is divided into areas with different wildlife management regimes, separated by fenced roads, leading to considerable spatial variation in ungulate abundance. In 2002, the average ungulate density was 14 individuals $\mathrm{km}^{-2}$ (Kuiters \& Slim 2002), with a considerable increase since then.

\section{Sampling design}

We selected in a large area $(50 \times 80 \mathrm{~km})$, ten research sites that were expected to widely range in deer abundance (Fig. 3.1 \& Table 3.1). The distances among sites with the closest proximity were on average $6 \mathrm{~km}$ apart. One contiguous square forest plot of $1 \mathrm{~km}^{2}$ was established in each site. Within each plot, 21 random points were generated using ArcGIS. At each sampling point, we measured deer utilization level with camera traps and forest regeneration with vegetation plots. Due to the heterogeneous and patchy character of these forests, vegetation varied greatly across sampling points and between plots. 


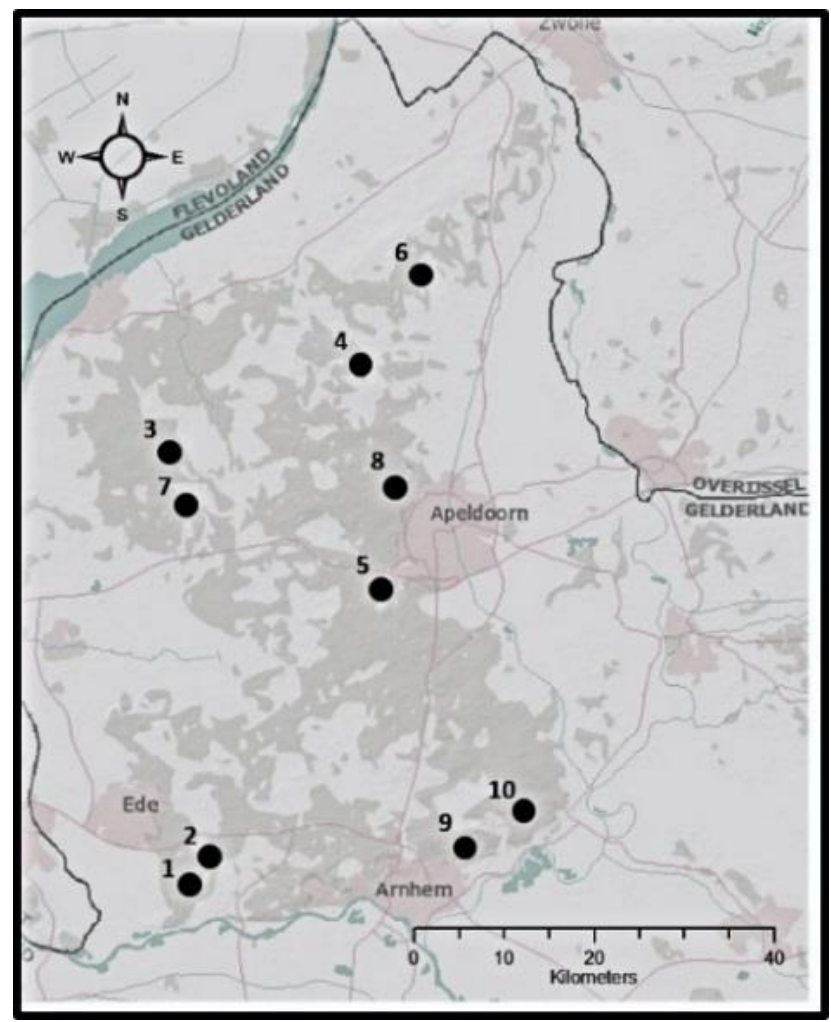

Figure 3.1. Map indicating the ten research sites in the Veluwe, the Netherlands. Numbers and black dots indicate research sites, and dark gray areas indicate forest. 1=Oostereng, 2=Buunderkamp, 3=Speulderbos, 4=Gortel, 5=Hoenderloo, 6=Dellen, 7=Garderen, 8=Achterpark, 9=Rozendaalse Bos and 10=Rheden.

\section{Deer Utilization Level}

We quantified the level of utilization by deer with camera traps (Rowcliffe et al. 2008; Kays et al. 2009). In each site, camera traps were deployed for $\sim 21$ days at each random point, during June-October of 2017. Each 21 days, three camera traps were moved to new random points, and this procedure was repeated until all 21 points had been sampled. We aimed for a minimum of 440 camera trap days per site. The sampling design and effort were determined based on previous camera trapping experiences.

Camera traps (Reconyx HyperFire HC500) were mounted onto trees at $50 \mathrm{~cm}$ height in steel enclosures with a security cable, facing north and aimed parallel to the ground. Cameras were then set to take ten simultaneous images with no delay after being triggered; cameras were programmed for fast shutter speed in order to also capture fast moving animals. The resolution was set to 3.1 MP. If necessary, understory vegetation directly in front of the camera was pruned below $50 \mathrm{~cm}$ to ensure a free view on the first three meters. Then maximum detection distance of a person at the time of placement was determined by walking away from the camera until the sensor stopped detecting movement. 
Images were grouped, annotated and stored with the software Agouti (https://agouti.eu/). Images were grouped into sequences that represented separate animal visits, regardless of whether or not the individual was the same. For each sequence of images, information on species, number of individuals, deer behaviour (browsing, fraying, stripping, defecating, moving \& resting) and the sequence duration (as multiples of ten seconds) were recorded. If multiple behaviours were seen in one sequence, they were separately considered. We then calculated deer Utilization Level (UL, $\left.\mathrm{kg}^{0.75} \cdot \mathrm{s}^{\mathrm{m}} \mathrm{m}^{-1} \cdot \mathrm{d}^{-1}\right)$ as the proportion of time that a deer, expressed as metabolic active tissue - i.e., body mass ${ }^{0.75}$ (Kleiber 1947) - spent in front of a camera trap in proportion to the deployment duration of the camera and the maximum detection distance. Metabolic weight allowed for the quantification of different deer species in the same axis and is expressed as a deployment duration in order to obtain the active time per day, which was calculated as:

$$
U L=\sum_{i=1}^{n} \frac{A \times B^{0.75} \times T}{D \times S}
$$

where $(A)$ is the number of deer image sequences and $(B)$ is the total number of kilograms per species raised to the power of $0.75,(T)$ is the time an animal spends in front of a camera trap in seconds, (D) is the maximal detection distance of the camera in meters and $(S)$ is the sampling effort in days. UL is a specification of Trap Rate (animals. $m^{-1} \cdot d^{-1}$ ), the number of deer captures per unit of time (days) and camera detection distance (meters) (Hofmeester et al. 2016).

\section{Forest attributes}

To quantify forest responses across sites, the 21 survey plots in each site were paired to the 21 camera points. Plots were positioned $3 \mathrm{~m}$ away from the camera, had a width of 4 meters and a variable length to assure that always a sufficient number of tree stems were included as some forest sites presented low amount of regeneration. The length varied to include 50 tree stems, with a height above $10 \mathrm{~cm}$ but less than $250 \mathrm{~cm}$. To measure understory vegetation cover ( $<1.5$ meters), a plot of $4 \times 4 \mathrm{~m}$ was established at $3 \mathrm{~m}$ from each camera trap.

For each plot, we quantified eleven response variables that described the forests and are commonly used in these types of studies (Comisky et al. 2005; Nuttle et al. 2014). To describe forest structure, we measured tree stem density and basal area (for detailed methods see below), as they are important for indicating whether deer have an effect on tree 
establishment and development. To describe tree composition, we measured species richness, Shannon diversity and conifer proportion. To describe forest functioning, we measured litter thickness as it indicates the amount of litter accumulated on the forest floor which serves as food source for invertebrates (Facelli \& Pickett 1991). To describe the direct impact of deer on tree regeneration, we measured the percentages of browsed broadleaved and conifer species (leaf removal). Finally, three variables were used to describe understory cover: moss, shrub and bare soil cover, as these variables compete directly with trees and are also prone to deer browsing.

Only woody plants $>10 \mathrm{~cm}$ in height were measured, as smaller individuals show large fluctuations in population size due external pressures. Each woody individual was identified and its height measured as the vertical distance between the forest floor and the apex. Browsing damage was quantified as the presence or absence of damaged branches and leaves on the whole plant. No distinction was made between damage on current and old shoots because we assumed that deer population levels were constant. Canopy cover, which determines understory light availability, was measured with a densiometer by standing at the beginning of the plot. The dominant canopy tree species determined the type of canopy cover (sparse or closed) and had a large effect on the composition of the local seed rain. For each sampling point, we identified the two species with the highest abundance in the forest canopy. Basal area was estimated with the Bitterlich Prism-method, with a counting factor of 3 (Bruce 1955). Because understory vegetation competes directly for light and or nutrients with tree saplings (Naaf \& Wulf 2007), we estimated canopy cover and understory vegetation cover by determining, with the use of a grid, the percentage cover of: shrub (Rubus spp.) up to $1.5 \mathrm{~m}$ height, moss (Bryophyta) and bare land (rocks, dead wood and soil). With a ruler, we quantified litter depth by averaging the depth at two points of the plot. Litter depth represents the amount of un-fragmented litter available for decomposition and nutrient cycling in the understory. A litter layer also acts as a barrier for the establishment of species in the seedbank (Facelli \& Pickett 1991; Schramm \& Ehrenfeld 2010). One soil sample was collected from the plot in order to determine soil $\mathrm{pH}$ in the laboratory, for which soil was dissolved in $\mathrm{KCl}$ and measured with a pH meter (inoLab pH Plus).

Finally, forest type was measured with the broadleaf canopy dominance index, which quantifies the monodominance of the forest stand ranging from dominance by a single coniferous species (coded as zero) to dominance by a single broadleaved from the same 
species (coded as one), while mixed stands have intermediate values. If the canopy was composed of two different broadleaved species 0.75 was assigned, if the canopy consisted of one broadleaved and one conifer species 0.5 was assigned and if the canopy consisted only of two different conifer species 0.25 was assigned.

Saplings were counted within each plot, and the density was calculated as the total number of individuals per ha. Sapling species richness was quantified as the total number of woody species per 50 stems present in the transect. Shannon diversity of trees was calculated based on species abundance (Shannon 1948). Conifer proportion was calculated as the proportion between broadleaf and conifer saplings. Notably, weak ungulate and forest relationships are expected because field studies include confounding factors and interactions.

\section{Statistical analyses}

Generalized Mixed Linear Models (GLMM) were used to assess the relationship between UL and the proportion of time that deer spent browsing in front of the camera trap. For this analysis deer feeding time was the dependent variable, UL, light and stem density were fixed factors and forest site (i.e., the 10 forests) was a grouping random factor. An exponential function was included to test for non-linearity. To assess the shape of the relationship between deer and the eleven forest attributes we used Generalized Additive Mixes Models (GAMM). For this analysis forest attributes were the dependent variables, UL, light, soil pH and broadleaf canopy dominance were explanatory variables and site was a random factor. The results suggested a strong linearity and thus we proceeded with GLMM for the final analysis and explanatory variables are only shown for Cervidae. To normalize data, we $\log _{10^{-}}$ transformed UL. To verify that fixed factors were not collinear, an unconstrained Principal Component Analysis (PCA) and a Pearson correlation test were performed; the results showed no collinearity (Dormann et al. 2013). For all statistical analysis, we used "R, version 3.4.0" and the "nlme" and "gamm4" packages (R Core Team 2017; Wood et al. 2017; Pinheiro et al. 2018).

\section{Results}

Sampling effort, Utilization Level and Covariates

Sampling effort was on average 462 camera days per site (range 400-516, Table 3.1), yielding on average 16,978 photographs per site (range 6,226-43,436). UL ranged more than five orders of magnitude across sites $\left(4-953,292 \mathrm{~kg}{ }^{0.75} . \mathrm{s}^{\mathrm{m}} \mathrm{m}^{-1} \cdot \mathrm{d}^{-1}\right)$. Camera trapping showed a large 
variation in deer abundance and composition (Appendix A.1), with the main species being red deer $(90.6 \%$ of the observations), roe deer $(7.7 \%)$ and fallow deer $(1.7 \%)$.

Table 3.1. Sampling effort and Utilization Level (UL) of deer across the ten forest sites at the Veluwe, the Netherlands. UL represents the average time (in seconds) that animals (in metabolic $\mathrm{kg}$ ) spent in front of the camera trap. Kruskal-Wallis test for UL Total (Chi-squared=147.81, df=9, $p<0.000$ ).

\begin{tabular}{|c|c|c|c|c|c|c|c|}
\hline \multirow[t]{2}{*}{ Site } & \multirow[t]{2}{*}{ Code } & \multirow{2}{*}{$\begin{array}{l}\text { Sampling } \\
\text { effort (d) }\end{array}$} & \multirow{2}{*}{$\begin{array}{c}\text { Pictures } \\
\text { (\#) }\end{array}$} & \multicolumn{4}{|c|}{ Utilization Level $\left(\mathrm{kg}^{0.75} \cdot \mathrm{s} \cdot \mathrm{m}^{-1} \cdot \mathrm{d}^{-1}\right)$} \\
\hline & & & & Red deer & Fallow deer & Roe deer & Total \\
\hline Achterpark & $\mathrm{ACH}$ & 467 & 6226 & 1 & 0 & 3 & 4 \\
\hline Buunderkamp & BUU & 476 & 10850 & 15 & 0 & 12 & 27 \\
\hline Dellen & DEL & 472 & 20855 & 9 & 0 & 5 & 14 \\
\hline Garderen & GAR & 471 & 19239 & 2 & 0 & 10 & 12 \\
\hline Oostereng & oOs & 516 & 8227 & 0 & 0 & 276 & 276 \\
\hline $\begin{array}{l}\text { Rozendaalse } \\
\text { Bos }\end{array}$ & ROZ & 456 & 13701 & 601 & 0 & 169 & 770 \\
\hline Rheden & RHE & 400 & 15563 & 2602 & 94 & 1071 & 3767 \\
\hline Speulderbos & SPE & 446 & 13017 & 2799 & 32 & 6199 & 9030 \\
\hline Gortel & GOR & 459 & 43463 & 195490 & 2355 & 8489 & 206334 \\
\hline Hoenderloo & $\mathrm{HOE}$ & 466 & 18640 & 861610 & 17965 & 73717 & 953292 \\
\hline
\end{tabular}

Results of the Pearson correlation and PCA (Fig. 3.2) indicated that none of the explanatory variables had a strong collinearity $\left(\log _{10} \mathrm{UL}\right.$, light, soil pH and broadleaf canopy dominance), which allowed the proper implementation of UL as independent variables and the rest as fixed factors. The PCA analysis, which included all response variables, presented a clear association among variables. Principal component one (PC1) explained $25.5 \%$ of the variation and was associated with sapling diversity, richness, shrub cover, litter depth and levels of browsed broadleaves on the right side and with stem density on the left side. PC2 explained $16.8 \%$ of the variation and was associated with levels of browsed conifers, moss cover and conifer proportion on the upper section and bare soil cover and basal area on the lower section. Regarding the associated (a)biotic factors (as superimposed variables in blue dashed arrows), cervidae, roe, red and fallow deer UL were positively associated with bare soil and negatively associated with broadleaf canopy dominance, light, soil $\mathrm{pH}$, browsed conifer sapling, diversity, richness and shrub cover. 


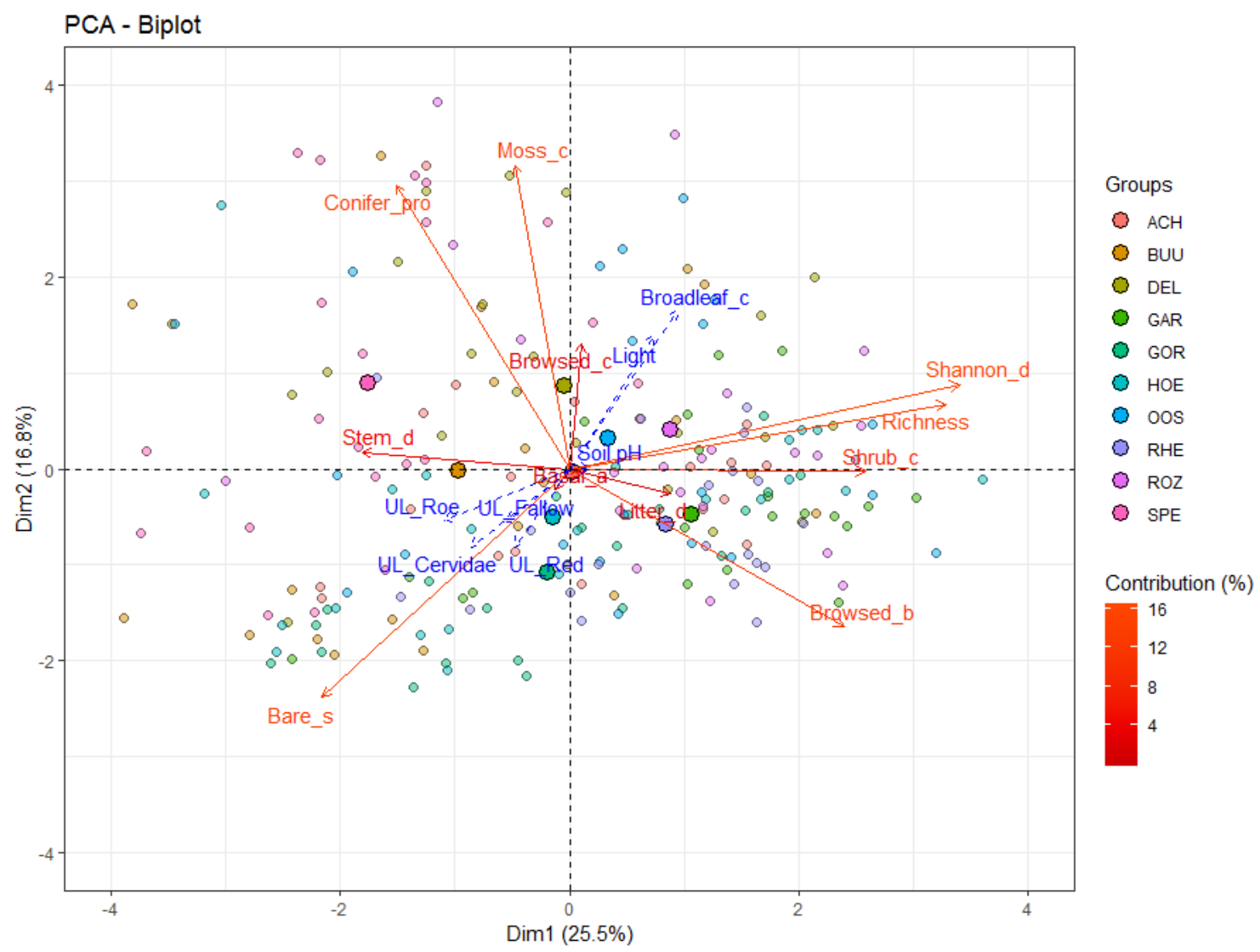

Figure 3.2. Variation in forest attributes across the study sites at the Veluwe, the Netherlands. Principal Component Analysis (PCA) for the vegetation response variables (in red arrows) and (a)biotic explanatory variables (as superimposed variables in blue arrows) that are used in the Generalized Mixed Linear Model presented in Table 2. The length of the arrow is proportional to its importance and the length combined with the angle between two arrows reflects the magnitude of the correlation between variables. Each small circle represents a sampling point $(N=212)$ and colour indicates the forest site where the camera trap was placed. Each large circle represents the site average. Forests were coded as in Table 1. Superimposed variables with no effect on the PCA were coded as: UL_Cervidae=utilization level Cervidae, UL_Red=utilization level red deer, UL_Roe=utilization level roe deer, UL_Fallow=utilization level fallow deer, Light=light, Soil $p H=s o i l ~ p H$, Broadleaf_c=broadleaf canopy dominance. Response variables were coded as: Stem_d=stem density, Basal_a=basal area, Richness=sapling richness, Shannon_d=sapling Shannon diversity, Conifer_pro=seedling conifer, Browsed_b=browsed broadleaves, Browsed_c=browsed conifers, Shrub_c=shrub cover, Moss_c=moss cover, Bare_s=bare soil, Litter_d=litter depth. Pearson correlation test suggested that there is no collinearity among fixed factors (UL-broadleaf canopy dominance=-0.22, UL-soil pH=0.07, UL-total light=-0.14, soil pH-total light=0.03, soil pH-broadleaf canopy dominance=-0.04, broadleaf canopy dominance-total light=0.38). 
Dose-response relationships discriminated by species

The main species driving the relationship with different forest attributes was roe deer, followed by red and fallow deer (Table 3.2, Fig. 3.3). The GLMM analysis that was carried out per species, indicated that roe deer UL had a significant positive relationship with stem density (absolute regression coefficient $B=0.05$, Fig. $3.3 A$ ) and a negative relationship with sapling richness ( $6=-0.26$, Fig. 3.3D), Shannon diversity $(B=-0.11$, Fig. 3.3F) and shrub cover $(b=-0.04$ Fig. 3.3H). Red deer UL had a negative relationship with litter depth ( $6=-0.14$, Fig. 3.3I). Fallow deer only had a negative relationship with sapling richness ( $B=-0.26$, Fig. $3.3 C$ ).

\section{Dose-response relationships for the entire browsing guild}

The GLMM results indicated a significant relationship of Cervidae UL with $36 \%$ (four of the eleven) of the forest response variables (Table 3.2 \& Fig. 3.3). Cervidae UL had a negative relationship with tree species richness (absolute regression coefficient $B=-0.21$, Fig. 3.3E), Shannon diversity ( $6=-0.09$, Fig. 3.3G), and litter depth ( $6=-0.14$. Fig. 3.3J) and a positive relationship with stem density ( $B=0.04$ Fig. 3.3B). Although UL did not explain a significant amount of the variation in the percentage of browsed conifers and broadleaves, a MannWhitney $U$ test indicated that broadleaf saplings (median $26 \%$ ) were browsed significantly more than conifer saplings (median $0 \%, W=41150, p<0.001$, Fig. 3.4). Broadleaf canopy dominance had significant positive relationship with sapling richness, diversity, conifer proportion in the understory and moss cover, and a negative relationship with bare land cover and browsed conifers. Soil $\mathrm{pH}$ had a positive relationship with browsed conifers and a negative relation with basal area. Light on the understory had a positive relation with shrub cover and a negative relationship with browsed conifers, bare land cover and litter depth. 
Table 3.2. Generalized Linear Mixed Models (GLMM) for the relationship of forest variables with Utilization Level $\left(U L, \mathrm{~kg}^{0.75} . \mathrm{s}^{\mathrm{m}} \mathrm{m}^{-1} \cdot \mathrm{d}^{-1}\right)$ in ten forest sites across the Veluwe, the Netherland. The model consists of $\log _{10} U L$ (discriminated by species: red, fallow, roe deer as well as the UL of the entire browsing guild), understory light, soil $\mathrm{pH}$ and broadleaf canopy dominance as fixed factors, ten forest sites and camera location were included as random effects. Models are accompanied by their units; absolute regression coefficients of the predictor variables and significance is presented in bold. All models were tested independently, however light, soil pH and broadleaf canopy dominance is provided only for UL Cervidae.

\begin{tabular}{|c|c|c|c|c|c|c|c|c|}
\hline \multirow[b]{2}{*}{ Variable } & \multirow[b]{2}{*}{ Units } & \multicolumn{7}{|c|}{ Coefficients } \\
\hline & & $\begin{array}{l}\text { UL R. } \\
\text { deer }\end{array}$ & $\begin{array}{l}\text { UL F. } \\
\text { deer }\end{array}$ & $\begin{array}{l}\text { UL R. } \\
\text { deer }\end{array}$ & $\begin{array}{c}\text { UL } \\
\text { Cervidae }\end{array}$ & Light & $\begin{array}{l}\text { Soil } \\
\text { pH }\end{array}$ & Broadleaf \\
\hline \multicolumn{9}{|l|}{ Forest regeneration } \\
\hline Stem density & ind.ha $\mathrm{a}^{-1}$ & -0.01 & -0.01 & 0.06 & 0.04 & 0.01 & -0.10 & -0.13 \\
\hline Basal area & $\mathrm{m}^{2} \cdot h \mathrm{ha}^{-1}$ & 0.10 & 0.47 & -0.58 & -0.39 & $\mathrm{n} / \mathrm{a}$ & -8.48 & 5.35 \\
\hline Richness & $\#$ & -0.10 & -0.26 & -0.26 & -0.21 & 0.01 & 0.55 & 2.61 \\
\hline Shannon Div. & $\mathrm{h}$ index & -0.01 & -0.11 & -0.11 & -0.09 & 0,01 & 0.31 & 1.64 \\
\hline Conifer proportion & $\propto$ & 0.21 & 0.21 & 0.36 & 0.23 & 0.26 & -0.30 & 0.46 \\
\hline \multicolumn{9}{|l|}{ Forest Browsing } \\
\hline Brw. Broadleaves & $\%$ & -0.02 & 0.11 & 0.06 & 0.27 & 0.27 & -0.14 & -0.13 \\
\hline Brw. Conifers & $\%$ & -0.01 & 0.13 & -0.01 & -0.01 & -0.74 & 0.02 & -0.67 \\
\hline \multicolumn{9}{|l|}{ Forest understory } \\
\hline Shrub cover & $\%$ & -0.24 & -0.23 & -0.04 & -0.26 & 0.69 & 0.10 & 0.12 \\
\hline Moss cover & $\%$ & -0.55 & -0.20 & -0.24 & -0.40 & 0.08 & -0.20 & 0.88 \\
\hline Bare land cover & $\%$ & -0.04 & 0.13 & 0.31 & 0.18 & -0.74 & 0.01 & -0.64 \\
\hline Litter depth & $\mathrm{cm}$ & -0.14 & -0.09 & -0.10 & -0.14 & -0.02 & 0.08 & 0.71 \\
\hline
\end{tabular}

Bold values $p<0.05$ 

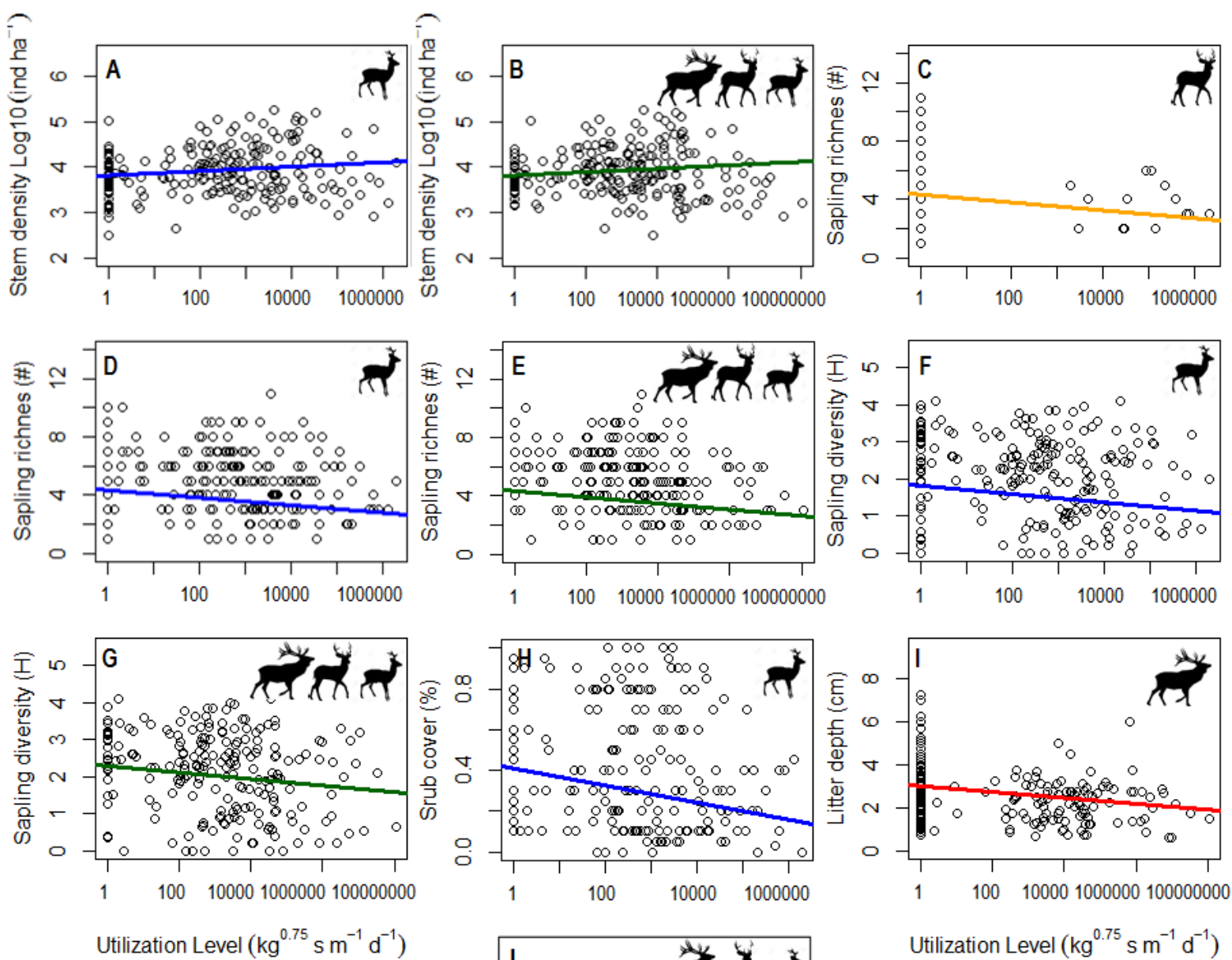

Utilization Level $\left(\mathrm{kg}^{0.75} \mathrm{~s} \mathrm{~m}^{-1} \mathrm{~d}^{-1}\right)$

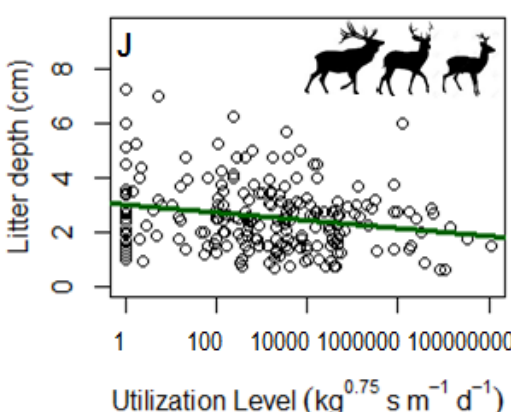

Utilization Level $\left(\mathrm{kg}^{0.75} \mathrm{~s} \mathrm{~m}^{-1} \mathrm{~d}^{-1}\right)$

Figure 3.3. Relationships of forest attributes with deer Utilization Level (UL) in forests across the Veluwe, the Netherlands. Generalized Linear Mixed Model (GLMM) fits for different forest attributes, for deer species (red deer $=H \& J$, fallow deer $=C$, roe deer $=A, D, F \& I)$ and the entire browsing guild $(B, E, G \& K)$. The regression lines were calculated based on the results of the GLMM presented in Table 3.2, where UL is set as a predictive variable and eleven different forest attributes as response variables. Forest site and camera location were included as random effects. All relationships shown are statistically significant. 


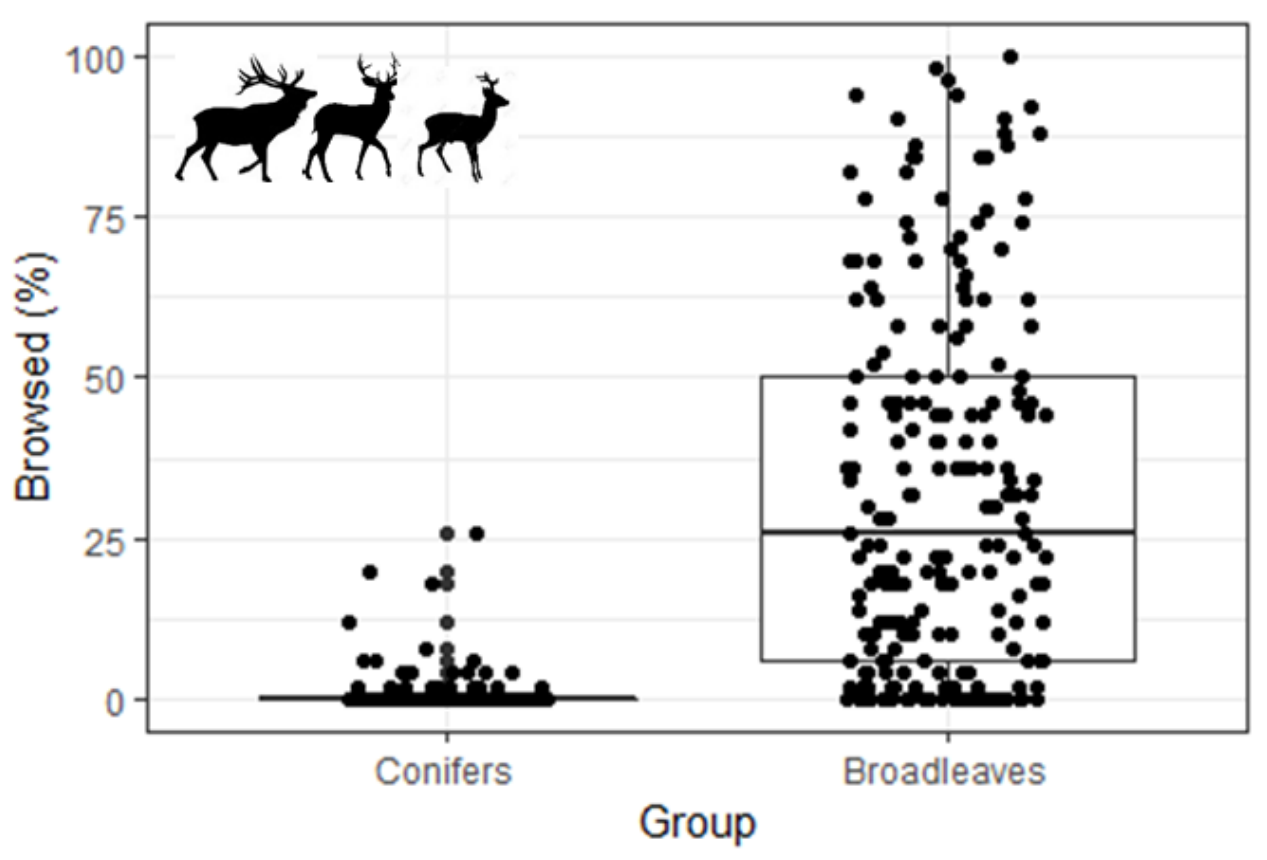

Figure 3.4. Boxplot for the percentage of browsed conifers and broadleaves stems by the entire browsing guild (red, fallow and roe deer). The difference is significant (Mann-Whitney $U$ test: $W=41150, p<0.001$ ).

\section{Discussion}

To reconcile the contrasting findings in the shape of the dose-response relationship between deer abundance and forest attributes, this study aimed to evaluate the dose-response relationship between deer Utilization Level (UL) and forest attributes along a full deer abundance gradient. $\mathrm{UL}$ is the proportion of time that a deer expressed in metabolic weight units spent in front of a camera trap in proportion to the deployment duration of the camera. We found that browsing levels increased exponentially with deer UL (Appendix A.2 \& A.3) because animals spend more time feeding and less time vigilant when they are in larger groups as they find safety in numbers (Altendorf et al. 2001). Deer UL was associated with a reduced sapling richness \& diversity, shrub cover and litter depth and with an increase in sapling density and browsed broadleaves. The relationship followed a $\log _{10}$ linear response; however, when back transforming, it followed a reverse asymptote. For didactical purposes, from here onwards the shape will be discussed as $\log _{10}$ back transformation. All these relationships were found because camera detection distance was controlled. Here we discuss the underlying ecological mechanisms, the potential and limitations of the camera trapping approach and research outlook. 


\section{Browsing incidence was driven by red deer}

We predicted $(\mathrm{H} 1)$ that browsing of broadleaf seedlings will increase with deer UL, yet we did not find evidence for this relationship (Table 3.2). Two possible explanations are that fallow and roe deer have much smaller home range than red deer (Pellerin et al. 2008; Gill \& Morgan 2010) and fallow and roe deer tend to browse in specific spots making it more difficult to quantify their damage on the vegetation (Gill 1992a). Furthermore, red deer has a limit distribution to only the central and northern part of the Veluwe (Table 3.1). However, from all 2370 feeding events registered by our camera traps, red deer dominated, which reflects their high metabolic weight and their higher UL at our sites (Appendix A.4). Soil pH had a positive relation with the percentage of browsed conifers (Table 3.2), possibly because better soil conditions favour development of plant shoots (Smilde 1973), hence attractiveness to deer. Light had a negative relationship with browsed conifers possibly because deer avoid open areas that are associated with higher predation risk (Gill 1992a). Broadleaf canopy dominance had a negative relationship with the percentage of browsed conifers because in forest dominated by broadleaves, there is little conifer regeneration, and hence, less opportunities for browsing of conifers.

\section{Forest structure was driven by roe deer}

We predicted $(\mathrm{H} 2)$ that an increase in deer UL would promote browsing and trampling of forest regeneration, and therefore result in a decreased stem density and plot basal area (Klopcic et al. 2010; Salk et al. 2011). An increase in deer UL indeed increased the amount of deer feeding time that disturbed forest vegetation (Fig.3.3). Roe deer UL had a positive relation with stem density $(<250 \mathrm{~cm}$ high, Fig. 3.3A). A plausible explanation is that browsing reduced the cover of the competing shrub layer (Fig. 3.3H), which may enhance the amount of light reaching the forest floor, thus releasing tree seedlings from shade suppression (Whitmore 1989). However, UL had no significant relationship with sapling basal area, meaning that trees do not fully develop (Table 3.2). Soil pH had negative relation with stand basal area (Table 3.2), probably because trees cannot develop to their full potential on poor sandy soils, typically characterized by an average pH of 3.44 (Smilde 1973). 


\section{Cervidae reduced tree species richness and diversity}

We predicted $(\mathrm{H} 3)$ that increased deer UL would promote an increase in the proportion of conifers in the vegetation, because deer preferentially browse on palatable broadleaved individuals, thus favouring conifers through competitive release (Rooney \& Waller 2003). We indeed found that broadleaved saplings were browsed significantly more frequently (26\%) than conifer saplings (0\%, Fig. 3.4), but there was no significant relationship of UL with the proportion of conifer species in the sapling layer (Table 3.2). This finding agrees with a North American study in which there was no browsing effect on tree species composition (McGarvey et al. 2013). A possible explanation is that seed trees in the forest canopy have an overriding, stronger effect on tree species composition (Gill \& Beardall 2001), which was supported by our GLMM results, as broadleaf canopy dominance increased the proportion of conifers in the sapling community (Table 3.2). Light had no relationship with the proportion of conifers in the sapling layer (Table 3.2), perhaps because half of the dominant conifer species at the Veluwe consists of light-demanding species (Pinus sylvestris and Larix kaempferi) and the other half of shade tolerant species (Pseudotsuga menziesi and Picea abies).

We predicted $(\mathrm{H} 3)$ and found that deer UL would decrease tree sapling richness and diversity. We hypothesized that deer would preferentially browse and remove broadleaved species, and there was indeed a negative relation between deer and tree diversity, and this relationship will only increase over time as shown in a long-term effect study (Ramirez et al. 2019). UL had a stronger relationship with tree richness than Shannon diversity (Table 3.2), probably because rare species that are browsed can be extinct at local scale and thus affecting species richness, whereas Shannon diversity considers the abundance and proportion of the different species and thus Shannon index is less susceptible to deer disturbance. However, the slopes of the relationships are very low, meaning that limited tree diversity and richness is lost with increasing UL (sapling richness decreased from 3.94 to 2.12 and diversity from 2.11 to 1.48). Chollet et al. (2013), suggested that species loss can be avoided by the presence of plant refuges in temperate forests which provide suitable habitat for species sensitive to browsing to grow fast and outcompete herbivory or simply because browsing does not kill the individual but rather maintain them in a small size class (Kuijper et al. 2013). Broadleaf canopy dominance played a major role on sapling diversity (Table 3.2) as a broadleaved forest allows for different sapling species to coexist, whereas a conifer forest through allelopathy inhibits other sapling species (Kuiters \& Sarink 1986). 


\section{Roe deer: driver of change}

The main species driving the different forest attributes was roe, whereas red and fallow deer had weak affects. This result can be explained by the fact that roe deer have a wider distribution across sites, whereas red and fallow deer had a narrower distribution (Table 3.1). The GLMM results indicated that roe is a key species in Dutch temperate forests, as they have the potential to reduce forest understory diversity and shift mixed forest composed of broadleaves and conifers to a conifer dominated forest by selectively browsing broadleaved saplings. Conifer forests are characteristic for having a lower canopy cover and a higher light permeability than mixed forest because of crown architecture and use of space (Ishii \& Asano 2010), however due to their inherently low quality leaves (Maes et al. 2019), conifers can form a recalcitrant thick litter layer in the forest understory, which prevents the establishment of seedlings.

Roe deer reduced understory shrub cover

We predicted $(\mathrm{H} 4)$ that deer would decrease understory shrub cover by browsing and trampling and indirectly decrease moss cover because of the increased understory light availability. Our results partially support our prediction because roe deer UL indeed had a negative relationship with shrub cover (Fig. 3.3H) but no relationship with moss cover (Table 3.2). We also found that understory light had a positive relationship with shrub cover and that broadleaf canopy dominance had a negative relationship with bare land cover and a positive relationship with moss cover (Table 3.2). Our results are aligned with literature because broadleaf trees such as Fagus sy/vatica form a thick recalcitrant litter layer that helps maintain humidity and control light in the understory which are beneficial for moss establishment (Mills \& Macdonald 2004; Maes et al. 2019).

\section{Red deer has a strong relationship with litter depth}

We predicted ( $\mathrm{H} 5)$ that deer would reduce litter thickness on the forest floor because trampling can either compact litter, or mix litter with the soil (Hobbs 1996). We indeed found that litter depth decreased with red deer UL (Table 3.2, Fig. 3.3I). A reduction in litter thickness can have cascading effects on other trophic levels as it reduces food availability for invertebrates (Allombert et al. 2005b). A reduced litter thickness also affects soil and invertebrates as it exposes the soil to an increased irradiance and temperature, leading to 
desiccation and potentially erosion. On eroded soils, with limited organic matter and microfauna to decompose, the turnover of nutrients can be compromised till the point that plants cannot establish and develop (Ingham et al. 1985).

\section{Browsing guild shaping temperate forests}

Considering that temperate forests are complex systems, which not only harbour a single deer species but actually several deer species, it is necessary to understand the relationship between a browsing guild and different forest attributes. Our results indicated that when the three deer species were combined, these browsers had a positive relationship with stem density (Fig. 3.3B) and a negative relationship with litter depth (Fig. 3.3J), sapling richness (Fig. 3.3E) and diversity (Fig. 3.3G). However, the relationship was weaker when comparing to the individual deer species, indicating that not all deer species are strict browsers (Gill 1992a), and that different deer species have different impacts on the forest ecosystem.

\section{A non-linear dose-response relationship}

Our findings suggest that tree species richness and diversity respond in a curvilinear way to Cervidae UL, where initial changes are large (please note that we log-transformed UL) followed by small changes at higher UL (Fig. 3.3C-G). This agrees with Rooney and Waller (2003) who reasoned that ungulate density has a negative exponential relationship with tree diversity. Similarly, a global literature review showed that ungulate density has a non-linear relation with regeneration diversity (Ramirez et al. 2018); however the shape of the curve in that review was negatively sigmoidal: where small increases in ungulate density would lead to large decreases in tree diversity. Local studies in lowland Britain and Canada indeed showed such a negative exponential relationship (non-linear) with seedling density (Gill \& Morgan 2010) and aboveground tree biomass (Tremblay et al. 2006). On the contrary, two North American studies showed that tree regeneration decreased linearly with an increase in deer abundance (Kamler et al. 2010; Nuttle et al. 2014). Other studies suggest that forest attributes should show a hump-shaped relationship with deer density (Rooney \& Waller 2003), as at intermediate densities deer might increase habitat and tree heterogeneity, whereas at high densities they may decrease, but we found no evidence for such a shape for any of the forest attributes. 
The lack of evidence for a hump shape can be directly related with three aspects: (1) the fact that herbivores have a scale dependent effect on forest diversity, meaning that they reduce diversity at a patch level (this is what we studied) but can increase diversity at a landscape scale by creating different patches. (2) The lack of predation enables deer to browse intensively and homogenously through the landscape as deer population size and behaviour is not top-down control (Kuijper et al. 2013) and thus forest diversity patches are not established. (3) On poor sandy soils, such as the Veluwe, primary productivity is limited (Lieth \& Whittaker 2012) and thus vegetation is highly susceptible to browsing; whereas in a high primary productivity system, saplings can mitigate herbivory by developing defences or escaping it by growing past the browsing height.

We found that species composition and the extent of the deer abundance gradient played a major role in the shape of the dose-response relationship. Earlier studies found very different dose-response relationships but also used very distinct deer gradients: from 0 to 30 individuals $\mathrm{km}^{-2}$ (Nuttle et al. 2014), from 0 to 60 individuals $\mathrm{km}^{-2}$ (Gill \& Morgan 2010) and from 15 to 56 individuals $\mathrm{km}^{-2}$ (Kamler et al. 2010). Similarly primary productivity of the research site (Ramirez et al. 2018) and how data is collected (Gill 1992a; Rooney \& Waller 2003) affects the shape of the dose-response relationship. By pairing camera traps to regeneration plots, we were able to quantify the dose-response relationship with a higher accuracy than past studies. Our results suggest that the dose-response is negative and curvilinear (Fig. 3.3), which is supported by the response shape of UL and feeding time in our camera trap network (Appendix A.3), which presented an exponential increase of feeding time with UL.

Past studies estimated ungulate abundance and density by implementing different methods, such as indirect and incomplete animal counts and thus presenting a great variation in the dose-response relationships between ungulate abundance and temperate forests. Typical inherent constraints related to indirect and incomplete animals involve the accumulation or decay of signs left behind by animals (bite marks, tracks and faeces) over time, animals hiding from human sight and the behaviour of one animal may reflect the behaviour of the entire population (Koster \& Hart 1988). On the other hand, camera traps being portable and easy to use can monitor wildlife over a wide territory, 24 hours a day, 365 days a year and have fixed detection distances. Yet, their elevated cost and the fact that they remain stationary might be important limitations for projects with restricted budget. 


\section{Conclusions}

Using a network of camera traps, we were able to closely assess the dose-response relationship between deer and forest regeneration at small spatial scales. We found that deer had a moderate relationship with understory attributes of mixed forests on poor sandy soils. Roe deer UL had a significant relationship with four, red and fallow deer with one of the eleven forest attributes evaluated, and when combining all deer species, we found a significant relationship with four of the response variables. Red and fallow deer had very little effect on forests due to their limited distribution across the Veluwe. UL had a weaker impact on forest attributes than broadleaf canopy dominance (55\%), but a similar or stronger impact than understory light (40\%) and soil pH (18\%, Table 2). Deer had negative curvilinear relationship with forest attributes, large changes followed by small changes at high UL. Deer decreased tree species richness and diversity and the depth of the litter layer and increased sapling density. Considering the variation of response variables in relation to UL (stem density varied from 3.86 to 4.28 ind.ha ${ }^{-1}$, sapling richness from 3.94 to 2.12 , diversity from 2.11 to 1.48 and litter depth from 3.06 to $2.08 \mathrm{~cm}$ ), we can conclude that the influence that deer have on temperate forest structure and diversity is existent, yet limited. We made an important first step by monitoring vegetation and wildlife during summer and autumn, yet for future studies, annual monitoring repeated over years should be implemented because animal populations can fluctuate as a response to seasonality.

\section{Acknowledgements}

This work was supported and financed by the "Secretaría de Educación Superior, Ciencia, Tecnología e Inovación del Ecuador, Convocatoria Abierta 2012" and the Grant of the Ecology Fund of the Royal Netherlands Academy of Arts and Sciences. Access to forest areas was kindly granted and coordinated directly with management officers and staff members from Staatsbosbeheer, Kroondomein Het Loo, Cooperatie Bosgroep Midden Nederland, Geldersch Landschap en Kasteelen and Gemeente Epe. 


\section{Appendix A.}

\section{A.1}

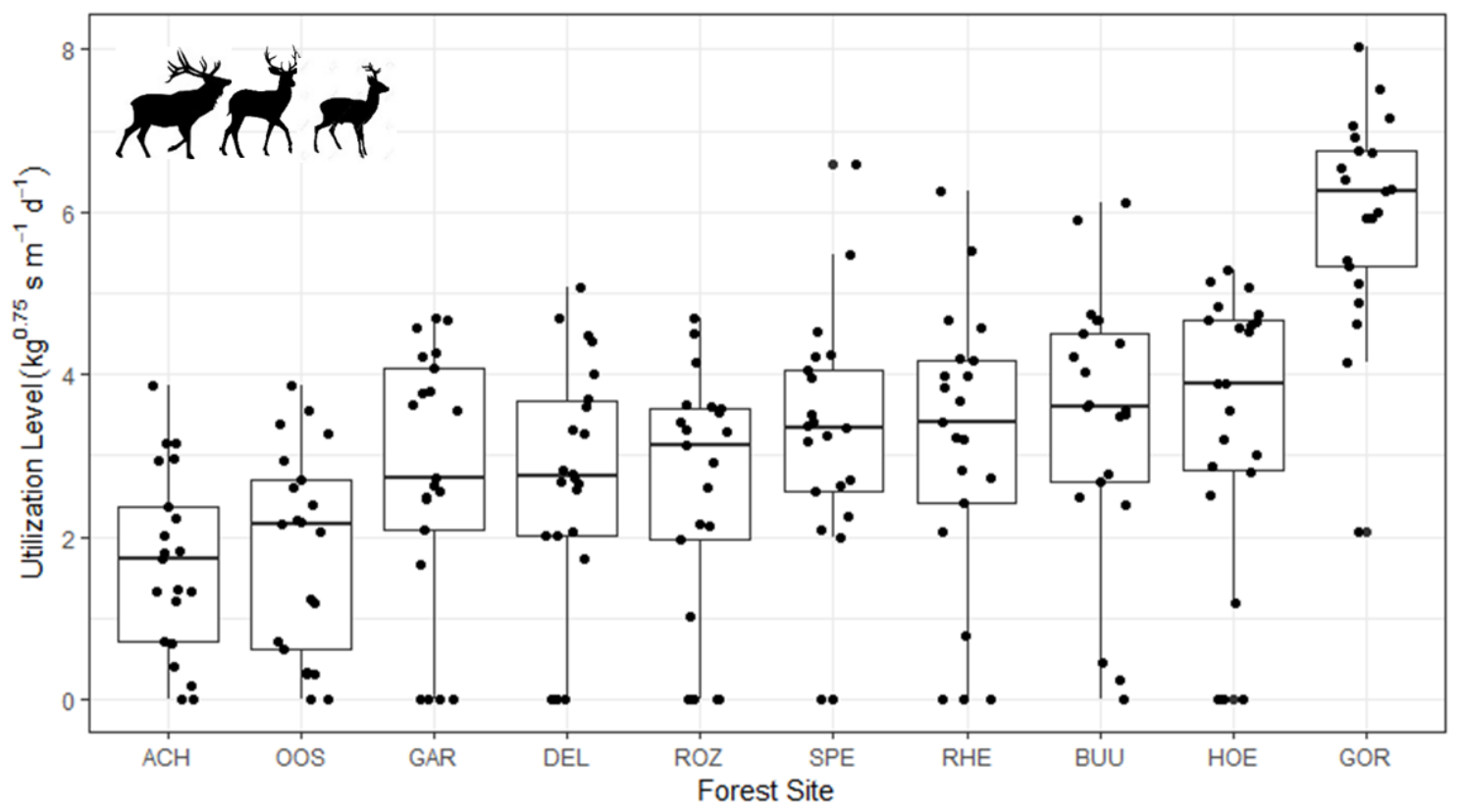

Appendix A1. Boxplot for deer (red, fallow\& roe deer) and Utilization Level per research site at the Veluwe, the Netherlands. Sites are coded as in Table 3.1.

\section{A. 2 \& A.3}

Deer browsing in relation to their Utilization Level

The GLMM results showed that UL indeed predicted the amount of time that deer (red, roe \& fallow deer) spent feeding in front of the camera traps (Appendix A.2 \& A.3). As a contrast, UL is the total amount of time and animal spends in front of the camera, whereas feeding time only considers the time that the animal feeds in front of the camera. Light level also predicted the time that red deer and Cervidae spend feeding in front of a camera trap, whereas stem density did not. The shape of dose-response relationship is characterized by an exponential function, with a slow increase in feeding time at lower UL, followed by a rapid increase in feeding time at higher UL. From all 2370 feeding events registered by our camera traps, red deer was responsible for $55 \%$ of the incidences followed by roe deer $(44 \%)$ and fallow deer (1\%, Appendix A.4).

Appendix A2. Generalized linear mixed model (GLMM) results for the relationship between Utilization Level (UL, $\left.k g^{0.75} . \mathrm{s} . \mathrm{m}^{-1} \cdot \mathrm{d}^{-1}\right)$ and feeding time $\left(\mathrm{s} . \mathrm{d}^{-1}\right)$ by deer species alone and combined. UL, understory light and stem density (of stems between 10 and $250 \mathrm{~cm}$ height) were used as fixed factors, feeding time was set as a response variable and site and camera location were included as random effects. Models are accompanied by their $R^{2}$ conditional 
\& marginal values, explained variation of the random forest site effect and absolute regression coefficients of the predictor variables. Significant coefficients are shown in bold.

\begin{tabular}{|c|c|c|c|c|c|c|c|}
\hline \multirow[b]{2}{*}{ Family } & \multicolumn{3}{|c|}{ Random effect } & \multicolumn{4}{|c|}{ Regression Coefficients } \\
\hline & $\begin{array}{c}\mathbf{R}^{\mathbf{2}} \\
\text { marginal }\end{array}$ & $\begin{array}{c}\mathbf{R}^{\mathbf{2}} \\
\text { conditional }\end{array}$ & $\begin{array}{l}\text { Std. } \\
\text { Dev. }\end{array}$ & Intercept & ^UL & Light & Stem D. \\
\hline Red deer & 0.82 & 0.84 & 2.38 & 0.01 & 0.04 & 0.08 & $<0.00$ \\
\hline Fallow deer & 0.49 & 0.90 & 0.57 & 0.01 & 0.01 & $<0.00$ & $<0.00$ \\
\hline Roe deer & 0.46 & 0.59 & 1.52 & 0.01 & 0.04 & 0.020 & $<0.00$ \\
\hline Cervidae & 0.80 & 0.84 & 2.73 & 0.01 & 0.04 & 0.06 & $<0.00$ \\
\hline
\end{tabular}

Bold $p<0.05$
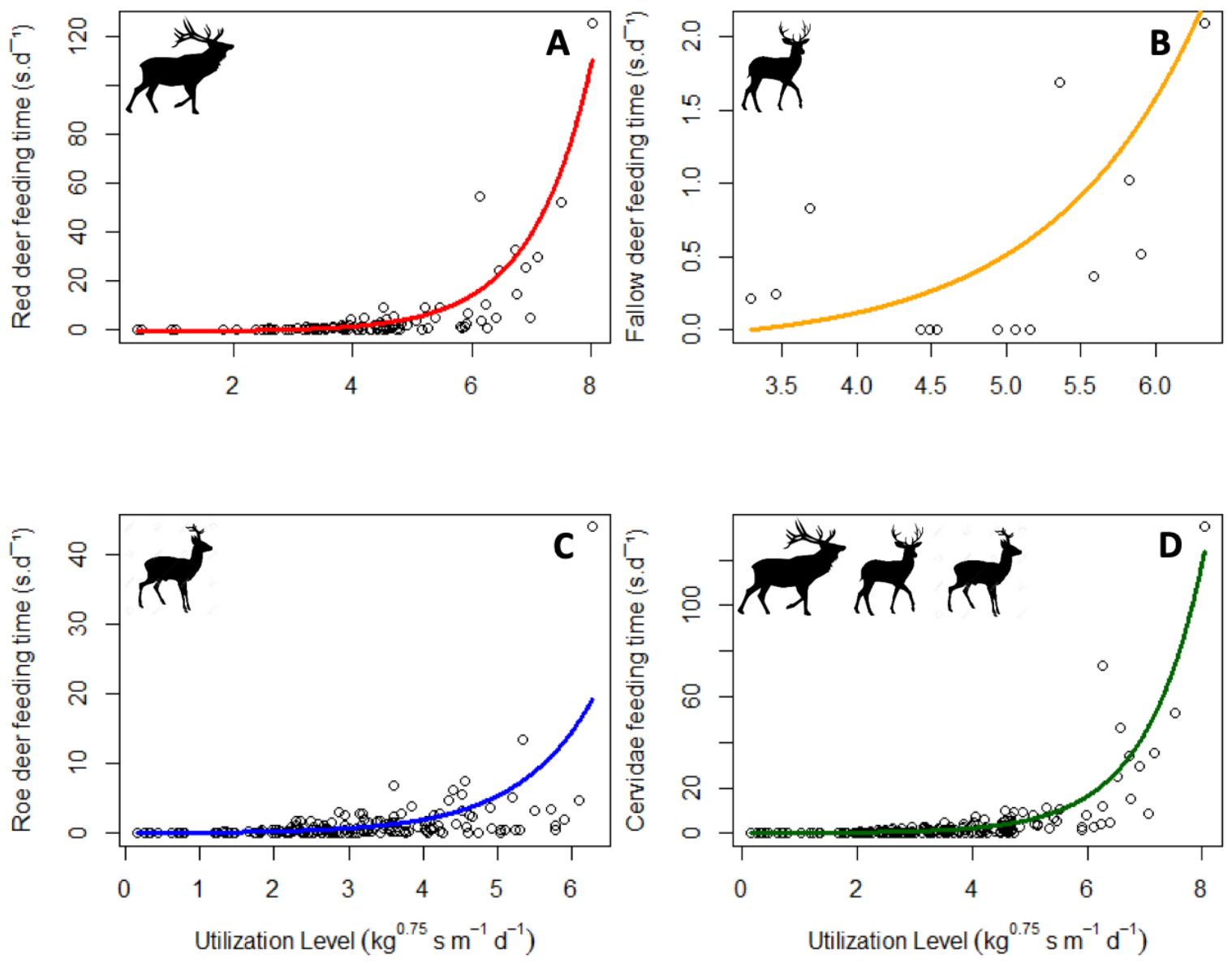

Appendix A3. Relationships between feeding time and deer Utilization Level (UL) in forests across the Veluwe, the Netherlands. Generalized Linear Mixed Model (GLMM) fits for the relationship between deer UL and the time that deer spend feeing in front of the camera trap for red deer ( $A$ - red curve), fallow deer ( $B$ - orange curve), roe deer (C-blue curve) and Cervidae (D-green curve). The functions were calculated based on the results of the GLMM presented in Appendix A2, where UL is the predictive variable and feeding time is the response variable. Finally, 
forest site and camera location were included as random effects. All relationships shown are statistically significant.

\section{A. 4}

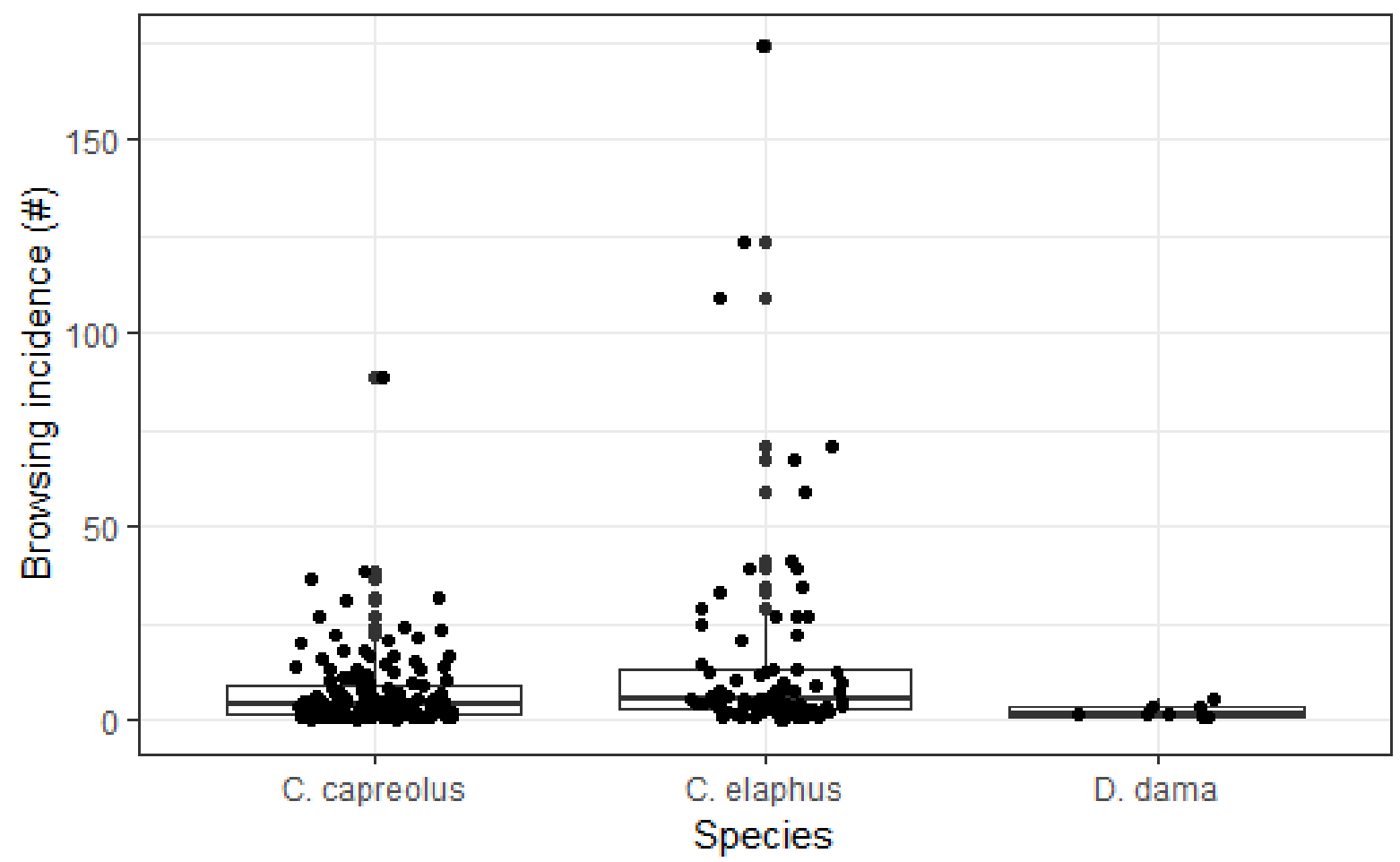

Figure A4. Boxplot showing the browsing incidence discriminated by ungulate species captured by our camera network installed in the Veluwe, the Netherlands. 


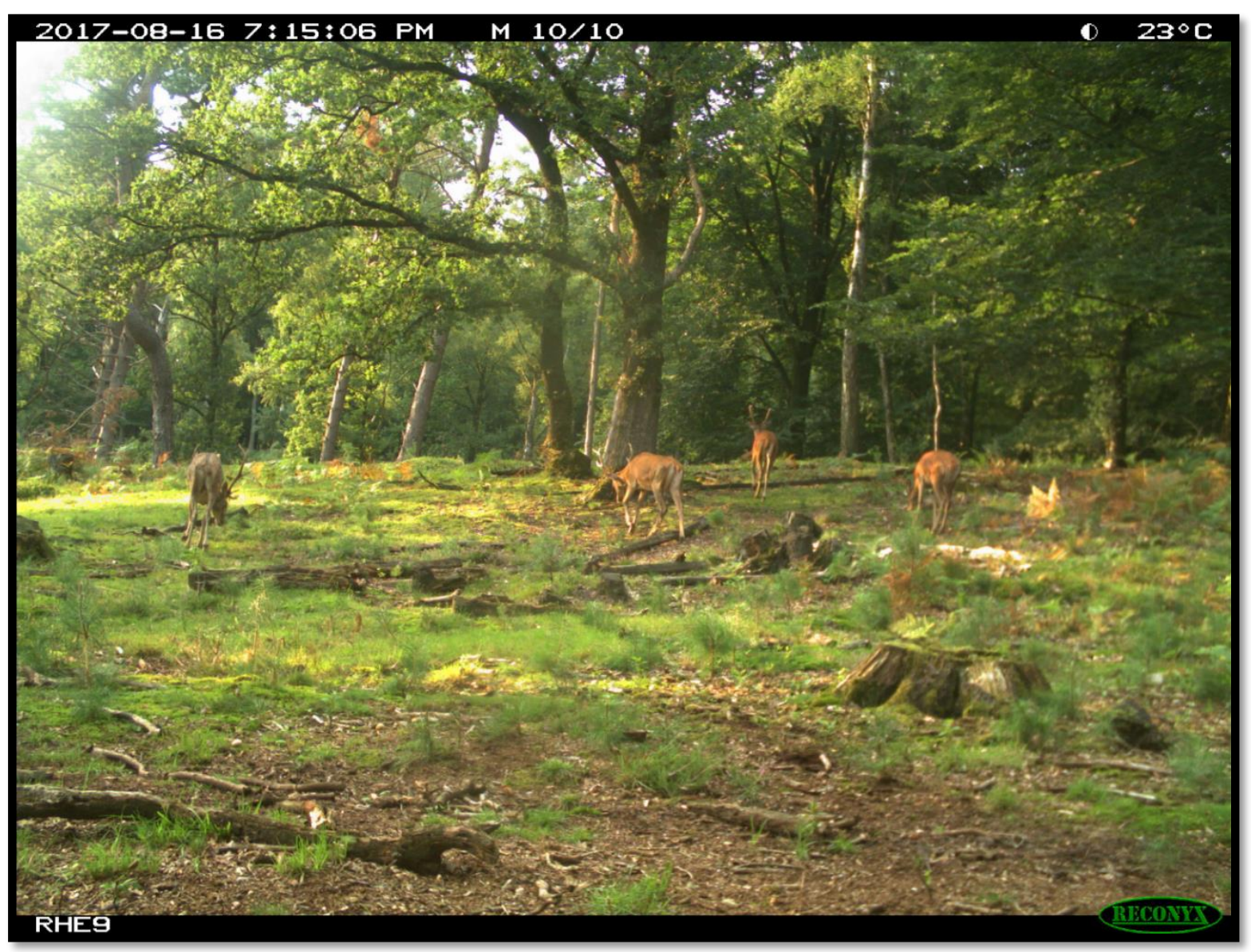




\section{CHAPTER FOUR}

Long-term effects of wild ungulates on the structure, composition and succession of temperate forests

Published in Forest Ecology and Management 432 (2019) 478-488

Authors

J. Ignacio Ramirez; Patrick A. Jansen; Jan den Ouden; Leo Goudzwaard \& Lourens Poorter 


\begin{abstract}
Ungulates in temperate regions are increasing in range and abundance, leading to concerns that browsing and trampling reach levels that hamper tree recruitment and forest regeneration. However, studies that actually quantify the long-term effects of ungulates on forest succession are scarce. Here, we use a chronosequence of ungulate exclosures (fenced) and control (unfenced) plots to assess the long-term effects of ungulates on forest structure, diversity and litter depth in forests on poor sandy soils at the Veluwe, the Netherlands, which have moderate ungulate densities $\left(\bar{x}=13.6\right.$ ungulates $\left.\mathrm{km}^{-2}\right)$. We surveyed the vegetation in 27 paired fenced and unfenced plots that ranged from 1 to 33 years old, and measured eight variables to characterize forest structure (stem density, canopy cover \& understory vegetation cover), composition (Shannon diversity, species richness \& conifer proportion) and leaf litter depth. We found that fencing compared to unfencing reduced understory vegetation cover (fenced $\bar{x}=64.3 \%, \mathrm{SD}=20.2$, unfenced $\bar{x}=80.3 \%, \mathrm{SD}=19.4$ ), increased canopy cover (fenced $\bar{x}=47.4 \%, \mathrm{SD}=30.1$, unfenced $\bar{x}=29.3 \%, \mathrm{SD}=21.1$ ), tree species richness (fenced $\bar{x}=4.5, \mathrm{SD}=1.3$, unfenced $\bar{x}=2.7, \mathrm{SD}=1.2$ ), tree Shannon diversity (fenced $\bar{x}=1.1, \mathrm{SD}=0.3$, unfenced $\bar{x}=0.7$, $\mathrm{SD}=0.3$ ) and litter layer depth (fenced $\bar{x}=4.4 \mathrm{~cm}, \mathrm{SD}=1.4$, unfenced $\bar{x}=2.4 \mathrm{~cm}, \mathrm{SD}=1.1$ ). While fenced plots developed woody vegetation with palatable broadleaved species such as Betula pendula, Betula pubescens, Prunus serotina, and Quercus robur, unfenced plots were not associated with any particular tree species. Our results show that current ungulate densities in this system have pronounced long-term effects on forest structure, composition and litter depth, implying that ungulates can slow down natural succession of temperate forest, from light demanding to shade tolerant species, by keeping the system in an arrested state consisting of light demanding species.
\end{abstract}

\title{
Abbreviations
}

PCA $=$ Principal Component Analysis; GLMM =Generalized Linear Mixed Models

\section{Introduction}

Wild ungulates are expanding in temperate forests and have reached historical peaks in abundance during the last decades (Clutton-Brock \& Albon 1992; Rooney 2001; Pellerin et al. 2010a) due to a variety of reasons including reintroduction, reduced competition with 
domestic cattle, abandonment of agricultural pastures that induce woody species encroachment which favour preferential habitat type for ungulate species, reduced hunting levels and absence of top predators (Kuiters et al. 1996; Rooney 2001). Ungulates are keystone species and ecosystem engineers (Power et al. 1996; Waller \& Alverson 1997; Rooney 2001) because through browsing they shape the structure and dynamics of entire ecosystems, from the micro scale (e.g., tree diversity in the forest stand) up to the landscape scale (e.g., open understory on a regional forest) (Russell et al. 2001; Rooney \& Waller 2003). Ungulates can modify vegetation and steer succession through a variety of mechanisms, such as herbivory (browsing \& grazing), disturbance (trampling, fraying \& uprooting), and nutrient translocation (defecation) (Reimoser 2003).

Ungulates may steer forest composition in two major ways. The first is preferential browsing and grazing of more palatable species such as broadleaved tree species, which indirectly favours less palatable species such as most conifers (Rooney \& Waller 2003). This preference may cause a shift from mixed broadleaved-conifer forests to conifer-dominated forests in temperate regions (Gill 1992b; White 2012), and may facilitate the establishment of less palatable invasive species through competitive release and increased resource availability (Kalisz et al. 2014). Second, frequent and intense physical disturbance such as trampling, fraying and uprooting can eliminate entire cohorts of seedlings and saplings from a forest stand (Gill 1992b). Such damage to recruits in the forest understory may slow down forest succession and may eventually lead to forest collapse if there are no young trees to replace senescent adult trees (Côté et al. 2004). Thus, ungulates may determine the boundaries between open and closed vegetation between biomes (e.g., modifying the transition from forest to savannah) as well as within biomes (e.g., modifying the transition between open and closed forest patches).

In northwest European forests, ecological succession normally proceeds from an earlysuccessional vegetation dominated by light-demanding Betula, Pinus and Quercus species towards a late-successional vegetation dominated by shade-tolerant species such as Fagus sylvatica (Zerbe 2002). However, when ungulates are present at high densities, browsing may reduce tree density and shift species composition towards an arrested, early-successional vegetation, dominated by light-demanding pine species (Kuiters \& Slim 2002). These shifts in species composition may also have cascading effects on other trophic levels, such as a reduced number of invertebrate decomposers resulting in reduced litter decomposition, and a 
decreased diversity of small mammals that need heterogeneous forest structure as shelter from weather and predation. (Fuller 2001; Chollet et al. 2015).

The short-term effects (e.g. $<5$ years) of ungulates on forest regeneration have been widely documented. At low densities and on relatively fertile soils, ungulates can promote structural heterogeneity (Gordon \& Prins 2008; Prins \& Fritz 2008; Svenning et al. 2015) leading to an increase in herbaceous and woody plants and animal diversity (invertebrates \& vertebrates) and improved ecosystem functioning such as transfer of energy up the food chain (Kuiters et al. 1996; Gill \& Morgan 2010; Estes et al. 2011). However, it is not clear how the effects of ungulates play out on the longer-term (e.g. >15 years) (Scott et al. 2009); as ungulates in the short-term tend to browse mainly on palatable (broadleaved) species such as Sorbus aucuparia and Betula pendula, leading to a competitive release of unpalatable (coniferous) species such as Pinus sylvestris and Picea abies that are hardly browsed. The potential long-term effect of ungulates is difficult to evaluate due to the lack of long-term and replicated experiments (White 2012).

Here, we aimed to assess the long-term effects of a relative moderate ungulate density on forest structure, diversity and functioning under relatively poor nutrient conditions at the Veluwe, the Netherlands (Kuiters \& Slim 2002). We applied a chronosequence approach that uses a space-for-time substitution to infer long-term successional trends (Kennard 2002). Specifically, we surveyed 27 pairs of fenced and unfenced plots, ranging in age from 1 to 33 years old, at 17 sites. We asked what the long-term effects of ungulates are on forest structure, composition and succession.

We tested four predictions: (1) ungulates reduce stem density, understory vegetation and canopy cover through browsing and trampling (Gill \& Beardall 2001; Russell et al. 2001), with an accumulating impact over time. (2) ungulates reduce seedling and sapling richness and diversity by selectively browsing on broadleaved trees, and favour conifers through competitive release (Côté et al. 2004). (3) ungulates can either reduce or increase the depth of litter and fragmented layers. Ungulates can reduce litter thickness by removing litter, or by compacting litter through trampling. Ungulates can also change litter thickness by preferentially feeding (Husheer et al. 2005) on broadleaved species, which leads to a stand dominated by coniferous species. Conifer stands may either have a thin litter layer because of their evergreen leaf habit, which is associated with low annual litter production rate. Alternatively, conifer stands may have a thicker litter layer because of the low 
decomposability of their needles, and their irregular packing. The relative importance of these two processes determine in the end the depth of the litter layer. (4) in the absence of ungulates, succession proceeds from stands dominated by light-demanding species towards stands dominated by shade-tolerant species. Active browsing by ungulates on palatable species leads towards an arrested, early-successional vegetation, dominated by lightdemanding conifer species in the forest understory (Kuiters \& Slim 2002).

\section{Methods}

\section{Study area}

The Veluwe is located in the central part of the Netherlands with a total extension of 1200 $\mathrm{km}^{2}$. Annual average precipitation is $900 \mathrm{~mm} \mathrm{yr}^{-1}$, whereas the annual average temperature is $9.4^{\circ} \mathrm{C}$, with monthly temperature means ranging from $2.5^{\circ} \mathrm{C}$ in January to $16.4^{\circ} \mathrm{C}$ in July (Kuiters \& Slim 2002). The main soil types consist of xeric humic podzols and brown earths (inceptisols), depending on the parent material that range from aeolic drift and cover sands to Pleistocene loamy fluvioglacial sands (Kuiters \& Slim 2002). The Veluwe is covered by a mosaic of forests, drift sands and heathland, where forests cover two thirds of the total area. The main species are Pinus sylvestris, Quercus robur, Fagus sylvatica, Larix kaempferi, Pseudotsuga menziesii and Betula pendula. Although ungulate assemblage varies across the Veluwe, the main species are roe deer (Capreolus capreolus), fallow deer (Dama dama), red deer (Cervus elaphus) and wild boar (Sus scrofa), with an average density of 13.6 individuals $\mathrm{km}^{-2}$ in 1998 (Kuiters \& Slim 2002) and considerable increase during the last decades. Forest managers in this area generally aim to transform even-aged single coniferous species into mixed forest stands, and create small clearings to stimulate natural regeneration of a mix of native species.

\section{Study design}

To assess the effects of wild ungulates on long-term forest succession, we compiled a set of existing fenced plots that were established in recent clear cuts to protect forest regeneration from ungulates, paired with neighbouring unfenced plots, that were ca. $10 \mathrm{~m}$ apart. In total, we identified 27 fenced and unfenced plots in 17 different forest sites with plots ranging in age from 1 to 33 years since establishment. Plot size varied from 0.01 to 0.75 ha, and the number of pairs per site varied from 1 to 6 (Appendix A.1). We surveyed the vegetation during 
the late summer of 2016 and 2017. Within each pair of fenced/unfenced plots, $5 \times 5$ m quadrats were randomly established by drawing numbers for the $\mathrm{x}$ and $\mathrm{y}$ axis, which represented $\mathrm{a}$ coordinate system. We established two quadrats per plot when regeneration heterogeneity was low (i.e., low species diversity and little variation in forest structure), and three or four quadrats per plot when heterogeneity was high. Data from all quadrats were averaged to obtain values for a plot.

\section{Response variables}

We quantified 15 response variables that are commonly used in studies into ungulate-forest interactions. Each variable was then averaged across all $5 \times 5 \mathrm{~m}$ quadrats within treatments for each of the 17 forest sites. Eleven response variables were used to describe forest structure: stem density of trees 0.1-0.49 m height, 0.5-4.99 m height, and 5-30 m height, total understory vegetation cover, heath (heather and Ulex) cover, fern (Polypodiopsida and Pteridium) cover, shrub cover (bramble (Rubus spp.) and woody shrub species), moss (Bryophyta) cover, grass (Gramineae) cover, non-living "other" (branches, litter and exposed soil) cover and canopy (overstory) cover. Heath was recorded separate to shrub cover because this type of vegetation is quite common in Dutch forests. Three variables were used to describe forest composition: species richness, Shannon diversity and proportion of coniferous trees in the vegetation. Finally, litter depth was measured. Only woody plants $>10 \mathrm{~cm}$ in height were measured, as smaller recent germinants show large fluctuations in population size.

Each woody individual was identified, its height measured as the vertical distance between the forest floor and the apex and browsing damage was quantified as the presence (coded as 1 ) or absence (coded as 0 ) of damaged branches and leaves on any part of the plant, independent of the number of browsed leaves sort by branches. Canopy cover, which determines understory light availability, was measured in each quadrat with a spherical densitometer, taking one reading per cardinal direction (Millington et al. 2011). The dominant canopy tree species determine to certain extend the type of canopy cover (sparse or closed) and have a large effect on the composition of the local seed rain (Gill \& Beardall 2001). We identified therefore the two species with the highest abundance in the canopy of the residual forest. Because understory vegetation competes directly for light and nutrients with tree seedlings and saplings (Naaf \& Wulf 2007) we estimated understory vegetation cover by determining, with the use of a grid $(1 \times 1 \mathrm{~m})$, the cover percentage of the different vegetation 
types (heath, fern, shrub, moss, grass and non-living) up to $1.5 \mathrm{~m}$ height for each quadrat. Litter depth represents the amount of un-fragmented and fragmented litter layer, which is available for decomposition. Litter depth also acts as a barrier for the establishment of species in the seedbank (Facelli \& Pickett 1991; Schramm \& Ehrenfeld 2010). We quantified litter depth at two points per quadrat, by measuring the thickness of the litter layer with a ruler, then we averaged the values for the entire plot.

Stem density was quantified as the average number of trees per square meter. Stem density was than categorized in three classes: stem density for individuals with a height ranging from 0.1 to $0.49 \mathrm{~m}$ (saplings), from 0.5 to $4.99 \mathrm{~m}$ (poles) and from 5 to $30 \mathrm{~m}$ (trees) to differentiate between the different developmental stages of trees.

To evaluate the effect of ungulates on forest understory $(<1.5 \mathrm{~m}$ height), vegetation cover was visually quantified as the projected cover area of different understory vegetation on the forest floor (expressed as cover percentage, varying from $0 \%$ to $100 \%$ ). Vegetation cover was then subdivided in five categories heath, fern, shrub, moss, grass and other, all together add up to $100 \%$. Species richness was quantified by the average number of tree species per plot. Shannon diversity was calculated as:

$$
H^{\prime}=-\sum_{i=1}^{s} p_{i} * \ln \left(p_{i}\right)
$$

where $\left(p_{i}\right)$ is the proportion of individuals of one particular species found relative to all individuals, $(\ln )$ is the natural $\log ,\left(\sum\right)$ is the sum of the calculation and $(s)$ is the number of species. The conifer proportion (Cp) was calculated as:

$$
C p=\frac{C}{C+B}
$$

where $(C)$ is the number of conifer individuals and (B) is the number of broadleaved individuals. Litter depth was calculated as the average height of the litter layer. Finally, forest type was determined by the canopy tree composition index that highlight the monodominance of the forest stand. If dominant and subdominant trees were broadleaved from the same species it was assigned a code of 1 , if the canopy was composed of two different broadleaved species 0.75 was assigned, if the canopy consisted of one broadleaved and one conifer species 0.5 was assigned, if the canopy consisted only of two different conifer species 0.25 was assigned and if the canopy was composed of conifer species of the same species 0 was assigned. 


\section{Statistical analysis}

To test the three predictions of ungulate impacts on vegetation characteristics, we used a series of Generalized Linear Mixed Models (GLMM), with ungulate treatment (fenced vs unfenced), time since establishment and forest type as fixed factors and forest site (i.e., the 17 forests) as a random grouping factor. We also included current ungulate abundance as fixed factors because ungulate historical records were not available, but the results were not significant, thus it was excluded from the analysis. The ungulate data was gathered using camera traps during summer and autumn of 2017. Abundance ranged from 2 to 102 ungulates trapped per 100 camera-days, with an average of 25 ungulates per 100 camera-days across all sites (corresponding to an average of 20 Sus scrofa, 3 Cervus elaphus, 2 Capreolus capreolus and 0 Dama dama). Because response variables typically show a non-linear, saturating relationship over age, with rapid changes just after disturbance and slow changes as the stand closes, we $\log _{10}$-transformed age. To test the fourth prediction that ungulate browsing leads towards an arrested early-successional vegetation, dominated by light demanding species, we used an unconstrained Principal Component Analysis (PCA) (Borcard et al. 2018) with the abundance of 13 species as response variables (Amelanchier lamarckii, Betula pendula, Betula pubescens, Castanea sativa, Fagus sylvatica, Larix kaempferi, Pinus sylvestris, Prunus serotina, Pseudotsuga menziesii, Quercus robur, Quercus rubra, Rhamnus frangula and Sorbus aucuparia), six understory vegetation cover variables (fern, shrub, moss, grass, Vaccinium and "other"), two stand variables (light and canopy) and three treatment variables (age, fenced and unfenced). For all statistical analyses, R (R Core Team 2017) was used in combination with "nlme" and "stats" packages (Pinheiro et al. 2014; R Core Team 2017)

\section{Results}

\section{Forest structure}

None of the forest structure attributes differed between treatments (fenced or unfenced). Two of the eleven variables evaluated varied significantly over age, or showed an agetreatment interaction (understory vegetation cover and canopy cover. Table 4.1). Canopy cover increased overage, more strongly so for the fenced than for the unfenced plots (the slope for the fenced plots is $\beta=63.8$, unfenced $\beta=42$, please note that age has been $\log _{10^{-}}$ 
transformed, Fig. 4.1K). Understory cover increased with age for the unfenced plots but it decreased with age for the fenced plots (unfenced $\beta=6.1$, fenced $\beta=-14.9$, Fig. 4.1D).

\section{Forest composition}

The response variables related to forest composition did not differ significantly between treatments. Nevertheless, age and age-treatment interaction had a significant effect on species richness and Shannon diversity. Thus, species richness decreased with age in the unfenced plots but not in the fenced plots (unfenced $\beta=-2.5$, fenced $\beta=-0.6$, Fig. 4.1L). Shannon diversity also decreased with age in the unfenced plots but not in the fenced plots (unfenced $\beta=-0.6$, fenced $\beta=-0.1$, Fig. 4.1M). Browsing intensity was highest for Sorbus aucuparia (88\% of the individuals, Fig. 4.2) followed by Rhamnus frangula (86\%), Amelanchier lamarckii (85\%), Quercus robur (77\%), Betula pendula (48\%), Larix kaempferi (21\%), Pinus sylvestris (20\%), Quercus petrea (8\%) and Pseudotsuga menziesii (0\%).

\section{Forest litter depth}

Litter depth differed significantly between treatments. Litter depth increased with age on the fenced plots but decreased with age on the unfenced plots (fenced $\beta=2.8$, unfenced $\beta=-0.4$, Fig. 4.10). 
Table 4.1. Mixed linear model fits for the effects of exposure to ungulates on 15 attributes from vegetation development in 17 forest clearings on poor sandy soils at the Veluwe, the Netherlands ( $n=27$ plots). For each component: units and the coefficient of determination $\left(R^{2}\right)$ is given as well as the coefficients of age since vegetation development, treatment (i.e., fenced vs. unfenced), interaction (age and treatment) and forest type (when the forest canopy is composed only by a single conifer species is coded as 0 and 1 for a single broadleaved species and values in between represent a mix of tree species) are given. The slope of fenced and unfenced plots is calculated based only on the coefficients of age ( $\log _{10}$ Age), treatment and interaction. All models were fitted with 3 degrees of freedom. Significant coefficients are indicated by an asterisk.

\begin{tabular}{|c|c|c|c|c|c|c|c|c|}
\hline \multirow[b]{3}{*}{ Component } & \multirow[b]{3}{*}{ Units } & \multicolumn{2}{|c|}{ Slope } & \multirow[b]{3}{*}{$\mathbf{R}^{2}$} & \multicolumn{4}{|c|}{ Coefficients } \\
\hline & & & & & & & & Forest \\
\hline & & Unfenced & Fenced & & Age & Treatment & Interaction & type \\
\hline \multicolumn{9}{|l|}{ Structure } \\
\hline Density saplings & Stems $/ \mathrm{m}^{2}$ & -0.6 & -0.5 & 0.49 & -0.6 & -0.1 & 0.1 & 0.2 \\
\hline Density poles & Stems $/ \mathrm{m}^{2}$ & -0.3 & 1.2 & 0.26 & -0.3 & -0.4 & 1.5 & 2.4 \\
\hline Density trees & Stems $/ \mathrm{m}^{2}$ & 0.1 & 0.2 & 0.37 & 0.1 & -0.1 & 0.1 & -0.3 \\
\hline Und. Veg. cover & $\%$ & 6.1 & -14.9 & 0.49 & 6.1 & 1.6 & $-21^{*}$ & -9.6 \\
\hline Heath cover & $\%$ & 5.4 & -10.8 & 0.73 & 5.4 & 3.2 & -16.2 & -29.2 \\
\hline Fern cover & $\%$ & 5.4 & -1.3 & 0.18 & 5.4 & 3.6 & -6.7 & -0.9 \\
\hline Shrub cover & $\%$ & 29.2 & 14.6 & 0.39 & 29.2 & 8.1 & -14.6 & 49.3 \\
\hline Moss cover & $\%$ & -4.1 & 6.2 & 0.23 & -4.1 & 2.7 & 10.3 & -34.9 \\
\hline Grass cover & $\%$ & -31.2 & -17.3 & 0.44 & -31.2 & -20.6 & 13.9 & -7.4 \\
\hline Other cover & $\%$ & -6.4 & 7.0 & 0.4 & -6.4 & 3.0 & 13.4 & 6.5 \\
\hline Canopy cover & $\%$ & 42.0 & 63.8 & 0.83 & $42.0^{* *}$ & -0.3 & $21.9 * *$ & -26.2 \\
\hline \multicolumn{9}{|l|}{ Composition } \\
\hline Richness & Species & -2.5 & -0.6 & 0.66 & $-2.5 * *$ & 0.1 & $1.9 *$ & -2.8 \\
\hline Shannon diversity & Index & -0.6 & -0.1 & 0.94 & $-0.6^{*}$ & $<0.1$ & $0.5^{*}$ & -0.7 \\
\hline Conifer prop. & Index & -0.1 & -0.2 & 0.41 & -0.1 & $<0.1$ & -0.1 & 0.6 \\
\hline \multicolumn{9}{|l|}{ Functioning } \\
\hline Litter depth & $\mathrm{cm}$ & 0.4 & 2.8 & 0.85 & 0.4 & 0.1 & $2.3^{* *}$ & 1.28 \\
\hline
\end{tabular}



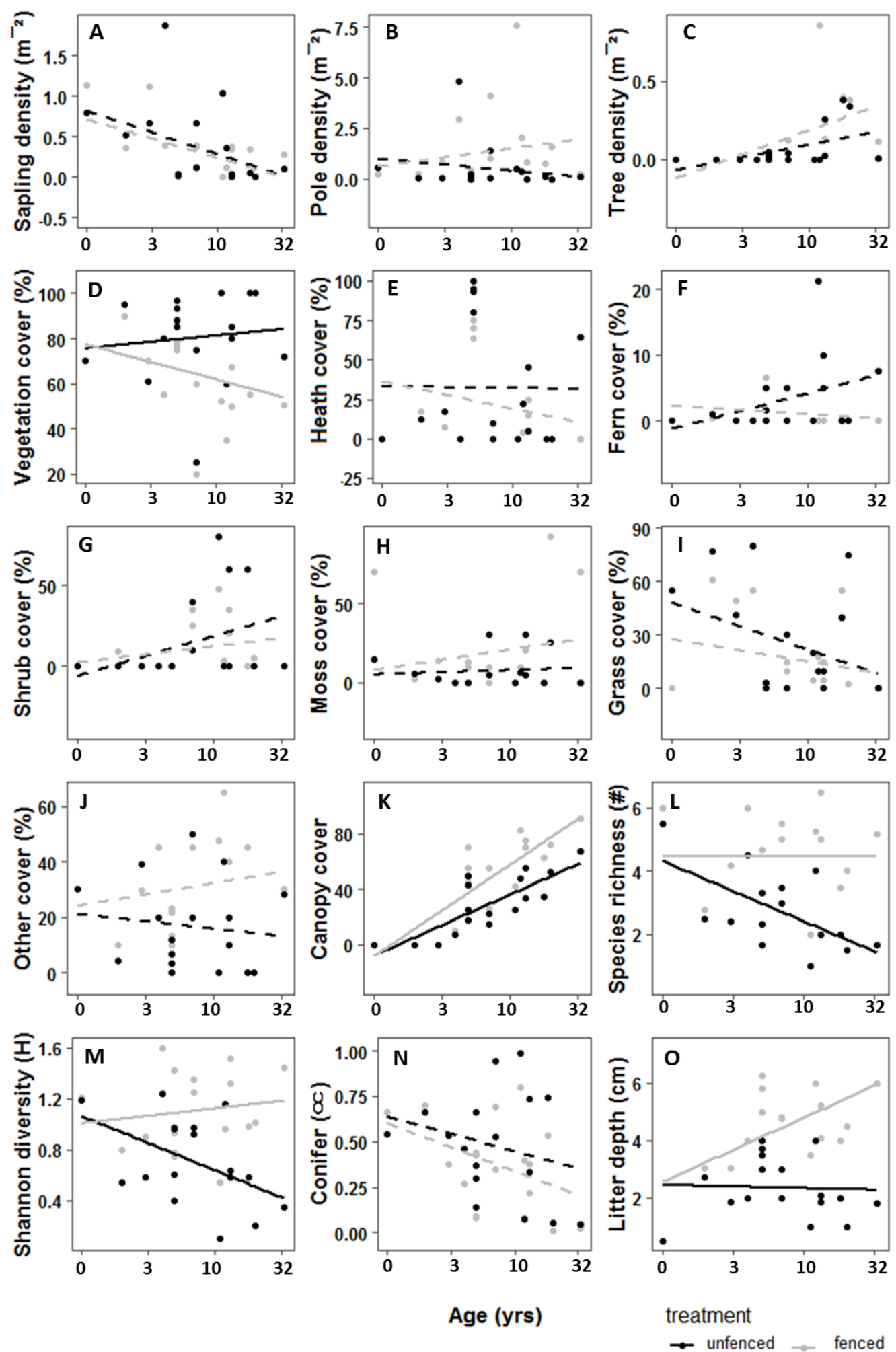

Figure 4.1. Effects of exposure to ungulates (i.e.,17 fenced and 17 unfenced plots) on vegetation development over age in forest clearings on poor sandy soils at the Veluwe, the Netherlands. Plots compare 15 vegetation characteristics between fenced and unfenced plots of different age. Lines are simple linear regression fits (independent variables=age:treatment and response variables) for unfenced (black) and fenced (gray) plots. Each pannel has a letter assigned in upper left corner, solid lines indicate significance in the model whereas dashed lines are non-significant. 


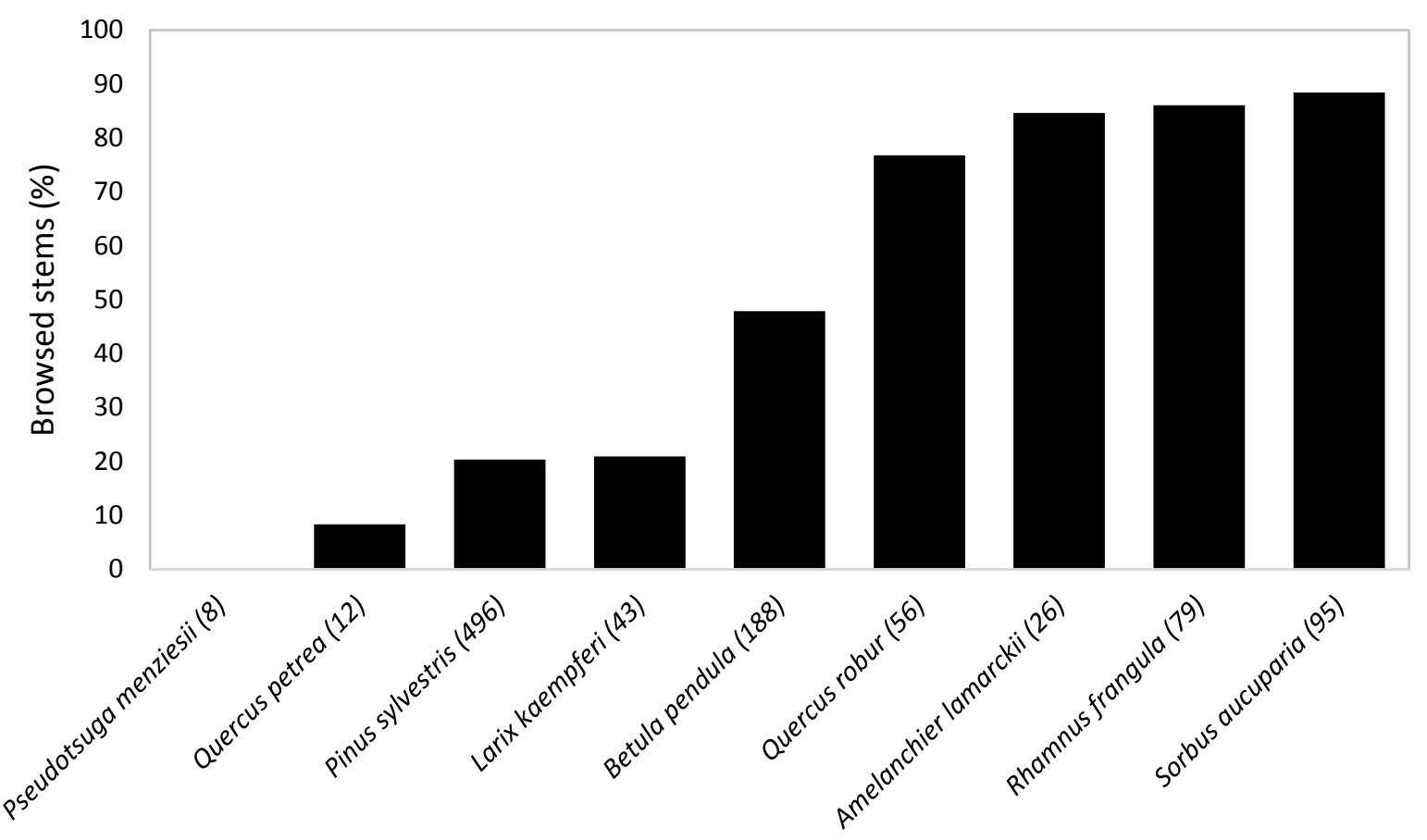

Figure 4.2. Percentage of browsed stems for main species present (>7 individuals) across all unfenced quadrats $\left(25 \mathrm{~m}^{2}\right)$ in the Veluwe, the Netherlands. The number of replicate stems are shown in parenthesis. Browsing intensity differed significantly among species (Kruskal-Wallis test, $x^{2}=316, d f=8, p<0.000$ ).

\section{Forest succession}

The first two component axes of the PCA explained $34.3 \%$ of the variation in species composition (Fig. 4.3). On the PCA ordination biplot a diagonal axis from upper left (fenced plots), to lower right (unfenced plots) is perceived. High abundance of Betula pendula, Prunus serotina, Quercus robur, Betula pubescens and shrubs is largely associated with fenced plots and low abundance of these species was associated with unfenced plots. No species was particularly abundant in unfenced plots. A second axis from lower left (canopy cover) to upper right (light availability) is perceived. Fagus sylvatica, Castanea sativa, Pseudotsuga menziesii and moss are largely associated with time and canopy cover, whereas Sorbus aucuparia, Rhamnus frangula, Amelanchier lamarckii and grass are associated with high light availability. 


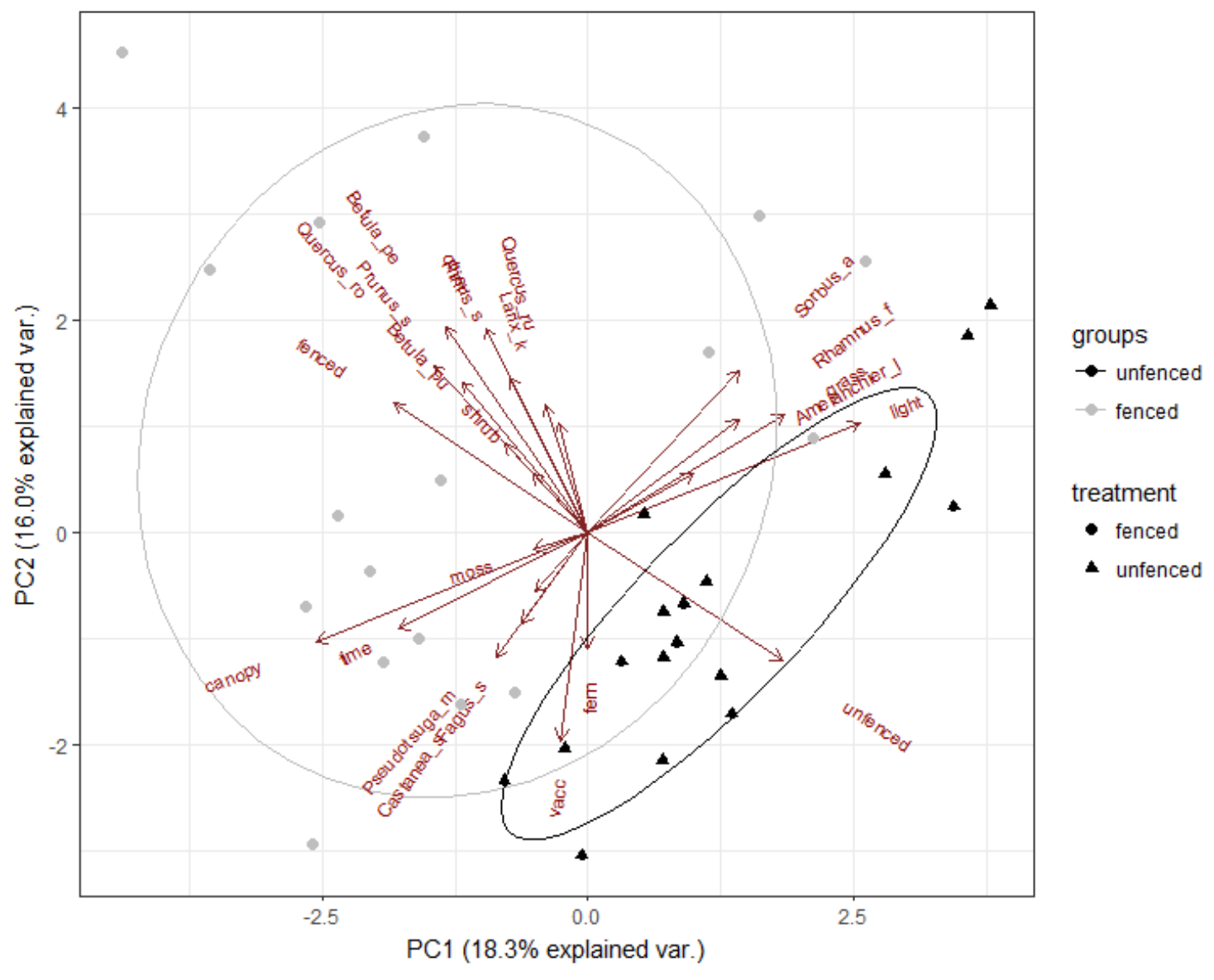

Fig. 4.3. Results of a Principal Components Analysis (PCA) of forest structure, composition and functioning of 17 fenced (grey circles) and 17 unfenced (black triangles) plots with different age since vegetation development in forest clearing. The plots were established on poor sandy soils at the Veluwe, the Netherlands and all woody plants $>10 \mathrm{~cm}$ height were included. The length of the arrow is proportional to its importance and the angle between two arrows reflects the magnitude of the correlation between variables. Principal Component Axis 1 (PC 1) explains $18.3 \%$ of variation and PC2 explains $16 \%$ of the variation. The ellipse indicates the confidence region of fenced and unfenced plots in the plane. Variables are coded as follows: time=age, fenced=fenced, unfenced=unfenced, vacc=Vaccinium, fern=fern, shrub=shrub, moss=moss, grass=grass, other=non-living, canopy=canopy cover, light=light availability, Amelanchier_I=Amelanchier lamarckii, Betula_pe=Betula pendula, Betula_pu=Betula pubescens, Castanea_s=Castanea sativa, Fagus_s=Fagus sylvatica, Larix_k=Larix kaempferi, Pinus_s=Pinus sylvestris, Prunus_s=Prunus serotina, Pseudotsuga_m=Pseudotsuga menziesii, Quercus_ro=Quercus robur, Quercus_ru=Quercus rubra, Rhamnus_f=Rhamnus frangula, Sorbus_a=Sorbus aucuparia.

\section{Discussion}

We used a chronosequence of ungulate exclosure experiments to assess the long-term effects of ungulates on tree recruitment and forest regrowth in forest clearings on poor sandy soils in the Netherlands. Our results indicate that ungulates steer succession by reducing species 
diversity and litter accumulation, and by shifting forest structure and species composition, where palatable species such as Betula pendula and Quercus robur are favoured by fencing, shade-tolerant species such as Pseudotsuga menziesii, Castanea sativa and Fagus sylvatica were unaffected by ungulate fencing, but influenced by time.

\section{Forest structure}

We predicted that browsing by ungulates would reduce canopy and understory vegetation cover. In the unfenced plots, presence of ungulates indeed led to a slower closure of the canopy (Fig. 4.1K), which resulted in reduced shading and an increased understory vegetation cover (Fig. 4.1D). Similarly, in a Japanese temperate forest, browsing and stripping by sika deer reduced the number of trees reaching the forest canopy, resulting in a more open forest stand (Akashi \& Nakashizuka 1999). Other studies also found that ungulates can promote grasses, ferns and sedges in open and thinned forest stands (Gill 1992b; Horsley et al. 2003) by removing competing trees and increasing light availability on the forest floor, although grasses and sedges can compete with tree seedlings by inhibiting their establishment (Gill 1992b).

Our finding that ungulates did not decrease sapling density (Fig. 4.1A) disagrees with several previous studies that found that ungulates reduce stem density by actively browsing on forest regeneration, leading to an open understory over time (Putman et al. 1989; Klopcic et al. 2010; Salk et al. 2011; Ramirez et al. 2018). Our result can be explained by the fact that forest in fenced plots had mature and young trees, which form several forest layers and a denser canopy cover that limited the amount of light reaching the understory, meaning that little regeneration establishes and develops under these circumstances (Whitmore 1989). Ungulates did not have a significant effect on the density of trees in larger size classes (Fig. 4.1B \& C), probably because at this stage trees are robust enough to tolerate browsing, or tall enough (e.g., >2 meters) to escape browsing (Rooney 2001; Lindroth \& Clair 2013). Yet, we do not know if they reduce the overall foliage of trees, which can result in a lower canopy cover (Fig. 4.1k).

\section{Forest composition}

We predicted that ungulates steer forest composition by reducing the richness and diversity of regenerating trees by selectively browsing on palatable broadleaved trees (Rooney \& Waller 2003), which leads to competitive release of conifers. Species richness and Shannon 
diversity indeed decreased rapidly over time in unfenced plots where ungulates were present

(Fig. 4.1L \& M). Our findings are in line with other studies, where the floristic composition and richness of mixed forests (Hedl et al. 2010) and understory diversity (McShea \& Rappole 2000; Ramirez et al. 2018) decreased with the continued presence of ungulates. In fenced plots, there was no passive accumulation of species over time, but rather a constant richness and diversity because of shading, probably due to the dominance of the shade-tolerant climax species, Fagus sylvatica.

We predicted that ungulate browsing leads to an increase in the proportion of conifer trees in the regeneration. Yet, the proportion of coniferous trees did not vary between fenced and unfenced plots (Fig. 4.1N). Similarly, (McGarvey et al. 2013), did not find a general effect of browsing on tree species composition. There are two potential explanations for this result. First, the composition of seed trees in the surrounding mature forest determines the species composition of the forest understory (Gill \& Beardall 2001) regardless of successional stage. However, the results of our GLMM, indicate that forest type did not have a significant effect in any of the forest components (Table 4.1). Second, ungulate density was not sufficiently high to trigger such effects. For instance, in a global temperate forest meta-analysis, it is shown that an ungulate density $>10-23$ roe deer per $\mathrm{km}^{2}$ or other similar sized ungulates may affect regeneration establishment, forest structure and succession (Ramirez et al. 2018), whereas in our forests the average density was a bit lower (13.6 ungulates $\mathrm{km}^{-2}$ ).

\section{Forest litter depth}

We predicted that ungulates can either reduce litter depth on the forest floor by removing a large amount of litter from the floor (Hobbs 1996) and by changing the species composition of the stand to evergreen coniferous species that have a lower litter production rate (Husheer et al. 2005); or increase the litter depth by shifting species composition toward conifers which have more recalcitrant leaves, resulting in an accumulation of litter over time. We indeed found that litter depth increased over time in fenced plots where ungulates were excluded, whereas in the unfenced plots the litter layer depth was lower and constant (Fig. 4.10). This means that the trade-off between litter quantity and quality in our system is mainly dominated by litter quantity. A reduction in litter depth by ungulates can have cascading effects on soil invertebrates as it may reduce food availability for invertebrates (Allombert et 
al. 2005b) and leads to a harsher microenvironment with increased soil erosion, irradiance and temperature and a reduced soil humidity.

\section{Forest succession}

We predicted that ungulates steer tree species composition and forest succession by preferentially feeding on palatable species, such as Sorbus aucuparia, Rhamnus frangula, Amelanchier lamarckii, Quercus robur and Betula pendula (Fig. 4.2). As expected palatable species such as Betula pendula, Prunus serotina, Quercus robur, Betula pubescens and shrubs were strongly associated with fenced plots and had a low abundance in unfenced plots, whereas no specific species were associated with unfenced plots (Fig. 4.3, Appendix A.3). In circumstances of low food availability, ungulates may even browse on less palatable species until all resources are depleted. This is the reason why no palatable and less palatable species were associated with unfenced plots (Kuiters et al. 1996; Fuller \& Gill 2001). Exclusion of ungulates from forest stands thus promotes the establishment and development of palatable species.

We hypothesized that forest succession is a major driver that shifts species composition in forest stands from light-demanding to shade-tolerant species. Because in the course of forest development the formation of a forest canopy limits the amount of light reaching the understory (Alverson et al. 1988). Our prediction was confirmed because smallstatured shrubs and treelets such as the intermediate shade tolerant Sorbus aucuparia, Rhamnus frangula, grasses and the generalist shrub Amelanchier lamarckii (Niinemets \& Valladares 2006) were strongly associated with an early successional stage, characterized by light. In contrast, shade tolerant (sub)canopy species such as: Fagus sylvatica, Castanea sativa, Pseudotsuga menziesii and the moss layer were strongly associated with later successional stage, characterized by higher canopy cover and deep shade.

This study is one of few studies that evaluated the long-term effects of ungulates on the development of European temperate and boreal forests (Scott et al. 2009; Klopcic et al. 2010; Biuw et al. 2014). All three other studies also found that ungulates altered forest structure, regeneration composition and recruitment within a time frame of approximately 25 years. We used a chronosequence approach, for which we paired fenced plots and unfenced plots in clearings of different age. Although all of our experimental sites belong to the same region, with similar abiotic and biotic conditions, an important limitation remains that it is 
impossible to control for all variables. In particular, local ungulate abundance will have differed between sites and over time. Our results give a first impression what the long-term effects of ungulates could be. Yet, to really assess these long-term effects it is necessary to use a longitudinal approach which monitors the same plots over a longer period of time.

According to the intermediate disturbance hypothesis, which states that species diversity and ecological functions are maximized when disturbance levels are intermediate (Connell 1978; Wilkinson 1999), ungulates by browsing and trampling can create opportunities for both early and late successional plant species to coexist and thus maximize species diversity. However, our results do not provide evidence that ungulates have positive effects on the different forest attributes besides understory vegetation cover. This can be explained by the relatively high ungulate density (13.6 ungulates $\mathrm{km}^{-2}$ ) in combination with the low primary productivity of this area. Due to low resource availability, on poor sandy soils, tree saplings cannot resist, tolerate or escape ungulate browsing (Lindroth \& St. Clair 2013), especially at a high browsing incidence.

\section{Recommendations}

Ungulates fulfil many functions in the forest such as seed dispersal, increase forest structure heterogeneity through browsing and enhance nutrient cycling in soil by defecation. However, a supra-optimal ungulate density may impair forest regeneration (Van Hees et al. 1996; Pellerin et al. 2010b) and diversity (Fig. 4.1L \& M). In an earlier study at global scale, we found that ungulate densities between 10 and 13 roe deer $\mathrm{km}^{-2}$, can impair forest recruitment, although critical threshold for densities vary and can be higher for more productive systems (Ramirez et al. 2018). In an earlier study at global scale, we found that ungulate densities between 10 and 13 roe deer $\mathrm{km}^{-2}$, can impair forest recruitment, although critical threshold for densities vary and can be higher for more productive systems (Ramirez et al. 2018). Once ungulates are removed or introduced to a forest system it is very unlikely that the forest structure and composition will change back to its original state.

In case forest managers would like to bring the system back to the previous conditions, they can exclude ungulates by using exclosures at different temporal and spatial scales, or they can control ungulate populations by reintroducing top predators, modifying forest edge to increase high-quality foliage (Miyashita et al. 2008), providing alternative foliage for ungulates, and/or by adaptively controlling the number of reproductive female ungulates 
through lethal or non-lethal management strategies (Augustine \& Frelich 1998; Clutton-Brock et al. 2004; Sergio et al. 2008; Reimoser \& Putman 2011).

\section{Conclusions}

In this temperate forest system, on sandy soils, ungulates had moderate long-term effects on forest structure, composition and succession. Ungulates significantly affected $38 \%$ of the 16 variables evaluated, by reducing canopy cover, species richness, Shannon diversity and litter depth, increasing understory vegetation cover and changing species composition. All the other variables had a high resilience to ungulates; they had either high resistance against browsing or a high recovery after browsing. Nevertheless, browsing by ungulates can eventually slow down regular forest succession that proceeds from light demanding species to shade tolerant species by keeping the system in an arrested state composed mainly of light demanding species. These effects can ultimately cascade to the entire ecological community.

\section{Acknowledgements}

This work was financially supported by grants from the "Secretaría de Educación Superior, Ciencia, Tecnología e Inovación del Ecuador, Convocatoria Abierta 2012" and the Ecology Fund of the Royal Netherlands Academy of Arts and Sciences. Access to forest areas was granted and coordinated directly with management officers and staff members from "Staatsbosbeheer" (Hoenderloo and Oostereng Departments), "Kroondomein Het Loo", "Het Nationale Park Hoge Veluwe", "Cooperatie Bosgroep Midden Nederland", "Geldersch Landschap en Kasteelen", "Landgoed De Ullerberg" and "Gemeente Epe". We thank two anonymous reviewers for their helpful comments. 


\section{Appendix A}

\section{A.1}

A.1. List of plots included in this study. Forest site refers to the location of the fenced/unfenced plots. Year refers to the plot establishment date and time indicates the years since establishment. Replicates specify the number of fenced/unfenced plots in each forest site. Quadrat refers to the number of vegetation plots measured. The size of all quadrats is of $25 \mathrm{~m}^{2}$.

\begin{tabular}{|c|c|c|c|c|c|}
\hline Forest site & $\begin{array}{c}\text { Establishment } \\
(y r)\end{array}$ & Age (yrs) & Replicates & $\begin{array}{l}\text { Quadrats } \\
\text { per plot }\end{array}$ & GPS coordinates \\
\hline Oostereng & 2016 & 1 & 1 & 2 & $51^{\circ} 59^{\prime} 09.9^{\prime \prime} 5^{\circ} 42^{\prime} 59.3^{\prime \prime E}$ \\
\hline Veluwe S. & 2015 & 2 & 5 & 2 & $52^{\circ} 03^{\prime} 15.8^{\prime \prime} 5^{\circ} 50^{\prime} 47.5^{\prime \prime} \mathrm{E}$ \\
\hline Veluwe N. & 2014 & 3 & 6 & 2 & $52^{\circ} 07^{\prime} 01.8^{\prime \prime} \mathrm{N} 5^{\circ} 50^{\prime} 05.7^{\prime \prime} \mathrm{E}$ \\
\hline Rheden & 2013 & 4 & 1 & 3 & $52^{\circ} 01^{\prime} 15.2^{\prime \prime} 5^{\circ} 59^{\prime} 02.0^{\prime \prime} \mathrm{E}$ \\
\hline Achterpark N. & 2012 & 5 & 1 & 3 & $52^{\circ} 13^{\prime} 44.3^{\prime \prime} \mathrm{N} 5^{\circ} 54^{\prime} 27.6^{\prime \prime} \mathrm{E}$ \\
\hline Achterpark S. & 2012 & 5 & 1 & 3 & $52^{\circ} 13^{\prime} 48.3^{\prime \prime} 5^{\circ} 54^{\prime} 13.5^{\prime \prime E}$ \\
\hline Achterpark E. & 2012 & 5 & 1 & 3 & $52^{\circ} 14^{\prime} 20.7^{\prime \prime} 5^{\circ} 54^{\prime} 25.5^{\prime \prime E}$ \\
\hline Achterpark W. & 2012 & 5 & 1 & 3 & $52^{\circ} 14^{\prime} 38.5^{\prime \prime} 5^{\circ} 55^{\prime} 05.5^{\prime \prime E}$ \\
\hline Dellen N. & 2010 & 7 & 1 & 2 & $52^{\circ} 22^{\prime} 31.7^{\prime \prime} 5^{\circ} 58^{\prime} 07.2^{\prime \prime} \mathrm{E}$ \\
\hline Dellen S. & 2010 & 7 & 1 & 2 & $52^{\circ} 22^{\prime} 37.4^{\prime \prime N} 5^{\circ} 57^{\prime} 46.9^{\prime \prime} \mathrm{E}$ \\
\hline Ullerberg $\mathrm{N}$. & 2006 & 11 & 1 & 2 & $52^{\circ} 18^{\prime} 03.2^{\prime \prime} 5^{\circ} 41^{\prime} 40.1^{\prime \prime E}$ \\
\hline Garderen & 2005 & 12 & 1 & 4 & $52^{\circ} 13^{\prime} 24.6^{\prime \prime N} 5^{\circ} 42^{\prime} 13.6^{\prime \prime E}$ \\
\hline Epe N. & 2004 & 13 & 1 & 2 & $52^{\circ} 23^{\prime} 04.9^{\prime \prime} 5^{\circ} 57^{\prime} 27.3^{\prime \prime} \mathrm{E}$ \\
\hline Epe $S$. & 2004 & 13 & 1 & 2 & $52^{\circ} 22^{\prime} 59.8^{\prime \prime} 5^{\circ} 57^{\prime} 11.3^{\prime \prime} \mathrm{E}$ \\
\hline Ullerberg S. & 1999 & 18 & 1 & 2 & $52^{\circ} 17^{\prime} 58.7^{\prime \prime N} 5^{\circ} 41^{\prime} 27.7^{\prime \prime E}$ \\
\hline Gortel & 1997 & 20 & 1 & 2 & $52^{\circ} 18^{\prime} 44.6^{\prime \prime} 5^{\circ} 53^{\prime} 08.3^{\prime \prime E}$ \\
\hline Hoenderloo & 1984 & 33 & 2 & 3 & $52^{\circ} 09^{\prime} 22.9^{\prime \prime N ~ 5} 52^{\prime} 53.1^{\prime \prime E}$ \\
\hline
\end{tabular}




\section{A.2}

A.2. Effect of ungulate fence and unfenced plots on 15 forest attributes related to structure (stem, sapling, pole, tree density, understory vegetation cover, Vaccinium, fern, shrub, moss, grass, other cover and canopy cover), composition (species richness, Shannon diversity, and conifer proportion) and litter depth. The mean and the 95\% confidence interval of the mixed linear models are given.
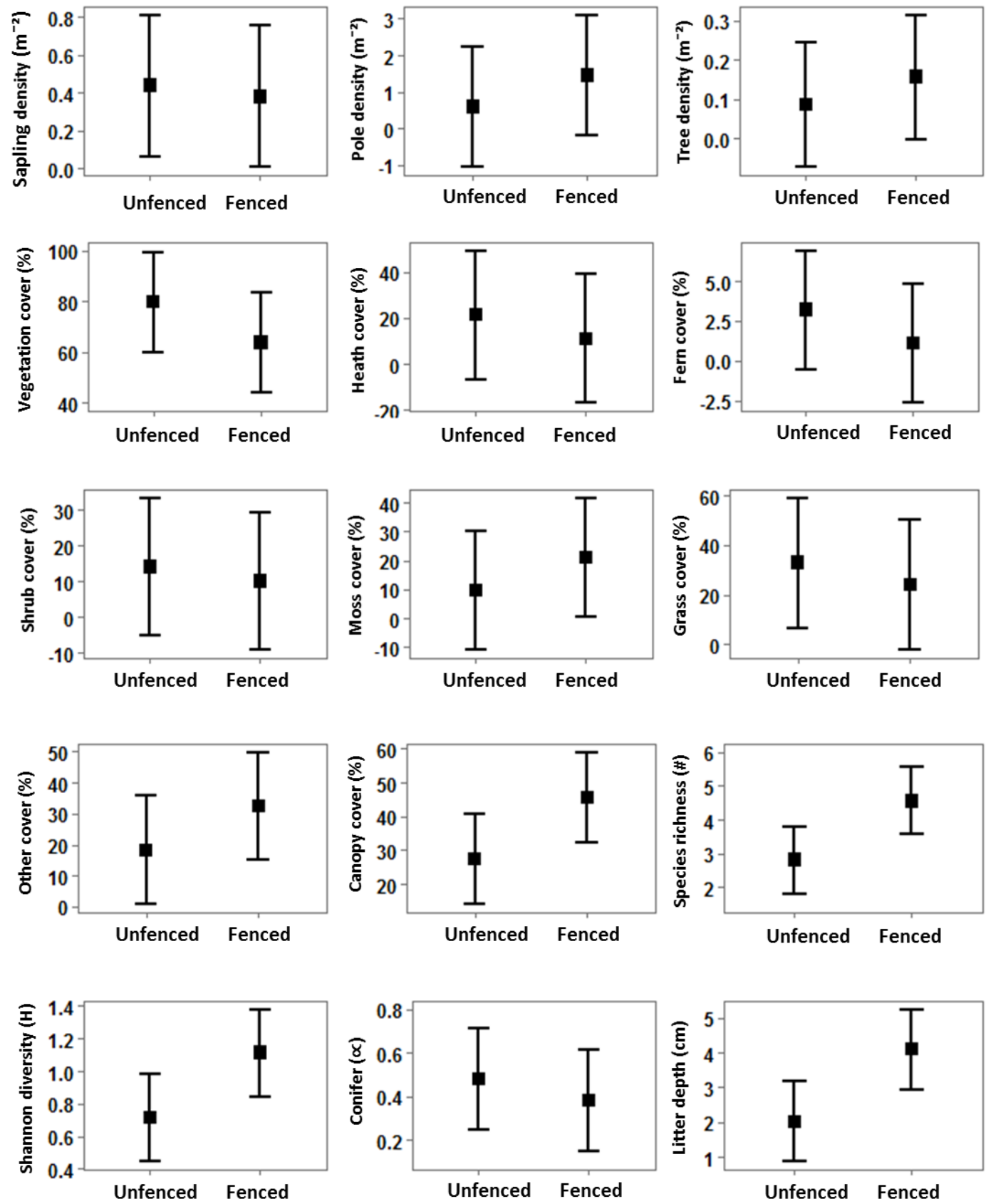

Treatment 
A.3. Averaged tree species composition for fenced and unfenced plots in the 17 forest sites in the Veluwe, the Netherlands. Species composition is shown for a quadrat of 25 $m^{2}$.

\begin{tabular}{|c|c|c|c|c|c|c|c|c|c|c|c|c|c|c|c|c|c|}
\hline & \multicolumn{17}{|c|}{ Establishment Year } \\
\hline & 2016 & 2015 & 2014 & 2013 & 2012 & 2012 & 2012 & 2012 & 2010 & 2010 & 2006 & 2005 & 2004 & 2004 & 1999 & 1997 & 1984 \\
\hline Species & \multicolumn{17}{|c|}{ Fenced } \\
\hline Sorbus aucuparia & 2,5 & 0,6 & 10,6 & 7,0 & 0,0 & 2,3 & 1,3 & 0,0 & 3,5 & 0,0 & 0,0 & 0,5 & 1,0 & 5,0 & 0,0 & 5,0 & 3,0 \\
\hline Amelanchier lamarckii & 0,5 & 1,9 & 2,6 & 0,0 & 0,0 & 1,3 & 0,3 & 0,0 & 0,0 & 0,0 & 0,0 & 0,8 & 0,0 & 0,0 & 0,0 & 0,0 & 0,0 \\
\hline Betula pendula & 5,5 & 2,5 & 7,3 & 36,0 & 26,3 & 0,3 & 0,0 & 2,0 & 25,5 & 61,0 & 55,0 & 40,5 & 5,5 & 49,0 & 6,0 & 7,0 & 3,7 \\
\hline Betula pubescens & 0,0 & 0,0 & 0,2 & 6,0 & 0,0 & 0,0 & 0,3 & 0,0 & 0,0 & 0,0 & 0,0 & 1,5 & 0,0 & 22,0 & 0,0 & 1,0 & 0,0 \\
\hline Rhamnus frangula & 0,5 & 0,1 & 4,5 & 18,0 & 0,0 & 0,0 & 0,0 & 0,0 & 0,0 & 0,0 & 0,0 & 0,3 & 0,0 & 0,0 & 0,0 & 0,0 & 7,7 \\
\hline Castanea sativa & 0,0 & 0,0 & 0,0 & 0,0 & 1,3 & 0,3 & 0,0 & 0,0 & 0,0 & 0,0 & 0,0 & 0,0 & 0,0 & 0,0 & 0,0 & 0,0 & 0,7 \\
\hline Prunus serotina & 0,0 & 0,0 & 0,2 & 0,0 & 0,3 & 0,3 & 0,0 & 0,0 & 1,5 & 17,0 & 0,0 & 0,0 & 4,0 & 0,0 & 0,0 & 0,0 & 0,0 \\
\hline Quercus robur & 0,0 & 0,6 & 1,3 & 12,0 & 1,0 & 1,7 & 0,7 & 0,0 & 4,0 & 22,0 & 0,0 & 2,0 & 3,0 & 8,0 & 8,5 & 0,0 & 2,7 \\
\hline Quercus rubra & 2,5 & 0,0 & 0,8 & 0,0 & 0,0 & 1,0 & 0,0 & 0,0 & 3,0 & 0,0 & 0,0 & 0,0 & 0,5 & 0,0 & 0,0 & 0,0 & 0,0 \\
\hline Populus tremula & 0,0 & 0,0 & 0,0 & 0,0 & 0,0 & 0,0 & 0,0 & 0,0 & 0,0 & 0,0 & 0,0 & 0,0 & 0,0 & 0,0 & 0,0 & 35,0 & 0,0 \\
\hline Fagus sylvatica & 0,0 & 0,1 & 0,0 & 0,0 & 0,7 & 0,0 & 0,7 & 0,3 & 0,0 & 0,0 & 0,0 & 0,0 & 0,0 & 0,0 & 0,0 & 0,0 & 0,0 \\
\hline Larix kaempferi & 3,0 & 0,0 & 0,2 & 0,0 & 0,0 & 0,0 & 0,0 & 0,0 & 47,0 & 4,0 & 0,0 & 0,3 & 1,0 & 0,0 & 0,5 & 0,0 & 0,0 \\
\hline Pinus sylvestris & 20,0 & 9,2 & 18,8 & 29,0 & 2,3 & 0,7 & 2,3 & 2,0 & 30,5 & 49,0 & 135,0 & 28,8 & 2,0 & 51,0 & 23,0 & 0,0 & 0,7 \\
\hline \multirow[t]{2}{*}{ Pseudotsuga menziesii } & 0,0 & 0,0 & 1,0 & 0,0 & 0,7 & 0,0 & 0,3 & 0,0 & 0,0 & 0,0 & 0,0 & 1,0 & 0,5 & 0,0 & 0,0 & 0,0 & 0,0 \\
\hline & \multicolumn{17}{|c|}{ Unfenced } \\
\hline Sorbus aucuparia & 6,5 & 0,7 & 3,5 & 5,5 & 0,0 & 0,7 & 0,3 & 0,7 & 0,0 & 0,0 & 0,0 & 3,3 & 0,0 & 0,0 & 0,0 & 0,0 & 0,2 \\
\hline Amelanchier lamarckii & 0,0 & 1,5 & 0,5 & 0,0 & 0,0 & 0,0 & 0,0 & 0,0 & 0,0 & 0,0 & 0,0 & 1,3 & 0,0 & 0,0 & 0,0 & 0,0 & 0,0 \\
\hline Betula pendula & 3,5 & 1,1 & 0,5 & 26,0 & 1,3 & 1,7 & 0,0 & 8,3 & 6,0 & 5,0 & 0,0 & 5,5 & 2,0 & 0,0 & 4,5 & 8,0 & 0,0 \\
\hline Betula pubescens & 0,0 & 0,1 & 0,1 & 0,0 & 0,0 & 0,0 & 0,3 & 0,0 & 0,0 & 0,0 & 0,0 & 0,0 & 0,0 & 0,0 & 0,0 & 0,0 & 0,0 \\
\hline Rhamnus frangula & 3,5 & 0,2 & 2,9 & 10,5 & 0,0 & 0,0 & 1,0 & 0,0 & 0,0 & 0,0 & 0,0 & 1,5 & 0,0 & 0,0 & 0,0 & 0,0 & 0,5 \\
\hline Castanea sativa & 0,0 & 0,0 & 0,0 & 0,0 & 0,3 & 0,0 & 0,0 & 0,0 & 0,0 & 0,0 & 0,0 & 0,0 & 0,0 & 0,0 & 0,0 & 0,0 & 0,0 \\
\hline Prunus serotina & 1,0 & 0,0 & 0,0 & 0,0 & 0,0 & 0,0 & 0,0 & 0,0 & 0,0 & 0,0 & 0,0 & 0,0 & 0,0 & 0,0 & 0,0 & 0,0 & 0,0 \\
\hline Quercus robur & 0,5 & 1,2 & 0,3 & 0,0 & 0,7 & 0,0 & 2,3 & 1,0 & 0,0 & 2,0 & 0,0 & 4,8 & 0,0 & 4,0 & 0,0 & 0,0 & 1,2 \\
\hline Quercus rubra & 0,5 & 0,2 & 0,0 & 0,0 & 0,0 & 0,0 & 0,0 & 0,0 & 0,0 & 0,0 & 0,0 & 0,0 & 0,0 & 0,0 & 0,0 & 0,0 & 0,0 \\
\hline Populus tremula & 0,0 & 0,0 & 0,0 & 0,0 & 0,0 & 0,0 & 0,0 & 0,0 & 0,0 & 0,0 & 0,0 & 0,0 & 0,0 & 0,0 & 0,0 & 0,0 & 0,0 \\
\hline Fagus sylvatica & 0,0 & 0,0 & 0,0 & 0,0 & 0,0 & 0,0 & 0,0 & 0,0 & 0,0 & 0,0 & 0,0 & 0,0 & 0,0 & 0,0 & 0,0 & 0,0 & 0,0 \\
\hline Larix kaempferi & 0,5 & 0,0 & 0,2 & 0,5 & 0,0 & 0,0 & 0,0 & 0,0 & 29,0 & 0,0 & 0,0 & 0,0 & 0,0 & 0,0 & 0,0 & 0,0 & 0,0 \\
\hline Pinus sylvestris & 18,0 & 8,7 & 8,3 & 28,5 & 4,3 & 1,0 & 0,7 & 4,3 & 20,0 & 8,0 & 39,0 & 1,3 & 4,5 & 2,0 & 9,5 & 0,0 & 0,0 \\
\hline Pseudotsuga menziesii & 0,0 & 0,0 & 0,5 & 0,0 & 0,3 & 0,0 & 0,0 & 0,0 & 0,5 & 0,0 & 0,0 & 0,0 & 0,0 & 0,0 & 0,0 & 0,0 & 0,0 \\
\hline
\end{tabular}




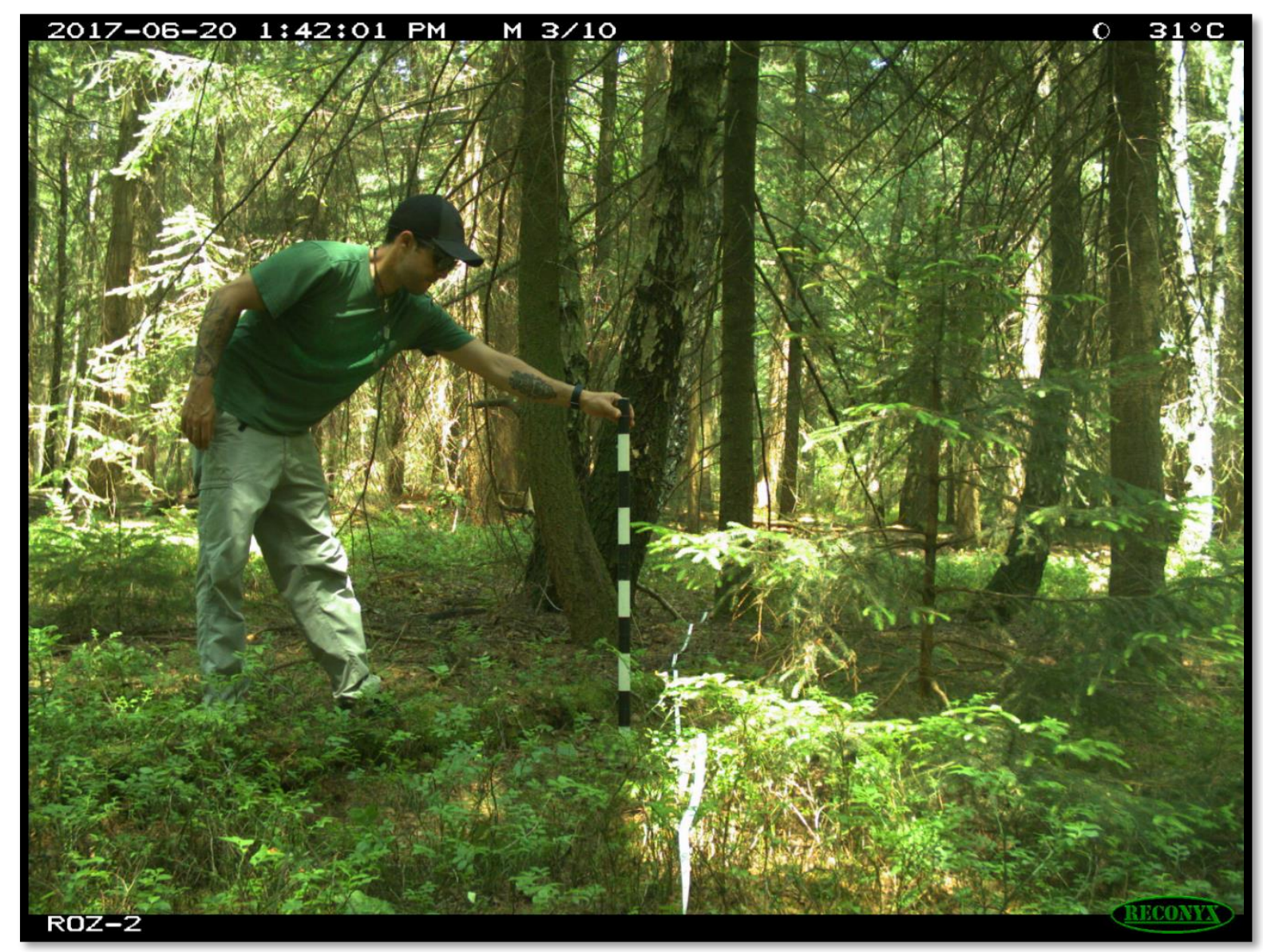


CHAPTER FIVE

\section{Above and below-ground cascading effects of wild ungulates in a temperate forest}

Submitted to Journal of Ecology (July 2019)

Authors

Juan Ignacio Ramirez; Patrick A. Jansen; Jan den Ouden; Laxmi Moktan \& Lourens Poorter 


\begin{abstract}
Ungulates have become abundant in many northern temperate forests, shifting tree species composition by selective browsing and altering soil conditions by trampling. Whether these effects cascade down to other trophic levels and ecosystem processes is poorly known. Here we assess the paths through which ungulates have cascading effects on other trophic levels, such as quantity and quality of forest regeneration, litter thickness, rodent activity, soil macroinvertebrates, litter decomposition and nutrient mineralization. We compared ungulate effects by contrasting 22 response variables at different trophic levels between paired fenced and unfenced plots in twelve temperate forest sites across the Veluwe, the Netherlands, and used Pathway Analysis Model to identify the direct and indirect pathways through which ungulates have influenced these variables. We found that plots with ungulates had significantly higher soil compaction, but lower litter depth, tree diversity and density, rodent activity, invertebrate biomass and litter decomposition rate. Ungulate presence: (1) decreased sapling density which indirectly decreased rodent activity; (2) decreased litter depth which indirectly reduced macro-invertebrate diversity and mineralization rates of magnesium and nitrogen in pine and oak litter, and (3) increased soil compaction which decreased invertebrate diversity and mineralization rates of magnesium and nitrogen in pine and oak litter. These findings suggest that ungulates can indeed trigger, through browsing and trampling, a positive feedback loop in forest ecosystems. Ungulates by browsing on palatable species can decrease plant diversity, litter quality and invertebrate diversity which indirectly halts mineralization rates of nutrients. As a result of this, the system can no longer sustain a diverse plant community due to nutrient limitations in soil.
\end{abstract}

\title{
Abbreviations
}

Principal Component Analysis (PCA), Linear Mixed Models (LMM), Generalized Linear Mixed Models (GLMM), Pathway Analysis Model (PAM)

\section{Introduction}

Ungulates are important ecosystem engineers in temperate forests; through browsing and trampling they directly modify aboveground vegetation structure and composition (Ramirez et al. 2019), with potentially large cascading effects on litter production, soil detritivores, litter decomposition and mineralization rates (Allombert et al. 2005b; Bressette et al. 2012). This 
may trigger a feedback loop, in which the altered nutrient availability affects the abundance and composition of trees and ungulate communities (Wardle et al. 2002). Ungulate feeding preferences determine the speed of this feedback loop, where preferential feeding on slowgrowing species with nutrient-poor leaves results in a fast feedback loop and a more fertile and productive ecosystem, whereas preferential feeding on fast-growing species with nutrient-rich leaves results in a slow feedback loop, and a more infertile and unproductive ecosystem (Ritchie et al. 1998; Wardle et al. 2002).

Feedback loops may become more important as with the loss of apex top predators in temperate forests because ungulates are released from top-down control, thus increasing their pressure on lower trophic levels and the potential for trophic cascades and feedback loops (Kardol et al. 2014). Yet, important literature advocates that feedback loops across biomes are strongly mediated by primary productivity, seasonality, natural disturbance (e.g., fires and storms) and the ratio between conifers and broadleaves (Pastor et al. 1988; Hobbs 1996; Augustine \& McNaughton 1998; Frank et al. 2000; Pringle et al. 2007). Thus, feedback loops are complex mechanisms that are highly dependent on multiple external factors.

In any ecosystem, ungulates may indirectly affect decomposition via litter quantity and quality, which affect the abundance of detritivores (Moretto et al. 2001; Mason et al. 2010; Frouz et al. 2015). Ungulates can either reduce litter depth on the forest floor by removing a large amount of litter from the floor (Hobbs 1996) and by changing the species composition of the stand to evergreen coniferous species that have a lower litter production rate (Pastor et al. 1988; Pastor et al. 1993; Husheer et al. 2005; Ramirez et al. 2018). Alternatively, ungulates may increase the litter depth by shifting species composition toward conifers which have more recalcitrant litter, resulting in an accumulation of litter over time. The relative importance of these two processes determines in the end the depth of the litter layer. Detritivores decompose litter first by fragmenting it into small bits and then by converting organic compounds into inorganic compounds like phosphate, ammonium, water and carbon dioxide (Aerts 2006).

Invertebrates form a fundamental component of ecosystems, as through feeding, nesting and burrowing they regulate organic matter decomposition, nutrient cycling and soil structure (Jones et al. 1994; Brussaard 1997; Lavelle et al. 2006; Kamau et al. 2017). Decomposition is also highly dependent on the micro-environment (Vasconcelos \& Laurance 2005). For instance, ungulates can increase soil compaction and the amount of light in the 
understory (Ramirez et al. 2019), thus triggering cascading effects to other trophic levels. Soil compaction leads to a reduction in soil porosity. As a result, less oxygen and resources are available for macro-invertebrates, thus stalling decomposition rates (Lavelle et al. 1992; Van Klink et al. 2015). Overall, trampling may reduce the amount of soil biota (Bressette et al. 2012), and thus slow down decomposition by macro-invertebrates, fungi and bacteria (Hättenschwiler et al. 2005).

Several studies have evaluated cascading effects of wild ungulates on temperate forests in Europe, North America, and Oceania (Wardle et al. 2002; Allombert et al. 2005b; Bressette et al. 2012; Kardol et al. 2014; Lilleeng et al. 2018) by using fencing experiments that included or exclude ungulates. These studies suggest that there are strong top-down effects of ungulates on vegetation composition, which in turn influences soil invertebrate community and decomposition rate (Allombert et al. 2005b). However, none of these studies have evaluated the complete cascading chain across all the trophic levels. For instance, most studies only measured invertebrate composition (Allombert et al. 2005b; Bressette et al. 2012; Lilleeng et al. 2018) or decomposition rates (Wardle et al. 2002). There is a need to evaluate ungulate cascading effects across the complete chain, ranging from understory vegetation, soil attributes, soil invertebrates to litter decomposition.

To understand the direct and indirect effects of ungulates on temperate forests we conducted a study in which red deer (Cervus elaphus), roe deer (Capreolus capreolus), fallow deer (Dama dama), wild boar (Sus scrofa) and mouflon (Ovis orientalis) were experimentally excluded. We compared vegetation, soil, rodent activity, macro-invertebrates, litter decomposition and mineralization between paired fenced and unfenced plots established in 11 forests across the Veluwe, the Netherlands. We evaluated litter decomposition and mineralization rates using litter of three tree species that dominate forest succession on sandy soils (Betula pendula, Pinus sylvestris, and Quercus robur). We predicted that, through browsing and trampling, ungulates can trigger cascading effects on lower trophic levels and litter decomposition rate (Fig. 1) by homogenizing tree diversity and density, litter depth, invertebrate diversity and biomass as well as soil properties by means of browsing and trampling (McGarvey et al. 2013; Lilleeng et al. 2018; Ramirez et al. 2019). Due to feedback loops, we theoretically expect a decrease in tree regeneration diversity in unfenced compared to the fended plots because ungulate browsing and trampling reduces nutrient cycling in soil and thus enhancing bottom-up control of vegetation (Ritchie et al. 1998; Wardle et al. 2002). 


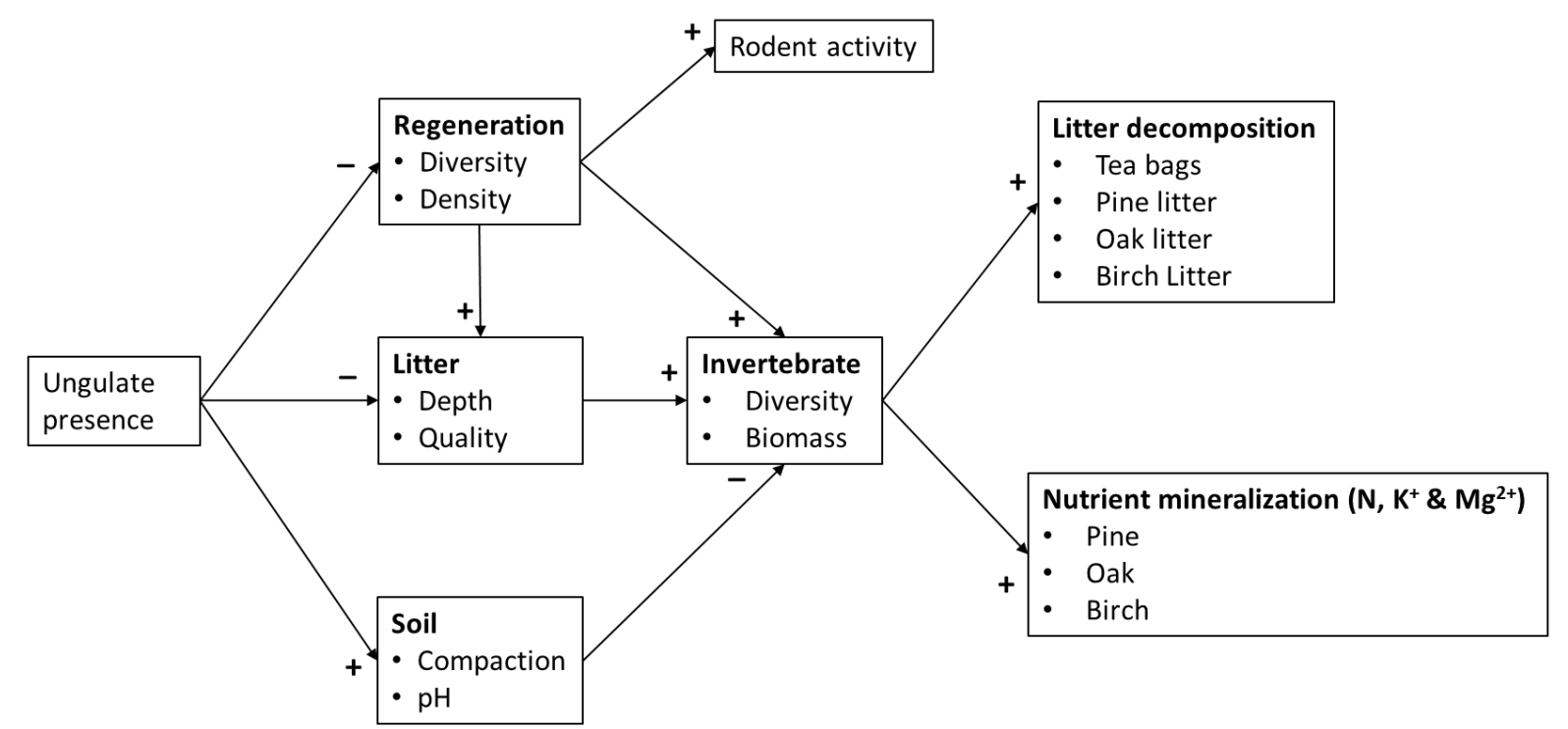

Figure 5.1. Conceptual model of the cascading effects (represented by solid lines) of wild ungulate presence on forest regeneration (diversity \& density), litter (depth \& quality) soil (compaction \& pH), rodent activity, invertebrates (diversity \& biomass), litter decomposition (tea, pine, oak \& birch) and nutrient (Nitrogen=N, Potassium $=K^{+} \&$ Magnesium $=M^{2+}$ ) mineralization on leaves (pine, oak \& birch). Solid lines represent the relationship between components and the symbols positive $(+)$ and negative $(-)$ symbols represent the direction of the relationships.

\section{Methods}

\section{Study area}

Data were collected at the Veluwe, a $1200 \mathrm{~km}^{2}$ area located in the central part of the Netherlands $\left(52^{\circ} 5^{\prime} \mathrm{N}, 5^{\circ} 48^{\prime} \mathrm{E}\right)$. Average precipitation is $900 \mathrm{~mm} \mathrm{yr}^{-1}$, and annual average temperature is $9.4^{\circ} \mathrm{C}$ with mean monthly temperature ranging from $2.5^{\circ} \mathrm{C}$ in January to $16.4^{\circ} \mathrm{C}$ in July (Kuiters \& Slim 2002). The main soil types are xeric humic podzols and brown earths (inceptisols), depending on the parent material that ranges from aeolic driftsand and cover sands to Pleistocene loamy fluvioglacial sands (Kuiters \& Slim 2002). The Veluwe is covered by a mosaic of forests, drift sands and heathland, where forests cover two thirds of the total area. The main species are Scots pine (Pinus sy/vestris), European oak (Quercus robur), European beech (Fagus sylvatica), Japanese larch (Larix kaempferi), Douglas fir (Pseudotsuga menziesii) and European birch (Betula pendula). The main ungulate species at the Veluwe are roe deer (Capreolus capreolus), fallow deer (Dama dama), red deer (Cervus elaphus) and wild boar (Sus scrofa), with an average density of 13.6 individuals $\mathrm{km}^{-2}$ in 1998 (Kuiters \& Slim 2002). 


\section{Experimental design}

Research was carried out at twelve sites distributed across the entire Veluwe region (Fig. 5.2), in an area of 80 by $45 \mathrm{~km}$. At each site a fenced forest plot had been established to protect forest regeneration from ungulate browsing, and was paired with an unfenced control plot, ca. $10 \mathrm{~m}$ apart. For plots without a control plot, we randomly assigned a control area within 10 meters distance from the fenced plot. Plot size was on average $2227 \mathrm{~m}^{2}$ (range 100-5000 $\mathrm{m}^{2}$ ) and fencing consisted of a $2.10 \mathrm{~m}$ tall metal fence. The fenced/unfenced plots were established 1 to 33 years ago, in logging gaps. Ungulate abundance and species composition varied across sites (Ramirez et al. unp. ms.).

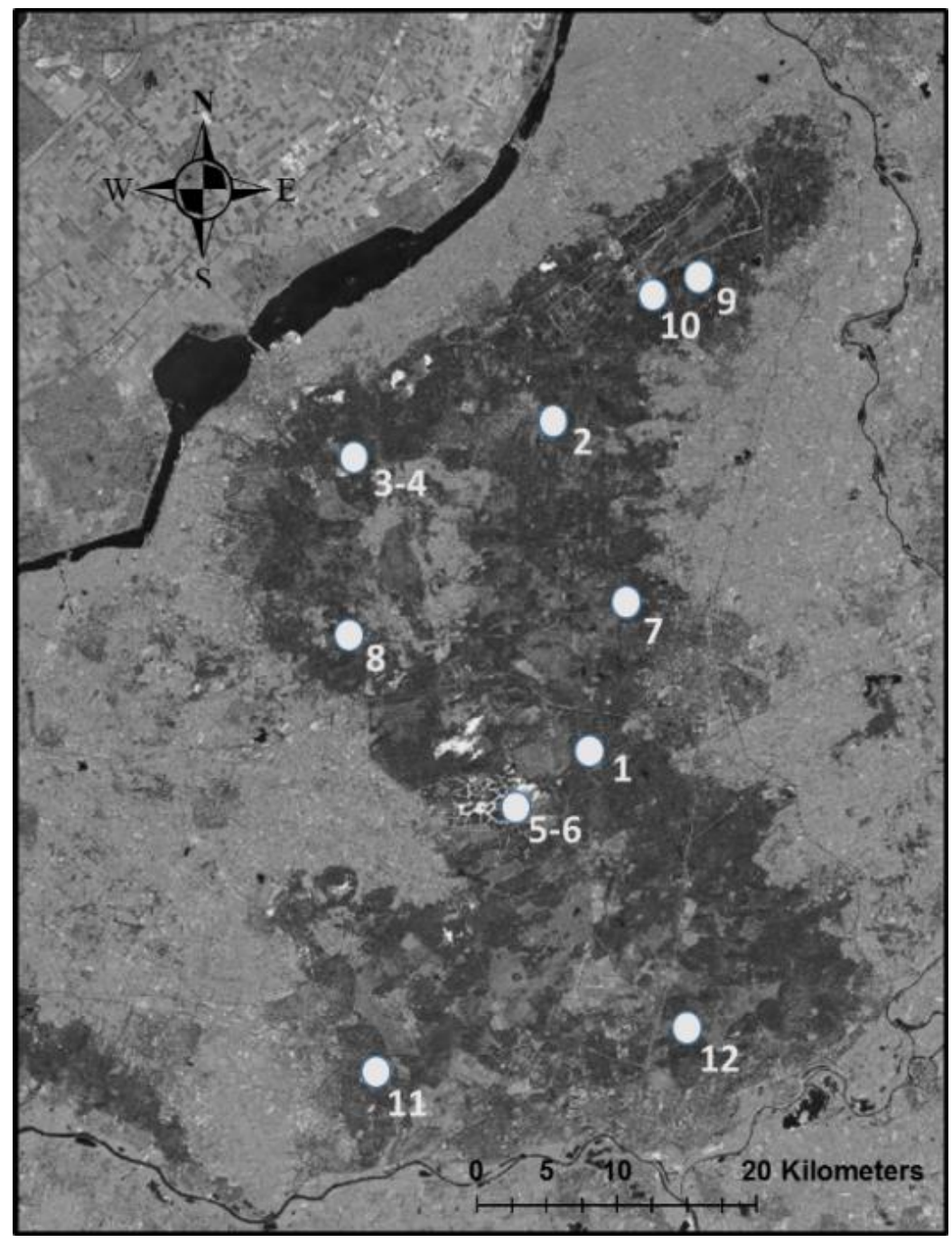

Figure 5.2. Map of the twelve research sites at the Veluwe, the Netherlands. The dark grey area is covered by forest. 1. Hoenderloo, 2. Gortel, 3. Ullerberg south, 4. Ullerberg north, 5. Hoge Veluwe north, 6. Hoge Veluwe south, 7. Achterpark, 8. Garderen, 9. Dellen, 10. Epe, 11. Oostereng and 12. Rheden (Appendix A.1). 


\section{Above-ground vegetation}

To quantify vegetation structure and diversity, the vegetation was surveyed during spring and summer of 2016 and 2017. Within each pair of fenced/unfenced plots, $5 \times 5 \mathrm{~m}$ quadrats were randomly established by drawing numbers for the $\mathrm{x}$ and $\mathrm{y}$ axis, which represented $\mathrm{a}$ coordinate system. We established two quadrats per plot when regeneration heterogeneity was low (i.e., low species diversity and little variation in forest structure), and three or four quadrats per plot when heterogeneity was high. Data from all 2-4 quadrats were averaged to obtain a single value per plot. Each woody individual within the quadrat was identified and measured for its height. Shannon Diversity was then calculated as:

$$
H^{\prime}=-\sum_{i=1}^{s} p_{i} * \ln \left(p_{i}\right)
$$

where (pi) is the proportion of individuals of one particular species found relative to all individuals, $(\mathrm{In})$ is the natural log and $(\mathrm{s})$ is the number of species in the plot (Shannon 1948).

To quantify vegetation structure, stem density was calculated as number of stems per $25 \mathrm{~m}^{2}$. Plot litter quality was derived by scoring the regeneration composition with the species litter quality score and then averaging the values for the entire plot as in Maes et al. (2019); this was done to quantify the quality of litter available for decomposition. We measured litter depth, because litter can act as a barrier for the establishment of woody species from the seedbank (Facelli \& Pickett 1991; Schramm \& Ehrenfeld 2010) while it can provide shelter and resources for invertebrates. Litter depth was measured with a ruler at two points in each quadrat, as the distance between the litter surface layer and the mineral soil. Finally, rodents are important seed predators and dispersal agents in temperate forests (Nathan \& MullerLandau 2000; lida 2006). Thus, rodent activity was quantified as the number of litter and tea bags in the experiment (see below) that were altered by nibbling which resulted in small holes.

\section{Decomposition rate}

To quantify litter decomposition rates, we used litter bags with natural leaf litter of three common and dominant tree species, and tea bags as a standardized litter. The three species were the coniferous Pinus sylvestris (pine), and broadleaved Betula pendula (birch) and Quercus robur (oak). These species were selected because they occupy different successional positions in the forest and their leaves have different composition which makes them more or less palatable for ungulates. In each plot, 18 leaf litter bags were placed belonging to the three 
species, 6 bags per species. Litter bags consisted of $15 \times 15 \mathrm{~cm}$ polyethylene mesh with a pore size of $1.5 \mathrm{~mm}$, filled with approximately 2.0 grams of air-dried litter (Gartner \& Cardon 2004; Bärlocher 2005). Additionally, twelve tea bags were placed in each plot: six with Lipton Rooibos tea and six with Lipton Green tea (Keuskamp et al. 2013), in order to have a decomposition base line with standardized litter. Furthermore, by using two tea types with contrasting decomposability: green tea (fast decomposition) and rooibos (slow decomposition), a decomposition curve can be drawn from using a single measurement in time (Keuskamp et al. 2013). Two resin bags were buried below the litter layer per plot to quantify nitrogen $(\mathrm{N})$ and phosphate $\left(\mathrm{PO}_{43}\right)$ mineralization rate in soil. During spring of 2017, when decomposition started, all tea, resin, and litter bags were buried at an approximate depth of $15 \mathrm{~cm}$ in order to prevent uprooting by ungulates. The tea bags and resin bags were harvested at three months because at this time their mineralization curve stabilizes (Keuskamp et al. 2013), half of the litter bags were harvested after six months, and the remaining litter bags were harvested after twelve months in order to have decomposition constants at two moments in time. Harvested bags were oven-dried at $60^{\circ} \mathrm{C}$ for three days, dirt particles were gently removed with an air blow gun, and litter dry mass was measured.

To quantify nutrient mineralization in litter, ten samples were taken from pine, oak and birch litter before placing the biomass in each bag. These ten samples were used to determine the baseline content of nitrogen $(\mathrm{N})$, potassium $\left(\mathrm{K}^{+}\right)$and magnesium $\left(\mathrm{Mg}^{2+}\right)$, which are important macronutrients in temperate forests. After harvest, a litter sample from each bag was collected (including baseline) and grinded to measure nutrient concentrations. The grinded litter was weighted to the nearest 0.30 grams and transferred to a digestion tube with $2.50 \mathrm{ml}$ of sulphuric acid, which was then stirred until the litter was moistened. The digestion tubes were left at room temperature for 24 hours, after which tubes were heated to $100{ }^{\circ} \mathrm{C}$ for two hours with the use of a heating block. After the solution cooled, $2.00 \mathrm{ml}$ aliquots of hydrogen peroxide were added and heated to $330{ }^{\circ} \mathrm{C}$. When solution turned yellow or colourless, the digestion tubes were removed from the heating block and cooled. The digestion was mixed with $48.30 \mathrm{ml}$ of water and left to stand overnight. Next morning, digestions were placed into a Segment Flow Analyser apparatus (Skalar SAN++ System) and an Absorption Spectrometer apparatus (Varian AA240FS) to measure nitrogen, potassium and magnesium respectively by determining the concentration of each compound in a micro 
sample. Resin bags were prepared and processed as in Lajtha (1988) and samples were analysed with the Segment Flow Analyser.

Then, decay rates for leaf litter mass and nutrient mineralization were calculated using the negative exponential decay model (Hasanuzzaman \& Hossain 2014):

$$
\frac{L f}{L i}=e^{-k * t}
$$

where (Lf) is the final litter mass and (Li) is initial litter mass. (k) is the litter decomposition rate and $(t)$ is time. The annual decomposition exponent $(k)$ for pine, oak and birch litter was calculated as:

$$
k=365 * \frac{\ln (L f)-\ln (L i)}{\text { time }}
$$

Time was the duration in days that samples were in the field. The mineralization rates in litter of nitrogen, potassium and magnesium were calculated based on initial and final nutrient contents, calculated as the initial and final mass, multiplied by their respective nutrient concentrations. Nitrogen and phosphate mineralization rate were calculated as:

$$
\text { Nutrient }\left(\frac{m g}{l}\right)=\left(\frac{C}{\frac{1000}{V}} * \frac{1000}{W}\right) / \text { time }
$$

Where $(C)$ is the nutrient concentration in the soil extract, $(V)$ is the volume of potassium chloride used for the extraction and (W) is the exact weight of the resin sample used for extraction and (time) is the duration in days that samples were in the field (Griffin et al. 1995).

\section{Below ground}

To quantify ungulate trampling, we measured soil compaction. Soil compaction is defined as the densification of soil grains in a given area as a result of external pressure and it is important for nutrient cycling in soil (Bassett et al. 2005). For each location where a litter bag was placed, soil compaction (in $\mathrm{kPa}$ ) was measured with a soil penetrometer (Eijkelkampm Serie 2518611) (Bassett et al. 2005). As soil pH affects tree development by controlling plant nutrient availability (Lucas \& Davis 1961), pH was measured by extracting a soil sample from each litter bag placement and measuring it with a pH meter (inoLab pH Plus). We quantified invertebrate diversity and biomass because invertebrates play an important role in litter decomposition. We extracted two soil samples of $2.00 \mathrm{~kg}$ from each plot and with the use of a metal screen and tweezers, macro-invertebrates $(>2 \mathrm{~mm}$ ) were collected and stored in $70 \%$ ethanol. All invertebrates were identified to order level with the use of a compound microscope (Novex, 
P-serie) and a soil invertebrate guide, body size (length*width*depth) was measured with the use of a calliper. With this information, Shannon Diversity of invertebrates was calculated.

\section{Data analysis}

All statistical analysis were done in R. version 3.4.0 (R Core Team 2017). To assess how the 22 response variables were associated amongst themselves and with the fencing treatments, we carried out a Principal Component Analysis (PCA) using the "vegan, version 2.5-2" package (Oksanen et al. 2013). To quantify the effect of fencing on each of the 22 forest response variables we used a combination of Linear Mixed Models (LMM) and Generalized Linear Mixed Models (GLMM) with forest site as random grouping factor, using the packages " $\mathrm{nlme}$, version 3.1-137" and "stats, version 3.4.0" (Pinheiro et al. 2014).

To test our conceptual model of ungulate cascading effects on litter decomposition and mice activity (Fig. 5.1), a Pathway Analyses Model (PAM) was used (Shipley 2016; van der Sande et al. 2017). PAM is a multivariate statistical method that tests direct dependencies among a set of variables in complex path networks and normally consist of dependent and independent variables. A total of 22 models were needed to test all the pathways of the conceptual model (Fig. 5.1), and each model consisted of one response variable and one to five predictors, depending on the tested path section. For example, litter depth depends on ungulates, sapling density and sapling diversity, whereas soil compaction only depends on ungulates. Site was included as random factor and Akaike's Information Criterion (AIC) was used to select the best-fitting model. The best fit are all models within 2 AIC units from the lowest AIC. The packages "lavaan, version 0.6-3" and "lavaan.survey, version 1.1.3.1" were used for this analysis (Rosseel 2012; Oberski 2014).

\section{Study limitation}

The sites used for this study, ranged widely in the age of the fencing treatment ( 1 to 33 years) and in ungulate abundance. This may have affected the results because the sites differ in successional stage and ungulate pressure. However, we statistically controlled for this by using site as a random grouping factor. 


\section{Results}

Treatment effect: fenced vs unfenced

The PCA analysis indicated clear correlations among the 22 response variables (Fig. 5.3). Principal component 1 (Dim. 1) explained $23 \%$ of the variation and was mainly associated with litter quality, high decomposition and mineralization of birch, pine and oak litter at the right side, and with soil compaction and pine $\mathrm{K}^{+}$mineralization at the left side. Principal component 2 (Dim. 2) explained $18 \%$ of the variation and was associated with high sapling density and diversity, invertebrate biomass and diversity, rodent activity, litter depth and tea decomposition at the upper section of the graph and with soil $\mathrm{pH}$ at the lower section. Ungulate treatment effect was mainly found along the first PCA dimension, as fenced plots without ungulates in red were found at the top of the PCA (with the 95\% confidence interval indicated by a red ellipse) whereas unfenced plots with ungulates in green were found at the bottom (left) part of the PCA (indicated by a green ellipse). The ellipse of the unfenced treatment was much smaller than the ellipse of the fenced treatments, indicating that ungulates had a homogenizing effect on vegetation, soil, invertebrates and decomposition. The 12 forest sites separated more out on the first dimension, indicating that site conditions modify decomposition and mineralization rates. In terms of browsing, palatable species (e.g. Sorbus aucuparia, Rhamnus frangula, Quercus robur, Amelanchier lamarckii and Betula pendula) were highly browsed compared to not palatable species (e.g. Pinus sylvestris and Larix kaempferi, Fig. 5.4). Concerning invertebrate composition, Hemiptera (aphids \& planthoppers), Megadrilacea (earthworms), Diplopoda (millipedes), Hymenoptera (bees \& ants), Coleoptera (beetles) and Geophilomorpha (centipedes) were associated with fenced plots, whereas Diptera (flies) and Araneida (spiders) were associated with unfenced plots where ungulates were present (Appendix A.2). 


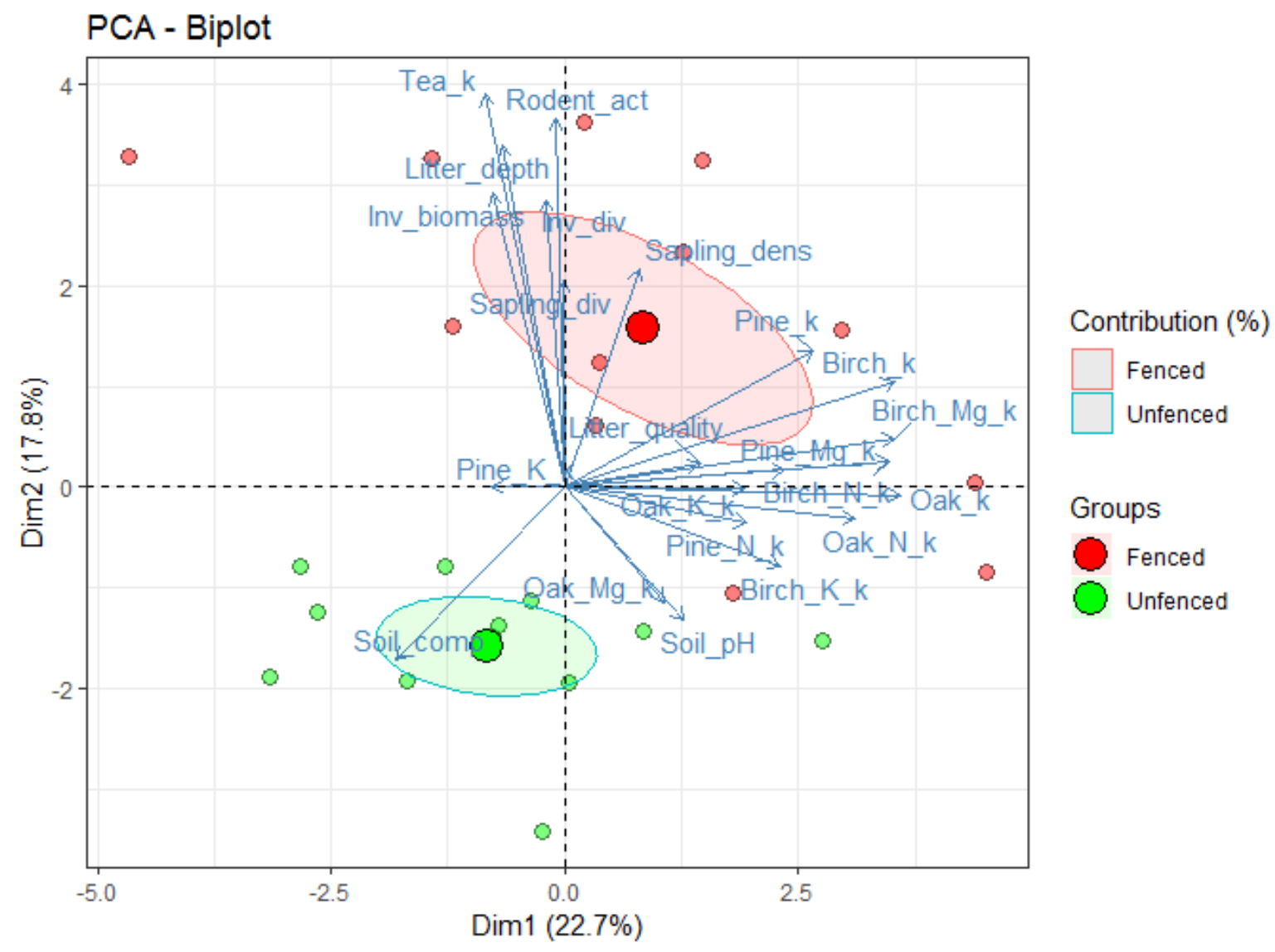

Figure 5.3. Principal Component Analysis (PCA) for 22 variables related to vegetation, soils, decomposers, and decomposition and mineralization rates of three litter types (birch, pine, and oak) in forests across the Veluwe, the Netherlands. Unfenced treatments are indicated by green and fenced treatments by red symbols and ellipse. Large symbols indicate the centroid of the plots. The ellipse indicates the 95\% confidence interval of the treatment plots. The length of the blue solid arrows is proportional to its importance and the angle between two arrows reflects the magnitude of the correlation between variables. Response variables were coded as: Soil_comp=soil compaction, Soil_pH=soil pH, Litter_depth=litter depth, Litter_quality=litter quality, Saping_div=sapling Shannon diversity, Sapling_dens=sapling density, Rodent_acti=rodent activity, Inv_div=invertebrate Shannon diversity, Inv_biomass=invertebrate biomass, Tea_k=tea decomposition, Pine_k=pine decomposition, Oak_k=oak decomposition, Birch_k=birch decomposition, Pine_N_k=nitrogen decomposition in pine, Oak_N_k=nitrogen decomposition in oak, Birch_N_k=nitrogen decomposition in birch, Pine_K_k=potassium decomposition in pine, Oak_K_k=potassium decomposition in oak, Birch_K_k=potassium decomposition in birch, Pine_Mg_k=magnesium decomposition in pine, Oak_Mg_k=magnesium decomposition in oak, Birch_Mg_k=magnesium decomposition in birch. 


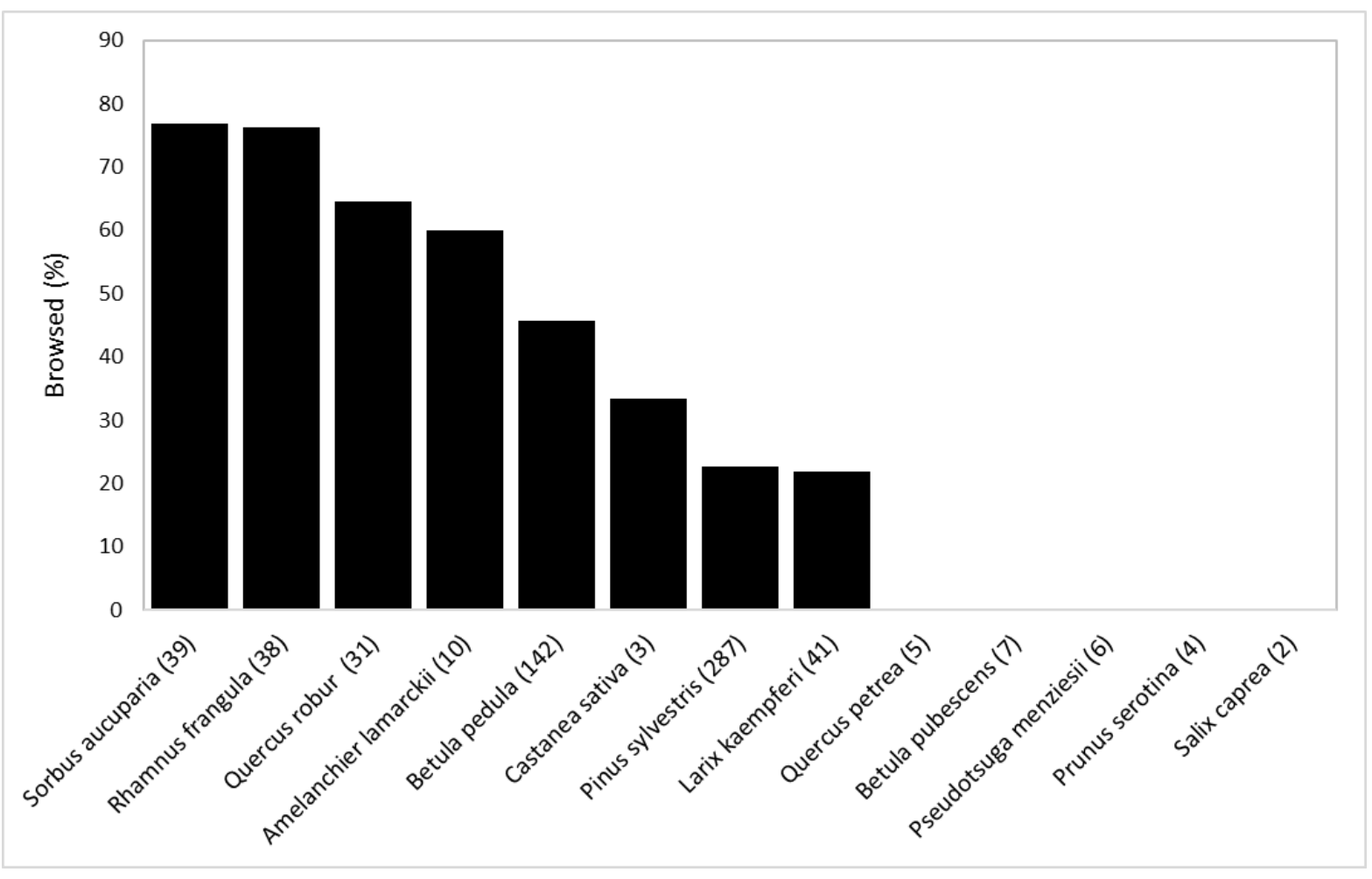

Figure 5.4. Browsed stems results in percentage for all species across all unfenced plots in the Veluwe, the Netherlands. The number of replicate stems is shown in parenthesis. Browsing intensity differed significantly among species (Kruskal-Wallis test, $x^{2}=432$, d.f. $=12, p<0.001$ ). Some species (Quercus petrea, Betula pubescens, Pseudotsuga menziesii, Prunus serotine \& Salix caprea) could not be quantified precisely because they had a low stem number.

Fencing significantly affected nine out of 22 response variables, as indicated by the (G)LMM analyses (Fig. 5.5, Table 5.1). Plots where ungulates were present (i.e., unfenced plots) had significantly higher soil compaction (Fig. 5.5A) whereas plots without ungulates (i.e., fenced plots) had significantly larger litter depth (Fig. 5.5C), sapling density and diversity (Fig. 5.5E, D), rodent activity (Fig. 5.5F), and invertebrate biomass (Fig. 5.5H). Plots without ungulates also had significantly higher decomposition rates of tea bags and pine and birch litter (Fig. 5.5I, J, L). All the other variables, such as litter mineralization rates of $\mathrm{N} \mathrm{K}^{+}, \mathrm{Mg}^{2+}$ and litter quality, did not differ significantly between fenced and unfenced plots. Finally, there was no difference in soil mineralization rate of $\mathrm{N}$ and $\mathrm{PO}_{43}$ - in fenced and unfenced plots (Table 5.1). 
Table 5.1. GLMM results for treatment effect (fencing=1 vs. unfencing=0) on 22 response variables. All variables are accompanied by their coefficient of determination $\left(R^{2}\right)$ for fixed factors (marginal) and fixed plus random factors (conditional), treatment absolute coefficient, degrees of freedom (D.F.) and $p$ value. Bold $p$ values indicate significant effects $(P<0.05)$.

\begin{tabular}{|c|c|c|c|c|c|}
\hline Variable & $\begin{array}{c}\mathbf{R}^{\mathbf{2}} \\
\text { marginal }\end{array}$ & $\begin{array}{c}\mathbf{R}^{\mathbf{2}} \\
\text { conditional }\end{array}$ & $\begin{array}{l}\text { Treatment } \\
\text { coefficient }\end{array}$ & D.F. & $p$ value \\
\hline Soil compaction & 0.19 & 0.71 & -61.00 & 71 & $<0.01$ \\
\hline Soil pH & $<0.01$ & 0.10 & $<0.01$ & 22 & 0.81 \\
\hline Litter depth & 0.20 & 0.62 & 1.77 & 27 & $<0.01$ \\
\hline Litter quality & 0.03 & 0.05 & 0.15 & 11 & 0.40 \\
\hline Sapling diversity & 0.26 & 0.36 & 0.37 & 27 & $<0.01$ \\
\hline Sapling density & 0.17 & 0.72 & 36.86 & 27 & $<0.01$ \\
\hline Rodent activity & 0.51 & 0.70 & 2.51 & 11 & $<0.01$ \\
\hline Invertebrate diversity & 0.06 & 0.07 & 0.24 & 23 & 0.91 \\
\hline Invertebrate biomass & 0.08 & 0.15 & 0.43 & 23 & 0.04 \\
\hline Tea bag decomposition & 0.41 & 0.70 & 0.01 & 52 & $<0.01$ \\
\hline Pine decomposition & 0.13 & 0.22 & 0.09 & 22 & 0.01 \\
\hline Oak decomposition & 0.05 & 0.20 & 0.07 & 22 & 0.10 \\
\hline Birch decomposition & 0.12 & 0.43 & 0.11 & 22 & 0.03 \\
\hline Nitrogen mineralization in Pine & 0.01 & 0.07 & 0.04 & 22 & 0.49 \\
\hline Nitrogen mineralization in Oak & $<0.01$ & 0.29 & 0.03 & 22 & 0.69 \\
\hline Nitrogen mineralization in Birch & 0.09 & 0.49 & 0.15 & 22 & 0.06 \\
\hline Potassium mineralization in Pine & $<0.01$ & 0.32 & -0.15 & 22 & 0.65 \\
\hline Potassium mineralization in Oak & $<0.01$ & 0.81 & 0.18 & 22 & 0.75 \\
\hline Potassium mineralization in Birch & 0.01 & 0.42 & 0.18 & 22 & 0.65 \\
\hline Magnesium mineralization in Pine & 0.03 & 0.45 & 0.21 & 22 & 0.26 \\
\hline Magnesium mineralization in Oak & $<0.01$ & 0.01 & 0.01 & 22 & 0.99 \\
\hline Magnesium mineralization in Birch & 0.04 & 0.23 & 0.21 & 22 & 0.14 \\
\hline Nitrogen mineralization in soil & 0.01 & 0.34 & 5.23 & 24 & 0.41 \\
\hline Phosphate mineralization in soil & 0.01 & 0.80 & $-0,43$ & 24 & 0.30 \\
\hline
\end{tabular}



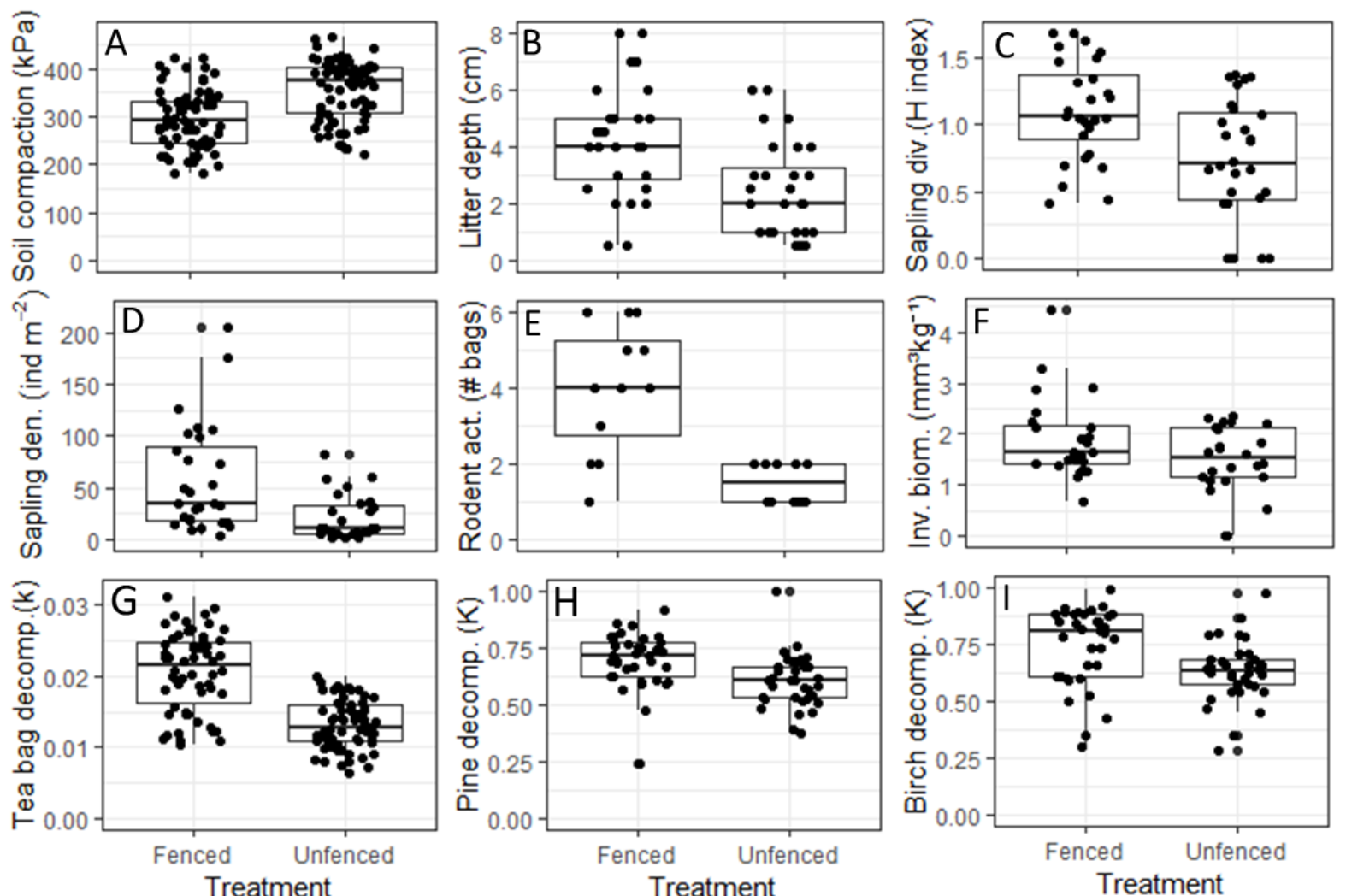

Treatment

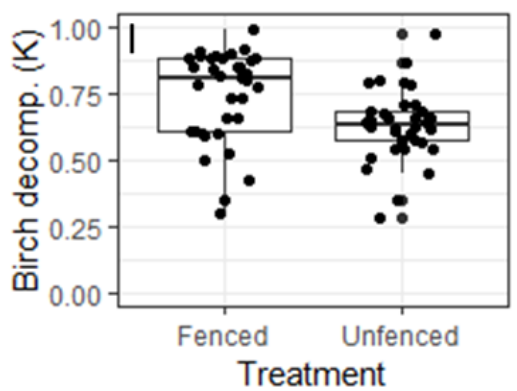

Figure 5.5. Differences between treatment effect (fencing=1 vs. unfencing=0) for the nine significant response variables. All the individual data points (dots) are plotted as well. Significance $(P<0.05)$ was tested with Linear Mixed Models (LMM) and Generalized Linear Mixed Models (GLMM, see Table 5.1). Rodent activity refers to the number of bags altered by rodents in the forest. Tea bag decomposition represents the combining values of green (fast) and red tea (slow) for one moment in time.

\section{Cascading effects}

There are several direct pathways through which wild ungulates triggered cascading effects in temperate forests (Fig. 5.6, Appendix A.3). The Pathway Analysis Model showed that in unfenced plots ungulates significantly increased soil compaction (standardized regression coefficient $\beta=0.48)$, and decreased litter depth $(\beta=-0.44)$, sapling density $(\beta=-0.42)$ and diversity $(\beta=-0.51)$. Litter quality significantly decreased litter depth $(\beta=-0.27)$. These soil and vegetation variables had, in turn, effects on other trophic levels. Sapling density significantly increased rodent activity $(\beta=0.42)$. Soil $\mathrm{pH}$ significantly decreased invertebrate biomass $(\beta=-$ 0.45). Litter depth significantly increased invertebrate diversity $(\beta=0.33)$, while soil compaction $(\beta=-0.38)$ and soil $\mathrm{pH}(\beta=-0.37)$ decreased invertebrate diversity. Ungulates did not affect litter quality; similarly, tea bag, pine, oak and birch litter decomposition rate were not affected by either invertebrate diversity or invertebrate biomass. Regarding nutrient 
mineralization rate, invertebrate diversity significantly increased magnesium mineralization in pine $(\beta=0.46)$ and nitrogen mineralization in oak $(\beta=0.55)$, whereas invertebrate biomass decreased nitrogen mineralization in oak $(\beta=-0.59)$.

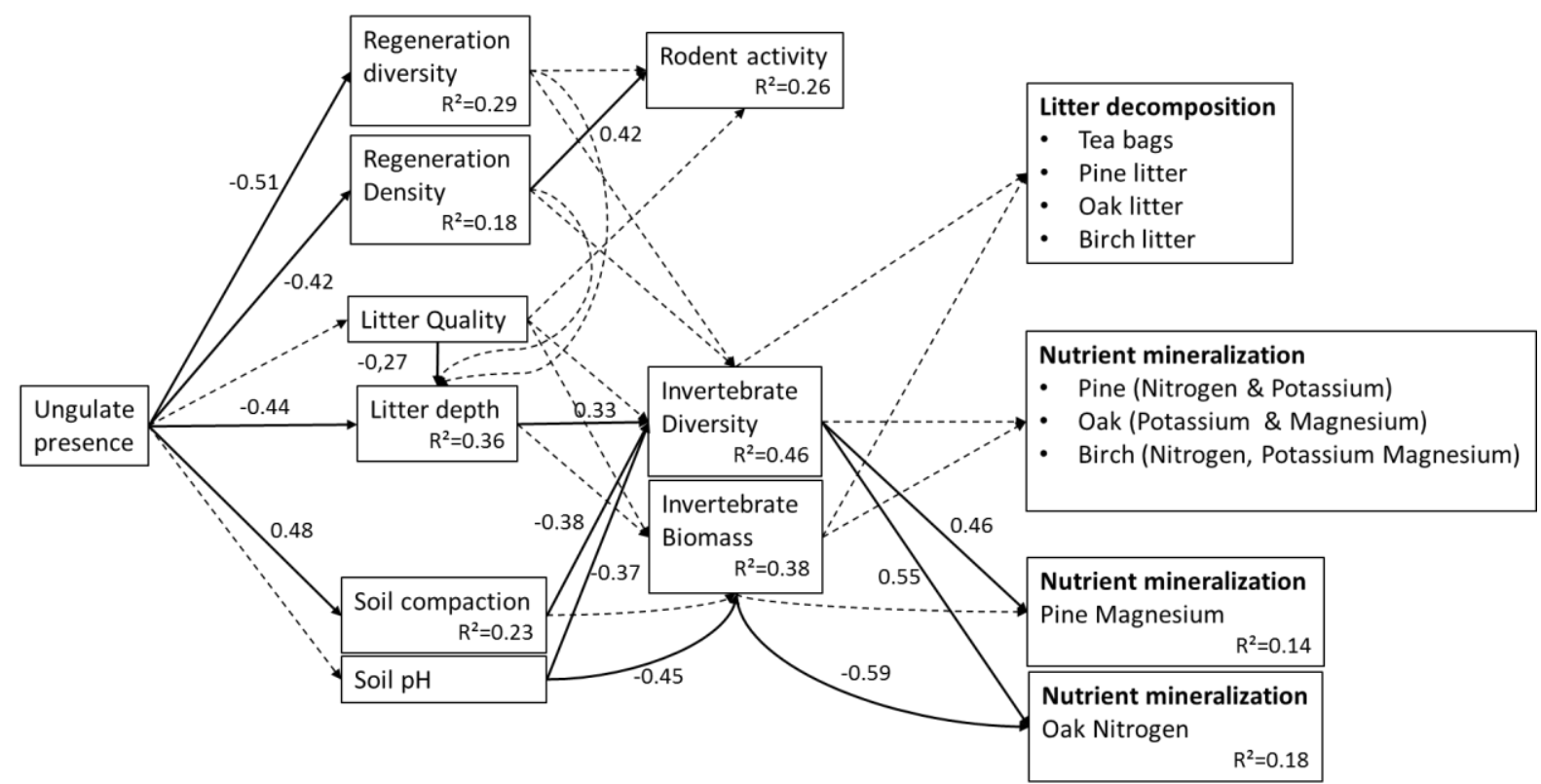

Figure 5.6. Direct and indirect effects of presence of wild ungulates on forest functioning, assessed with a fencing experiment. The results of a Pathway Analyses Mode (PAM) are shown. The figure is based on the results of Appendix A.3. All model components were measured with $N=24$. Solid arrows indicate significant $(P<0.05)$ relationships and dashed lines non-significant relationships. Numbers next to arrows are standardized regression coefficients, which are only given for significant relationships and inside the boxes the coefficient of determination $\left(R^{2}\right)$ are specified for the significant models only.

\section{Discussion}

We analysed the different pathways through which ungulates trigger cascading effects on lower trophic levels and ecosystem properties. We found that ungulate exclusion had cascading effects on forest ecosystems by modifying different trophic levels. Ungulates changed the plant community, soil conditions and the soil invertebrate decomposer community, but did not have a significant effect on litter decomposition rates, and a limited effect on nutrient mineralization rate. This suggest that ungulates are therefore important ecosystem engineers, although in our system they play a limited role in nutrient cycling. 


\section{Fencing effect}

We found some support for our prediction that ungulate exclusion increases diversity on lower trophic levels and decomposition rate of litter, but also increases soil compaction. Litter depth, sapling diversity, sapling density, rodent activity, invertebrate biomass, tea bag, pine and birch decomposition (Table 5.1, Fig. 5.5) were indeed significantly higher in the fenced compared to the unfenced plots. This implies that browsing and trampling directly and/or indirectly altered the vegetation and the composition of soil invertebrates (Gill \& Beardall 2001; Allombert et al. 2005b; Kuijper et al. 2010a). Invertebrate decomposers were mainly associated with fenced plots whereas invertebrate predators were associated with unfenced plots (Appendix A.2). Oak decomposition tended to be higher in the fenced plots although it was not significant $(P=0.09)$. Soil compaction was significantly higher in unfenced plots (Fig. 5.5A), indicating that trampling exerted pressure on soil which directly translated to a higher soil density (Ramirez et al. 2019). Fencing had no significant effect on litter nutrient mineralization rates and this was also confirmed by a non-significant fencing effect on $\mathrm{N}$ and $\mathrm{PO}_{43}$ - soil mineralization rates (Table 5.1), probably because nutrients tend to mineralize at initial stages of decomposition, and a one year harvest might therefore be too long to still detect mineralization effects (Hasanuzzaman \& Hossain 2014). Overall, the fencing experiment suggested that ungulates regulated forest succession into a poor state characterized by a reduced trophic chain, high browsing incidence on palatable species and limited litter decomposition rates (Fig. 5.3-5.5, Appendix A.2).

\section{Above-ground cascading effects}

We used PAM to analyse the pathways through which ungulates have cascading effects. Ungulates reduced understory stem density (Fig. 5.6, Appendix A.3, $\beta=-0.42$ ) and tree species diversity ( $\beta=-0.51$ ) (Allombert et al. 2005a; Allombert et al. 2005b). Regeneration density had, in turn, a positive relationship with rodent activity $(\beta=0.42)$, possibly because it protects rodents against extreme climatic conditions and provides refuge against predators (Flowerdew \& Ellwood 2001). These results are confirmed by a study conducted in the United Kingdom, where bank vole (Myodes glareolus) and wood mice (Apodemus sylvaticus) population was lower in animal unfenced plots compared to fenced plots, and population size was directly related with the number of shrubs (Buesching et al. 2011). Our results suggest 
that ungulates indirectly decreased rodent activity by shifting forest structure towards a less dense understory.

\section{Below-ground cascading effects}

We hypothesized that ungulates would affect soil macro invertebrates by shifting tree species composition in the forest understory, which can reduce substrate quantity (litter depth) and soil quality. Sequentially our results showed that ungulate fencing indeed reduced invertebrate diversity by first reducing substrate quantity (Fig. 5.6, Appendix A.3, i.e., litter depth $\beta=-0.44)$ and by increasing soil compaction $(\beta=0.48)$. In turn, litter depth $(\beta=0.33)$ increased invertebrate diversity whereas soil compaction $(\beta=-0.38)$ decreased it. These results suggest that ungulates by trampling directly reduced the litter layer depth by mixing litter with soil (Bruinderink \& Hazebroek 1996; Hobbs 1996). The litter layer plays a vital role for soil invertebrates, as first it represents an important food source for decomposers and second, it acts as a barrier that controls for humidity, temperature and light on the forest floor (Mills \& Macdonald 2004). The negative relationship between soil compaction and invertebrate diversity is in agreement with the findings of Lavelle et al. (2006), where invertebrate abundance decreased with increasing soil compaction and its side effects: limitations on soil water storage, soil aeration and invertebrate movement (Lal 1988; Althoff \& Thien 2005).

The prediction that ungulates would reduce litter decomposition by limiting the quantity and diversity of soil invertebrates was only partly supported (Fig. 5.6, Appendix A.3). Invertebrate biomass did not have a significant impact on tea, pine, oak and birch decomposition rate, whereas invertebrate diversity had only a positive effect on the mineralization rate of magnesium in pine $(\beta=0.46)$ and nitrogen in oak $(\beta=0.55)$. These results are supported by our resin bag analysis, which also indicated no treatment effect on soil $\mathrm{N}$ and $\mathrm{PO}_{43-}$ mineralization rate (Table 5.1). In agreement, an experimental study showed that invertebrate richness increased decomposition and mineralization rates (Jonsson \& Malmqvist 2000), probably because of the cooperation among the decomposer guild (Gessner et al. 2010). However, not all studies support the hypothesis of fast decomposition rate due to species cooperation (Hättenschwiler et al. 2005), probably because environmental variables such as temperature and precipitation play a major role in litter decomposition rate (Zhang et al. 2008). 


\section{Feedback loops promoted by browsing}

Feedback loops represent regulating forces on natural systems that make exploitative and symbiotic interactions persistent in time (Patten \& Odum 1981) and the combination of different feedback loops allow systems to maintain their stability (Soto-Ortiz 2015). Feedback loops happen when the output of a particular ecosystem mechanism amplifies the input of the same system. For example ungulate browsing can trigger a positive feedback on savannah ecosystems, which leads to more intense fires by increasing the fuel load of grass and thus facilitating for grass biome (Van Langevelde et al. 2003). Similarly, our results suggest that ungulates, through browsing on palatable species, may arrest forest ecosystems into an early successional stage with low primary productivity. By browsing on palatable species (Figure 4), the quantity and quality of litter production may be reduced leading to a decrease in soil invertebrate diversity and composition (Fig. 5.3, Appendix A.2), which in turn stalls decomposition and mineralization rates (Fig. 5.5-5.6). A slow nutrient cycle in the soil, results, in turn, in less nutrients for plant development, and selects for plant species with low nutrient requirements and nutrient poor litter (Fig. 5.6) (Augustine \& McNaughton 1998).

A fair amount of literature has addressed ungulate effects on multi-trophic systems across different biomes: from boreal forests to savannahs. The majority of studies agree that ungulates exert through browsing and trampling a strong top-down control on vegetation, which triggers negative cascading effects on lower trophic levels and ecosystem processes. These effects promote slow feedback loops that reinforce the establishment of less palatable species (e.g., conifer) that require a limited amount of soil nutrients (Pastor et al. 1993; Ritchie et al. 1998). Yet, a group of studies demonstrated that under certain environmental conditions, ungulates could trigger positive cascading effects on systems, which can lead to fast feedback loops (Pastor et al. 1988). For example, Frank et al. (2000) demonstrated that ungulates on unfenced compared to fenced plots in Yellowstone National Park promoted nitrogen availability by stimulating microbial activity and microbial turnover rates. Similarly, through a literature review Augustine and McNaughton (1998) proposed with empirical evidence that ungulate browsing may also establish the dominance of highly palatable species when there is a high level of nutrient inputs which facilitate individuals to recover from tissue loss or by when there is a good balance between tolerant and intolerant tree species to browsing. Finally, Pringle et al. (2007) revealed that ungulate presence decreased the abundance of trees, lizards and arthropods in a series of ungulate fenced compared to 
unfenced plots that ranged in productivity in an African savannah; yet, the strength of these trophic effects decreased with increasing primary productivity.

The growing amount of evidence across biomes suggests that external factors such as climate and primary productivity may be more important on mediating trophic interactions and ecosystem processes (Hobbs 1996). Considering that our project was conducted in a nutrient deficient system and with limited primary productivity, we expected that ungulate presence would have strong cascading effects on vegetation, soil quality, invertebrate community, litter decomposition and nutrient mineralization. Indeed, we found that ungulates had strong effects on vegetation, soil quality and invertebrates, yet we only found weak effects on litter decomposition and nutrient mineralization. Suggesting that not only external factors such as climate and primary productivity mediate trophic interactions, but actually, the community organization and structure of each trophic level may also have an overriding effect.

\section{Conclusions}

Our experiment suggest that wild ungulates have strong direct and indirect cascading effects on forest ecosystems. By browsing on palatable tree species, they can trigger slow feedback loops in the system, which have the theoretical potential to arrest forest succession to an early stage mostly composed by light demanding tree species which are less palatable. Yet, nutrient cycling was not affected by ungulates, but instead, probably by site conditions. The homogenizing effect of ungulates is expected to be higher in situations where forests harbour (1) large herbivore density, (2) when primary productivity is low and (3) when there is an unbalanced organization in the different trophic levels.

\section{Acknowledgements}

This work was supported and financed by a "Convocatoria Abierta 2012" grant from the "Secretaría de Educación Superior, Ciencia, Tecnología e Inovación del Ecuador" and a Grant from the Ecology Fund of the Royal Netherlands Academy of Arts and Sciences. Access to forest areas and field support were kindly provided by Staatsbosbeheer, Kroondomein Het Loo, Cooperatie Bosgroep Midden Nederland, Geldersch Landschap en Kasteelen and Gemeente Epe. We kindly aknowledge Natalie Herdoiza and Leo Goudzwaard for their valueable support during fieldwork. 


\section{Appendix A}

\section{A.1}

A.1. List of forest sites included in this study. Forest site refers to the location (nearest city or park name) of the fenced and unfenced plots. Establishment indicates the year when the plots were established. Forest type indicates the composition of the canopy cover (broadleaf, mainly broadleaf, mix, mainly conifer and conifer). Canopy cover refers to the percentage of canopy cover.

\begin{tabular}{lclllc}
\hline & & \multicolumn{2}{c}{ Fenced } & \multicolumn{2}{c}{ Unfenced } \\
\hline Forest site & $\begin{array}{c}\text { Establishment } \\
\text { (year) }\end{array}$ & Forest type & $\begin{array}{c}\text { Canopy cover } \\
\text { (\%) }\end{array}$ & Forest type & $\begin{array}{c}\text { Canopy cover } \\
\text { (\%) }\end{array}$ \\
\hline Oostereng & 2016 & Mix & 0 & Mix & 0 \\
Veluwe S. & 2015 & Conifer & 0 & Conifer & 0 \\
Veluwe N. & 2014 & Mainly conifer & 0 & Mainly conifer & 0 \\
Rheden & 2013 & Mix & 15 & Mix & 10 \\
Achterpark & 2012 & Mix & 55 & Mix & 50 \\
Dellen & 2010 & Mix & 30 & Mix & 15 \\
Ullerberg N. & 2006 & Mix & 65 & Mix & 35 \\
Garderen & 2005 & Mix & 85 & Mix & 50 \\
Epe & 2004 & Mix & 70 & Mix & 55 \\
Ullerber S. & 1999 & Conifer & 45 & Conifer & 25 \\
Gortel & 1997 & Mainly broadleaf & 75 & Mainly broadleaf & 50 \\
Hoenderloo & 1984 & Conifer & 90 & Conifer & 70 \\
\hline
\end{tabular}




\section{A.2}

A.2. Principal Component Analysis (PCA) for ten invertebrate species found in the soil samples taken from all the vegetation plots. Unfenced treatments are indicated by green and fenced treatments by red symbols and ellipse. The centroids of the treatment plots are indicated by large symbols. The ellipse indicates the 95\% confidence interval of the treatment plots. The length of the blue solid arrows is proportional to its importance and the angle between two arrows reflects the magnitude of the correlation between variables. Supplementary variables with no effect on the analysis are plotted in dark blue.

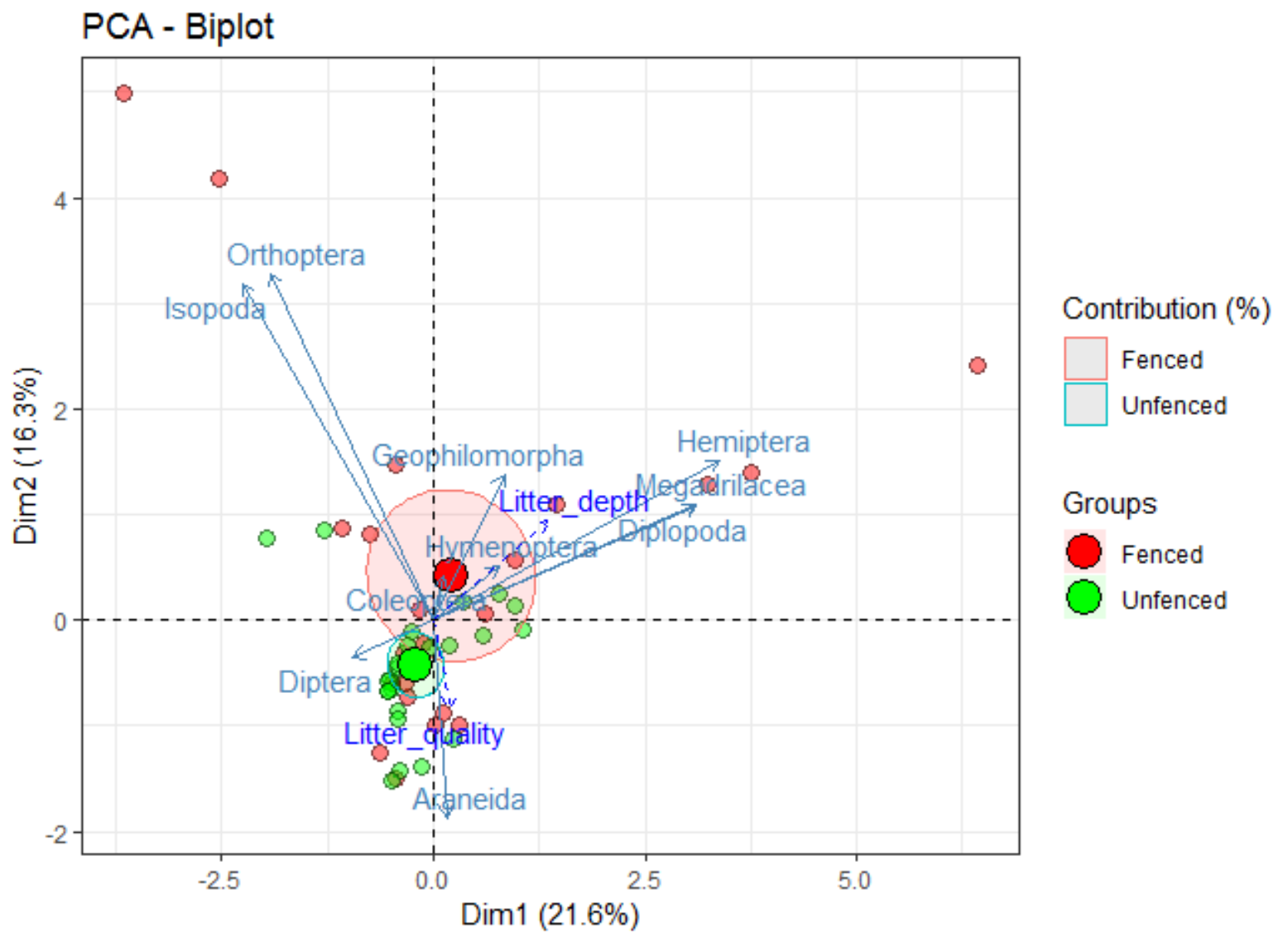

\section{A.3}

A.3. Pathway Analyses Model (PAM) showing ungulate cascading effects on Dutch temperate forests. A pathway analysis is composed of a series of regression analyses, which was performed with one or more predictors and one response variable. All regressions included forest site as grouping random effect. Each regression is accompanied by its standardized regression coefficients, standard error of the regression coefficient (SE), (Z) value and $(P)$ value. Bold numbers represent a significant $p$ value.

\begin{tabular}{llcccc}
\hline Response & Predictor & Std. Coeff & SE & Z & P \\
\hline Soil compaction & Ungulate presence & 0.48 & 15.85 & 3.85 & $<\mathbf{0 . 0 0 1}$ \\
Soil pH & Ungulate presence & 0.05 & 0.04 & 0.27 & 0.79 \\
Litter depth & Ungulate presence & -0.44 & 0.52 & -2.82 & $<\mathbf{0 . 0 0 1}$ \\
& Sapling diversity & 0.13 & 0.77 & 0.70 & 0.48 \\
& Sapling density & 0.05 & 0.01 & 0.34 & 0.73
\end{tabular}




\begin{tabular}{|c|c|c|c|c|c|}
\hline & Litter quality & -0.27 & 0.38 & -2.94 & $<0.01$ \\
\hline Regeneration diversity & Ungulate presence & -0.51 & 0.12 & -3.40 & $<0.001$ \\
\hline Regeneration density & Ungulate presence & -0.42 & 12.37 & 2.95 & $<0.001$ \\
\hline Litter quality & Ungulate presence & -0.18 & 0.17 & -0.85 & 0.40 \\
\hline \multirow[t]{3}{*}{ Rodent activity } & Sapling diversity & 0.23 & 0.78 & 1,28 & 0.20 \\
\hline & Sapling density & 0.42 & 0.01 & 2.89 & $<0.001$ \\
\hline & Litter quality & 0.01 & 0.94 & 0.05 & 0.95 \\
\hline \multirow[t]{6}{*}{ Invertebrate diversity } & Sapling diversity & 0.24 & 0.09 & 1.88 & 0.06 \\
\hline & Sapling density & -0.16 & $<0.01$ & -0.81 & 0.42 \\
\hline & Litter depth & 0.33 & 0.03 & 2.09 & 0.03 \\
\hline & Soil compaction & -0.38 & $<0.01$ & -2.17 & 0.03 \\
\hline & Soil pH & -0.37 & 0.48 & -2.43 & 0.02 \\
\hline & Litter quality & -0.04 & 0.20 & -0.16 & 0.87 \\
\hline \multirow[t]{6}{*}{ Invertebrate biomass } & Sapling diversity & 0.11 & 0.23 & 0.66 & 0.51 \\
\hline & Sapling density & -0.11 & $<0.01$ & -0.62 & 0.54 \\
\hline & Litter depth & 0.35 & 0.07 & 1.64 & 0.10 \\
\hline & Soil compaction & -0.15 & $<0.01$ & -0.83 & 0.41 \\
\hline & Soil pH & -0.45 & 1.27 & -2.15 & 0.03 \\
\hline & Litter quality & 0.07 & 0.23 & 0.40 & 0.69 \\
\hline \multirow[t]{2}{*}{ Tea bag decomposition } & Invertebrate diversity & 0.13 & 0.01 & 0.46 & 0.65 \\
\hline & Invertebrate biomass & 0.37 & $<0.01$ & 1.68 & 0.09 \\
\hline \multirow[t]{2}{*}{ Pine decomposition } & Invertebrate diversity & -0.01 & 0.08 & -0.05 & 0.96 \\
\hline & Invertebrate biomass & 0.17 & 0.05 & 0.51 & 0.61 \\
\hline \multirow[t]{2}{*}{ Oak decomposition } & Invertebrate diversity & $<0.01$ & 0.07 & 0.02 & 0.98 \\
\hline & Invertebrate biomass & -0.33 & 0.04 & -1.55 & 0.12 \\
\hline \multirow[t]{2}{*}{ Birch decomposition } & Invertebrate diversity & -0.01 & 0.12 & -0.02 & 0.99 \\
\hline & Invertebrate biomass & -0.11 & 0.08 & -0.30 & 0.77 \\
\hline \multirow[t]{2}{*}{ Pine $\mathrm{N}$ decomposition } & Invertebrate diversity & -0.10 & 0.17 & -0.28 & 0.78 \\
\hline & Invertebrate biomass & 0.08 & 0.08 & 0.25 & 0.80 \\
\hline \multirow[t]{2}{*}{ Oak $\mathrm{N}$ decomposition } & Invertebrate diversity & 0.55 & 0.14 & 2.00 & 0.04 \\
\hline & Invertebrate biomass & -0.59 & 0.08 & -1.95 & 0.05 \\
\hline \multirow[t]{2}{*}{ Birch $\mathrm{N}$ decomposition } & Invertebrate diversity & -0.08 & 0.16 & -0.31 & 0.76 \\
\hline & Invertebrate biomass & 0.05 & 0.12 & 0.15 & 0.89 \\
\hline \multirow[t]{2}{*}{ Pine $\mathrm{K}$ decomposition } & Invertebrate diversity & 0.29 & 0.87 & 0.88 & 0.38 \\
\hline & Invertebrate biomass & -0.04 & 0.46 & -0.11 & 0.91 \\
\hline \multirow[t]{2}{*}{ Oak K decomposition } & Invertebrate diversity & -0.08 & 0.96 & -0.35 & 0.73 \\
\hline & Invertebrate biomass & 0.25 & 0.46 & 1.22 & 0.22 \\
\hline Birch $\mathrm{K}$ decomposition & Invertebrate diversity & -0.06 & 0.82 & -0.22 & 0.83 \\
\hline
\end{tabular}


CHAPTER 5

\begin{tabular}{llllll} 
& & & & & \\
& Invertebrate biomass & -0.34 & 0.33 & -1.64 & 0.10 \\
Pine Mg decomposition & Invertebrate diversity & 0.46 & 0.19 & 3.63 & $<0.001$ \\
& Invertebrate biomass & -0.16 & 0.12 & -1.00 & 0.32 \\
Oak Mg decomposition & Invertebrate diversity & 0.53 & 0.37 & 1.72 & 0.08 \\
& Invertebrate biomass & -0.57 & 0.21 & -1.75 & 0.08 \\
Birch Mg decomposition & Invertebrate diversity & 0.29 & 0.24 & 1.36 & 0.18 \\
& Invertebrate biomass & -0.13 & 0.20 & -0.41 & 0.68 \\
\hline
\end{tabular}




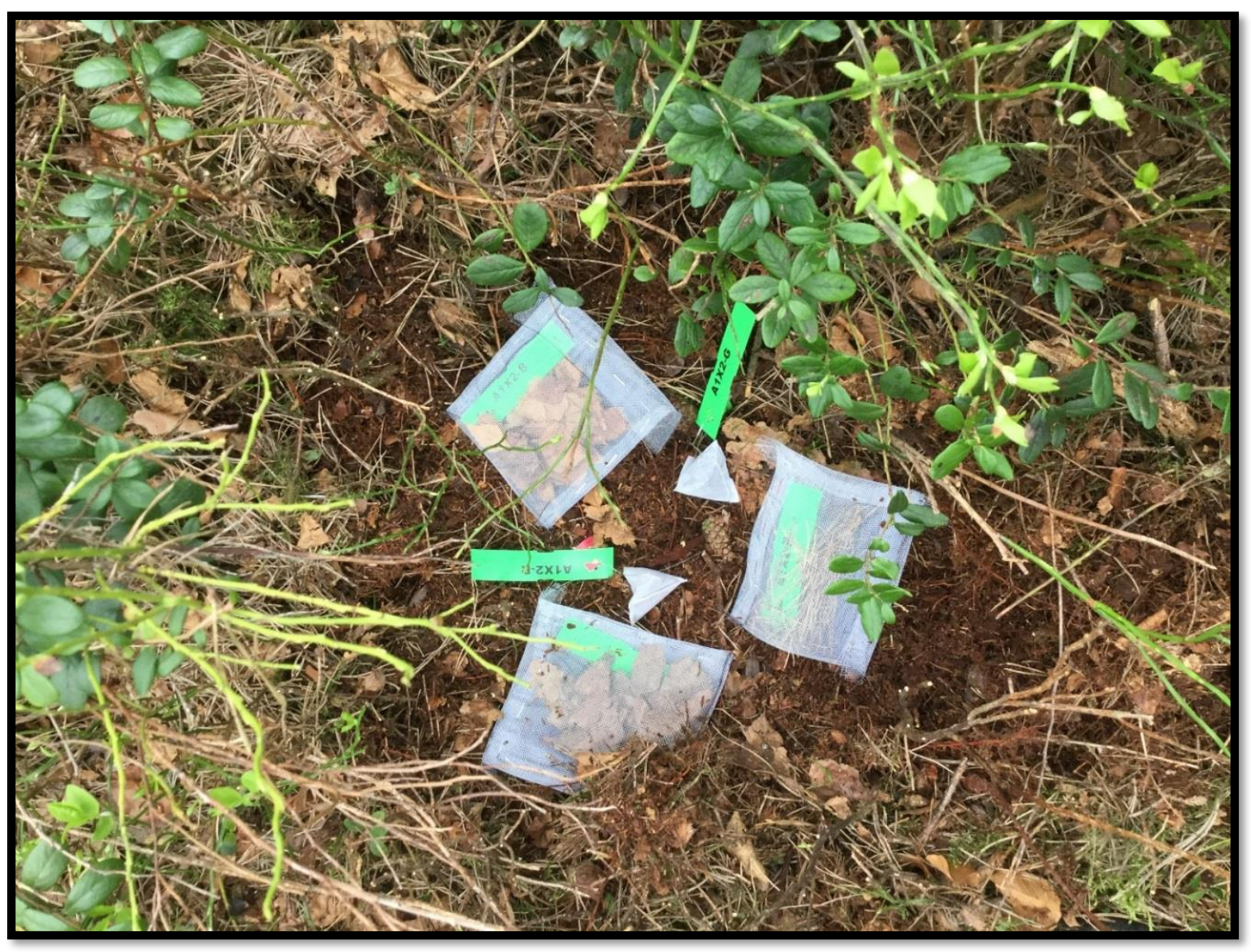




\section{CHAPTER SIX}

\section{General synthesis}

Author

Juan Ignacio Ramírez 


\section{The role of wild ungulates on temperate forests across scales}

Wild ungulates play an important role in the structure and functioning of temperate forests. High ungulate abundance can reduce forest diversity, structure and functioning, and bring forests into a stage of arrested succession (Reimoser 2003). These effects are not only dependent on ungulate abundance, but also on ungulate assemblage composition and successional forest stage (Kuijper et al. 2010b; Ramirez et al. 2019). Yet, there is a limited number of field and experimental studies that elaborate on these important factors, mainly because there is a lack of long-term exclosures and varying ungulate populations with different species across the same region. This is why, this thesis aims to evaluate the effects of wild ungulates on temperate forests at different scales. That is, how do wild ungulates affect forests at different 1 ) spatial scales (from areas with low to areas with high ungulate abundance)? 2) temporal scales (from short-term to long-term effects)? and 3) hierarchical scales (from trophic levels of primary producers to detritivores)?

Next, a description of the research aim, methods and findings for each of the content chapters (Ch. 2-5) is provided. Further on, the main findings of the content chapters are compared and contrasted, in order to draw an overall conclusion. Finally, the overall research outlook is presented, including the benefits of downscaling/upscaling ungulate-forest research, overcoming main challenges and suggestions for restoring temperate forest systems.

\section{Research findings}

To evaluate how ungulates affect different temperate forest attributes, a global quantitative literature review was made in chapter two. This meta-analysis provided a better understanding on how ungulate density interacts with forests at a global scale and identifies critical thresholds in ungulate density and tipping points in forests when the effect of ungulate density switches from neutral to negative in forests. From a total of 164 studies, ungulate density averaged 23.6 individuals $\mathrm{km}^{-2}$ across studies. Ungulate density had a negative effect on forest regeneration, structure and functioning in $70 \%$ of the evaluated cases. The doseresponse curves had a sigmoidal shape. Critical tipping points, where ungulates started to have a negative effect on forest regeneration, were found at an ungulate metabolic weight density of $115 \mathrm{~kg} \mathrm{~km}^{-2}$ for forest regeneration, $141 \mathrm{~kg} \mathrm{~km}^{-2}$ for forest structure, and $251 \mathrm{~kg} \mathrm{~km}^{-}$ 2 for forest functioning, which is roughly equivalent to 10,13 and 23 roe deer $\mathrm{km}^{-2}$. Forest 
regeneration was most sensitive to immediate browsing and trampling impacts of small seedlings, while forest functioning was least sensitive because of time lags. However, these effects may build-up over time.

Chapter three on the short-term evaluated the shape of the dose-response for ten sites across at the Veluwe, the Netherlands, using approx. 210 camera points paired with vegetation plots. Five of the eleven forest variables measured were related with deer utilization level. With increasing red deer utilization there was a decrease of litter depth. With increasing fallow deer utilization, there was a decrease in sapling richness. With increasing roe deer utilization, there was a decrease in sapling richness and diversity and shrub cover, and an increase of sapling stem density. The dose-response curve between deer utilization and different forest attributes followed a curvilinear response, large changes at low followed by small changes at high utilization level, yet the exact shape of the curve can vary according to (a)biotic factors of each study location. Considering that the slopes of the responses were quite slight, it is possible to conclude that the influence that deer have on temperate forest structure and diversity is limited. Yet these relationships may be different in a long-term study.

To provide a better understanding on how forest succession proceeds in a situation of chronic browsing and trampling, chapter four evaluated the long-term effect of ungulates on a temperate forest. A chronosequence approach was used, in which 17 paired fenced and unfenced plots were compared, ranging in age from 1 to 33 years since establishment at the Veluwe. In fenced plots, where ungulates were excluded, there was a reduced understory vegetation cover and an increased canopy cover, tree species richness, tree Shannon diversity and litter layer compared to unfenced plots. In fenced compared to unfenced plots, woody vegetation developed with palatable broadleaved species such as Betula pendula, Betula pubescens, Prunus serotina, and Quercus robur. These results suggest that current ungulate densities in this system have pronounced long-term effects on forest structure, composition and litter depth, implying that ungulates can slow down natural succession of temperate forests, from light demanding to shade tolerant species. Yet, it remains unclear whether these long-term effects on vegetation trigger cascading effects on lower trophic levels.

In chapter five, the potential cascading effects promoted by ungulates on a temperate forest was evaluated. Using a network of twelve paired fenced and unfenced plots established across the Veluwe, soil quality, litter depth, forest regeneration, soil macro-invertebrates and decomposition rates were evaluated. Plots with ungulates had significantly higher soil 
compaction, but lower litter depth, tree diversity and density, rodent activity, invertebrate biomass and litter decomposition rate compared to plots with ungulates. Furthermore, ungulates presence: decreased sapling density which indirectly decreased rodent activity; decreased litter depth which indirectly reduced macro-invertebrate diversity and mineralization rates of magnesium and nitrogen in pine and oak litter, and increased soil compaction which decreased invertebrate diversity and mineralization rates of magnesium and nitrogen in pine and oak litter. If the system continues in the same direction, in the future it will no longer sustain a diverse plant community due to nutrient limitations in soil.

Although the literature review (Ch.2) and the long-term effect chapter (Ch.4) reported a strong top-down relationship between ungulates and different forest attributes, the shortterm effect chapter (Ch.3) and the cascading effect chapter (Ch.5) only reported weaker relationships. These results illustrate that current ungulate densities gradually shape the composition, structure and functioning of these Dutch temperate forests, although ungulates have a smaller effect on forest functioning compared to (a)biotic factors like soil pH, light availability and forest type (Ch. 3 and 4).

\section{Crosslinking scales: ungulate-forest interactions}

To qualitatively summarize the findings of the different chapters, all the response variables from the different chapters were grouped into positive (increasing), neutral (no effect) and negative (decreasing) relationships with ungulate presence or abundance (Fig. 6.1, Appendix A.1). In the literature review chapter (Ch. 2), $57 \%$ of the response variables had a negative relationship with ungulates and $43 \%$ had a neutral relationship. In the short-term relationship chapter (Ch. 3), $55 \%$ of the response variables had a neutral relationship, $36 \%$ had a negative and $9 \%$ had a positive relationship. In the long-term effect chapter (Ch. 4), 70\% of the response variables had a neutral relationship, $15 \%$ had positive and $15 \%$ had negative. Finally, in the cascading effect chapter (Ch. 5), $64 \%$ of the responses had a neutral relationship, $32 \%$ had a negative and $5 \%$ had a positive relationship. Across chapters, the main findings of this thesis suggest that ungulates in $60 \%$ of all response variables evaluated had neutral relationships with forests, in less percentage ungulates had negative relationships (32\%) and only in a fraction of cases, ungulates had positive relationships (8\%). 


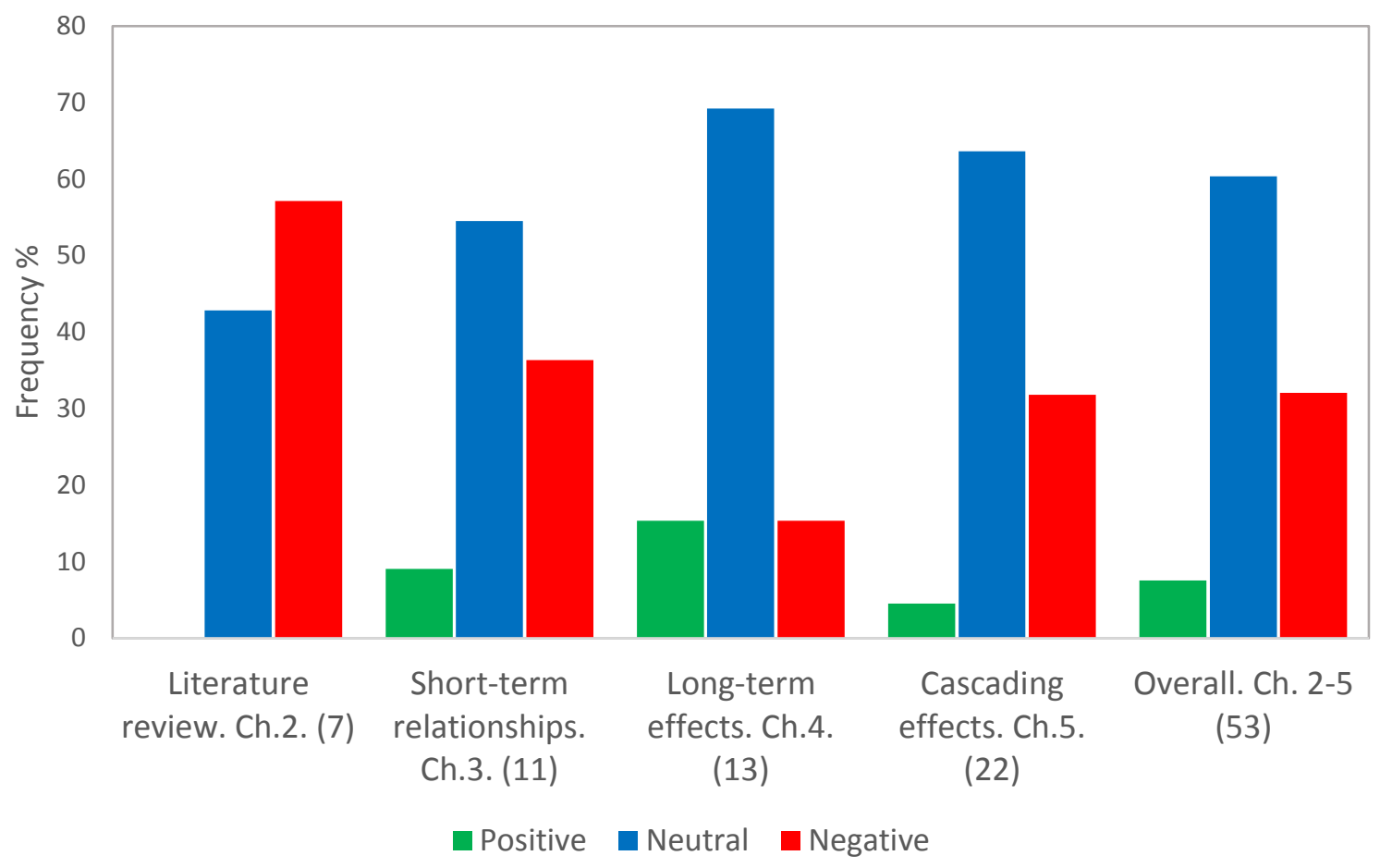

Figure 6.1. Summary of this thesis, showing the relative frequency of variables with significantly positive (green bars), non-significant or neutral (blue bars) and significantly negative (red bars) relationships with wild ungulates. This information was extracted from the four content chapters (Ch. 2-5). The number in parenthesis indicates the total number of variables evaluated in each chapter. Based on appendix A.1.

From all forest attributes evaluated, forest composition (tree diversity and richness) was the attribute most frequently negatively affected by ungulate browsing and trampling (Appendix A.1), probably because ungulates intensively browse on palatable species. Understory vegetation (e.g. moss, shrub and heather) was the least frequently significantly affected by ungulates, probably because understory vegetation is predominantly controlled by other factors such as light availability, precipitation and soil quality. Finally, ungulates had a predominant positive effect on forest structure, probably because browsing, defecating and seed dispersal promote a better distribution of tree species in the landscape (horizontal structure) and browsing enhances forest layering by maintaining vegetation at different heights (vertical structure). In the following paragraphs, the main methods and results from each of the chapters are analysed in order to find similarities and discrepancies among chapters' findings.

All four research chapters indicated that ungulates affect several forest attributes, regardless of the research approach used (i.e., a quantitative literature review, an 
experimental or a field study, whether it was a short-term or and long-term study or even with low or high ungulate abundances). Yet, the research approach determined if the relationships between ungulates and forest attributes were strong or weak. For example, the experimental studies that used exclosures to study the long-term effects (Ch.4) and the cascading effects (Ch.5), in general found stronger relationships than the field study that measured the relationships between an ungulate density gradient on vegetation, probably because the experimental study removes confounding factors and creates a stronger contrast (i.e., ungulates are present or not). Similarly, the global quantitative review (Ch.2) presented strong relationships because experimental studies were included in the analysis.

The dose-response relationships were negative in both the literature quantitative review (Ch.2) and the short-term relationship chapters (Ch.3), yet the shape of the doseresponse relationships differed. In general, the literature review presented sigmoidal curves characterized by having a slow decrease at low ungulate densities, a fast decrease at medium and a slow decrease at high. Whereas the dose-response shape from the short-term effect chapter presented a reversed asymptote, characterized by a fast decrease at low ungulate utilization level, followed by a slow decrease at intermediate utilization level. The shape of the response varies among the two chapters possibly because the quantitative review chapter traced the dose-response between an ungulate density gradient and a qualitative response (e.g. ungulates had a negative, neutral or positive effect on tree diversity), while in the shortterm relationship chapter, the response variables were measured with a quantitative approach (e.g. ungulates had a negative effect on the number of tree species). Tipping points were only observed in the literature review at 10,13 and 23 roe deer $\mathrm{km}^{-2}$, yet it is expected that the tipping points would be quite similar for the short-term chapter as the quantitative review included results from published articles across the entire temperate region (North America $=50.5 \%$, Europe $=31.9 \%$, Oceania $=7.2 \%$, Asia $=6.8 \%$ and South America $=3.6 \%$ of all studies). Yet, tipping points were not calculated for the short-term relationship chapter because the ungulate gradient was expressed in different units. For example, utilization level is (time an animal spends in metabolic weight ${ }^{0.75}$ in front of a camera trap) and not as a density estimate (metabolic weight $\mathrm{t}^{0.75} \mathrm{~km}^{-2}$ ).

The main thesis findings suggest that ungulate composition and abundance greatly modify temperate forests across different scales (temporal, spatial and hierarchical). For example, the short-term relationship chapter (Ch.3) examined and found that ungulates 
modify forests during several growing seasons, yet the results were weak compared to the long-term effect chapter (Ch.4). The long-term effect chapter evaluated and found that after 33 years ungulate presence vs. absence modified temperate forest succession. Regarding spatial scale, this thesis provides evidence that ungulate modify temperate forests across different spatial scales, for example: the quantitative review chapter (Ch. 2) globally assessed and found relationships between ungulate density and different forest attributes at a forest stand scale. The short-term relationship chapter (Ch.3) evaluated and found that ungulates modify forest attributes at a landscape scale by implementing camera-traps paired two vegetation plots at ten different forest sites $\left(1 \mathrm{~km}^{2}\right)$ across the Veluwe region. The long-term effect (Ch.4) and the cascading effect (Ch.5) chapters assessed and found that ungulates on fenced and unfenced plots also modify the forest at a patch scale. Finally, this thesis also evaluated the role of ungulates at different hierarchical scales, for example the cascading effect chapter (Ch. 5) evaluated and found that ungulate presence cascaded effects to other trophic levels such as: vegetation, macro-invertebrates and rodents.

To extrapolate these research findings (Fig. 6.2) to other temperate areas it is crucial to realise that the independent relationships found in this thesis, can shift completely, if there are large variations in (1) ungulate density, (2) ungulate assemblage composition, (3) predation level, (4) primary productivity and (5) forest successional stage (Cromsigt \& Kuijper 2011; Ramirez et al. 2018; Ramirez et al. 2019). Meaning that, above all, ungulate-forest interactions are context dependent. Yet, when considering the results of all the content chapters and scales, it is safe to state that the results of this thesis are relevant to all temperate forests because different spatial (local, landscape and global), temporal (short vs. long-term) and hierarchical (two vs. multiple trophic levels) scale were applied in this thesis. Furthermore, the results of this thesis can also be used with multiple species because ungulates were quantified as presence vs. absence or as a metabolic weight gradient, which gives the enormous flexibility to adapt metabolic weight to multiple ungulate species. However, the results presented in here can be mostly applied to areas with low primary productivity, low top-down control on ungulate populations and relatively small forest fragments, such as in Western Europe. 


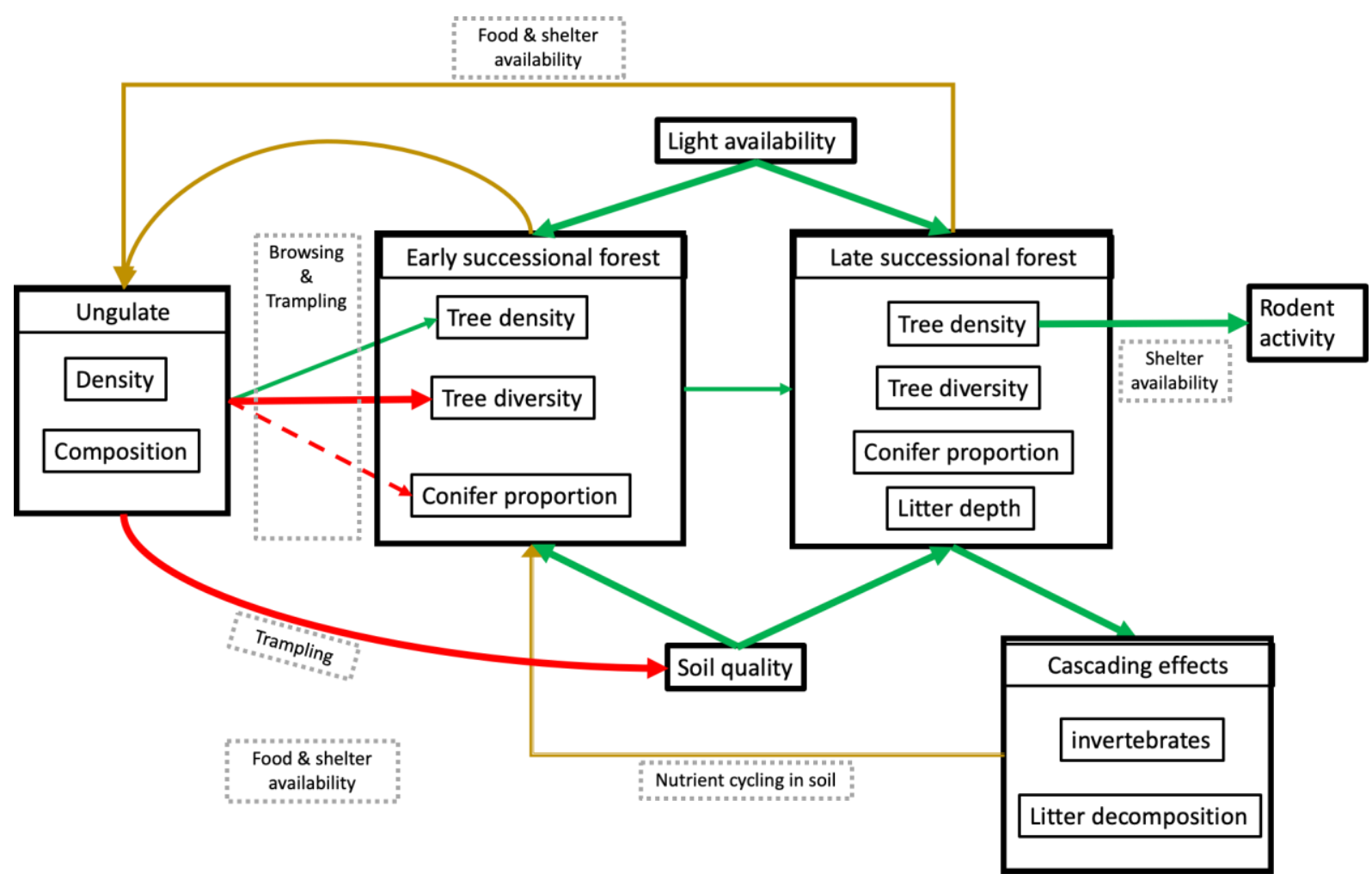

Figure 6.2. Conceptual diagram illustrating the main relationships found in the content chapters (Ch.2-5) of this thesis. Red arrows represent negative relationships mainly because of ungulate browsing and trampling, green arrows are for positive relationships and yellow arrows indicate theoretical feedback loops. Dashed arrows indicate no relationships. The thickness of the arrows determines the magnitude of the relationship (thick=strong and thin=weak relationships). Black solid rectangles are independent response variables or they group response variables within a category and dashed grey rectangles indicate the mechanism for the main interactions (arrows).

\section{Ungulates and temperate forests: a research outlook}

Ungulate relationships on the environment can be difficult to understand because of the system complexity (Weisberg \& Bugmann 2003). For instance the direction of the response depends on the legacy effects of the site, the intensity of browsing and the opportunity of regrowth, which includes plant and environmental characteristics (Hobbs 1996). To truly understand the role of ungulates in temperate forests it is necessary to include (1) a scalingdown approach that aims to understand the mechanisms involved in the interactions, i.e., lab and field experiments, and (2) a scaling-up approach which evaluates the interactions in the entire system, for example through field studies and modelling. Novel technologies can help to understand the complexities in ungulate forest interactions, and novel management 
strategies can also restore past ungulate populations in the northern hemisphere while maintaining desired forest targets. All these topics are addressed below.

\section{Scaling-down}

An approach that emphasizes the mechanisms involved in ungulate and forest interactions, is essential to understand the role of ungulates in temperate forests, as many times cofounding factors such as primary productivity might shift the relationships (Gill 1992a) by providing enough resources so plants can resist browsing. To limit the effect of confounding factors, researchers can implement experiments in controlled environments (e.g., laboratory and field) that isolate the ungulate mechanism from the confounding effects that are present in forests (Putman 1996; Weisberg \& Bugmann 2003). From the topics (partially) explored in this thesis, the next logical step would be to check for these mediating effects. For example: (1) primary productivity on ungulate-forest interactions can reveal the resistance capability of plants towards browsing as with higher nutrient availability plants can allocate more energy to resist herbivory (Lindroth \& St. Clair 2013). (2) Predation and human presence can shape the spatial and temporal scale in which ungulates browse by increasing their vigilance time when they are in high-risk predation areas (Brown 1988; Brown et al. 1999). (3) Changes in ungulate assemblage composition can shift the patch selection and the browsing intensity on trees because small ungulates might select poorer forest patches when ungulate composition is dominated by large ungulates in accordance with the optimal foraging theory (MacArthur \& Pianka 1966). (4) The successional stage of forests may shape ungulate impact on vegetation, for example old-growth forest with less light in the forest understory provides less food than young forests (Putman 1996), thus ungulates tend more to rest and hide in these areas than in young forest stands (Reimoser \& Gossow 1996). Providing critical points and thresholds when applicable can simplify the understanding of how complex systems behave, but at the same time provides guidelines on how to manage these ecosystems (Putman 1996; Reimoser et al. 1999).

\section{Scaling-up}

Some of the topics studied here should also be studied at different scales, especially at spatial and temporal scales (Hobbs 1996; Weisberg \& Bugmann 2003). By upscaling and including confounding factors, it is possible to better understand how forests really work because in the 
contrary by only implementing experimental and laboratory studies the understanding is limited to the mechanisms, which are isolated from the natural environment.

For example: ungulates at a landscape scale might increase overall plant diversity by creating opportunity for rare species and thus it is important to study not only alpha diversity, but as well beta and gamma diversity. For example, deer promote the establishment of small forest patches which sustain a great variety of species that are not present in areas without deer (Chollet et al. 2013). Performing animal and vegetation surveys at a landscape scale provides a better understanding of animal-plant interactions than typical field studies that conduct surveys on small forest sites. By implementing surveys on small forest sites, the relationship between ungulate and forests can be underestimated because the home range of ungulates (e.g. $4.5-10.4 \mathrm{~km}^{2}$ for red deer) normally exceeds the size of the forest site (Gill 1992a; Gill \& Morgan 2010). Fenced plots are a common approach used to study animal effects on vegetation; however, in many occasions these fenced plots are small in size due to their excessive labour costs. Fenced plots are typically associated with spatial scale effects and thus the relationship between ungulates and vegetation might also be misinterpreted (Wiens 1989). This can be solved by increasing the size of fenced plots or using natural islands which have presence and absence of ungulates (Allombert et al. 2005b). Similarly, animal and vegetation surveys are typically conducted in one moment of time, thus incorporating temporal scale effect to the results. By tagging individual trees and following them through time would solve temporal scale effects and provide a better understanding on ungulate effects at different forest successional stages (Schneider 2001).

Scaling-up and down is something that is frequently done in ecology in the $21^{\text {st }}$ century because experiments unravel the mechanisms, studies check whether these mechanisms are still ecologically relevant in the field or are overruled by other important factors, like interactions and feedback loops. However, this demands a substantial increase in human effort and money investment to both study the mechanisms and the surrounding environment. New and affordable technology may allow to overcome these scaling challenges. In the next section it is discussed the potential use of technology to study ungulateforest interactions. 


\section{Overcoming challenges with technology}

The largest obstacle within this research domain is acquiring systematically and replicable information which is also reliable and representative of ungulate-forest interactions (Gill 1992a; Putman et al. 2011b). To overcome this challenge, relying on technology might be the way forward. For example: drones can be used to survey landscape vegetation cover and track animal movement, camera-traps and audio-traps can be used to determine ungulate assemblage composition and GPS trackers and heart rate monitors can be used to track animal movement and activity. However, most scientific advances will occur by combining new technology with field tested methods, for instance by implementing GPS trackers to monitor animal activity, heart rate monitor to measure landscape of fear and transects to determine vegetation composition and browsing damage; it is possible to tackle complex research question: such as: in natural landscapes, which areas are commonly used by ungulates for feeding, escaping predation and for ungulate intra-specific competition?

\section{Restoring degraded forest ecosystems}

Ungulates are vital in forest ecosystems as they fulfil important functions such as seed dispersal, creating heterogeneity by browsing and relocating nutrients in the system by defecating. However these functions may be compromised in a case of ungulate overabundance (Côté et al. 2004). Thus, finding a balance between ungulate abundance and the desired forest vegetation attributes is of extreme importance in temperate regions. This can be achieved by managing forests and ungulates.

If management desires to have low ungulate impact on understory vegetation and to reduce soil compaction in the inner forest, modifying the forest edge can be a practical solution. By increasing light permeability, which promotes the development of high-quality foliage that can attract ungulates to the forest edge (Miyashita et al. 2008). Also, implementing and rotating animal exclosures after a couple of years at different temporal and spatial scales is an important strategy that promotes forest regeneration as it provides a window of opportunity so trees can escape or resist herbivory (Motta 2003). For example, trees with a height of $2 \mathrm{~m}$ are tall enough so their top shoot is out of the animals reach and robust enough to resist herbivory. Finally designing future forests which prioritize the establishment of target tree species in areas that ungulates avoid - such as areas with high predation risk - can significantly reduce damage in forests. For example, the rapid decrease of 
aspen trees in north America would be the ideal target species to prioritize in areas with high predation risks for ungulates (Baker et al. 1997).

Management strategies such as trophic rewilding with apex predators (Svenning et al. 2015) may reduce ungulate density and activity, thus securing the establishment and regeneration of trees and the development of the forest stand. Controlling ungulate population through management can also decrease the excessive top-down control that ungulates have on forest regeneration (Clutton-Brock et al. 2004). Introducing landscape of fear in areas sensitive to browsing, such as young broadleaved stands might keep ungulates away from these areas, and this can be done by shooting a fire arm, introducing predator smell or broadcasting a wolf howl (Sergio et al. 2008; Cromsigt et al. 2013). Prioritizing species with slow reproductive cycles and low food requirements (e.g., roe deer) can aid the stability of forest systems by limiting the number of ungulate individuals within one area and the impact on vegetation, whereas species with fast reproductive cycles and high food requirements (e.g., wild boar and fallow deer) can increase pressure on an already less resilient system. Finally, supplementary feeding during winter can also release the pressure that ungulates have on saplings by providing them an alternative food source (Reimoser 2003).

\section{Conclusions}

This thesis shows that in general, ungulates have in most cases no significant (i.e., neutral) impacts on forests, followed by negative impacts, and few positive impacts (Fig. 1). Forests are therefore quite resilient towards ungulate disturbance. Yet, when analysing the results at different scales (spatial, temporal and hierarchical), ungulates at high abundance may have stronger and more negative effects in forests because they reduce plant performance. Weaker and more positive effects occur at lower ungulate abundance, where they increase patch heterogeneity. The shape of the ungulate-forest dose-response curve is determined by site conditions; but notably, it presents a strong nonlinearity. Ungulates on forests might have more effects on the short-term, but when they accumulate their effects are stronger and cascade down to other trophic levels. For example, ungulates might arrest forest succession (from a forest composed of a climax community to an early successional stage composed of a pioneer community), especially if their effects continue to accumulate and if ungulate abundance continues to rise. In sum, despite the complexity of the system, ungulate 
relationships with forests are robust and enduring. Hence, when their interactions occur at extreme scales (high spatial, temporal and hierarchical scales), their effects on forest can be irreversible. 


\section{Appendix A}

\section{A.1}

A.1. Overall results indicating if response variables grouped by forest attribute present a significant positive, neutral or significantly negative relationship with wild ungulates. Results were extracted from the statistical models from the four content chapters (Ch. 2-5).

\begin{tabular}{|c|c|c|c|c|c|}
\hline Forest attribute & Effect & $\begin{array}{l}\text { Literature } \\
\text { review. Ch. } 2\end{array}$ & $\begin{array}{c}\text { Short-term } \\
\text { relationships. Ch. } 3\end{array}$ & $\begin{array}{l}\text { Long-term } \\
\text { effects. Ch. } 4\end{array}$ & $\begin{array}{l}\text { Cascading } \\
\text { effects. Ch. } 5\end{array}$ \\
\hline \multirow[t]{3}{*}{ Forest understory } & Positive & & 0 & 1 & 0 \\
\hline & Neutral & & 2 & 7 & 1 \\
\hline & Negative & & 2 & 0 & 1 \\
\hline \multirow[t]{3}{*}{ Forest structure } & Positive & 0 & 1 & 1 & 0 \\
\hline & Neutral & 1 & 1 & 1 & 0 \\
\hline & Negative & 2 & 0 & 0 & 1 \\
\hline \multirow[t]{3}{*}{ Forest composition } & Positive & 0 & 0 & 0 & 0 \\
\hline & Neutral & 1 & 1 & 1 & 0 \\
\hline & Negative & 1 & 2 & 2 & 1 \\
\hline \multirow[t]{3}{*}{ Browsing } & Positive & & 0 & & \\
\hline & Neutral & & 2 & & \\
\hline & Negative & & 0 & & \\
\hline \multirow[t]{3}{*}{ Invertebrates } & Positive & & & & 0 \\
\hline & Neutral & & & & 1 \\
\hline & Negative & & & & 1 \\
\hline \multirow[t]{3}{*}{ Soil quality } & Positive & & & & 1 \\
\hline & Neutral & & & & 1 \\
\hline & Negative & & & & 0 \\
\hline \multirow[t]{3}{*}{ Decomposition rate } & Positive & 0 & & & 0 \\
\hline & Neutral & 0 & & & 4 \\
\hline & Negative & 1 & & & 0 \\
\hline \multirow[t]{3}{*}{ Mineralization rate } & Positive & & & & 0 \\
\hline & Neutral & & & & 7 \\
\hline & Negative & & & & 2 \\
\hline \multirow[t]{3}{*}{ Forest food } & Positive & 0 & & & \\
\hline & Neutral & 1 & & & \\
\hline & Negative & 0 & & & \\
\hline \multirow[t]{3}{*}{ Mammals } & Positive & & & & 0 \\
\hline & Neutral & & & & 0 \\
\hline & Negative & & & & 1 \\
\hline
\end{tabular}




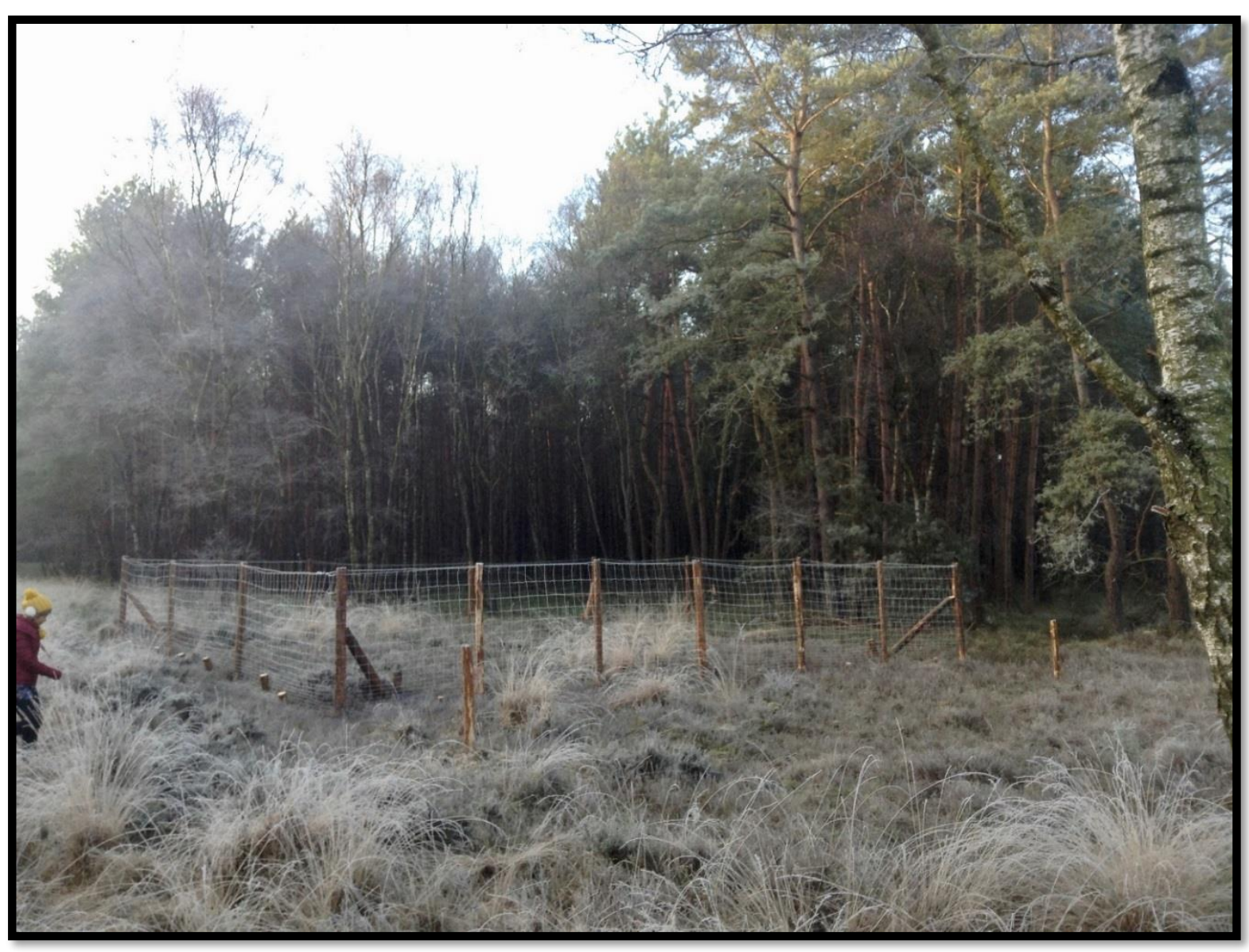


REFERENCES 
Aerts R. 2006. The freezer defrosting: global warming and litter decomposition rates in cold biomes. Journal of Ecology 94:713-724.

Akashi N, Nakashizuka T. 1999. Effects of bark-stripping by Sika deer (Cervus nippon) on population dynamics of a mixed forest in Japan. Forest Ecology and Management 113:75-82.

Allombert S, Gaston AJ, Martin JL. 2005a. A natural experiment on the impact of overabundant deer on songbird populations. Biological Conservation 126:1-13.

Allombert S, Stockton S, Martin JL. 2005b. A natural experiment on the impact of overabundant deer on forest invertebrates. Conservation Biology 19:1917-1929.

Altendorf KB, Laundré JW, López González CA, Brown JS. 2001. Assessing effects of predation risk on foraging behavior of mule deer. Journal of Mammalogy 82:430-439.

Althoff PS, Thien SJ. 2005. Impact of M1A1 main battle tank disturbance on soil quality, invertebrates, and vegetation characteristics. Journal of Terramechanics 42:159-176.

Alverson WS, Waller DM, Solheim SL. 1988. Forests too deer: edge effects in northern Wisconsin. Conservation Biology 2:348-358.

Apollonio M, Andersen R, Putman R 2010. European ungulates and their management in the 21st century. Cambridge University Press.

Augustin NH, Cummins RP, French DD. 2001. Exploring spatial vegetation dynamics using logistic regression and a multinomial logit model. Journal of Applied Ecology 38:991-1006.

Augustine DJ, Frelich LE. 1998. Effects of white-tailed deer on populations of an understory forb in fragmented deciduous forests. Conservation Biology 12:995-1004.

Augustine DJ, McNaughton SJ. 1998. Ungulate effects on the functional species composition of plant communities: herbivore selectivity and plant tolerance. The Journal of wildlife management:11651183.

Baker WL, Munroe JA, Hessl AE. 1997. The effects of elk on aspen in the winter range in Rocky Mountain National Park. Ecography 20:155-165.

Bärlocher F. 2005. Leaf mass loss estimated by litter bag technique. Pages 37-42. Methods to study litter decomposition. Springer.

Bassett I, Simcock R, Mitchell N. 2005. Consequences of soil compaction for seedling establishment: Implications for natural regeneration and restoration. Austral Ecology 30:827-833.

Biuw M, et al. 2014. Long-term Impacts of Contrasting Management of Large Ungulates in the Arctic TundraForest Ecotone: Ecosystem Structure and Climate Feedback. Ecosystems 17:890-905.

Borcard D, Gillet F, Legendre P. 2018. Unconstrained ordination. Pages 151-201. Numerical Ecology with R. Springer.

Bressette JW, Beck H, Beauchamp VB. 2012. Beyond the browse line: complex cascade effects mediated by white-tailed deer. Oikos 121:1749-1760.

Brown JS. 1988. Patch use as an indicator of habitat preference, predation risk, and competition. Behavioral ecology and sociobiology 22:37-47.

Brown JS, Laundré JW, Gurung M. 1999. The ecology of fear: optimal foraging, game theory, and trophic interactions. Journal of mammalogy 80:385-399.

Bruce D. 1955. A new way to look at trees. Journal of Forestry 53:163-167.

Bruinderink G, Hazebroek E. 1996. Wild boar (Sus scrofa scrofa L.) rooting and forest regeneration on podzolic soils in the Netherlands. Forest Ecology and Management 88:71-80.

Brullhardt M, Risch AC, Filli F, Haller RM, Schutz M. 2015. Spatiotemporal dynamics of natural tree regeneration in unmanaged subalpine conifer forests with high wild ungulate densities. Canadian Journal of Forest Research 45:607-614.

Brussaard L. 1997. Biodiversity and ecosystem functioning in soil. Ambio:563-570.

Buesching CD, Newman C, Jones JT, Macdonald DW. 2011. Testing the effects of deer grazing on two woodland rodents, bankvoles and woodmice. Basic and Applied Ecology 12:207-214.

Chollet S, Baltzinger C, Ostermann L, Saint-Andre F, Martin JL. 2013. Importance for forest plant communities of refuges protecting from deer browsing. Forest Ecology and Management 289:470-477.

Chollet S, Bergman C, Gaston AJ, Martin JL. 2015. Long-term consequences of invasive deer on songbird communities: Going from bad to worse? Biological Invasions 17:777-790.

Clutton-Brock T, Albon S. 1992. Trial and error in the Highlands. Nature 358:11-12.

Clutton-Brock TH, Coulson T, Milner JM. 2004. Red deer stocks in the highlands of Scotland. Nature 429:261262.

Comisky L, Royo AA, Carson WP. 2005. Deer browsing creates rock refugia gardens on large boulders in the Allegheny National Forest, Pennsylvania. American Midland Naturalist 154:201-206. 
Connell JH. 1978. Diversity in tropical rain forests and coral reefs. Science 199:1302-1310.

Cook RC, Cook JG, Irwin LL. 2003. Estimating elk body mass using chest-girth circumference. Wildlife Society Bulletin:536-543.

Côté SD, Rooney TP, Tremblay J-P, Dussault C, Waller DM. 2004. Ecological impacts of deer overabundance. Annual Review of Ecology, Evolution, and Systematics:113-147.

Courchamp F, Clutton-Brock T, Grenfell B. 1999. Inverse density dependence and the Allee effect. Trends in ecology \& evolution 14:405-410.

Coverdale TC, Kartzinel TR, Grabowski KL, Shriver RK, Hassan AA, Goheen JR, Palmer TM, Pringle RM. 2016. Elephants in the understory: opposing direct and indirect effects of consumption and ecosystem engineering by megaherbivores. Ecology 97:3219-3230.

Cromsigt JP, Kuijper DP. 2011. Revisiting the browsing lawn concept: Evolutionary Interactions or pruning herbivores? Perspectives in Plant Ecology, Evolution and Systematics 13:207-215.

Cromsigt JP, Kuijper DP, Adam M, Beschta RL, Churski M, Eycott A, Kerley GI, Mysterud A, Schmidt K, West K. 2013. Hunting for fear: innovating management of human-wildlife conflicts. Journal of Applied Ecology 50:544-549.

Cyr H, Face ML. 1993. Magnitude and patterns of herbivory in aquatic and terrestrial ecosystems. Nature 361:148.

Damuth J. 1987. Interspecific allometry of population density in mammals and other animals: the independence of body mass and population energy-use. Biological Journal of the Linnean Society 31:193-246.

Danell K, Bergstrom R, Edenius L, Ericsson G. 2003. Ungulates as drivers of tree population dynamics at module and genet levels. Forest Ecology and Management 181:67-76.

De Jong C, Gill R, Van Wieren S, Burlton F. 1995. Diet selection by roe deer Capreolus capreolus in Kielder Forest in relation to plant cover. Forest Ecology and Management 79:91-97.

Dormann CF, Elith J, Bacher S, Buchmann C, Carl G, Carré G, Marquéz JRG, Gruber B, Lafourcade B, Leitão PJ. 2013. Collinearity: a review of methods to deal with it and a simulation study evaluating their performance. Ecography 36:27-46.

Estes JA, Terborgh J, Brashares JS, Power ME, Berger J, Bond WJ, Carpenter SR, Essington TE, Holt RD, Jackson JB. 2011. Trophic downgrading of planet Earth. science 333:301-306.

Eycott AE, Watkinson AR, Hemami MR, Dolman PM. 2007. The dispersal of vascular plants in a forest mosaic by a guild of mammalian herbivores. Oecologia 154:107-118.

Facelli JM, Pickett ST. 1991. Plant litter: its dynamics and effects on plant community structure. The botanical review 57:1-32.

Flowerdew J, Ellwood S. 2001. Impacts of woodland deer on small mammal ecology. Forestry 74:277-287.

Folke C, Carpenter S, Walker B, Scheffer M, Elmqvist T, Gunderson L, Holling C. 2004. Regime shifts, resilience, and biodiversity in ecosystem management. Annual Review of Ecology, Evolution, and Systematics:557-581.

Frank DA, Groffman PM, Evans RD, Tracy BF. 2000. Ungulate stimulation of nitrogen cycling and retention in Yellowstone Park grasslands. Oecologia 123:116-121.

Frouz J, Roubíčková A, Heděnec $P$, Tajovský K. 2015. Do soil fauna really hasten litter decomposition? A metaanalysis of enclosure studies. European Journal of Soil Biology 68:18-24.

Fuller R. 2001. Responses of woodland birds to increasing numbers of deer: a review of evidence and mechanisms. Forestry 74:289-298.

Fuller RJ, Gill RM. 2001. Ecological impacts of increasing numbers of deer in British woodland. Forestry 74:193199.

Garcia-Gonzalez R, Cuartas P. 1996. Trophic utilization of a montane/subalpine forest by chamois (Rupicapra pyrenaica) in the Central Pyrenees. Forest Ecology and Management 88:15-23.

Gartner TB, Cardon ZG. 2004. Decomposition dynamics in mixed-species leaf litter. Oikos 104:230-246.

Genov PV, Massei G. 2004. The environmental impact of wild boar. Galemys: Boletín informativo de la Sociedad Española para la conservación y estudio de los mamíferos 16:135-145.

Gessner MO, Swan CM, Dang CK, McKie BG, Bardgett RD, Wall DH, Hättenschwiler S. 2010. Diversity meets decomposition. Trends in ecology \& evolution 25:372-380.

Gill R. 1992a. A review of damage by mammals in north temperate forests: 1 . Deer. Forestry: An International Journal of Forest Research 65:145-169.

Gill R. 1992b. A review of damage by mammals in north temperate forests: 3 . Impact on trees and forests. Forestry 65:363-388. 
Gill R, Beardall V. 2001. The impact of deer on woodlands: the effects of browsing and seed dispersal on vegetation structure and composition. Forestry 74:209-218.

Gill R, Morgan G. 2010. The effects of varying deer density on natural regeneration in woodlands in lowland Britain. Forestry 83:53-63.

Gordon IJ, Prins HH 2008. Introduction: Grazers and browsers in a changing world. Springer.

Griffin G, Jokela W, Ross D, Pettinelli D, Morris T, Wolf A. 1995. Recommended soil nitrate tests. Recommended soil testing procedures for the Northeastern United States.

Groot Bruinderink GWTA, Hazebroek E. 1996. Wild boar (Sus scrofa scrofa L.) rooting and forest regeneration on podzolic soils in the Netherlands. Forest Ecology and Management 88:71-80.

Hager MC, Helfman GS. 1991. Safety in numbers: shoal size choice by minnows under predatory threat. Behavioral Ecology and Sociobiology 29:271-276.

Hardin G. 1960. The competitive exclusion principle. science 131:1292-1297.

Hasanuzzaman M, Hossain M. 2014. Leaf litter decomposition and nutrient dynamics associated with common horticultural cropland agroforest tree species of Bangladesh. International Journal of Forestry Research 2014.

Hättenschwiler S, Tiunov AV, Scheu S. 2005. Biodiversity and litter decomposition in terrestrial ecosystems. Annu. Rev. Ecol. Evol. Syst. 36:191-218.

Heckel CD, Bourg NA, McShea WJ, Kalisz S. 2010. Nonconsumptive effects of a generalist ungulate herbivore drive decline of unpalatable forest herbs. Ecology 91:319-326.

Hedl R, Kopecky M, Komarek J. 2010. Half a century of succession in a temperate oakwood: from species-rich community to mesic forest. Diversity and Distributions 16:267-276.

Hefley TJ, Hygnstrom SE, Gilsdorf JM, Clements GM, Clements MJ, Tyre AJ, Baasch DM, VerCauteren KC. 2013. Effects of deer density and land use on mass of white-tailed deer. Journal of Fish and Wildlife Management 4:20-32.

Hobbs NT. 1996. Modification of ecosystems by ungulates. The Journal of Wildlife Management:695-713.

Hofmeester TR, Rowcliffe JM, Jansen PA. 2016. A simple method for estimating the effective detection distance of camera traps. Remote Sensing in Ecology and Conservation.

Holling CS. 1973. Resilience and stability of ecological systems. Annual review of ecology and systematics 4:123.

Holloway CW. 1967. The effect of red deer and other animals on naturally regenerated Scots pine. University of Aberdeen, United Kingdom.

Horsley SB, Stout SL, DeCalesta DS. 2003. White-tailed deer impact on the vegetation dynamics of a northern hardwood forest. Ecological Applications 13:98-118.

Husheer SW, Hansen QW, Urlich SC. 2005. Effects of red deer on tree regeneration and growth in Aorangi Forest, Wairarapa. New Zealand Journal of Ecology 29:271-277.

lida S. 2006. Dispersal patterns of Quercus serrata acorns by wood mice in and around canopy gaps in a temperate forest. Forest Ecology and Management 227:71-78.

Ingham RE, Trofymow J, Ingham ER, Coleman DC. 1985. Interactions of bacteria, fungi, and their nematode grazers: effects on nutrient cycling and plant growth. Ecological monographs 55:119-140.

Ishii H, Asano S. 2010. The role of crown architecture, leaf phenology and photosynthetic activity in promoting complementary use of light among coexisting species in temperate forests. Ecological Research 25:715-722.

Jones CG, Lawton JH, Shachak M. 1994. Organisms as ecosystem engineers. Pages 130-147. Ecosystem management. Springer.

Jonsson M, Malmqvist B. 2000. Ecosystem process rate increases with animal species richness: evidence from leaf-eating, aquatic insects. Oikos 89:519-523.

Kalisz S, Spigler RB, Horvitz CC. 2014. In a long-term experimental demography study, excluding ungulates reversed invader's explosive population growth rate and restored natives. Proceedings of the National Academy of Sciences of the United States of America 111:4501-4506.

Kamau S, Barrios E, Karanja NK, Ayuke FO, Lehmann J. 2017. Soil macrofauna abundance under dominant tree species increases along a soil degradation gradient. Soil Biology and Biochemistry 112:35-46.

Kamler J, Homolka M, Barancekova M, Krojerova-Prokesova J. 2010. Reduction of herbivore density as a tool for reduction of herbivore browsing on palatable tree species. European Journal of Forest Research 129:155-162.

Kardol P, Dickie IA, John MGS, Husheer SW, Bonner KI, Bellingham PJ, Wardle DA. 2014. Soil-mediated effects of invasive ungulates on native tree seedlings. Journal of Ecology 102:622-631. 
Kays R, Kranstauber B, Jansen P, Carbone C, Rowcliffe M, Fountain T, Tilak S. 2009. Camera traps as sensor networks for monitoring animal communities. 2009 leee 34th Conference on Local Computer Networks (Lcn 2009):811-818,1117

Kennard DK. 2002. Secondary forest succession in a tropical dry forest: patterns of development across a 50year chronosequence in lowland Bolivia. Journal of tropical ecology 18:53-66.

Keuskamp JA, Dingemans BJ, Lehtinen T, Sarneel JM, Hefting MM. 2013. Tea Bag Index: a novel approach to collect uniform decomposition data across ecosystems. Methods in Ecology and Evolution 4:10701075.

Kleiber M. 1947. Body size and metabolic rate. Physiol. rev 27:511-541.

Klopcic M, Jerina K, Boncina A. 2010. Long-term changes of structure and tree species composition in Dinaric uneven-aged forests: are red deer an important factor? European Journal of Forest Research 129:277288.

Knight TM, Dunn JL, Smith LA, Davis J, Kalisz S. 2009. Deer facilitate invasive plant success in a Pennsylvania forest understory. Natural Areas Journal 29:110-116.

KNMI. 2018. Royal Netherlands Meteorological Institute, the Netherlands. Available from www.knmi.nl (accessed 03-08-2018 2018).

Koster SH, Hart JA. 1988. Methods of estimating ungulate populations in tropical forests. African Journal of Ecology 26:117-126.

Kuijper D, De Kleine C, Churski M, Van Hooft P, Bubnicki J, Jędrzejewska B. 2013. Landscape of fear in Europe: wolves affect spatial patterns of ungulate browsing in Białowieża Primeval Forest, Poland. Ecography 36:1263-1275.

Kuijper DPJ, Cromsigt J, Jedrzejewska B, Miscicki S, Churski M, Jedrzejewski W, Kweczlich I. 2010a. Bottom-up versus top-down control of tree regeneration in the Bialowieza Primeval Forest, Poland. Journal of Ecology 98:888-899.

Kuijper DPJ, Jedrzejewska B, Brzeziecki B, Churski M, Jedrzejewski W, Zybura H. 2010b. Fluctuating ungulate density shapes tree recruitment in natural stands of the Bialowieza Primeval Forest, Poland. Journal of Vegetation Science 21:1082-1098.

Kuiters A, Mohren G, Van Wieren S. 1996. Ungulates in temperate forest ecosystems. Forest Ecology and Management 88:1-5.

Kuiters A, Sarink H. 1986. Leaching of phenolic compounds from leaf and needle litter of several deciduous and coniferous trees. Soil Biology and Biochemistry 18:475-480.

Kuiters AT, Slim PA. 2002. Regeneration of mixed deciduous forest in a Dutch forest-heathland,following a reduction of ungulate densities. Biological Conservation 105:65-74.

Lajtha K. 1988. The use of ion-exchange resin bags for measuring nutrient availability in an arid ecosystem. Plant and Soil 105:105-111.

Lal R. 1988. Effects of macrofauna on soil properties in tropical ecosystems. Agriculture, ecosystems \& environment 24:101-116.

Lavelle P, Decaëns T, Aubert M, Barot Sb, Blouin M, Bureau F, Margerie P, Mora P, Rossi J-P. 2006. Soil invertebrates and ecosystem services. European journal of soil biology 42:S3-S15.

Lavelle P, Spain A, Blanchart E, Martin A, Martin S. 1992. Impact of soil fauna on the properties of soils in the humid tropics. SSSA Special Publication 29:157-157.

Lieth H, Whittaker RH 2012. Primary productivity of the biosphere. Springer Science \& Business Media, New York.

Lilleeng MS, Rydgren K, Halvorsen R, Moe SR, Hegland SJ. 2018. Red deer structure the ground-dwelling beetle community in boreal forest. Biodiversity and Conservation:1-19.

Lindroth RL, Clair SBS. 2013. Adaptations of quaking aspen (Populus tremuloides Michx.) for defense against herbivores. Forest Ecology and Management 299:14-21.

Lindroth RL, St. Clair SB. 2013. Adaptations of quaking aspen (Populus tremuloides Michx.) for defense against herbivores. Forest Ecology and Management 299:14-21.

Lott DF, Galland JC. 1987. Body mass as a factor influencing dominance status in American bison cows. Journal of Mammalogy 68:683-685.

Lucas R, Davis JF. 1961. Relationships between pH values of organic soils and availabilities of 12 plant nutrients. Soil Science 92:177-182.

Lucas RW, Salguero-Gomez R, Cobb DB, Waring BG, Anderson F, McShea WJ, Casper BB. 2013. White-tailed deer (Odocoileus virginianus) positively affect the growth of mature northern red oak (Quercus rubra) trees. Ecosphere 4:15. 
MacArthur RH, Pianka ER. 1966. On optimal use of a patchy environment. The American Naturalist 100:603609.

Maes SL, Blondeel H, Perring MP, Depauw L, Brūmelis G, Brunet J, Decocq G, den Ouden J, Härdtle W, Hédl R. 2019. Litter quality, land-use history, and nitrogen deposition effects on topsoil conditions across European temperate deciduous forests. Forest Ecology and Management 433:405-418.

Mason NW, Peltzer DA, Richardson SJ, Bellingham PJ, Allen RB. 2010. Stand development moderates effects of ungulate exclusion on foliar traits in the forests of New Zealand. Journal of Ecology 98:1422-1433.

Mathisen KM, Buhtz F, Danell K, Bergstrom R, Skarpe C, Suominen O, Persson IL. 2010. Moose density and habitat productivity affects reproduction, growth and species composition in field layer vegetation. Journal of Vegetation Science 21:705-716.

McGarvey JC, Bourg NA, Thompson JR, McShea WJ, Shen XL. 2013. Effects of Twenty Years of Deer Exclusion on Woody Vegetation at Three Life-History Stages in a Mid-Atlantic Temperate Deciduous Forest. Northeastern Naturalist 20:451-468.

McGraw JB, Furedi MA. 2005. Deer browsing and population viability of a forest understory plant. Science 307:920-922.

McShea WJ, Rappole JH. 2000. Managing the abundance and diversity of breeding bird populations through manipulation of deer populations. Conservation Biology 14:1161-1170.

Merino ML, Milne N, Vizcaíno SF. 2005. A cranial morphometric study of deer (Mammalia, Cervidae) from Argentina using three-dimensional landmarks. Acta Theriologica 50:91-108.

Millington JDA, Walters MB, Matonis MS, Laurent EJ, Hall KR, Liu JG. 2011. Combined long-term effects of variable tree regeneration and timber management on forest songbirds and timber production. Forest Ecology and Management 262:718-729.

Mills SE, Macdonald SE. 2004. Predictors of moss and liverwort species diversity of microsites in coniferdominated boreal forest. Journal of Vegetation Science 15:189-198.

Miyashita T, Suzuki M, Ando D, Fujita G, Ochiai K, Asada M. 2008. Forest edge creates small-scale variation in reproductive rate of sika deer. Population ecology 50:111-120.

Moretto AS, Distel RA, Didoné NG. 2001. Decomposition and nutrient dynamic of leaf litter and roots from palatable and unpalatable grasses in a semi-arid grassland. Applied Soil Ecology 18:31-37.

Motta R. 2003. Ungulate impact on rowan (Sorbus aucuparia L.) and Norway spruce (Picea abies (L.) Karst.) height structure in mountain forests in the eastern Italian Alps. Forest Ecology and Management 181:139-150.

Murray BD, Webster CR, Bump JK. 2014. A Migratory Ungulate Facilitates Cross-Boundary Nitrogen Transport in Forested Landscapes. Ecosystems 17:1002-1013.

Naaf T, Wulf M. 2007. Effects of gap size, light and herbivory on the herb layer vegetation in European beech forest gaps. Forest Ecology and Management 244:141-149.

Nathan R, Muller-Landau HC. 2000. Spatial patterns of seed dispersal, their determinants and consequences for recruitment. Trends in ecology \& evolution 15:278-285.

Niinemets Ü, Valladares F. 2006. Tolerance to shade, drought, and waterlogging of temperate Northern Hemisphere trees and shrubs. Ecological monographs 76:521-547.

Nuttle T, Ristau TE, Royo AA. 2014. Long-term biological legacies of herbivore density in a landscape-scale experiment: forest understoreys reflect past deer density treatments for at least 20 years. Journal of Ecology 102:221-228.

Oberski D. 2014. lavaan. survey: An R package for complex survey analysis of structural equation models. Journal of Statistical Software 57:1-27.

Oksanen J, Blanchet FG, Kindt R, Legendre P, Minchin PR, O’hara R, Simpson GL, Solymos P, Stevens MHH, Wagner H. 2013. Package 'vegan'. Community ecology package, version 2.

Parker KL, Gillingham MP, Hanley TA, Robbins CT. 1993. Seasonal patterns in body mass, body composition, and water transfer rates of free-ranging and captive black-tailed deer (Odocoileus hemionus sitkensis) in Alaska. Canadian Journal of Zoology 71:1397-1404.

Pastor J, Dewey B, Naiman R, McInnes P, Cohen Y. 1993. Moose browsing and soil fertility in the boreal forests of Isle Royale National Park. Ecology 74:467-480.

Pastor J, Naiman RJ, Dewey B, McInnes P. 1988. Moose, microbes, and the boreal forest. BioScience 38:770777.

Patten BC, Odum EP. 1981. The cybernetic nature of ecosystems. The American Naturalist 118:886-895.

Pellerin M, Saïd S, Gaillard J-M. 2008. Roe deer Capreolus capreolus home-range sizes estimated from VHF and GPS data. Wildlife Biology 14:101-110. 
Pellerin M, Said S, Richard E, Hamann J-L, Dubois-Coli C, Hum P. 2010a. Impact of deer on temperate forest vegetation and woody debris as protection of forest regeneration against browsing. Forest Ecology \& Management 260:429-437.

Pellerin M, Said S, Richard E, Hamann JL, Dubois-Coli C, Hum P. 2010b. Impact of deer on temperate forest vegetation and woody debris as protection of forest regeneration against browsing. Forest Ecology and Management 260:429-437.

Pianka ER. 1970. On r-and K-selection. The American Naturalist 104:592-597.

Picton HD. 1984. Climate and the prediction of reproduction of three ungulate species. Journal of Applied Ecology:869-879.

Pinheiro J, Bates B, DebRoy S, Sarkar D, R Core Team. 2018. nlme: Linear and Nonlinear Mixed Effects Models.

Pinheiro J, Bates D, DebRoy S, Sarkar D. 2014. Linear and nonlinear mixed effects models. Springer 3.

Power ME, Tilman D, Estes JA, Menge BA, Bond WJ, Mills LS, Daily G, Castilla JC, Lubchenco J, Paine RT. 1996. Challenges in the quest for keystones. BioScience 46:609-620.

Pringle RM, Young TP, Rubenstein DI, McCauley DJ. 2007. Herbivore-initiated interaction cascades and their modulation by productivity in an African savanna. Proceedings of the National Academy of Sciences 104:193-197.

Prins HH, Fritz H. 2008. Species diversity of browsing and grazing ungulates: consequences for the structure and abundance of secondary production. Pages 179-200. The ecology of browsing and grazing. Springer.

Putman R. 1996. Ungulates in temperate forest ecosystems: perspectives and recommendations for future research. Forest Ecology and Management 88:205-214.

Putman R, Edwards P, Mann J, How R, Hill S. 1989. Vegetational and faunal changes in an area of heavily grazed woodland following relief of grazing. Biological Conservation 47:13-32.

Putman R, Langbein J, Green P, Watson P. 2011a. Identifying threshold densities for wild deer in the UK above which negative impacts may occur. Mammal Review 41:175-196.

Putman R, Watson P, Langbein J. 2011b. Assessing deer densities and impacts at the appropriate level for management: a review of methodologies for use beyond the site scale. Mammal Review 41:197-219.

R Core Team. 2017. R: A Language and Environment for Statistical Computing, Vienna, Austria.

Ramirez JI, Jansen PA, den Ouden J, Goudzwaard L, Poorter L. 2019. Long-term effects of wild ungulates on the structure, composition and succession of temperate forests. Forest Ecology and Management 432:478-488.

Ramirez JI, Jansen PA, Poorter L. 2018. Effects of wild ungulates on the regeneration, structure and functioning of temperate forests: A semi-quantitative review. Forest Ecology and Management 424:406-419.

Reimoser F. 2003. Steering the impacts of ungulates on temperate forests. Journal for Nature Conservation 10:243-252.

Reimoser F, Armstrong H, Suchant R. 1999. Measuring forest damage of ungulates: What should be considered. Forest Ecology and Management 120:47-58.

Reimoser F, Gossow H. 1996. Impact of ungulates on forest vegetation and its dependence on the silvicultural system. Forest Ecology and Management 88:107-119.

Reimoser F, Putman R. 2011. Impacts of wild ungulates on vegetation: costs and benefits. Ungulate management in Europe: problems and practices. Cambridge University Press, Cambridge:144-191.

Reiss J, Bridle JR, Montoya JM, Woodward G. 2009. Emerging horizons in biodiversity and ecosystem functioning research. Trends in ecology \& evolution 24:505-514.

Renaud P, Verheyden-Tixier H, Dumont B. 2003. Damage to saplings by red deer (Cervus elaphus): effect of foliage height and structure. Forest ecology and management 181:31-37.

Riginos C, Grace JB. 2008. Savanna tree density, herbivores, and the herbaceous community: bottom-up vs. top-down effects. Ecology 89:2228-2238.

Ritchie ME, Tilman D, Knops JM. 1998. Herbivore effects on plant and nitrogen dynamics in oak savanna. Ecology 79:165-177.

Rooney TP. 2001. Deer impacts on forest ecosystems: a North American perspective. Forestry 74:201-208.

Rooney TP, Waller DM. 2003. Direct and indirect effects of white-tailed deer in forest ecosystems. Forest Ecology and Management 181:165-176.

Rosseel Y. 2012. Lavaan: An R package for structural equation modeling and more. Version 0.5-12 (BETA). Journal of statistical software 48:1-36.

Rossow LJ, Bryant JP, Kielland K. 1997. Effects of above-ground browsing by mammals on mycorrhizal infection in an early successional taiga ecosystem. Oecologia 110:94-98.

Rowcliffe JM, Field J, Turvey ST, Carbone C. 2008. Estimating animal density using camera traps without the need for individual recognition. Journal of Applied Ecology 45:1228-1236. 
Rowcliffe MJ, Carbone C, Jansen PA, Kays R, Kranstauber B. 2011. Quantifying the sensitivity of camera traps: an adapted distance sampling approach. Methods in Ecology and Evolution 2:464-476.

Russell FL, Zippin DB, Fowler NL. 2001. Effects of white-tailed deer (Odocoileus virginianus) on plants, plant populations and communities: a review. The American Midland Naturalist 146:1-26.

Salk TT, Frelich LE, Sugita S, Calcote R, Ferrari JB, Montgomery RA. 2011. Poor recruitment is changing the structure and species composition of an old-growth hemlock-hardwood forest. Forest Ecology and Management 261:1998-2006.

Scheffer M, Carpenter S, Foley JA, Folke C, Walker B. 2001. Catastrophic shifts in ecosystems. Nature 413:591596.

Schippers P, van Teeffelen AJA, Verboom J, Vos CC, Kramer K, WallisDeVries MF. 2014. The impact of large herbivores on woodland-grassland dynamics in fragmented landscapes: The role of spatial configuration and disturbance. Ecological Complexity 17:20-31.

Schneider DC. 2001. The rise of the concept of scale in ecology: The concept of scale is evolving from verbal expression to quantitative expression. BioScience 51:545-553.

Schramm JW, Ehrenfeld JG. 2010. Leaf litter and understory canopy shade limit the establishment, growth and reproduction of Microstegium vimineum. Biological Invasions 12:3195-3204.

Scott D, Welch D, Elston DA. 2009. Long-term effects of leader browsing by deer on the growth of Sitka spruce (Picea sitchensis). Forestry 82:387-401.

Sergio F, Caro T, Brown D, Clucas B, Hunter J, Ketchum J, McHugh K, Hiraldo F. 2008. Top predators as conservation tools: ecological rationale, assumptions, and efficacy. Annual review of ecology, evolution, and systematics:1-19.

Shannon CE. 1948. A mathematical theory of communication. Bell system technical journal 27:379-423.

Shipley B 2016. Cause and correlation in biology: a user's guide to path analysis, structural equations and causal inference with R. Cambridge University Press.

Smilde K. 1973. Phosphorus and micronutrient metal uptake by some tree species as affected by phosphate and lime applied to an acid sandy soil. Plant and soil 39:131-148.

Soto-Ortiz L. 2015. The regulation of ecological communities through feedback loops: a review. Res. Zool 5:115.

Stephenson TR, Hundertmark KJ, Schwartz CC, Ballenberghe VV. 1998. Predicting body fat and body mass in moose with ultrasonography. Canadian Journal of Zoology 76:717-722.

Suzuki M, Onuma M, Yokoyama M, Kaji K, Yamanaka M, Ohtaishi N. 2001. Body size, sexual dimorphism, and seasonal mass fluctuations in a larger sika deer subspecies, the Hokkaido sika deer (Cervus nippon yesoensis Heude, 1884). Canadian Journal of Zoology 79:154-159.

Svenning J-C, Pedersen PB, Donlan CJ, Ejrnæs R, Faurby S, Galetti M, Hansen DM, Sandel B, Sandom CJ, Terborgh JW. 2015. Science for a wilder Anthropocene: Synthesis and future directions for trophic rewilding research. Proceedings of the National Academy of Sciences:201502556.

Terborgh J, Lopez L, Nunez P, Rao M, Shahabuddin G, Orihuela G, Riveros M, Ascanio R, Adler GH, Lambert TD. 2001. Ecological meltdown in predator-free forest fragments. Science 294:1923-1926.

Tilghman NG. 1989. Impacts of white-tailed deer on forest regeneration in northwestern Pennsylvania. The Journal of Wildlife Management:524-532.

Tremblay J-P, Huot J, Potvin F. 2006. Divergent nonlinear responses of the boreal forest field layer along an experimental gradient of deer densities. Oecologia 150:78-88.

Tyler CM, Davis FW, Mahall BE. 2008. The relative importance of factors affecting age-specific seedling survival of two co-occurring oak species in southern California. Forest Ecology and Management 255:30633074.

van der Sande MT, Peña-Claros M, Ascarrunz N, Arets EJ, Licona JC, Toledo M, Poorter L. 2017. Abiotic and biotic drivers of biomass change in a Neotropical forest. Journal of Ecology 105:1223-1234.

Van Hees AFM, Kuiters AT, Slim PA. 1996. Growth and development of silver birch, pedunculate oak and beech as affected by deer browsing. Forest Ecology and Management 88:55-63.

Van Klink R, Schrama M, Nolte S, Bakker JP, WallisDeVries M, Berg M. 2015. Defoliation and soil compaction jointly drive large-herbivore grazing effects on plants and soil arthropods on clay soil. Ecosystems 18:671-685.

Van Langevelde F, Van De Vijver CA, Kumar L, Van De Koppel J, De Ridder N, Van Andel J, Skidmore AK, Hearne JW, Stroosnijder L, Bond WJ. 2003. Effects of fire and herbivory on the stability of savanna ecosystems. Ecology 84:337-350.

Vasconcelos HL, Laurance WF. 2005. Influence of habitat, litter type, and soil invertebrates on leaf-litter decomposition in a fragmented Amazonian landscape. Oecologia 144:456-462. 
Waller DM, Alverson WS. 1997. The white-tailed deer: a keystone herbivore. Wildlife Society Bulletin (19732006) 25:217-226.

Wardle D, Bonner K, Barker G. 2002. Linkages between plant litter decomposition, litter quality, and vegetation responses to herbivores. Functional Ecology 16:585-595.

Weisberg PJ, Bugmann H. 2003. Forest dynamics and ungulate herbivory: from leaf to landscape. Forest Ecology and Management 181:1-12.

Welch D, Scott D. 1998. Bark-stripping damage by red deer in a Sitka spruce forest in western Scotland - IV. Survival and performance of wounded trees. Forestry 71:225-235.

White MA. 2012. Long-term effects of deer browsing: Composition, structure and productivity in a northeastern Minnesota old-growth forest. Forest Ecology and Management 269:222-228.

Whitmore T. 1989. Canopy gaps and the two major groups of forest trees. Ecology 70:536-538.

Wiens JA. 1989. Spatial scaling in ecology. Functional ecology 3:385-397.

Wilkinson DM. 1999. The disturbing history of intermediate disturbance. Oikos:145-147.

Wood S, Scheipl F, Wood MS. 2017. Package 'gamm4'. Am. Stat. 45:339.

Zerbe S. 2002. Restoration of natural broad-leaved woodland in Central Europe on sites with coniferous forest plantations. Forest Ecology and Management 167:27-42.

Zhang D, Hui D, Luo Y, Zhou G. 2008. Rates of litter decomposition in terrestrial ecosystems: global patterns and controlling factors. Journal of Plant Ecology 1:85-93. 


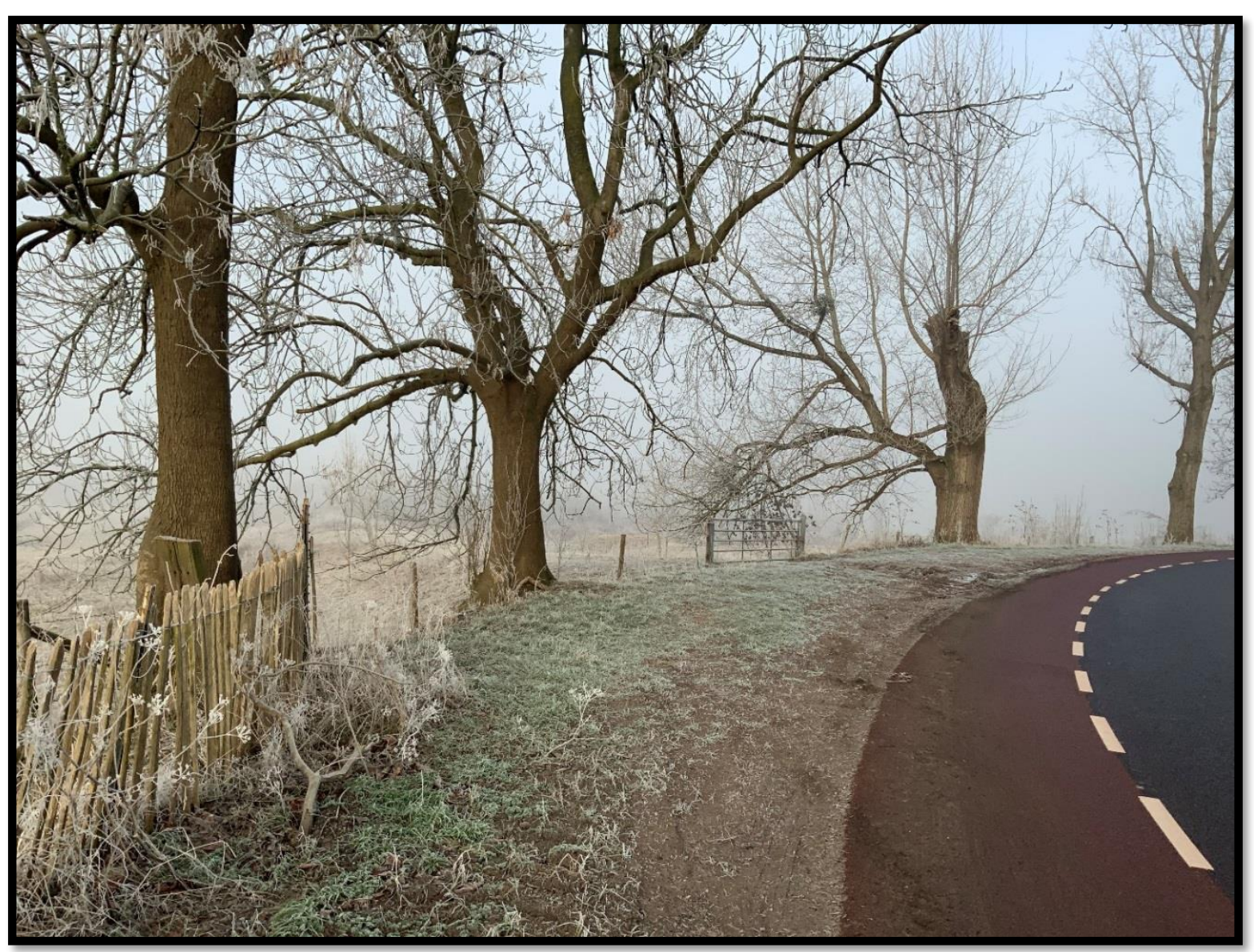


SUMMARY 
Earth's surface is changing rapidly due to anthropogenic disturbance and thus threatening the conservation of entire biomes: from deserts to tropical rainforests and from oceans to mountains. Within this spectrum, forests are one of the biomes which has suffered the most due to the exploitation of natural resources and the expansion of the urban environment into natural landscapes. Specially the case of temperate forests which offer favourable conditions for a variety of economic activities, such as: food and timber production but as well for a blooming human life. The high concentration of humans in temperate forests has led to high indices of land conversion and fragmentation, threatening the conservation of the unique biodiversity harboured in these forests. For example, the loss of apex predators has led to the overabundance of wild ungulates in most of the temperate forests, increasing the top-down control that these animals have over vegetation.

The top-down control of wild ungulates can influence several forest attributes such as forest diversity, structure and functioning. However, these effects are highly dependent on ungulate density, successional forest stage and the ungulate assemblage composition. Yet, there is a limited amount of field and experimental studies that elaborate on these important factors, mainly because there is a lack of long-term exclosures and a lack of studies that have evaluated the effect of a complete ungulate density gradient on forests in the same region. This thesis aims to evaluate the effects of wild ungulates on temperate forests at different scales. That is, how do wild ungulates affect forests at different 1) spatial scales (from areas with low to areas with high ungulate abundance)?, 2) temporal scales (from short-term to long-term effects)?, and 3) hierarchical scales (from trophic levels of primary producers to detritivores)? To tackle these questions, robust methods were designed in this thesis, such as a chronosequence of forest succession in presence and absence of ungulates, camera-traps paired to vegetation plots across a landscape, a global literature review on the effects of ungulate density on vegetation and litter bags placed inside and outside ungulate exclosures. Next, a description is provided for each of the chapters on their research and findings.

To evaluate how ungulates affect different temperate forest attributes, a global quantitative literature review was conducted in chapter two. This meta-analysis provided a better understanding on how ungulate density interacts with forests at a global scale and identifies critical thresholds in ungulate density and tipping points in forests when the effect of ungulate density switches from neutral to negative in forests. From a total of 164 studies, ungulate density averaged $23.6 \mathrm{~km}^{-2}$ across studies. Ungulate density had negative effects on 
forest regeneration, structure and functioning in $70 \%$ of the evaluated cases. The doseresponse curves had a sigmoidal shape. Critical tipping points, where ungulates started to have a negative effect on forest regeneration, were found at an ungulate metabolic weight density of $115 \mathrm{~kg} \mathrm{~km}^{-2}$ for forest regeneration, $141 \mathrm{~kg} \mathrm{~km}^{-2}$ for forest structure, and $251 \mathrm{~kg} \mathrm{~km}^{-}$ 2 for forest functioning, which is roughly equivalent to 10,13 and 23 roe deer $\mathrm{km}^{-2}$. Forest regeneration was most sensitive to immediate browsing and trampling impacts of small seedlings, while forest functioning was least sensitive because of time lags. However, these effects may build-up over time.

Chapter three on the short-term evaluated the shape of the dose-response for ten sites across at the Veluwe, the Netherlands, using approx. 210 camera points paired with vegetation plots. Five of the eleven forest variables measured were related to deer utilization level. With increasing red deer utilization, there was a decrease in litter depth. With increasing fallow deer utilization, there was a decrease in sapling richness. With increasing roe deer utilization, there was a decrease in sapling richness and diversity and shrub cover and an increase of sapling stem density. The dose-response curve between deer utilization and different forest attributes followed a curvilinear response, large changes at low followed by small changes at high utilization level, yet the exact shape of the curve can vary according to (a)biotic factors from each study location. Considering that the slopes of the responses were quite slight, it is possible to conclude that the influence that deer have on temperate forest structure and diversity is limited. Yet, these relationships may be different in a long-term study.

To provide a better understanding of how forest succession proceeds in a situation of chronic browsing and trampling, chapter four evaluated the long-term effect of ungulates on temperate forests. A chronosequence approach was used, in which 17 paired fenced and unfenced plots were compared, ranging in age from 1 to 33 years since their establishment at the Veluwe. In fenced plots, where ungulates were excluded, there was a reduced understory vegetation cover and an increased canopy cover, tree species richness, tree Shannon diversity and litter layer compared to unfenced plots. In fenced compared to unfenced plots, woody vegetation developed with palatable broadleaved species such as Betula pendula, Betula pubescens, Prunus serotina, and Quercus robur. These results suggest that current ungulate densities in this system have pronounced long-term effects on forest structure, composition and litter depth, implying that ungulates can slow down natural succession of temperate 
forests, from light demanding to shade tolerant tree species. Yet, it remains unclear whether these long-term effects on vegetation trigger cascading effects on lower trophic levels.

In chapter five, the potential cascading effects promoted by ungulates on temperate forests were evaluated. Using a network of twelve paired fenced and unfenced plots established across the Veluwe, soil quality, litter depth, forest regeneration, soil macroinvertebrates and decomposition rates were evaluated. Plots with ungulates had significantly higher soil compaction, but lower litter depth, tree diversity and density, rodent activity, invertebrate biomass and litter decomposition rate compared to plots with ungulates. Furthermore, ungulates presence: decreased sapling density which indirectly decreased rodent activity; decreased litter depth which indirectly reduced macro-invertebrate diversity and mineralization rates of magnesium and nitrogen in pine and oak litter, and increased soil compaction which decreased invertebrate diversity and mineralization rates of magnesium and nitrogen in pine and oak litter. If the system continues in the same direction, in the future, it will no longer sustain a diverse plant community due to nutrient limitation in soil.

In chapter six, the main outcomes of each of the chapters were discussed and contextualized in a broader perspective of temperate forest ecology and plant-animal interactions. Although the literature review (Ch. 2) and the long-term effect chapter (Ch. 4) reported a strong top-down relationship between ungulates and different forest attributes, the short-term effect chapter (Ch. 3) and the cascading effect chapter (Ch. 5) only reported slight relationships. These results illustrate that current ungulate densities have a gradual shaping effect on forest composition, structure and functioning of these Dutch temperate forests; although, ungulates have a smaller effect on forest functioning than (a)biotic factors like soil pH, light availability and forest type (Ch. 3 and 4).

Coming back to the main research question: what is the role of wild ungulates in temperate forests across different scales (spatial, temporal and hierarchical)? In sum, ungulates are important disturbance agents that can either create (positive relationships) opportunities for new species, maintain (neutral relationships) forest properties or arrest forest succession (negative relationships). In this thesis ungulates in the majority of cases had neutral relationships with forests ( $60 \%$ of all response variables evaluated), in less percentage ungulates had negative relationships (32\%) and only in a fraction of cases, ungulates had positive relationships (8\%). Considering the spatial scale, an increasing ungulate abundance has a negative effect on different forest attributes and the dose-response shape is 
characterized by a curvilinear response, with large changes at low followed by small changes at high ungulate abundance. Temporally, ungulates have steeper relationships with forest vegetation at the long-term scale compared to the short-term because effects on vegetation tend to accumulate in time. Finally, hierarchically, ungulates do not only alter forest vegetation but can also cascade-down their effects to other trophic levels and ecosystem processes. Taking all into account, ungulate relationships with forests are difficult to understand due to the system's complexity, yet when their interactions occur at extreme scales (high spatial, temporal and hierarchical scales), their effects on forest can be irreversible. 


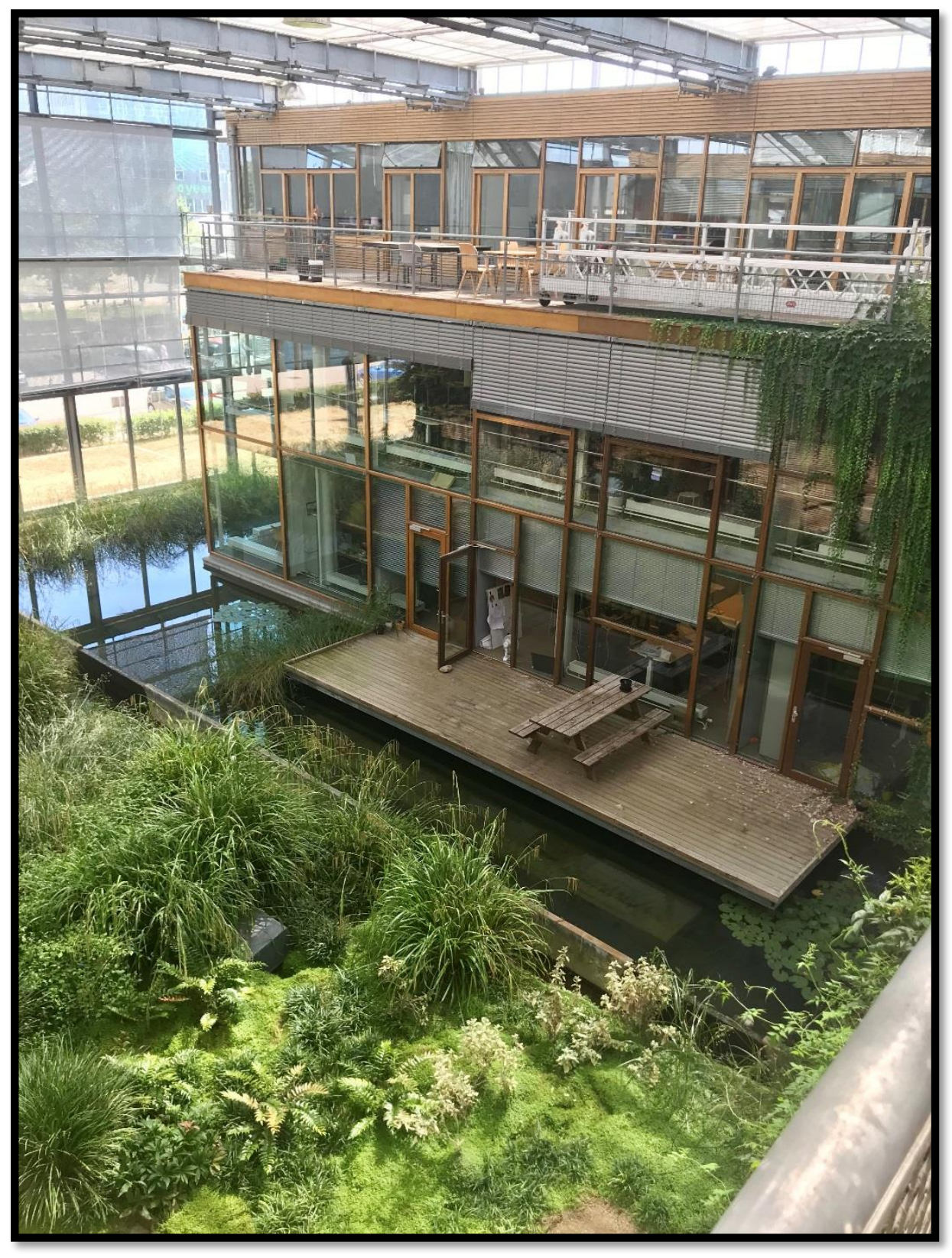


ACKNOWLEDGEMENTS 
At a young age, I enjoyed exploring the steep Andes mountains and the vast Amazon rainforest; hence, when the moment arrived to study a bachelor degree, it became obvious I should continue to explore nature, but from the ecological and biological perspectives. Since then, a good part of my life has been dedicated to continue studying animal-plant interactions; but also, exploring nature in my free time. Therefore, I am grateful with all the people who were there at the right moment and time, to show me the true value of nature.

From the academic domain, my promotor Lourens Poorter, since day one, became my scientific mentor. I thank him for providing new challenges, that took me to the limit; but also, for providing innovative solutions when necessary. His feedback was always spot on; I had the impression that he knew exactly what I needed to hear. I also acknowledge the jovial time we had outside the university, particularly at the craft brewery in Utrecht and the all-nighter at the Bilderbeg Castle (Doorwerth). Similarly, I am thankful for the academic support provided by Patrick Jansen and Jan den Ouden, my co-promotors. Patrick is a true camera trap wizard, who gave me the necessary skills to make my research cutting edge. Over 220 camera traps deployed across ten research site, 250,000 images processed and 80 hours' worth of animal material, just to mention some numbers. During my last phase as a PhD, Patrick was very supportive by submitting a research proposal (which got funded). Jan's critical approach to my research was of great value, because it gave me the opportunity to reflect on what I was doing and how to move forward.

This thesis would not have been possible without the direct support from different people. First, I would like to thank Leo Goudzwaard, who taught me about tree species in the temperate forest, showed me every corner of the Veluwe, and helped me gather data. Similarly, I am grateful for the field and laboratory work conducted by Casper Kuipers, Mohammad Kibria, Palma lacobelli, Xuqing Li, Laxmi Moktan and Natalie Herdoiza. Regarding data analysis, I recognize José Anibal Medina's, Masha van der Sande's and Rodrigo Munoz's effort for providing guidance with R statistics. Federico Alice Guier, Lan Zhang, Shanshan Yang and Ursula Revilla were kind enough to help with the thesis layout.

I am grateful with all the people from the Forest Ecology and Forest Management Group, for creating an inspiring and cosy environment. Notably, I acknowledge the work from Frans Bongers and Frits Mohren for setting a creative and stimulating environment in the group and to all the staff members (Lourens, Jan, Koen, Gert-Jan, Marielos, Ute, Frank, Pieter, Maaike, Leo, Joke and Ellen). This atmosphere also transcended the university setting; and for that, I recognize the dedication of Marielos Pena Claros and Lourens for actively hosting international dinners at their house. I thank Joke Jansen-Klijn, for assisting me with tedious administrative issues and for binding my thesis when I was running late for my deadline. 
Considering my project involved wildlife, I would like to thank all the people from the Resource Ecology Group, especially Frank van Langevelde and Yorick Liefting, for supporting my research. From the graduate school for Production Ecology \& Resource Conservation, I am grateful with Claudius van de Vijver and Lennart Suselbeek, for creating a friendly and academic environment.

I thank all the PhD's and postdocs from the group (FEMsters), for always being there and sharing unique moments; specially the PhD candidates from my generation (Federico, José, Katheline, Linar, Meike, Alan, Alejandra, Carolina, Lan, Qi, Surya, Shanshan and Yanjun) and my climbing buddies (Merel and Catarina). A special shout-out to my paranymphs Federico and José, who made sure I smoothly defended my thesis, and were always there to drink my beer without complaining.

Finally, I thank my spouse Natalie Herdoiza, for making every moment special and for making countless sacrifice to help me getting to this point. But most importantly, for sharing her wonderful life journey with me and our three dogs: Mimi, Luna and Sisa. Also, I am grateful to my parents: María Eulalia, Roberto and Torben, to my brothers Fabricio and Martín and my sister Mariela, for always keeping me in their thoughts. 


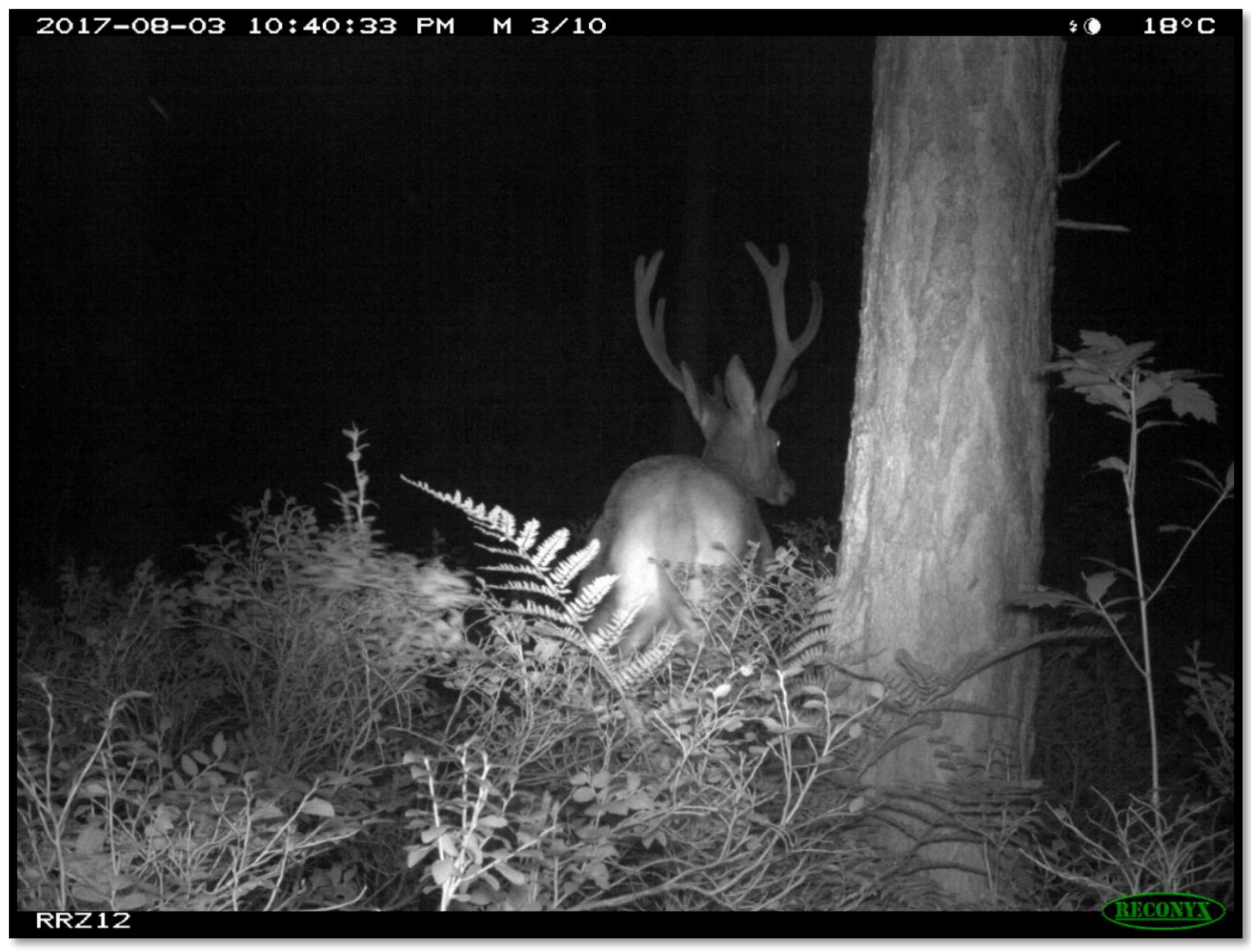




\section{SHORT BIOGRAPHY}

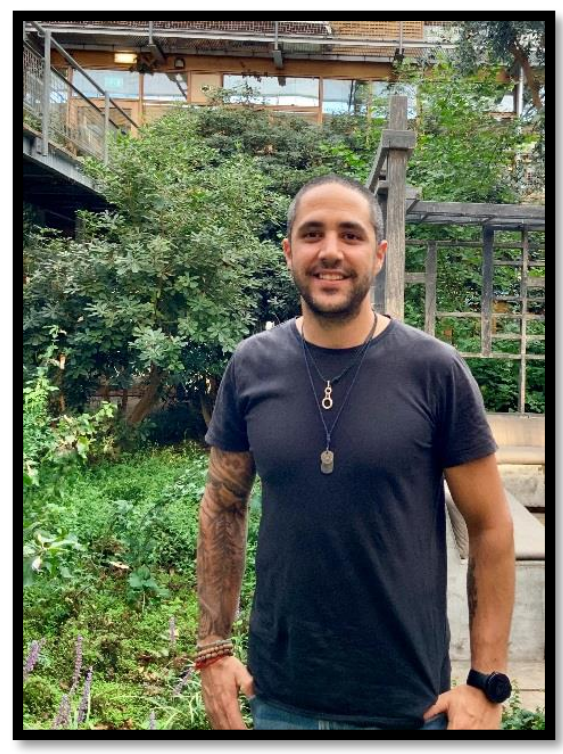

Juan Ignacio Ramírez Chiriboga, was born on January $23^{\text {rd }}$ of 1986 in Quito, Ecuador. As a kid, he spent most of the time exploring outside; since then, he developed a passion for nature. In 2005, he decided to pursue a double Bsc. in Biology and Applied Ecology at Universidad San Francisco de Quito in Ecuador. In 2009, he travelled for six months to Australia to attend environmental and wildlife courses in the University of the Sunshine Coast. During his undergraduate studies he worked as an Herbarium assistant, where he digitalized the hyperdiverse collection of useful plants from Ecuador. After his graduation in 2009, he proceeded to work as a science school teacher. In 2011, he worked in the Ministry of Natural Heritage and in the Presidency of Ecuador; where he coordinated activities for the Yasuní-ITT Initiative, including the dissemination of nature ancestral knowledge and the importance of Yasuní National Park for the local and the international community.

In 2015, after securing a full scholarship from the Government of Ecuador (SENESCYT), he completed his Msc. in Biology at Wageningen University, the Netherlands. His research aimed to explore the environmental impact of humans in Yasuní National Park, including oil extraction, agriculture and tourism. Later that year, he obtained a second full scholarship from the Government of Ecuador, to start his PhD program at the Forest Ecology and Forest Management Group, Wageningen University. His research explored the interactions between wild ungulates and temperate forests. For this, he surveyed vegetation across the Veluwe, the Netherlands, set-up animal exclosure experiments, used camera traps to quantify ungulate populations, and buried litter bags to measure decomposition rates. During his PhD, he presented his research finding in three international seminars (winning the first prize for Best Scientific Presentation for one of them). Moreover, he supervised seven master students with research in the Netherlands and Ecuador, and lectured in two Wageningen University courses.

Recently, Juan Ignacio obtained funds from PE\&RC graduate school, to work in a collaboration research project between Utrecht University and Wageningen University. This research aimed to understand how ungulate population size mediates ungulate behaviour. Also, he obtained a two-month contract with Wageningen University, to work as a lecturer in the Ecology 2 course for bachelor students.

Outside academia, Juan Ignacio spends most of his free time rock climbing around the world, brewing beers to share with his friends and exploring life with his spouse and his three dogs. 


\section{LIST OF PUBLICATIONS}

\section{Published}

Ramirez J. I., Jansen P. A., \& Poorter L. (2018). Effects of wild ungulates on the regeneration, structure and functioning of temperate forests: A semi-quantitative review. Forest Ecology and Management, 424, 406-419.

Ramirez J. I., Jansen P. A., den Ouden J., Goudzwaard L., \& Poorter L. (2019). Long-term effects of wild ungulates on the structure, composition and succession of temperate forests. Forest Ecology and Management, 432, 478-488.

\section{Submitted}

Ramirez J. I., Jansen P. A., den Ouden J., Moktan L., \& Poorter L. (2019) Above and below cascading effects of wild ungulates in a temperate forest. Journal of Ecology.

Ramirez J. I., Jansen P. A., den Ouden J., Li X., lacobelli P., Herdoiza N., Poorter L. (2019) The dose-response relationship between deer and a temperate forest understory: a camera trapping approach. Ecosystems. 


\section{PE\&RC Training and Education Statement}

With the training and education activities listed below the PhD candidate has complied with the requirements set by the C.T. de Wit Graduate School for Production Ecology and Resource Conservation (PE\&RC) which comprises of a minimum total of 32 ECTS (= 22 weeks of activities)

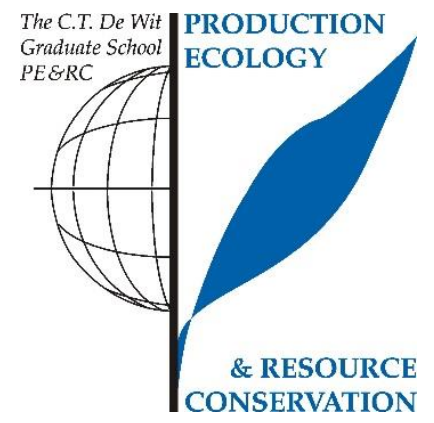

\section{Review of literature (6 ECTS)}

- Wild ungulate effects from micro-patch to landscape scale on global temperate forests

\section{Writing of project proposal (4.5 ECTS)}

- The role of ungulates in shaping tree regeneration on a temperate forest

\section{Post-graduate courses (10.2 ECTS)}

- The Science of Conservation: South Africa; WUR (2016)

- Resilience of Living Systems; WUR (2018)

- Consumer-Resource Interactions; WUR (2018)

- Basic Statistics; WUR (2016)

- $\quad$ Generalized Linear Models; WUR (2017)

- Mixed Linear Models; WUR (2017)

Laboratory training and working visits (2.2 ECTS)

- Ecology and management of Swedish boreal forests; SLU (2017)

Invited review of (unpublished) journal manuscript (1 ECTS)

- Ecoscience: the effects of deer and an invasive shrub, Lonicera maackii, on forest understory plant composition (2018)

\section{Competence strengthening / skills courses (3 ECTS)}

- Information literacy including Endnotes; WUR (2015)

- Competence assessment; WUR (2016)

- Research integrity; WUR (2016)

- Efficiency writing strategies; WUR (2017)

- Data management; WUR (2018)

PE\&RC Annual meetings, seminars and the PE\&RC weekend (2.4 ECTS)

- PE\&RC First years weekend (2015)

- PE\&RC Day (2016-2018)

- PE\&RC Last years weekend (2018)

\section{Discussion groups / local seminars / other scientific meetings (5.7 ECTS)}

- Ecological theory and application discussion group (2015-2019)

- Wageningen evolution and ecology seminars (2015-2019) 
- Camera trap laboratory (2015-2019)

- FEM Journal club (2015-2019)

- $\quad 3^{\text {rd }}$ Wageningen PhD symposium: diversity in science (2016)

- Nature conservation: from fundamental knowledge to sustainable conservation (2016)

- Rewilding natural areas symposium (2016)

- Animal monitoring in tropical forests (2018)

- Towards convivial conservation: governing human-wildlife relationships in the Anthropocene (2018)

International symposia, workshops and conferences (3.9 ECTS)

- $\quad 4^{\text {th }}$ PhD Symposium from local to global (2017)

- $\quad 5^{\text {th }} \mathrm{PhD}$ Symposium bridging science and society unifying knowledge (2018)

- Netherlands Annual Ecology Meeting, NAEM (2019)

\section{Lecturing / Supervision of practicals / tutorials (38.7 ECTS)}

- Ecology (2016-2019)

- Advanced forest ecology and management (2016-2019)

- Resource dynamics and sustainable utilization (2018)

\section{Supervision of MSc students (21 ECTS)}

- The effect of succession and wild ungulates on the functional composition of species in Dutch temperate forests

- Explaining heterogeneity of forest use by red deer (Cervus elaphus) and roe deer (Capreolus capreolus) across the Veluwe

- The effects of wild ungulate density on tree regeneration in Dutch temperate forests

- Cascading effects of ungulates on forest invertebrates and litter decomposition rate

- The impact of wild ungulates on tree species composition under different light regimens

- The influence of large herbivores on forest composition and functional traits of trees in the proximity of mineral licks in Yasuni National Park, Ecuador

- The influence of large herbivores on forest structure and functional traits of trees in the proximity of mineral licks in Yasuni National Park, Ecuador 
Cover illustrations

Front cover: Pille Kirsi

Back cover: StockSnap 
The research described in this thesis was financially supported by the "Convocatoria Abierta 2012" from the "Secretaria Nacional de Eduacion Superior, Ciencia, Tecnologia e Inovación (SENESCYT)", in representation of the Government of Ecuador.

Financial support from the Ecology Fund of the Royal Netherlands Academy of Arts and Sciences and the LEB foundation for fieldwork and analyses is gratefully aknowledged. Wageningen University financially supported the printing of this thesis.

\section{Cover design:}

Juan Ignacio Ramírez Chiriboga

\section{Photography:}

Juan Ignacio Ramírez Chiriboga

\section{Printed:}

ProefschriftMaken 